
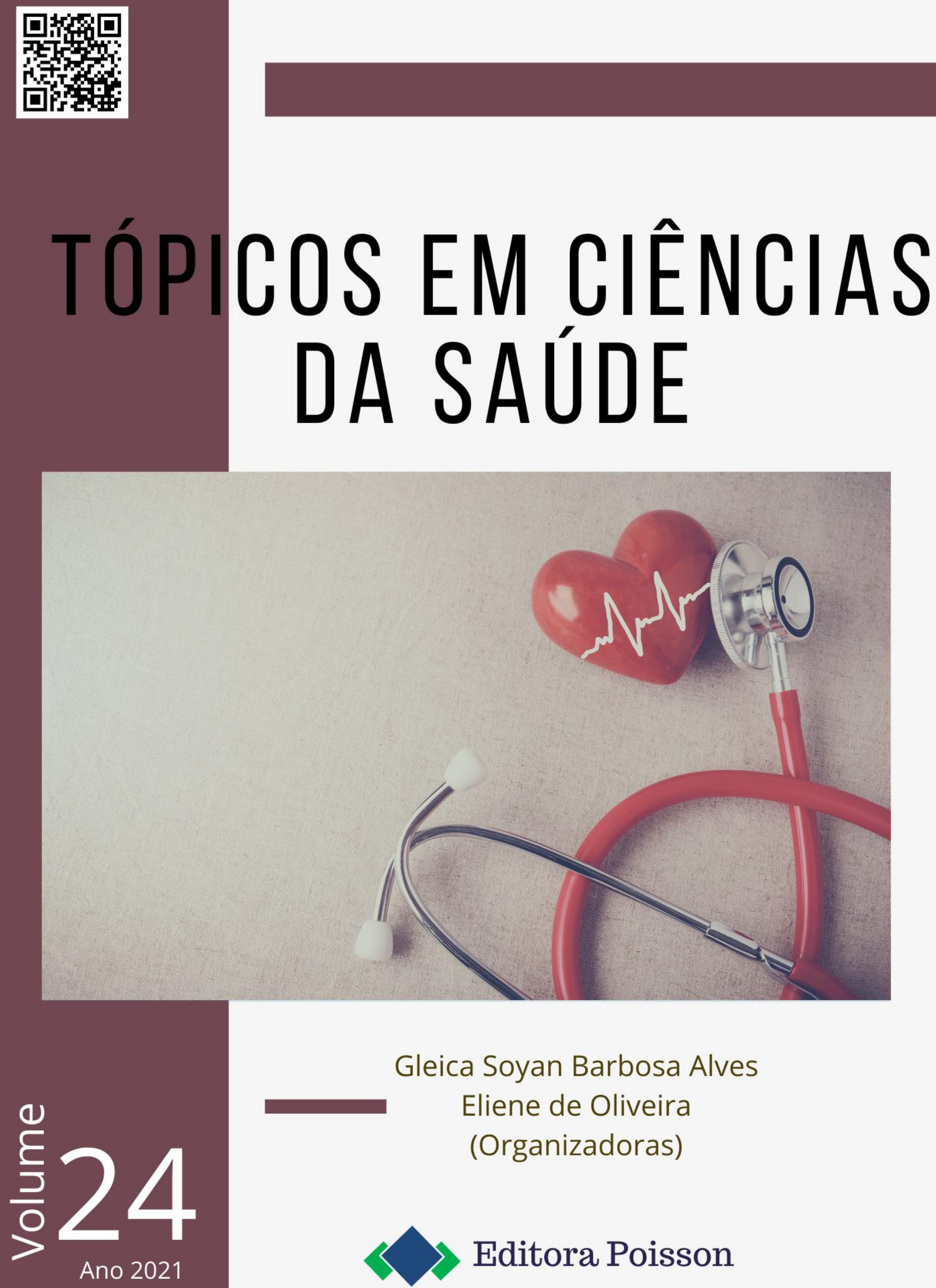

Gleica Soyan Barbosa Alves

Eliene de Oliveira

(Organizadoras)

Editora Poisson 
Gleica Soyan Barbosa Alves

Eliene de Oliveira

(Organizadoras)

Tópicos em Ciências da Saúde Volume 24

1a Edição

Belo Horizonte

Poisson

2021 
Editor Chefe: Dr. Darly Fernando Andrade

\section{Conselho Editorial}

Dr. Antônio Artur de Souza - Universidade Federal de Minas Gerais Msc. Davilson Eduardo Andrade

Dra. Elizângela de Jesus Oliveira - Universidade Federal do Amazonas

Msc. Fabiane dos Santos

Dr. José Eduardo Ferreira Lopes - Universidade Federal de Uberlândia

Dr. Otaviano Francisco Neves - Pontifícia Universidade Católica de Minas Gerais

Dr. Luiz Cláudio de Lima - Universidade FUMEC

Dr. Nelson Ferreira Filho - Faculdades Kennedy

Msc. Valdiney Alves de Oliveira - Universidade Federal de Uberlândia

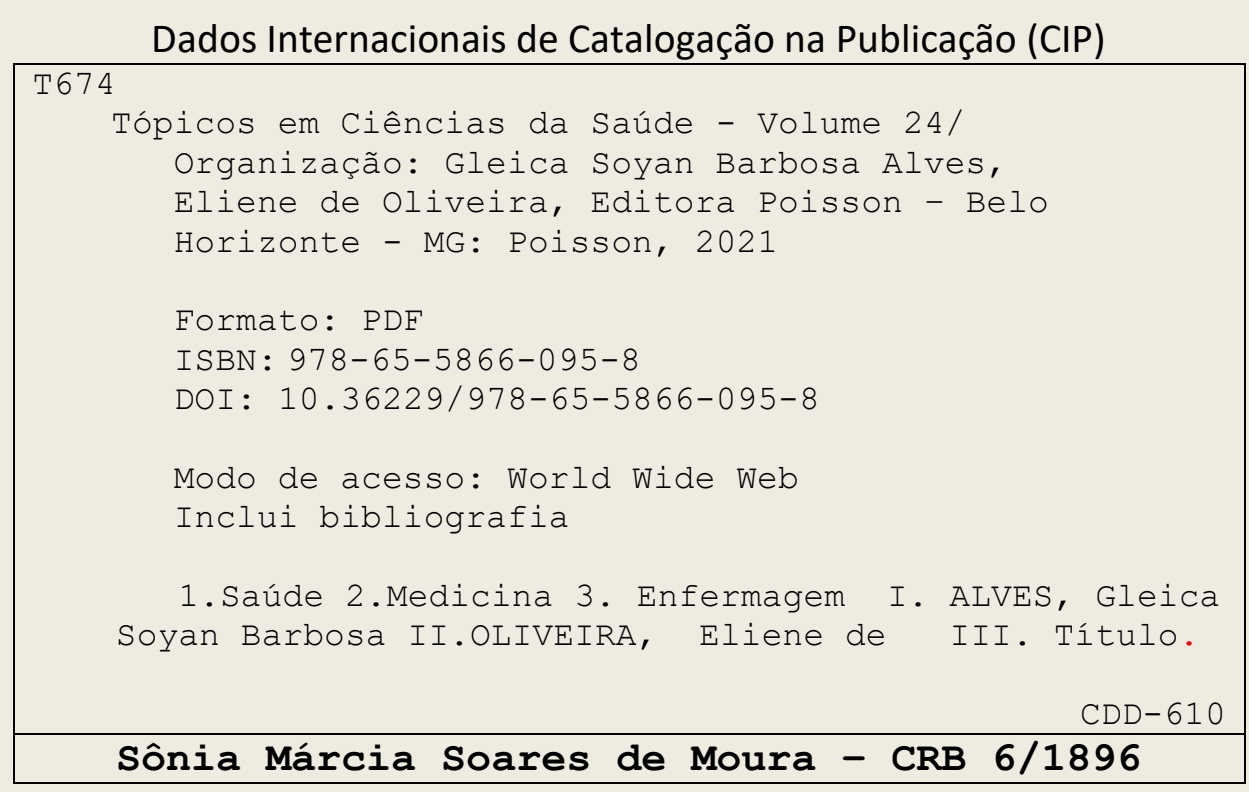

O conteúdo dos artigos e seus dados em sua forma, correção e confiabilidade são de responsabilidade exclusiva dos seus respectivos autores.

Esse e outros títulos podem ser baixados gratuitamente em www.poisson.com.br Entre em contato pelo contato@poisson.com.br 


\section{SUMÁRIO}

Capítulo 1: Proposta de uma plataforma de Cloud Computing para disponibilização de um sistema online para consultórios e clínicas por meio do modelo SaaS. 07

Robertson Ebling dos Santos, Alexandre de Oliveira Zamberlan, Sylvio André Garcia Vieira, Guilherme Chagas Kurtz, Ricardo Frohlich

DOI: 10.36229/978-65-5866-095-8.CAP.01

Capítulo 2: Separação e destinação dada ao lixo hospitalar perfurocortante: Das práticas da UFN ao Direito Ambiental 20

Fabiane Rosado Lorenzoni, Isadora Balestrin Guterres

DOI: 10.36229/978-65-5866-095-8.CAP.02

Capítulo 3: Noções de biossegurança no ambiente hospitalar: Um relato de experiência 26

Cynthia Pires Lorentz, Gabriele dos Santos Mota, Giulia Lopes Costa da Silva, Daniela Sanchotene Vaucher DOI: $10.36229 / 978-65-5866-095-8 . C A P .03$

Capítulo 4: Caracterização dos acidentes de trabalho graves no trânsito ocorridos em Santa Maria, Brasil 29

Nayara Martins Ribeiro, Ligia Maria Bueno Verdiani, Marlice Ceolin Druck

DOI: $10.36229 / 978-65-5866-095-8 . C A P .04$

Capítulo 5: Vivência dos acadêmicos de Enfermagem nas unidades de urgência e emergência.

Alisson Junior dos Santos, Gleida Maria Martins

DOI: 10.36229/978-65-5866-095-8.CAP.05

Capítulo 6: Violência obstétrica na percepção de enfermeiras e parturientes 37

Naiara Almeida Guedes

DOI: $10.36229 / 978-65-5866-095-8 . C A P .06$

Capítulo 7: Relato do aprender fazendo com educação em saúde: Grupo de gestantes de uma zona rural

Bárbara Adrya Prestes da Silva, Andréa Timóteo dos Santos Dec, Mackelly Simionatto, Margarete Aparecida Salina Maciel 


\section{SUMÁRIO}

Capítulo 8: Atenção à saúde do recém-nascido prematuro: Uma revisão integrativa52

Brenda Helen Freire Barbosa, José Deusvando Freire Campos, Josivan Felix da Silva, Assemcleves Aguiar da Silva, Alexandre Bezerra Silva

DOI: $10.36229 / 978-65-5866-095-8 . C A P .08$

Capítulo 9: Relação entre qualidade de vida, transtornos mentais menores e resiliência entre profissionais de enfermagem 59

Emerson Roberto dos Santos, Daniela Comelis Bertolin, Loiane Letícia dos Santos, Patrícia da Silva Fucuta, Daniele Alcalá Pompeo, Júlio César André

DOI: 10.36229/978-65-5866-095-8.CAP.09

Capítulo 10: Características associadas à depressão senil em idosos na Atenção Primária à Saúde: Scoping Review 88

Edith Monteiro de Oliveira, Davi Pereira Coelho, Flávia Reis da Silva, Taciely Campana Colli, Thainá Ribeiro Rezende de Morais, Daniele Knopp Ribeiro, Fabiola Lisboa da Silveira Fortes, Denise Barbosa de Castro Friedrich

DOI: $10.36229 / 978-65-5866-095-8 . C A P .10$

Capítulo 11: Programa UEPG Abraça: Práticas Integrativas Complementares em Saúde (PICS) na promoção de Saúde Mental 95

Anna Laura Martinelli, Lara Simone Messias Floriano, Thais Fernanda Chelsk, Guilherme Arcar, Alessandra Rodrigues Martin, Milena Dzazio de Oliveira, Jussany Cristine Miranda, Suellen Vienscoski Skupien

DOI: $10.36229 / 978-65-5866-095-8 . C A P .11$

Capítulo 12: Programa UEPG Abraça: Eventos de extensão que compartilham Saúde Mental para a comunidade 101

Millena Dzazio de Oliveira, Lara Simone Messias Floriano, Jussany Cristine Miranda, Suellen Vienscoski Skupien, Anna Laura Martinelli, Thais Fernanda Chelsk, Guilherme Arcaro, Alessandra Rodrigues Martins DOI: $10.36229 / 978-65-5866-095-8 . C A P .12$

Capítulo 13: Desafios frente ao cuidado à pessoa usuária de álcool e outras drogas.108 Laíse Ávila de Siqueira, Camila Andriele Nunes Martins Lopes, Mariana Kristosch dos Santos, Karen Brião da Costa, Juliana da Rosa Marinho, Priscilla La Flor Duarte, Bruna Rodrigues Maziero

DOI: $10.36229 / 978-65-5866-095-8 . C A P .13$

Capítulo 14: Vitamina D: Deficiência e suplementação relacionada à cirurgia Bariátrica 113 


\section{SUMÁRIO}

Capítulo 15: Percepções de idosos sobre prevenção de quedas em domicílios 120

Morgana Cristina Leôncio de Lima, Elaine Cristina dos Santos Oliveira Holanda, Monica Rita da Silva Simplicio, Elidiane Lira da Silva Pereira, Rebeca Bezerra Bonfim de Oliveira, Ana Priscila Duarte de Aguiar, Laryssa Grazielle Feitosa Lopes

DOI: $10.36229 / 978-65-5866-095-8 . C A P .15$

Capítulo 16: Prevalência de HIV/AIDS em adultos no município de Tucuruí de 2007 a 2017 127

Tayanne de Sousa Almeida, Ariane da Silva Santos, José Claudo de Sousa Monteiro, Juliana Cristina Schneider

DOI: 10.36229/978-65-5866-095-8.CAP.16

Autores: 


\section{Capítulo 1}

Proposta de uma plataforma de Cloud Computing para disponibilização de um sistema online para consultórios e clínicas por meio do modelo SaaS

\section{Robertson Ebling dos Santos}

Alexandre de Oliveira Zamberlan

\section{Sylvio André Garcia Vieira}

\section{Guilherme Chagas Kurtz}

Ricardo Frohlich

Resumo: Em um mundo cada vez mais conectado, é comum em ambientes corporativos a utilização de aplicativos instalados em servidores remotos que centralizam os dados da empresa e permitem o acesso dos usuários através da Internet. Em um consultório médico, a alta disponibilidade do sistema permite o acesso rápido ao prontuário do paciente que agiliza o diagnóstico e o início do tratamento. Assim o objetivo deste trabalho é propor e instalar uma arquitetura de Cloud Computing baseada nas características propostas pelo NIST (National Institute of Standards and Technology) que utilizando software livres implemente a alta disponibilidade e escalabilidade horizontal necessários para a disponibilização de um sistema online para gestão de consultórios e clínicas por meio do modelo SaaS. 


\section{INTRODUÇ̃̃O}

Segundo uma pesquisa realizada nos Estados Unidos [Informédica 1994], um médico gasta quase metade do seu tempo para obter e registrar informações acerca de seus pacientes. Fora isto, existe o tempo necessário para que o auxiliar/recepcionista controle a agenda, o cadastro de informações administrativas e financeiras sobre os pacientes. Dentro deste quadro, em um estudo realizado em 2014 (por meio de uma consulta realizada com 100 médicos do corpo clínico do Hospital de Caridade Dr. Astrogildo Azevedo de Santa Maria RS), foi identificada a alta taxa (cerca de 70\%) de utilização de métodos tradicionais baseado na ficha e agenda - manual em papel. No mesmo estudo, foi percebido que os resultados apontados por [Informédica 1994] sobre a alocação do tempo deste profissional condizem com a atualidade.

Um sistema de gestão de consultório instalado localmente auxilia no controle destes aspectos, porém traz a preocupação com manutenção do software que fica por conta e risco do profissional de saúde. Em [Taurion 2009], cita-se que alguns estudos têm mostrado que empresas de pequeno porte - consultórios gastam até $70 \%$ do seu tempo gerenciando os recursos de TI (algo que não gera valor agregado) e apenas $30 \%$ em atividades focadas no seu próprio negócio. Assim, conclui-se que um software baseado em Cloud Computing permite centralizar os dados e disponibiliza'-los em qualquer lugar com acesso á Internet. Também, libera o profissional das preocupações operacionais e técnicas que ficam, agora, de responsabilidade da empresa prestadora do SaaS (Software as a Service).

Assim, surge o objetivo deste trabalho, projetar, implementar e testar uma infra-estrutura de Cloud Computing no contexto do modelo SaaS para disponibilização de um sistema Web de gestão de consultórios e clínicas.

Para atingir o objetivo geral deste trabalho, foi fundamental realizar algumas açõe importantes, como: definir uma arquitetura para a infraestrutura de Cloud Computing utilizando ferramentas baseadas em software livre; instalar, configurar e conectar tecnologias; testar o escalonamento horizontal através do Balanceamento de Carga de uma aplicação Web desenvolvida com Python/Django utilizando o Servidor Web Nginx, o banco de dados Postgres em Cluster com Distribuição de carga e o escalonamento de storage com o GlusterFS.

0 presente artigo é apresentado em seções. Na revisão teórica, apresenta-se a definição e características de Cloud Computing, bem como seus modelos de serviço e implantação da tecnologia. Além disso, alguns trabalhos relacionados são apresentados. Na seção de proposta, apresenta-se a metodologia de trabalho, o sistema ER Clinic que é objeto do estudo de caso e a definição, implantação e teste da estrutura e tecnologias empregadas na plataforma. Finalmente, seguem as conclusões e as referências bibliográficas.

\section{REVISÃO TEÓRICA}

Nesta seção, é discutido o conjunto de tecnologias que auxiliam na compreensão da implementação do modelo SaaS (Software as a Service) que disponibiliza aplicações baseadas na Web como serviço.

\subsection{CLOUD COMPUTING}

Um estudo [CETIC 2014] aponta que 74\% das empresas que utilizam computador já oferecem alguma forma de compartilhamento de recursos através da Internet. Conforme [Gartner 2013], é evidenciado que a adoção de sistemas baseados na Web vêm crescendo de maneira acelerada em todo mundo. A estimativa prevê ainda que dentro do nicho de sistemas de escritório baseados na Web a quantidade de usuários passará de 4 milhões em 2015 para 16,5 milhões até 2017. Estima-se também que este número cresça para cerca de 695 milhões em 2022, representando 60\% de usuários de sistemas de escritório.

Percebe-se através desses estudos que existe a necessidade de uma infraestrutura flexílvel que proporcione uma forma indefinida de recursos de processamento, memória e armazenamento. Além disso, que responda ao aumento indeterminado na demanda por volume de acessos em sistemas baseado na Web. Portanto, acredita-se que Cloud Computing surge como um novo paradigma para esse cenário de impresivibilidade da demanda.

Empresas startups ${ }^{1}$ que possuem como característica o baixo custo inicial de manutenção e que precisam escalar proporcionalmente ao aumento da demanda do mercado pelos seus serviços e produtos,

\footnotetext{
${ }^{1}$ Empresa nova, inovadora, que conta com projetos promissores e normalmente pouco recurso financeiro.
} 
encontram nesse modelo de computação uma excelente ferramenta para acompanhar a evolução de seus negócios.

De acordo com [Taurion 2009], Cloud Computing pode ser definido como um conjunto de recursos com capacidade de processamento, armazenamento, conectividade, plataformas, aplicações e serviços disponibilizados na Internet.

Segundo [Cordeiro 2013], existem quatro problemas que (ainda) requerem constante inovação tecnológica e que a Computação em Nuvem serve como ferramenta integrante da solução, são eles: escalabilidade em Web, data centers distribuídos geograficamente, computação paralela e distribuída e aplicações Web interativas.

O Departamento Nacional de Comércio dos Estados Unidos por intermédio do National Institute of Standards and Technology (NIST) define Cloud Computing como um modelo projetado para permitir o acesso á rede ubíqua ${ }^{2}$ sob demanda (on-demand) para um compartilhamento de pool de recursos computacionais $^{3}$ configuráveis como por exemplo: redes, servidores, armazenamento, aplicações e serviços [NIST 2011]. Ademais, esses recursos podem ser rapidamente fornecidos e liberados com um esforço mínimo de gerenciamento ou interação com o provedor de serviços.

\section{CARACTERÍSTICAS ESSENCIAIS DE UM CLOUD COMPUTING}

Serviços sob demanda com capacidade de auto atendimento ${ }^{4}$ possibilitam que o cliente final possa a qualquer momento requerer maior ou menor quantidade de recursos computacionais que são oferecidos de forma automática, sem necessidade de interação humana por parte do prestador de serviço. Acesso multi-dispositivo significa que a nuvem deve ser o ponto de acesso de recursos para seus usuários. Esses recursos disponibilizados por meio da Internet devem estar disponíıveis para dispositivos computacionais padrão (PCs, laptops, smartphones, tablets e etc). Pool de recursos pode ser entendido como recursos computacionais físicos e virtuais que são organizados de maneira distribuída para atender de forma transparente os múltiplos usuários. Define-se como rápida elasticidade a capacidade em que o sistema tem de adicionar e/ou remover recursos computacionais em tempo de execução. Essa característica fornece a impressão para o usuário final de que os recursos parecem ser ilimitados. Por fim, monitoramento é o mecanismo de cobrança de utilização de recursos da nuvem de acordo com o consumo.

\section{MODELOS DE SERVIÇO}

Conforme [World 2010], existem 11 categorias principais de tecnologia para Computação em Nuvem: Armazenamento como Serviço (AaaS), Banco de Dados como Serviço (BaaS), Informação como Serviço, Processo como Serviço, Software como Serviço (SaaS), Plataforma como Serviço (PaaS), Integração como Serviço, Segurança como Serviço, Gestão/Governança como Serviço, Teste como Serviço e Infraestrutura como Serviço (IaaS).

IaaS é a camada que representa a base física que dá suporte de hardware para as demais camadas. Ademais, permite o fornecimento de recursos como alocação de datacenter, rede de energia e dados e servidores. Exemplos de fornecedores desse serviço: Amazon Elastic Cloud Computing (EC2) ${ }^{5}$, Microsoft Azure ${ }^{6}$ Digital Ocean ${ }^{7}$ e Locaweb ${ }^{8}$.

\footnotetext{
2 Integra mobilidade a computac ,a o pervasiva onde o computador esta' embarcado no ambiente de forma invis'ivel para o usua'rio [Arau'jo 2003].

${ }^{3}$ Conglomerado de computadores, software e rede de computadores que com a réplica de instâncias são capazes de distribuir o trabalho e assumir o trabalho de partes que esta o momentaneamente indispon'iveis

${ }_{4}^{4}$ self-service

${ }^{5}$ https://aws.amazon.com/pt/ec2

${ }^{6} \mathrm{https}$ ///azure.microsoft.com/pt-br

7 https://www.digitalocean.com

8http://www.locaweb.com.br/cloud
} 
PaaS é a camada que provê aos desenvolvedores de aplicação acesso de uma forma regular, estruturada e mais prática á camada de infraestrutura. Além disso, permite ações como compilar, desenvolver, monitorar, depurar e testar. Sistemas operacionais, sistemas gerenciadores de banco de dados, interfaces de programação de aplicações (APIs), sistemas de armazenamento em disco e demais aplicativos que dão suporte para a aplicação principal da arquitetura são características do que este modelo de serviços oferece. Enquadram-se como fornecedores desse serviço: Heroku ${ }^{9}$ e Google Cloud Platform ${ }^{10}$.

SaaS é o modelo que disponibiliza por meio da Internet sistemas com propósitos especílficos para o usuário consumidor. O usuário que contrata esta camada envolve-se apenas com configurações da aplicações. Percebe-se que este modelo faz com que o cliente pague somente pelo uso, manutenção e suporte técnico prestados. Servições como Google Docs ${ }^{11}$, Gmail ${ }^{12}$ e Dropbox ${ }^{13}$ são oferecidos como SaaS.

\section{MODELOS DE IMPLANTAÇÃO}

A implantação do Cloud Computing depende da necessidade da aplicação que executará sobre este meio. Aparentemente os serviços são disponibilizados de forma pública, mas foram desenvolvidos modelos de implantação que procuram garantir um nível adequado de controle da informação.

Os modelos de implantação apontados por NIST são: Nuvem Privada, Nuvem Comunidade, Nuvem Pública e Nuvem Híbrida.

\subsection{ESCALABILIDADE E ALTA DISPONIBILIDADE EM NUVENS}

Garantir o retorno das requisiçõees dos usuários ainda é um desafio para sistemas de alta demanda. Sistemas baseados em Cloud Computing devem ter a capacidade de adicionar e/ou remover recursos computacionais em tempo de execução deixando este procedimento totalmente transparente para o usuário final.

Em [Taurion 2009], destaca-se a imprevisibilidade da demanda como um complicador adicional ao ambiente de empresas cada vez mais interconectadas. Para o autor, esta demanda imprevisível exige que os sistemas tenham condições de adaptar-se instantaneamente a flutuações significativas.

Já em [Cipriani 2009], justifica-se a extrema importância da garantia do funcionamento contínuo de sistemas para que uma empresa informatizada opere em sua plenitude. Sua indisponibilidade, seja por falha do hardware ou do software, implica direta ou indiretamente em perda de dinheiro por parte da organização.

Três aspectos de alta disponibilidade relacionados ao sistema do estudo de caso deste trabalho são apresentados: balanceamento de carga, banco de dados clusterizado e escalonamento de armazenamento.

Balanceamento de carga, segundo [Bourke 2001], busca obter a distribuição de requisições de maneira equitativa sobre os nós de um ambiente distribuídos. As requisições chegam no balanceador de carga, que por meio do algorítimo de balanceamento define a prioridade pelo servidor de destino ao qual a requisição é encaminhada. Para o usuário final, esta arquitetura é vista como apenas um servidor - dando a impressão de ser apenas um grande servidor virtual. Em [Roger 2012], é apresentado um balanceador de carga com alta disponibilidade utilizando Nginx como proxy reverso e o Apache ${ }^{14}$ como servi- dor de aplicação HTTP nos nós secundários. Já em [de Moura Nóbrega 2013] o Nginx é destacado como um balanceador de carga largamente empregado pelo seu excelente desempenho e facilidade de configuração.

Banco de dados clusterizado entende-se como um recurso em que se o banco de dados principal tiver algum problema, outro banco de dados secundário assume automaticamente, sem prejudicar o serviço, deixando transparente para o usuário final. Bancos de dados como Oracle ${ }^{15}$, SQLServer ${ }^{16}$, MySQL ${ }^{17}$ e

\footnotetext{
${ }^{9}$ https://www.heroku.com

10 https://cloud.google.com/appengine

11 https://docs.google.com

12 https://www.gmail.com

13 https://www.dropbox.com

${ }^{14}$ https://httpd.apache.org

15 http://www.oracle.com

$16 \mathrm{http}: / /$ www.microsoft.com/pt-br/server-cloud/products/sql-server/Overview.aspx

17 https://www.mysql.com/products/enterprise/router.html
} 
Postgresq ${ }^{18}$ são exemplos de soluções compatíveis com a clusterização. Escalonamento de armazenamento (storage), éatecnologia capaz de aumentar o espaço em disco horizontalmente sem a necessidade de interferir na execução do sistema. São exemplos de soluções de alocação dinâmica de espaço em disco, sem a necessidade de parada no funcionamento do sistema, Amazon EFS (Elastic File System) ${ }^{19}$ e o GlusterFS ${ }^{20}$ Este último possibilita criar soluções de armazenamento grandes e dis- tribuído usando hardware comum máquinas físicas ou virtuais.

Finalmente, as técnicas apresentadas na seção têm como principal objetivo garantir a disponibilidade contíınua do sistema, evitando paradas para manutenção ou ampliação da capacidade de alocação de espaço e processamento da plataforma.

\section{TRABALHOS RELACIONADOS}

No trabalho [Boufleur 2013], foram aplicadas técnicas de clusterização para a otimização o da performance e promoção o da alta disponibilidade do software SIGA-ECPT ${ }^{21}$ (utilizadona Universidade Federal de Santa Maria). A ferramenta GlassFish ${ }^{22}$ foi utilizada como cluster de servidores de aplicação para garantir a escalabilidade horizontal da solução. Ao migrar o sistema SIGA-ECPT do modo sistema com único servidor (standalone) para o clusterizado, foram realizados alguns ajustes nos arquivos de configuração do sistema no GlassFish. A fim de corrigir erros que alertavam incompatibilidade com as demandas de compartilhamento de sessão do software clusterizado, mudanc,as no código-fonte do software SIGA-ECPT também foram necessárias. Com a estrutura proposta, conseguiu-se alta disponibilidade através do balanceamento de carga entre os nós. Ao contrário do esperado, percebeu-se através de testes que o tempo de execução do método clusterizado foi maior do que um servidor standalone.

Em relação ao trabalho apresentado em [de Moura Nóbrega 2013], realizou-se um estudo a fim de determinar qual a melhor configuração de um ambiente no data center da Universidade Estadual do Ceará23, utilizando computação em nuvem para atender as demandas dos sistemas Web da instituição. Destaca-se a forma como os testes foram conduzidos, como por exemplo, a análise de diferentes soluções em nuvem com plataformas pública e privada, interessantes para este estudo. Ainda com relação aos testes de carga, foram comparados os resultados obtidos com o emprego dos servidores Web - Nginx e Apache e os servidores de aplicação - GlassFish e Tomcat (tecnologias Java) - em cinco diferentes fornecedores de ambiente de nuvem. Nesse mesmo trabalho, definiu-se o uso do software OpenStack ${ }^{24}$ para gerenciar os recursos de nuvem privada juntamente com o cluster do GlassFish e o balancemento de carga do Nginx.

Já no trabalho [Roger 2012], foi desenvolvido um ambiente de alta disponibilidade utilizando Nginx como balanceador de carga entre os nós, Apache como servidor Web, RSYNC (software que sincroniza remotamente os dados entre duas máquinas) como replicador de arquivos entre os nós do cluster e compartilhamento de sessão com PHP. Nessa proposta, destaca-se pela eliminação do Ponto único de Falha (SPOF, Singe Point of Fai- lure) replicando também os balanceadores de carga através da utilização de failover ${ }^{25}$ e keepalive ${ }^{26}$.

Na Figura 1, são apresentadas as tecnologias empregadas na solução de problemas correlacionados a esta proposta.

É possível identificar nos trabalhos citados, que o foco principal está na garantia da escalabilidade e alta disponibilidade dos servidores de aplicação. Entretanto, nota-se uma lacuna quanto aos aspectos de escalabilidade e alta disponibilidade para armazenamento em disco e servidor de banco de dados.

\footnotetext{
18 http://www.postgresql.org

19 https://aws.amazon.com/pt/efs

20 http://www.gluster.org

${ }^{21}$ Sistema Integrado de Gestão Acade^mica da Educac,ão. [Boufleur 2013]

22 https://glassfish.java.net

23 http://www.uece.br

${ }^{24}$ https://www.openstack.org

25 Te'cnica que evita o ponto u'nico de falha. [Roger 2012].

26 Permite detectar a inoperância de um servidor e atribuir virtualmente o IP do servidor inoperante ao substituto [Roger 2012].
} 
Sendo assim, na próxima seção é apresentada o projeto que pretende gerar a escalabilidade e alta disponibilidade de servidores de aplicação, armazenamento em disco e banco de dados.

Figura 1. Quadro comparativo entre a proposta deste trabalho e as solucões propostas nos trabalhos relacionados

\begin{tabular}{|c|c|c|c|c|c|c|c|c|}
\hline Trabalhos relacionados & $\begin{array}{c}\text { Sistema } \\
\text { Operacional }\end{array}$ & $\begin{array}{c}\text { Tecnologia } \\
\text { (Linguagem de } \\
\text { Programação) }\end{array}$ & $\begin{array}{c}\text { Servidor } \\
\text { Web }\end{array}$ & $\begin{array}{c}\text { Método } \\
\text { de } \\
\text { Cache }\end{array}$ & $\begin{array}{c}\text { Balanceamento de Carga } \\
\text { de servidores de } \\
\text { aplicação }\end{array}$ & $\begin{array}{c}\text { Compartilhamento } \\
\text { de sessão }\end{array}$ & $\begin{array}{c}\text { Banco de } \\
\text { Dados }\end{array}$ & $\begin{array}{c}\text { Servidor de } \\
\text { dados (storage) }\end{array}$ \\
\hline [Boufleur 2013] & Linux / Ubuntu & Java & Apache & - & $\begin{array}{l}\text { GlassFish / Oracle iPlanet } \\
\text { Web Server } 7\end{array}$ & GlassFish & \begin{tabular}{|l|} 
PostgreSQL \\
nāo clusterizado
\end{tabular} & - \\
\hline [de Moura Nóbrega 2013] & - & Java & Nginx & - & $\begin{array}{l}\text { GlassFish / Ngin / } \\
\text { OpenStack }\end{array}$ & GlassFish & - & - \\
\hline [Roger 2012] & Linux / Debian & PHP & Apache & - & Nginx Proxy & $\begin{array}{l}\text { Memcached / } \\
\text { Repached }\end{array}$ & - & $\begin{array}{l}\text { Duplicado entre } \\
\text { os nós através de } \\
\text { RSYNC }\end{array}$ \\
\hline Proposta do trabalho & Linux / Ubuntu & Python/Django & Ngin $x$ & Varnish & Nginx Proxy & $\begin{array}{l}\text { Django Redis } \\
\text { Sessions }\end{array}$ & $\begin{array}{l}\text { Clusterizado } \\
\text { (Pgpool-II / } \\
\text { PostgreSQL) }\end{array}$ & $\begin{array}{l}\text { Clusterizado } \\
\text { (GlusterFS) }\end{array}$ \\
\hline
\end{tabular}

\section{PROPOSTA}

A seção tem como objetivo descrever a proposta de uma arquitetura para Cloud Computing baseada em software livre. Além disso, apresentar o estudo de caso do sistema de gestão para consultórios e clínnicas e avaliar se o conjunto (sistema mais arquitetura) atenderão os aspectos de: auto atendimento sobdemanda (self-service), acesso multi- dispositivo, escalabilidade (rápida elasticidade) e monitoramento. Por fim, é apresentado o emprego das tecnologias como solução do seu referido aspecto no contexto do Cloud Computing e apresentado o resultado dos testes avaliativos aplicados na infraestrutura.

\subsection{METODOLOGIA DE TRABALHO}

Com o objetivo de atender as diversas áreas nas quais este trabalho se correlaciona balanceamento de carga de servidores de aplicação, escalabilidade em servidores de sistema de arquivos e alta disponibilidade em servidores de banco de dados realizou-se pesquisa bibliográfica e projetou-se estudo de caso. Essas duas atividades definiram quatro etapas de investigação e implementação, que são mostradas no diagrama de atividades da Figura 2. Essa metodologia foi construída/pensada uma vez que não foi encontrado na literatura algum recurso que contemplasse os requisitos do presente trabalho.

\subsubsection{DESCRIÇÃO DAS ATIVIDADES}

- Levantamento de dados: Identificação do problema - ofertar o sistema discutido na subseção 3.2, aplicando o modelo Cloud Computing/SaaS. Estudo bibliográfico de Computação em Nuvem identificando e classificando pontos importantes para a solução do problema e levantamento de trabalhos correlacionados também foram previstos nesta etapa;

- Estudo de soluções: Levantamento de soluções comerciais e ferramentas livres que atendem a demanda de Cloud Computing;

- Criação e implantação da proposta: Criação do projeto de uma arquitetura que objetiva atender os pre'-requisitos de um ambiente de Computação em Nuvem. Nesta etapa está previsto a instalação e configurac, ão dos itens pertencentes a ar- quitetura;

- Testes e ajustes finais: Os testes foram previstos com intuito de identificar poss'ıveis falhas e pontos críticos da plataforma. Detalhes dos testes são mostrados na Subsecção 3.5. 
Figura 2. Diagrama de atividades da metodologia de trabalho proposta

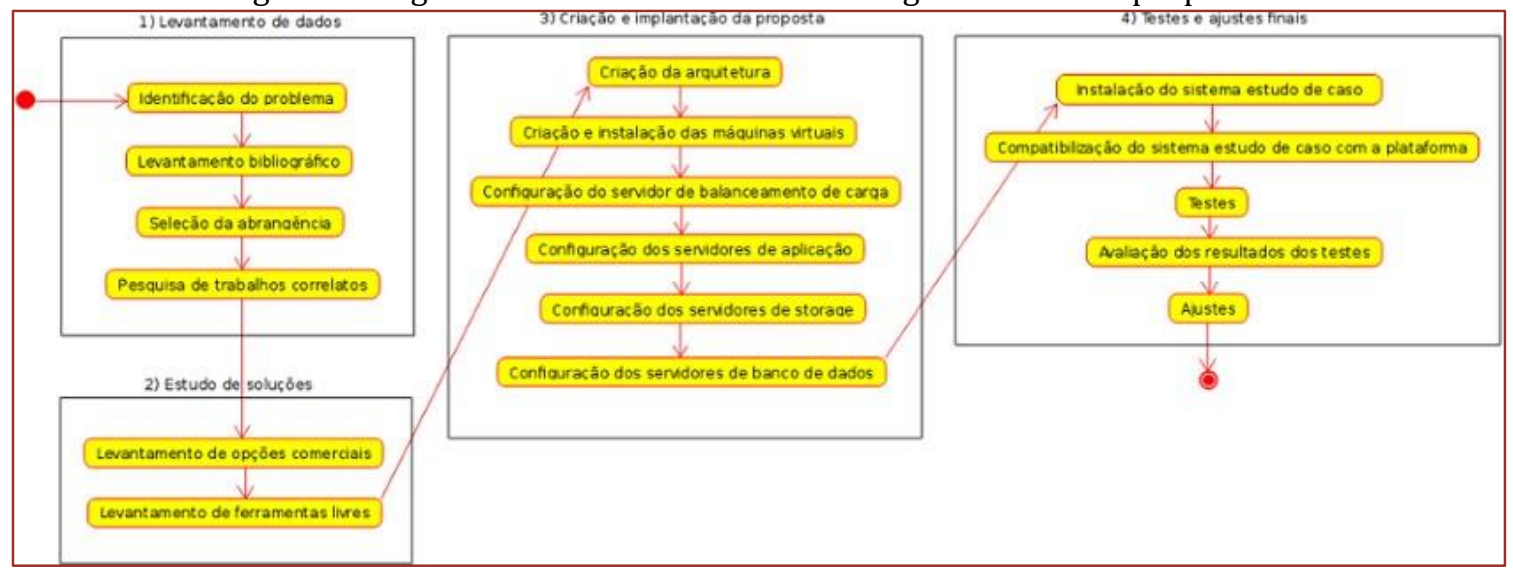

\subsection{ESTUDO DE CASO}

A partir de um sistema Web para gestão de consultórios e clínicas, pretende-se avaliar a infraestrutura proposta na Subseção 3.3. O ER Clinic ${ }^{27}$ é um sofware baseado na Web projetado para gestão ágil de consultórios e clínnicas. 0 sistema foi desenvolvido pela ER Sistemas ${ }^{28}$ como um serviço, visando o auto atendimento, em que o usuário monitora os recursos que estão sendo utilizados. 0 formato do sistema é SaaS.

Na Figura 3 é apresentada a tela principal do sistema ER Clinic e suas principais funcionalidades são:

- $\quad$ Cadastro de clientes;

- $\quad$ Agendamento de consultas com confirmação via SMS;

- Prontuário do paciente;

- Chat entre os profissionais da área de saúde e assistentes do consultório;

- Controle financeiro;

- Controle de estoque.

Figura 3. Estudo de caso: Sistema online para gestão de clínicas e consultórios - Dashboard

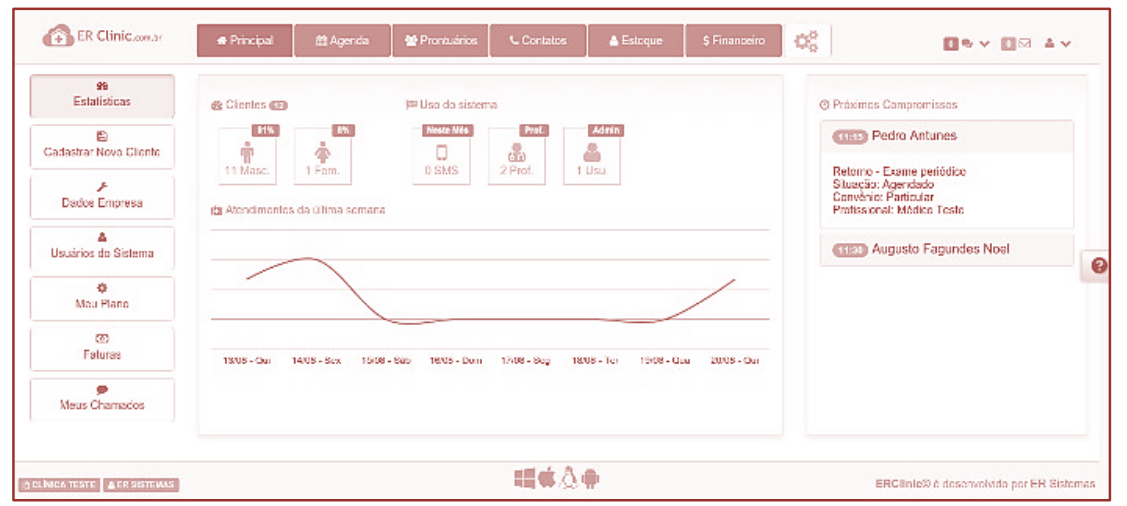


Dentre as diversas tecnologias empregadas no desenvolvimento da ferramenta, destacam-se: Linguagem de programação Python ${ }^{29}$ com o framework Django ${ }^{30}$; Node.js (https://nodejs.org) como Interpretador de código Javascript no lado do servidor; Sistema gerenciador de banco de dados Postgresqli1; Framework de frontend Bootstrap ${ }^{32}$.

\subsection{INFRAESTRUTURA DE CLOUD COMPUTING PROPOSTA}

O desafio de projetar uma arquitetura que atenda as demandas de Cloud Computing, siga os critérios do SaaS e ainda não dependa de soluções prontas comercializadas, oportunizou o estudo de algumas ferramentas livres que podem garantir isoladamente os requisitos de alta disponibilidade e rápida elasticidade.

Para eleger as ferramentas utilizadas na arquitetura proposta foram seguidos os seguintes critérios: uso de software livre, disponibilidade de uma ampla documentação e fácil acesso na comunidade envolvida com a ferramenta.

Optou-se pelo programa Nginx como servidor proxy reverso ${ }^{33}$ pela facilidade de configuração de rotas baseadas na URL (Uniform Resource Locator). Assim, as requisições são classificadas de acordo com o caminho da URL e encaminhada para o balanceamento de carga entre os servidores responsáveis pela requisição. Também o Nginx trabalha como ferramenta que disponibiliza o certificado digital SSL (Secure Soc- kets Layer) para ser homologado no órgão responsável, permitindo que o tráfego entre o cliente final e a plataforma seja utilizando conexão segura através do protocolo HTTPS (Hypertext Transfer Protocol Secure).

O Nginx também foi planejado para servir e fazer cacheamento de arquivos estáticos como imagens, CSS (Cascading Style Sheets) e Javascript além de servir o conteúdo dinâmico encaminhado pelo Gunicorn34, como resultado do processamento re- alizado pelo Python/Django.

Como solução de armazenamento distribuído, foi planejada a implantação de um cluster de servidores utilizando GlusterFS conforme foi apresentado na Subseção 2.2 .

Para atender a alta disponibilidade e escalabilidade do banco de dados, optou-se pela implantação do Postgresql com o middleware PgPoolII, cuja descrição e implantação foi apresentada no item da Subseção 2.2.

Decidiu-se por servidores virtuais privados para a instalação da plataforma pro- posta. Para a seleção de fornecedor, foram utilizados alguns critérios: qualidade do serviço, suporte e investimento mensal por servidor. Desta forma, escolheu-se a em- presa americana Digital Ocean ${ }^{35}$, onde serão instaladas instâncias virtuais com o Sistema Operacional Linux/Ubuntu 14.04 LTS de 64bits.

Alguns cuidados extras foram necessários ao implantar o cluster de servidores de aplicação no sistema do estudo de caso. Como haverá o balanceamento de carga, épossível que um mesmo usuário possa ser atendido por servidores de aplicação distintos. Neste caso, foi necessário a implantação de alguma tecnologia que compartilhe os dados de sessão entre os servidores de aplicação, para que não se perca nenhum dado do usuário logado no sistema.

A Figura 4 mostra de maneira ampla a infraestrutura proposta.

\footnotetext{
${ }^{29}$ https://www.python.org

30 https://www.djangoproject.com/

$31 \mathrm{http://www.postgresql.org}$

32 http://getbootstrap.com

${ }^{33}$ No contexto do trabalho, $\mathrm{e}^{\prime}$ um servidor que intermedia as requisic so es, fazendo o balanceamento de carga entre os servidores Web da plataforma. E' a camada externa da aplicac,ão.

34 http://gunicorn.org

35 https://www.digitalocean.co
} 
Figura 4. Diagrama estrutural

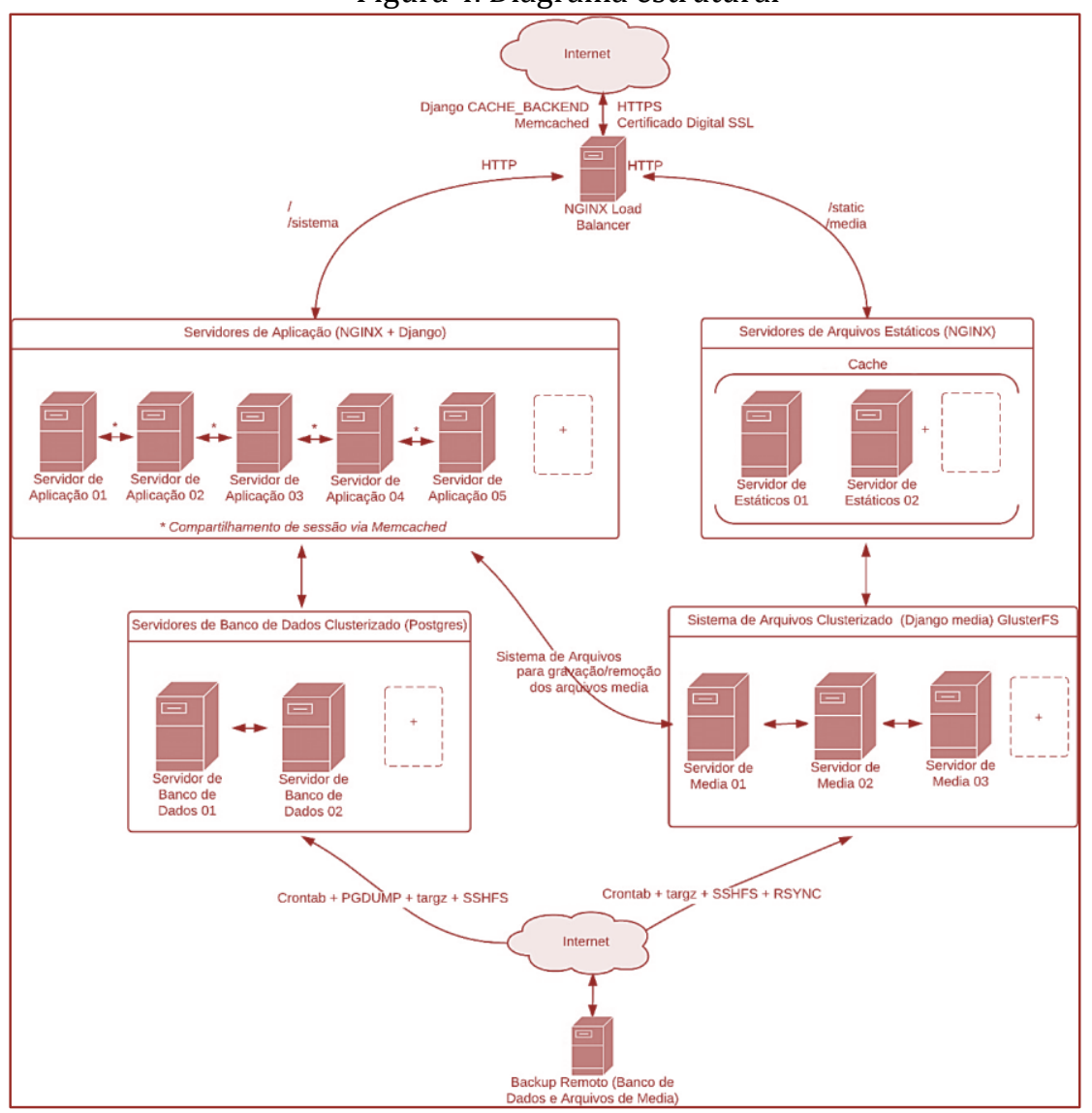

Um exemplo de atendimento de uma requisição HTTP/HTTPS atendida pela pla- taforma émostrado no diagrama de atividades da Figura 5.

Figura 5. Diagrama de atividades - Requisições HTTPS/HTTP

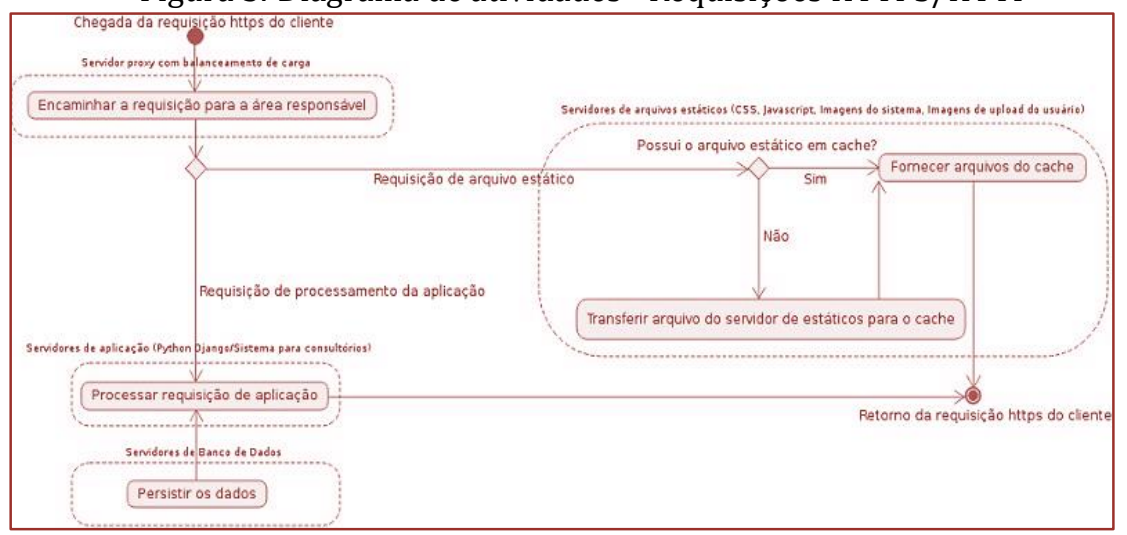

\subsection{IMPLANTAÇÃO}

A arquitetura resultante deste estudo implanta uma nuvem do tipo comunidade, caracterizado pelo atendimento de um grupo de diferentes empresas - consultórios e clínicas - que têm preocupações comuns como requisitos de segurança, regras de negócio e política, dando suporte a alta disponibilidade e escalabilidade do sistema online para gestão de consultórios e clínicas. 


\subsubsection{BALANCEADOR DE CARGA E SERVIDORES DE APLICAÇÃO}

Criou-se uma instância de máquina virtual com o sistema operacional Linux responsável pelo balanceamento de carga entre os servidores de aplicação, tunelamento HTTPS com certificado digital SSL e a disponibilização e cache de arquivos estáticos. A simples configuração do Nginx como proxy, proporcionou:

- Redirecionamento de requisições http para https, forçando que o dado trafegado entre o cliente e o cluster de servidores seja obrigatoriamente criptografado;

- Redirecionamento de requisições de arquivos estáticos para serem atendido pelos servidores espec'ificos deste tipo de arquivo (CSS, JS e imagens);

- Disponibilização do certificado digital para que a entidade certificadora confirme a validade e confiança do servidor;

- Balanceamento entre os servidores de aplicação.

Instâncias de máquinas virtuais com o sistema operacional Linux foram criadas para operar como servidores de aplicação. Um servidor de aplicação roda o núcleo de processamento do sistema apresentado no estudo de caso - subseção 3.2 - que foi desen- volvido em Python utilizando o framework Django.

Outras máquinas virtuais de servidores de aplicação podem ser criadas a partir de uma imagem (réplica) de uma máquina virtual configurada para o mesmo fim. Desta forma, sempre que é aumentado a demanda por processamento na aplicação, rapidamente novos servidores podem ser criados e colocados para trabalhar recebendo o redirecionamento de requisições originadas do balanceador de carga. Tem-se desta forma uma escalabilidade horizontal, dando recurso suficiente para atender um número crescente de requisicões.

Para cada novo nó de servidor de aplicação acrescentado na plataforma, torna-se necessário adicionar também na configuração do Nginx proxy. Esta parametrização não representa prejuíizo, uma vez que o Nginx permite recarga da configuração sem que seja necessário a parada do serviço.

A utilização do balanceamento de carga em servidores Web, que rodam sistemas que dependem de dados armazenados em sessão, demanda de um mecanismo de compartilhamento desses dados. Recomenda-se a leitura da subseção 4 que contém o resultado de dois métodos usados na implantação da infraestrutura proposta neste trabalho.

\subsubsection{BANCO DE DADOS CLUSTERIZADO}

Para a disponibilização do banco de dados em cluster, criou-se 3 novas instâncias virtuais de máquina Linux, sendo que uma delas é responsável pela execução do PGPoolII, que recebe a conexão de banco oriunda dos servidores de aplicação e redireciona para as duas máquinas servidoras de banco de dados Postgres, promovendo o balanceamento e a replicação dos dados entre os servidores.

A aplicação se conecta sempre que necessário com o PGPoolII, nunca direto nos servidores de Postgres. No caso de indisponibilidade de um dos servidores o PGPoolII promove o desvio para apenas o servidor ativo, sem que a conexão entre o servidor de aplicação e o banco de dados seja perdida.

Percebeu-se durante os testes, que ao retornar um servidor Postgres de uma pa- rada cr'itica, não houve a sincronização dos dados entre o servidor que estava ativo com o servidor que sofreu a parada. Para que houvesse a sincronia dos dados, um procedimento manual foi necessário, recomenda-se a leitura da subseção 4 como referência dos procedimentos executados para contornar esta situação.

\subsubsection{ESCALABILIDADE HORIZONTAL DO ARMAZENAMENTO EM DISCO}

Adquiriu-se duas novas instâncias de máquinas virtuais Linux, com o objetivo de com- portar os arquivos oriundos de upload realizados pelos usuários da aplicação. Estes computadores comportam-se como um grande disco virtual que aumentado a cada novo computador adicionado ao cluster.

Utilizou-se a tecnologia GlusterFS para que este espaço seja identificado como um todo na rede. Os servidores de aplicação montam remotamente a unidade virtual do cluster de armazenamento em disco 
que é utilizada para que a cada adição ou remoção de arquivos seja percebida em tempo real por qualquer um dos servidores de aplicação disponílveis na plataforma.

\subsection{AVALIAÇÃO}

Percebe-se que a proposta apresentada engloba diversos aspectos do Cloud Computing como: distribuiçaõ de carga e alta disponibilidade entre os servidores de aplicação, replicação e distribuição de carga entre servidores de banco de dados e a alta disponibilidade e escalabilidade horizontal de armazenamento em disco.

Optou-se pela aplicaçaõ de testes avaliativos para identificar se a plataforma atende os requisitos de Cloud Computing. 0 quadro da Figura 6 mostra os procedimentos de testes adotados durante o período de avaliação, com seus respectivos resultados alcançados.

Figura 6. Avaliação da plataforma

\begin{tabular}{|c|c|c|}
\hline Avaliação & Teste executado & Resultado obtido \\
\hline \multirow[b]{2}{*}{$\begin{array}{l}\text { Alta } \\
\text { disponibilidade }\end{array}$} & $\begin{array}{l}\text { Servidores de aplicação são } \\
\text { desligados aleatoriamente, } \\
\text { manualmente. }\end{array}$ & $\begin{array}{l}\text { Outro servidor pertencente ao cluster de } \\
\text { servidores de aplicação assume a requisição. } \\
\text { Confirmando o funcionamento do balanceador } \\
\text { de carga do servidor NGINX Proxy. }\end{array}$ \\
\hline & $\begin{array}{l}\text { Servidores de banco de dados } \\
\text { são desligados aleatoriamente, } \\
\text { manualmente. }\end{array}$ & $\begin{array}{l}\text { O servidor PGPoolII identifica o timeout do } \\
\text { servidor Postgres e redireciona o tráfego apenas } \\
\text { para o servidor ativo. A sincronização dos dados } \\
\text { entre o servidor que sofreu a parada critica e o } \\
\text { servidor ativo não ocorreu de forma automática, } \\
\text { conforme o esperado. Detalhes na subseção } 4 \text {. }\end{array}$ \\
\hline \multirow{2}{*}{$\begin{array}{l}\text { Rápida } \\
\text { elasticidade }\end{array}$} & $\begin{array}{l}\text { Servidores de aplicação são } \\
\text { criados a partir de imagens de } \\
\text { outros servidores de aplicação } \\
\text { e são adicionados ao cluster. }\end{array}$ & $\begin{array}{l}\text { Rapidamente a plataforma aumenta a sua } \\
\text { capacidade de processamento e memória } \\
\text { recebendo o novo servidor como parte } \\
\text { integrante do cluster. }\end{array}$ \\
\hline & $\begin{array}{l}\text { Aumento do espaço de } \\
\text { armazenamento em disco ao } \\
\text { adicionar um novo servidor } \\
\text { responsável pelo } \\
\text { armazenamento. }\end{array}$ & $\begin{array}{l}\text { Os servidores de aplicação têm seu espaço para } \\
\text { armazenamento em disco aumentado pronto } \\
\text { para receber novos uploads de arquivos. }\end{array}$ \\
\hline \multirow[t]{2}{*}{ Teste de carga } & $\begin{array}{l}\text { Teste manual de operação com } \\
\text { o sistema ( } 20 \text { usuários } \\
\text { simultâneos). }\end{array}$ & $\begin{array}{l}\text { Identificou-se o rápido esgotamento da } \\
\text { memória RAM do servidor Balanceador de } \\
\text { Carga que na configuração inicial mantinha o } \\
\text { compartilhamento dos dados da sessão HTTP } \\
\text { compartilhado entre os servidores de aplicação. } \\
\text { Problema solucionado ao substituir o método de } \\
\text { armazenamento em memória RAM para Banco } \\
\text { de Dados. Leia na subseção } 4 \text {. }\end{array}$ \\
\hline & $\begin{array}{l}\text { Teste automatizado simulando } \\
20 \text { usuários simultâneos } \\
\text { executando } 6,38 \text { requisições } \\
\text { por segundo. Tempo de teste: } \\
15 \text { minutos. }\end{array}$ & $\begin{array}{l}\text { Obteve-se como resultado: } 0 \% \text { de respostas } \\
\text { HTTP com erro; Média de tempo de resposta em } \\
145,29 \text { ms sendo que em } 90 \% \text { dos casos a média } \\
\text { de tempo de resposta foi de } 133 \mathrm{~ms} \text {. }\end{array}$ \\
\hline
\end{tabular}




\section{CONCLUSÕES}

Procurou-se, por meio deste trabalho, apresentar uma proposta de solução para promover a alta disponibilidade e rápida elasticidade em sistemas baseados na Web. Para isto, manteve-se a ideia de alinhar a pesquisa em torno das definições de Cloud Computing propostas pelo National Institute of Standards and Technology.

Percebe-se, durante a revisão bibliográfica, que soluções robustas de Cloud Com- puting comercializadas pela Amazon e Microsoft Azure resolvem o problema, sem a ne- cessidade de configurações mais detalhadas, como as exigidas pela arquitetura proposta neste trabalho.

Entretanto, o foco da solução definida é evidenciar através de um trabalho acadêmico as preocupações que a Computação em Nuvem envolve e dar mais uma opção de solução. Além disso, a plataforma sugerida procura atender os requisitos de empresas startups que buscam o rápido e incremental amadurecimeto com um baixo investimento inicial.

Em [Taurion 2009], destaca-se a importância da utilização de Open Source em soluções de arquitetura em Cloud Computing. Dentre as principais vantagens apontadas pela utilização do Open Source, destaca-se a eliminação de dependências críticas que afetam a entrega de serviços. Também o autor acredita que quanto mais a Computação em Nuvem utilizar Open Source, mais maduros e evoluídos estes sistemas se tornarão, amplificando seu uso.

\subsection{RESULTADOS}

A plataforma desenvolvida atendeu os requisitos da Computação em Nuvem, disponibilizando uma aplicação oferecida no modelo SaaS, com capacidade de ampliação de sua capacidade sem necessidade da parada no sistema. Contudo, alguns comportamentos inesperados ocorreram. O compartilhamento dos dados de sesssão utilizada pelos servidores de aplicação deu-se inicialmente pela configuração do serviço de memcached em memória RAM instalado no servidor Nginx proxy - balanceador de carga. Identificou-se o rápido esgotamento da memória RAM do balanceador de carga a cada novo usuário conectado simultaneamente no sistema ao utilizar este método. Para resolver este problema, configurou-se o framework Django para que os dados de sessão fossem compartilhados via memcached, porém em banco de dados.

A sincronização de dados entre os servidores Postgres após uma parada crítica em um dos servidores não ocorreu automaticamente, como havia sido esperado. A configuração do PGPoolII deverá ser revista, entretanto, para contornar a situação, fez-se necessário executar o sincronismo manual entre os dados dos servidores de banco de dados por meio de exportação/importação. 0 procedimento manual não ocasionou nenhuma parada do sistema.

Como trabalhos futuros, recomenda-se soluções que removam os pontos únicos de falha. Na estrutura proposta neste trabalho, pode-se mencionar como ponto único de falha o servidor balanceador de carga Nginx proxy e o PGPoolII que faz o balanceamento de carga entre os servidores de banco de dados. Uma solução para estes "gargalos"é a duplicação destes dois servidores e a implantação de IPs flutuantes, disponibilizados pela própria Digital Ocean, que por meio da técnica de failover redireciona o tráfego de rede para um servidor secundário, caso o primário apresente alguma falha.

\section{REFERÊNCIAS}

[1] Araújo, R. B. (2003). Computação ubílqua: Princípios, tecnologias e desafios. In Computação Ubíqua: Princípios, Tecnologias e Desafios, volume 1, pages 1-71. SBC, 1 edition.

[2] Barbosa, F. P. and ao, A. S. C. (2010). Grid computing e cloud computing - uma relação de diferenças, semelhanças, aplicabilidade e possibilidades de cooperação entre os dois paradigmas.

[3] Boufleur, R. (2013). Otimização de performance de sistemas web através de técnicas de clusterização monografia de curso - ctism - ufsm.

[4] Bourke, T. (2001). Server Load Balancing. OReilly e Associates, inc.

[5] CETIC (2014). Cetic.br divulga dados sobre provedores de internet e uso das tic por empresas brasileiras.

[6] Cipriani, O. N. (2009). Replicação de bases de dados postgresql utilizando pgcluster. 
[7] Cordeiro, D. (2013). Introdução a computação em nuvem - conceitos teóricos e práticos, evolução e novas possibilidades

[8] de Moura Nóbrega, P. B. (2013). Proposta de um ambiente de alta disponibilidade para sistemas java web usando computação em nuvem.

[9] Gartner (2013). Gartner says cloud office systems total 8 percent of the overall office market and will rise to 33 percent by 2017.

[10] Informe'dica (1994). Revista de informa'tica para me'dicos. Informédica, 8(10):12.

[11] Melo, C. A., Arcoverde, D. F., E' frem R. A. Moraes, ao H. C. Pimentel, J., and Freitas,

[12] R. Q. (2011). Software como servic,o: Um modelo de nega'cio emergente. In Centro de Informa'tica, volume 1, page 5. UFPE, 1 edition.

[13] NIST (2011). The nist definition of cloud computing - recommendations of the national institute of standards and technology.

[14] Roger, P. (2012). Implementando um sistema balanceador de carga http com alta disponi- bilidade utilizando nginx como proxy reverso, sincronizac, a $\mathrm{a}^{0}$ rsync, compartilhamento de sessões php e ssl.

[15] Taurion, C. (2009). Cloud Computing: Computação em nuvem. Brasport.

[16] World, C. (2010). 11 categorias de cloud computing.

http://computerworld.com.br/tecnologia/2010/03/03/11-categorias-de-cloud- computing. 


\section{Capítulo 2}

Separação e destinação dada ao lixo hospitalar perfurocortante: Das práticas da UFN ao Direito Ambiental

Fabiane Rosado Lorenzoni

Isadora Balestrin Guterres

Resumo: A presente pesquisa possui como enfoque primordial o modo de separação e destinação dada ao lixo hospitalar perfurocortante, na cidade de Santa Maria, em especial na Universidade Franciscana, objetivando estudar as problemáticas advindas do descarte inadequado desses utensílios. Ainda, será apresentado uma pesquisa de campo, realizada na UFN, na qual analisou-se o modo de separação e coleta dos materiais perfurocortantes utilizados na área de saúde da instituição. A partir desse estudo, obteve-se a seguinte indagação científica: considerando a legislação que regulamenta o tema, é possível afirmar que a UFN realiza o descarte do lixo perfurocortante de maneira adequada e em consonância com a lei? Para respondê-la, empregou-se a abordagem dedutiva e o método monográfico. Por fim, verificou-se que a UFN realiza adequadamente o descarte do material perfurocortante gerado na instituição, concluindo que essa apresenta correspondência com o Plano Municipal de Saneamento Ambiental de Santa Maria, e com o Direito Ambiental.

Palavras-chave: Descarte responsável; Resíduos perfurocortantes; Pesquisa de campo.

Trabalho orientado pela Professora Rosane Leal da Silva. 


\section{INTRODUÇÃO}

A cada ano, registra-se um aumento significativo no número de lixos produzidos no mundo, os quais são descartados inadequadamente e sem os cuidados necessários para com um meio ambiente ecologicamente preservado. Em virtude disso, a escolha de debater acerca da destinação dada ao lixo hospitalar é de fundamental relevância, se levado em conta às problemáticas que advém do descarte inadequado dessa espécie de material.

A pesquisa, assim, objetiva explanar sobre as características e os cuidados com o descarte dos lixos hospitalares perfurocortantes, desde o modo correto de separação e de destinação dada a esses resíduos, até com as cautelas que devem ser adotadas pelos profissionais que participam dessas etapas. Ainda, pretende-se apresentar a pesquisa de campo realizada na Universidade Franciscana a fim de apurar se a segregação e a destinação dada pós coleta pela Instituição está em consonância com as normas de Direito Ambiental.

Por fim, almeja-se responder a indagação científica responsável pela origem desta pesquisa: Considerando a legislação que regulamenta o tema, é possível afirmar que a Universidade Franciscana realiza o descarte do lixo perfurocortante de maneira adequada e em consonância com a lei? Para responder a esta problemática empregou-se o método dedutivo de abordagem e, como método de procedimento, o monográfico; e a técnica de pesquisa empregada foi a documentação direta na qual realizou-se uma pesquisa de campo na UFN. Essa problemática em conjunto com as normas de Direito Ambiental e as demais questões advindas da má destinação dada ao lixo estudado serão objetos de análise e discussão ao longo do trabalho.

\section{LIXO HOSPITALAR PERFUROCORTANTE: DESTINAÇÃO DADA PÓS COLETA}

De acordo com o IBGE ${ }^{36}$, somente no ano de 2010 foram recolhidos cerca de 60,9 milhões de toneladas de resíduos sólidos urbanos e, somado a esse exorbitante índice, aproximadamente, 200 mil toneladas de resíduos de serviço de saúde (BRASIL, 2012). Em razão disso, e do lixo hospitalar possuir graus de periculosidade e peculiaridades diferentes dos demais resíduos produzidos, foi preciso diferenciar o tratamento para materiais dessa natureza, sobretudo àqueles que são consideravelmente prejudiciais ao meio ambiente e à população.

Ainda, o lixo hospitalar, conhecido como resíduos de serviço de saúde, representa os diversos materiais descartáveis das unidades de saúde, os quais possuem altas taxas de propagação de doenças em decorrência dos processos em que são submetidos. Dessa forma, a Resolução RDC N 306, de 7 de Dezembro de $2004^{37}$ classificou cada material por grupos de acordo com sua tipologia, composição e seu nível de periculosidade, fornecendo as devidas informações para o seu manejo, com o intuito de evitar ou reduzir malefícios causados, tanto para o meio ambiente quanto para os profissionais responsáveis pelo tratamento daquele. Ressalta-se que

A identificação deve estar aposta nos sacos de acondicionamento, nos recipientes de coleta interna e externa, nos recipientes de transporte interno e externo, e nos locais de armazenamento, em local de fácil visualização, de forma indelével, utilizando- se símbolos, cores e frases, atendendo aos parâmetros referenciados na norma NBR $7.500^{38}$ da ABNT ${ }^{39}$ [...]. (BRASIL, 2004)

Ainda, os materiais perfurocortantes, objeto do presente trabalho, englobam utensílios advindos de procedimentos cirúrgicos como, por exemplo, agulhas, seringas, cateteres e peças anatómicas - as quais possuem capacidade de lesionar e de transmitir doenças - e devem ser identificados a partir de cores e símbolos de substância infectante constante, incluindo a descrição de resíduo perfurocortante (BRASIL, 2004). Ao encontro disso, através da criação da Agência Nacional de Vigilância Sanitária ${ }^{40}$ pela Lei 9.782/99, houve uma expansão nas atividades relacionadas à área dos serviços de saúde, originando o Regulamento Técnico para o Gerenciamento de Resíduos de Serviços à Saúde ${ }^{41}$ o qual dispõe sobre o

\footnotetext{
${ }^{36} 0$ OInstituto Brasileiro de Geografia e Estatística.

${ }^{37}$ Dispõe sobre o regulamento técnico voltado ao gerenciamento de resíduos de serviços de saúde.

${ }^{38}$ Símbolos de Risco e Manuseio para o Transporte e Armazenamento de Material.

${ }^{39}$ Associação Brasileira de Normas Técnicas.

${ }^{40}$ ANVISA.

${ }^{41}$ RGSS: possui como principais ações identificar os riscos e estabelecer medidas que sejam capazes de eliminar ou minimizar os riscos advindos do inadequado tratamento aplicado ao lixo hospitalar.
} 
manuseio, recolhimento, transporte e destinação final dos resíduos perfurocortantes, sendo realizadas em etapas.

Dessa forma, a primeira etapa corresponde à segregação, onde os resíduos já utilizados serão separados de acordo com as suas características e, após, armazenados em sacos ou recipientes que evitem vazamentos, rupturas e sejam impermeáveis (BRASIL, 2004). Em seguida, há o transporte interno que, de acordo com a Resolução RDC N³06 (2004), o lixo hospitalar perfurocortante é removido do local onde foi gerado até o seu armazenamento temporário, através de veículos constituídos de material lavável, impermeável, rígido e que resistam ao processo de descontaminação; no armazenamento temporário, os recipientes contendo resíduos já acondicionados são mantidos perto dos locais onde foram produzidos a fim de tornar célere o deslocamento entre os outros pontos de coleta.

Após, os resíduos são transportados ao local de tratamento. Este constitui na descontaminação, realizado por meios físicos ou químicos, com observância nas condições seguras e na eficácia do método adotado. Esses sistemas de tratamento necessitam de licenciamento ambiental, de acordo com a Resolução do Conselho Nacional do Meio Ambiente ${ }^{42}$ no 237/1997, e são fiscalizados pelos órgãos de vigilância sanitária e do meio ambiente, como consta a seguir:

Licenciamento Ambiental: procedimento administrativo pelo qual o órgão ambiental competente licencia a localização, instalação, ampliação e a operação de empreendimentos e atividades utilizadoras de recursos ambientais, consideradas efetiva ou potencialmente poluidoras ou daquelas que, sob qualquer forma, possam causar degradação ambiental, considerando as disposições legais e regulamentares e as normas técnicas aplicáveis ao caso. (BRASIL, 1997)

Após o armazenamento interno, os materiais perfurocortantes são armazenados externamente e acondicionados em um ambiente restrito e de fácil acesso aos coletores. Esses profissionais removem os resíduos até uma unidade de tratamento por meio de técnicas que mantenham a preservação e integridade da população e, sobretudo, dos próprios trabalhadores e do meio ambiente. Essa coleta deve estar de acordo com as normas NBR $12.810^{43}$, referente a coleta de resíduos de serviços de saúde, e NBR $14.652^{44}$, em que faz jus ao Coletor-transportador rodoviário de resíduos de serviços de saúde, sendo ambas da ABNT. Ressalta-se que, nesses casos, faz-se necessário a utilização de equipamentos ${ }^{45}$ de proteção individual, em que seu uso é destinado especialmente para esse tipo de atividade. Nesse sentido,

Todos os profissionais que trabalham no serviço, mesmo os que atuam temporariamente ou não estejam diretamente envolvidos nas atividades de gerenciamento de resíduos, devem conhecer o sistema adotado para o gerenciamento de RSS, a prática de segregação de resíduos, reconhecer os símbolos, expressões, padrões de cores adotados, conhecer a localização dos abrigos de resíduos, entre outros fatores [...] (BRASIL, 2004).

Por fim, todas as etapas em que os materiais perfurocortantes são submetidos representam uma forma de cuidado e de preservação com um meio ambiente ecologicamente equilibrado, bem como devem observar as normas de Direito Ambiental, como será analisado a seguir.

\section{LIXO HOSPITALAR E DIREITO AMBIENTAL}

A defesa por um ambiente equilibrado e saudável ganha força ao longo dos anos na medida em que a poluição relacionada ao meio ambiente aumenta gradativamente. Tratados e conferências internacionais ${ }^{46}$

\footnotetext{
42 CONAMA

43ASSOCIAÇÃO BRASILEIRA DE NORMAS TÉCNICAS. NBR 12.810, de 01 de abril de 1993. Coleta de resíduos de serviços de saúde. Rio de Janeiro. 01 abr. 1993. Disponível em: < http://wp.ufpel.edu.br/residuos/files/2014/04/NBR-12810-1993-Coleta-de-res\%C3\%ADduos-de-servi\%C3\%A7osde-sa\%C3\%BAde.pdf.>. Acesso em: 11 de maio de 2017

${ }^{44}$ ASSOCIAÇÃO BRASILEIRA DE NORMAS TÉCNICAS. NBR 14652, de 11 de julho de 2013. Implementos rodoviários coletor-transportador de resíduos de serviços de saúde - requisitos de construção e inspeção. Rio de Janeiro. 11 jul. 2013.

45Equipamentos fundamentais para a proteção individual como uniforme, luvas, avental impermeável, máscara, botas e óculos de segurança específicos a cada atividade.

46 O Protocolo de Kyoto (1997), a Agenda 21, a ECO-92 (1992), a RIO+10 (2002) e a RIO +20 (2012) são exemplos de tratados e convenções que ocorreram ao longo dos anos com o enfoque ao meio ambiente saudável, e ao desenvolvimento ecológico e sustentável.
} 
procuraram debater e refletir sobre os efeitos gerados ao meio ambiente, em virtude de uma sociedade que além de produzir e consumir em excesso, carece de preocupação acerca da poluição existente.

A poluição, voltada aos resíduos hospitalares perfurocortantes, refere-se a forma inadequada e imprudente com que é realizada o descarte desses materiais, e aos procedimentos em que são submetidos - como é o caso do processo de incineração, considerado silencioso e muito perigoso devido a liberação de gases poluentes durante a combustão - representando grande nocividade ao meio ambiente com impactos, na maioria das vezes, irreversíveis. De frente a isso, o Protocolo de Kyoto representa

Um tratado internacional com compromissos mais rígidos para a redução da emissão dos gases que provocam o efeito estufa, considerados, de acordo com a maioria das investigações científicas, como causa do aquecimento global. [...] Por ele se propõe um calendário pelo qual os países desenvolvidos têm a obrigação de reduzir a quantidade de gases poluentes em, pelo menos, 5,2\% até 2012, em relação aos níveis de 1990. (LEN,2007, p. 29)

Ou seja, é uma política afirmativa e que demonstra uma postura contrária às poluições decorrentes de processos incinerativos e descartes inadequados dos lixos hospitalares, em especial, o perfurocortante.

Contudo, atualmente, o método mais utilizado para o tratamento dos materiais perfurocortantes infecciosos é o térmico. Na incineração, por exemplo, os materiais são queimados a uma temperatura superior a $1.000^{\circ} \mathrm{C}$, emitindo uma significativa quantidade de gases poluentes à atmosfera. Infelizmente, isso vai de encontro ao Direito Ambiental e aos princípios que o norteia, como o Princípio da Precaução, da Prevenção e do Poluidor-Pagador, considerados fundamentais para o progresso da Doutrina.

Esses princípios estão dispostos na Lei 12.305 de 2 de agosto de 2010 em que institui a política nacional de resíduos sólidos: a precaução possui como objetivo a evitabilidade de qualquer risco mínimo de dano ambiental; enquanto que a prevenção está diretamente ligada ao dano e, consequentemente, a sua prevenção. Ambas não podem ser confundidas, em razão de que a prevenção apresenta uma certeza científica com relação ao dano material, e o Princípio da Precaução está voltado a uma incerteza científica, como explana Paulo Leme Machado:

No princípio da prevenção previne-se porque se sabe quais as conseqüências de se iniciar determinado ato, prosseguir com ele ou suprimi-lo. 0 nexo causal é cientificamente comprovado, é certo, decorre muitas vezes até da lógica. No princípio da precaução previne-se porque não se pode saber quais as conseqüências que determinado ato, ou empreendimento, ou aplicação científica causarão ao meio ambiente no espaço e/ou no tempo, quais os reflexos ou conseqüências. Há incerteza científica não dirimida. (MACHADO. 2001, p. 57)

Com relação ao Princípio do Poluidor-Pagador, seu objetivo é imputar ao autor, pelo dano causado ao ambiente ecológico, a responsabilidade de forma administrativa quanto civil e/ou penalmente.

Por fim, na cidade de Santa Maria, o método de descarte final do lixo perfurocortante ocorre na própria cidade, os quais são encaminhados para aterros sanitários, com licença de operação, localizados no Estado de Santa Catarina, de acordo com o Plano Municipal de Saneamento Ambiental de Santa Maria (Plano Diretor). Destaca-se que os aterros sanitários se apresentam como a melhor forma de dispor os resíduos sólidos de saúde, pois nele o solo é impermeabilizado, ou seja, recebe um tratamento especializado com o intuito de evitar a poluição do solo decorrente das substâncias nocivas que se encontram presentes nos materiais ali colocados.

Dessa forma, analisando o Plano Diretor de Santa Maria, essa forma de tratamento aplicado aos resíduos sólidos de saúde, em especial aos materiais perfurocortantes, está de acordo com a Política Nacional do Meio Ambiente em que zela pelos princípios, pilares do Direito Ambiental, explanados acima.

\section{METODOLOGIA}

Em razão da temática abordada na presente pesquisa e a problemática que o permeia, empregou-se a metodologia dedutiva como forma de objetivar stricto sensu a análise do material perfurocortante, isto é, inicialmente, apresentou-se os reflexos do lixo hospitalar no Brasil - lato sensu - até alcançar a cidade de Santa Maria, sobretudo a Universidade Franciscana. Ademais, utilizou-se como método de procedimento o monográfico, em razão da pesquisa se valer de legislações, doutrinas e artigos científicos que serviram de 
sustentáculo para a concretização do presente trabalho. Além de se fazer presente a documentação indireta, a pesquisa também abarcou a documentação direta, através de uma pesquisa de campo realizada na UFN, a partir da qual apurou-se, por meio de um questionário, a forma de separação e coleta dos materiais perfurocortantes utilizados na área de saúde da instituição, seguido de breves conclusões advindas da investigação.

\section{RESULTADOS E DISCUSSÕES}

Tendo em vista o importante papel que o Direito Ambiental possui em meio a sociedade, houve a necessidade de realizar uma pesquisa de campo, com a finalidade de investigar e comparar os estudos bibliográficos e as legislações com o que efetivamente ocorre nas instituições de saúde ou aquelas que produzem grandes quantidades de resíduos sólidos de saúde. Dessa forma, o lugar escolhido para desenvolver a pesquisa de campo foi a Universidade Franciscana que, mesmo não sendo uma instituição hospitalar, gera diariamente grandes quantidades de rejeitos, pelo fato de possuir cursos da área de saúde que se utilizam de materiais perfurocortantes para desempenhar suas atividades acadêmicas.

Com relação à coleta dos dados, utilizou-se um questionário referente à separação dos resíduos sólidos de saúde hospitalar produzidos na instituição, com as seguintes dúvidas e indagações: a) É feita a separação adequada do lixo hospitalar na instituição? Como é feito? E onde fica armazenado o lixo até que ocorra a coleta?; b) Quem realiza essa separação? De quanto em quanto tempo é realizada a coleta de lixo hospitalar na instituição?; c) Como é feito o recolhimento do lixo hospitalar, principalmente dos materiais perfurocortantes? Os profissionais que fazem o recolhimento utilizam alguma roupa ou vestimenta adequada? d) Que tipo de vestimenta é utilizada?; e) Qual é a empresa que realiza a coleta do lixo hospitalar? f) É pago uma taxa para que haja o recolhimento do lixo hospitalar? Em média como é feita a cobrança dessa taxa?.

Em meio a essas questões, verificou-se que os materiais perfurocortantes permanecem armazenados em caixas coletoras em uma sala apropriada, enquanto que o restante do lixo hospitalar é armazenado em bombonas. 0 recolhimento do lixo ocorre uma vez por semana, através de um profissional capacitado, o qual deve obedecer as regras de segurança, estando com vestimentas adequadas (luvas de manga longa, óculos, respirador semifacial, calçado de segurança, jaleco). 0 recolhimento final é feito pela empresa STERICYCLE - Gestão Ambiental Ltda, que firmou um contrato anual, com pagamento mensal com a instituição, facilitando, assim, o recolhimento do lixo hospitalar descartado (MACHADO, Adriana Marques. 2017).

Analisando as respostas do questionário, percebe-se que o material perfurocortante é separado adequadamente, com os cuidados necessários para o manejo dessa espécie de lixo, como previsto em lei mencionada neste trabalho. Desse modo, concluiu-se que a UFN segue adequadamente o Plano Municipal de Saneamento Ambiental de Santa Maria, bem como respeita os princípios basilares do Direito Ambiental.

\section{CONCLUSÃO}

A presente pesquisa visou, no decorrer das análises e explanações feitas, demonstrar a importância de debater sobre a separação e a destinação da aos lixos hospitalares, em especial sobre os materiais perfurocortantes, em razão das consequências que esses podem gerar em situações de segregação e descartes inadequados. Ressalta-se que foi estudado as peculiaridades do lixo hospitalar perfurocortante, bem como as etapas e procedimentos que são realizados, iniciando na coleta desses materiais, e encerrando-se no procedimento de descontaminação.

Ao encontro disso, realizou-se uma pesquisa de campo a fim de averiguar se a Universidade Franciscana realiza o descarte do lixo perfurocortante de maneira adequada e em consonância com a lei, sendo que o resultado obtivo foi positivo: a UFN, em consonância com o Direito Ambiental e com o Plano Diretor da cidade de Santa Maria, respeita os procedimentos que devem ser adotados à separação e à destinação dos materiais perfurocortantes contribuindo, sobretudo, para com um meio ambiente ecologicamente equilibrado e saudável.

Por fim, a escolha de debater acerca da destinação dada ao lixo hospitalar é de fundamental relevância, se levado em conta às problemáticas que advém do descarte inadequado dessa espécie de material. Em razão de, anualmente, haver aumentos significativos relacionados aos descartes desses materiais, mostra-se necessário a adoção de medidas que minimizem os impactos gerados ao meio ambiente e respeitem os princípios basilares do Direito Ambiental. 


\section{REFERÊNCIAS}

[1] BRASIL. Ministério da Saúde. Resolução RDC no 306. Diário Oficial da União, Brasília, DF, 07 dez. 2004. Disponível em: <http://bvsms.saude.gov.br/bvs/saudelegis/anvisa/2004/res0306_07_12_2004.html.>. Acesso em: 11 mai. 2017

[2] BRASIL. Ministério do Meio Ambiente. Conselho Nacional do Meio Ambiente. CONAMA. Resolução no 237. Diário Oficial da União, Brasília, DF, 29 dez. 1997. Disponível em: <http://www.mma.gov.br/port/conama/res/res97/res23797.html.>. Acesso em: 11 mai. 2017

[3] BRASIL. Ministério do Planejamento, Orçamento e Gestão. Instituto Brasileiro de Geografia e Estatística. Contagem $\quad$ Populacional. Disponivel em: http://www.ibge.gov.br/home/estatistica/populacao/condicaodevida/pnsb/>. Acesso em: 11 mai. 2017

[4] BRASIL. Lei 9782, de 26 de janeiro de 1999. Define o Sistema Nacional de Vigilância Sanitária, cria a Agência Nacional de Vigilância Sanitária, e dá outras providências. Diário Oficial da União, Brasília, DF, 26 jan. 1999. Disponível em: <http://www.planalto.gov.br/ccivil_03/leis/L9782.htm.>. Acesso em: 11 mai. 2017

[5] BRASIL. Lei 12.305 de 2 de agosto de 2010. Institui a Política Nacional de Resíduos Sólidos; altera a Lei 12 de fevereiro de 1008; e dá outras providências. Diário Oficial da União, Brasília, DF, 2 ago. 2010. Disponível em: <http://www.planalto.gov.br/ccivil_03/_ato2007-2010/2010/lei/l12305.htm.>. Acesso em: 11 mai. 2017

[6] BRASIL. Senado Federal. Jornal do Senado. Brasil produz 61 milhões de toneladas de lixo por ano. Brasília, DF, 09 de março de 2012. Disponível em: <http://www12.senado.leg.br/noticias/materias/2012/03/09/brasilproduz-61-milhoes-de-toneladas-de-lixo-por-ano>. Acesso em: 11 mai. 2017

[7] LEN, Lucília Marques Pereira. Lixo hospitalar e suas consequências sanitárias e ambientais: Estudo de caso em Fortaleza. Dissertação, curso de Mestrado Profissional em Planejamento de Políticas Públicas do Centro de Estudos Sociais aplicados, UECE, Universidade Estadual do Ceará, Fortaleza, 2007.

[8] MACHADO, Adriana Marques. A coleta de lixo hospitalar dos cursos de saúde da UFN. Centro Universitário Franciscano, Abr. 2017.

[9] MACHADO, Paulo Leme. Direito Ambiental Brasileiro. São Paulo: Malheiros, 2001. p. 57.

[10] SANTA MARIA. (Estado). Prefeitura de Santa Maria. Plano Municipal de Saneamento de Santa Maria. Plano Diretor. V. 4, p. 40, 70. Disponível em: <file:///C:/Users/CLIENTE/Downloads/Edital_de_abertura_-_012017.pdf>. Acesso em: 11 mai. 2017

[11] SÃo PAULO. (Estado). Emenda NBR 7500 de 30 de junho de 2004. Dispõe sobre os símbolos de risco e manuseio para o transporte e armazenamento. São Paulo, 2004. 


\section{Capítulo 3}

\section{Noções de biossegurança no ambiente hospitalar: Um relato de experiência}

\section{Cynthia Pires Lorentz \\ Gabriele dos Santos Mota \\ Giulia Lopes Costa da Silva \\ Daniela Sanchotene Vaucher}

Resumo:0 presente trabalho relata as atividades extensionistas realizadas na disciplina de Biossegurança no curso de Fisioterapia em um hospital na cidade de Santa Maria RS. Inicialmente ocorreu o reconhecimento do local e realização de um diagnóstico situacional, seguido da confecção e entrega de fôlderes explicativos com noções básicas de Biossegurança no ambiente hospitalar aos cuidadores e funcionários. Acredita-se que estas vivências de cunho extensionista foram importantes para a formação acadêmica, além de favorecer a educação em saúde sobre cuidados relacionados à segurança e inserção precoce dos discentes nos locais de práticas. Desta forma, a utilização dos dispositivos informativos auxiliou para a continuidade do cuidado, bem como promoveu a troca de saberes, priorizando a integralidade da assistência em saúde.

Palavras-chave: atenção terciária, atividade extensionista, educação em saúde. 


\section{INTRODUÇÃO}

A educação em saúde está associada à promoção de saúde, pois envolve processos com a participação da população, objetivando a capacitação desses indivíduos na busca da melhoria nas condições de saúde (MACHADO et al, 2007).

Os pesquisadores Duarte e Noro (2013) relatam a importância das ações educativas em hospitais, uma vez que estas instituições deveriam ser um campo de atuação de trabalho integrado para atender às necessidades de saúde dos usuários, e muitas vezes nestes locais ocorre pouca comunicação e o serviço encontra-se desarticulado dos outros serviços de atenção à saúde.

Silva e Ramos (2011) consideram que os profissionais que buscam a integralidade da atenção deverão utilizar estratégias que possam modificar o cenário para preencher as lacunas existentes na assistência e no cuidado, possibilitando a promoção da saúde e, consequentemente, a redução de reinternações.

A educação interprofissional em saúde (EIP) induz às mudanças no modelo de atenção à saúde e no atendimento de necessidades de saúde da comunidade em geral (BARR, 2015).

Percebe-se a importância do desenvolvimento de práticas educativas visando tanto à saúde individual quanto à coletiva, desta forma buscando a transformação da realidade e a participação da comunidade nesse processo. Uma vez que Freire (2006) considera que o conhecimento se constitui nas relações homem-mundo, nas relações de transformação, e através do seu aperfeiçoamento induz a problematização crítica destas relações.

A extensão universitária segundo Paula (2013) é o que convoca a universidade de forma permanente e sistemática para o aprofundamento de seu papel como instituição comprometida com a transformação social.

Este artigo tem como objetivo relatar as experiências de atividades educativas de extensão universitária desenvolvidas na atenção terciária.

\section{METODOLOGIA}

O presente artigo é do tipo relato de experiência, em que Gil et al. (2018) consideram que este tipo de pesquisa favorece ao pesquisador relatar suas experiências e vivências junto com o saber científico e assim contribuindo de forma relevante para sua área de atuação.

As atividades foram desenvolvidas durante o primeiro semestre de 2019, na disciplina de Biossegurança, em alunos do quarto semestre do curso de Fisioterapia da Universidade Franciscana (UFN).

A turma era composta por 36 discentes e que foram divididos em sete grupos. Durante a primeira visita a um hospital da cidade, observaram-se os aspectos relacionados à Biossegurança e foram elencados aspectos de potencialidades e fragilidades, e elaborado um diagnóstico situacional.

Em um segundo momento, estes mesmos grupos produziram sete fôlderes sobre diferentes temáticas abordadas durante o semestre, as quais três foram relacionados com cuidados posturais e ergonomia, voltados para técnicos de enfermagem, três relacionados à higienização das mãos e outro sobre os cuidados aos pacientes em isolamento, estes direcionados aos cuidadores.

Em uma data pré-agendada, estes materiais informativos foram entregues e apresentados pelos discentes à equipe de enfermagem e cuidadores que estavam naquela tarde no hospital, com o intuito de chamar a atenção destes sobre os temas abordados, buscando a conscientização. E posteriormente, os grupos entregaram um relatório sobre as atividades extensionistas realizadas para o encerramento da disciplina.

\section{RESULTADOS E DISCUSSÕES}

Atualmente em todos os níveis de atenção, inluindo o nível terciário ocorre uma fragilidade no funcionamento das Redes de Atenção a Saúde (RAS), pois muitas vezes não consegue prover ações e serviços de saúde com garantia de acesso para a atenção integral, resolutiva, de qualidade, humanizada em tempo adequado que buscam garantir a integralidade do cuidado (BRASIL, 2010). 
Os assuntos que foram abordados nos fôlderes foram aspectos do cotidiano hospitalar. Portanto, por apresentar um caráter explicativo, os dispositivos informativos facilitaram e trouxeram esclarecimentos sobre estes assuntos, e demonstraram a forma correta os cuidados posturais e a ergonomia, a higienização das mãos e os cuidados aos pacientes em isolamento.

Percebeu-se na visita, a necessidade de orientações acerca de cuidados ergonômicos. Segundo Valente, Gomes e Greco (2010) a ergonomia é o estudo científico da relação entre o homem e o seu ambiente de trabalho, onde ambiente não é somente o local, mas também seus materiais, métodos e organização do trabalho. Esta ainda está presente na Norma Regulamentadora - 17 (NR-17), que visa o conforto, a segurança e a adaptação do local de trabalho do funcionário. Portanto é um assunto necessário e considerável de ser abordado com os profissionais do hospital, já que nem sempre os mobiliários e equipamentos de proteção estão adequados para utilização.

Para os pesquisadores Ceccim e Ferla (2008) a formação dos profissionais da área da saúde necessita de criatividade na construção do conhecimento, baseando-se nas necessidades dinâmicas dos usuários, e nos seus aspectos sociais.

Algumas fragilidades foram identificadas, como a entrega dos materiais informativos ocorreu durante o turno de trabalho, esta atividade não englobou todos os profissionais, e muitas vezes, estes estavam envolvidos na rotina de cada setor, ou já tinham conhecimento sobre o tema abordado, e acabavam não dando atenção durante a explanação.

Esta atividade extensionista foi relevante durante a formação acadêmica, pois estas vivências aproximaram a teoria da prática, além de proporcionar uma vivência e intervenção precoce nos campos de prática, fornecendo um panorama ampliado da atuação profissional.

\section{CONCLUSÃO}

Conclui-se que a realização da visita para a elaboração do diagnóstico situacional e a posterior confecção e entrega dos dispositivos informativos trouxeram benefícios tanto aos acadêmicos da graduação pela abordagem precoce, quanto para os profissionais que executam as suas atividades e também pelas orientações fornecidas aos usuários dos serviços de saúde, visto que auxiliam na comunicação entre ensino-serviço e no compartilhamento de informações essenciais de biossegurança na área hospitalar.

Desta forma a realização de ações extensionistas estimulou a interação dialógica entre a universidade e a sociedade.

\section{REFERÊNCIAS}

[1] BARR, H. Interprofessional Education: the genesis of a global movement. United Kingdon: Center For The Advancement of Interprofessional Care. 2015.

[2] BRASIL. Ministério da Saúde. Portaria no 4.279, de 30 de dezembro de 2010, estabelece diretrizes para a organização da Rede de Atenção à Saúde no âmbito do Sistema Único de Saúde (SUS). Diário Oficial da União, Brasília, 30 dez. 2010.

[3] CECCIM, R. B.; FERLA, A. A. Educação e saúde: ensino e cidadania como travessia de fronteiras. Trab. Educ. Saúde, v.6, n.3, p.443-456, 2008

[4] DUARTE, M.L.C; NORO, A. Humanização do atendimento no setor de radiologia: dificuldades e sugestões dos profissionais de enfermagem. Cogitare Enfermagem, v. 18, n. 3, p. 532-538; 2013.

[5] FREIRE, P. Pedagogia da Autonomia: saberes necessários à pratica educativa. 34ạ ed. São Paulo: Paz e Terra, 2006.

[6] GIL, M. A. et al. Contribuições de atividades educativas realizadas na sala de espera para o acadêmico de enfermagem. Revista de Enfermagem do Centro-Oeste Mineiro, v. 8, p. 1-8; 2018.

[7] MACHADO, M.F.A.S et al. Integralidade, formação de saúde, educação em saúde e as propostas do SUS: uma revisão conceitual. Ciênc Saúde Coletiva, v. 12, n. 2, p. 335-42; 2007.

[8] PAULA, J.A. de. A extensão universitária: história, conceito e propostas Interfaces - Revista de Extensão, v. 1, n. 1, p. 05-23, jul./nov. 2013

[9] SILVA, R. V. G. O.; RAMOS, F. R. S. Processo de alta hospitalar da criança: percepções de enfermeiros acerca dos limites e das potencialidades de sua prática para a atenção integral. Texto Contexto Enferm, v. 20, n. 2, p. 247-254; 2011.

[10] VALENTE, G. S. C; GOMES, H. F ; GRECO, R. M. Condições ergonômicas do trabalho de enfermagem: análise da produção socializada entre os anos de 1998 e 2008 . Revista de Pesquisa: Cuidado é fundamental online, v. 2, n. 3, p. 1128-1148, 2010. 


\section{Capítulo 4}

Caracterização dos acidentes de trabalho graves no trânsito ocorridos em Santa Maria, Brasil

\section{Nayara Martins Ribeiro}

\section{Ligia Maria Bueno Verdiani}

\section{Marlice Ceolin Druck}

Resumo: A fim de caracterizar um perfil dos acidentes de trabalho graves no trânsito ocorridos no município de Santa Maria - RS no período de 2016 a 2018, foi realizado um estudo quantitativo, transversal e descritivo, junto a vigilância em saúde do trabalhador(a) do município, utilizando dados do Sistema de Informação de Agravos de Notificações (SINAN). As variáveis analisadas foram sexo, faixa etária, escolaridade, situação no mercado de trabalho, tipo de acidente, veículo envolvido e evolução do caso. Foram contabilizados 182 acidentes, sendo as vítimas em sua maioria do sexo masculino, na faixa etária de 25 a 44 anos, com baixa escolaridade e carteira de trabalho assinada, envolvidos principalmente em acidentes de trajeto. Considerando que acidentes de trabalho são preveníveis, conhecer o perfil dos trabalhadores acidentados no trânsito e as circustâncias envolvidas nesses acidentes se torna uma ferramenta essencial para embasar ações de prevenção deste tipo de acidente.

Palavras-chave: Causas externas; Motoristas; Risco ocupacional; Transporte; Violência urbana. 


\section{INTRODUÇ̃̃OO}

Um acidente de trabalho é aquele que ocorre durante o desenvolvimento da atividade laboral do indivíduo e por consequência provoca lesão corporal, ou perturbação com perda de função temporária ou permanente. Os acidentes de trabalho podem ser classificados em típicos, quando ocorrem no momento de exercício das atividades laborais; e de trajeto, quando o trabalhador sofre dano à sua saúde ou integridade física durante o deslocamento que realiza da sua residência ao trabalho, ou vice-versa (BRASIL,1991).

Os acidentes de trabalho são um grande problema de saúde pública, sendo o maior agravo relacionado a saúde dos trabalhadores brasileiros. Em seu boletim mais recente o Ministério da Previdência Social do Brasil registrou em 2017 aproximadamente um total de 539.705 acidentes de trabalho típicos e de trajeto em todo o território nacional, dos quais muitos resultaram em morte (MF, 2017). As causas de um acidente de trabalho são inúmeras, no entanto as mudanças socioeconômicas, bem como o aumento da violência nas últimas décadas tem refletido na ocorrência de acidentes de trabalho de tal forma que causas externas, como a violência no trânsito, tem se tornado um dos principais e mais importantes problemas de saúde do trabalhador.

Considera-se acidente de trânsito qualquer evento, ocasionada por uma colisão, tombamento, atropelamento, capotamento, saída da pista de rolamento, entre outros eventos, envolvendo motoristas, pedestres, veículos, animais, ou qualquer colisão ou situação com demais componentes nas vias (bicicleta, motocicletas, carroças, etc.). Por ano, aproximadamente 1,35 milhões de pessoas vão a óbito em decorrência a um acidente de trânsito no mundo e entre 20 e 50 milhões sofrem lesões não fatais, muitas delas resultando em incapacidade permanente. No Brasil, em 2017, dos 158.657 óbitos por causas externas notificados, 36.246 foram em em consequência a acidentes de trânsito. Das mortes no transito, em países desenvolvidos, aproximadamente de $20 \%$ a $40 \%$ das fatalidades são também classificadas como acidentes de trabalho. No Brasil os dados dos acidentes de trabalho no trânsito não são muito claros, mas em 2017 a Secretaria de Previdência Social concedeu perto de 900 benefícios de Auxílios-Doença a trabalhadores envolvidos em acidentes de trabalho caracterizados como de trânsito (MS, 2019; OPAS, 2019; MF, 2018).

As mudanças econômicas no últimos anos contribuíram para um aumento no número de automóveis, tornando-os mais acessíveis e atrativos a população, por serem ágeis para locomoção. No entanto, as recentes crises na economia transformaram esses meios de transporte em ferramentas de trabalho, o que tornou o trabalhador mais suscetível ao acometimento do acidente de trabalho.

Entretanto, acidentes de trabalho são preveníveis quando combatidos com conhecimento, boas práticas no local de trabalho e políticas públicas. Para isso, compreender o perfil dos acidentes de trabalho no trânsito é uma ferramenta essencial para embasar ações de prevenção de acidentes de trabalho. Assim, o presente trabalho teve como objetivo descrever um breve perfil dos acidentes de trabalho graves no trânsito ocorridos no município de Santa Maria/RS no período de janeiro de 2016 a dezembro de 2018, pois ao se analisar os acidentes graves registrados no SINAN no período descrito, foi constatado um grande número de acidentes graves ocorridos no trânsito, justificando com isso o presente estudo.

\section{METODOLOGIA}

Foi realizado um estudo quantitativo, transversal e descritivo, junto a vigilância em saúde do trabalhador(a) do município de Santa Maria - RS, a partir de dados secundários relativos aos acidentes de trabalho graves notificados no Sistema de Informação de Agravos de Notificação (SINAN), ocorridos no município entre janeiro de 2016 a dezembro de 2018.

Como critérios de inclusão foram considerados todos os casos de acidentes de trabalho graves que apresentaram o código de Classificação Internacional de Doenças (CID-10) relativo a acidentes de transporte registrados no SINAN, no período descrito, com trabalhadores entre 16 e 65 anos de idade. As variáveis analisadas foram sexo, faixa etária, escolaridade dos trabalhadores, bem como tipo de acidente (típico ou trajeto), principais meios de transporte envolvidos nos acidentes e evolução dos casos. Os dados registrados no sistema foram exportados e tabulados por meio do Microsoft Office Excel 365 ProPlus. Para análise estatística foram realizadas as medidas de frequência absoluta e relativa. Os critérios de exclusão adotados foram: os dados classificados pelo CID-10 como acidentes de transporte mas que não são relacionados ao trânsito, dados incompletos e sem padronização de preenchimento ou diversificação das informações que dificultam análise, porém não interferem no resultado da pesquisa. 
Conforme as diretrizes éticas, não foi necessária a aprovação pelo comitê de ética pois os dados aqui utilizados são de acesso público. Algumas informações extras foram conseguidas junto a vigilância em Saúde do trabalhador(a) do município, conforme o consentimento do gestor para a utilização dos dados.

\section{RESULTADOS E DISCUSSÕES}

A partir da análise das causas dos acidentes de trabalhos graves, por meio da CID-10 dos acidentes de transporte ocorridos de janeiro de 2016 a dezembro de 2018 foram contabilizados um total 182 casos de acidentes de trabalho graves relacionados ao trânsito no município de Santa Maria/RS. Dentre os casos notificados, $81,32 \%$ das vítimas eram do sexo masculino e mais da metade envolveu indivíduos na faixa etária de 25 a 44 anos (57,69\%). Uma melhor descrição do perfil dos acidentados pode ser visto na Tabela 1.

Tabela 1. Número e percentual de casos de acidentes de trânsito relacionados ao trabalho segundo sexo, faixa etária e escolaridade em Santa Maria/RS, no período de 2016 a 2018.

\begin{tabular}{|c|c|c|}
\hline $\begin{array}{l}\text { Variáveis } \\
\text { Sexo }\end{array}$ & $\mathrm{N}$ & $\%$ \\
\hline Feminino & 34 & 18,68 \\
\hline Masculino & 148 & 81,32 \\
\hline \multicolumn{3}{|l|}{ Faixa etária } \\
\hline $16-24$ & 28 & 15,38 \\
\hline $25-44$ & 105 & 57,69 \\
\hline $45-64$ & 44 & 24,18 \\
\hline \multicolumn{3}{|l|}{ Situação no mercado de trabalho } \\
\hline Autônomo & 54 & 29,67 \\
\hline Empregado não registrado & 11 & 6,04 \\
\hline Empregado registrado com carteira assinada & 86 & 47,25 \\
\hline Ignorado & 16 & 8,79 \\
\hline Outros & 2 & 1,10 \\
\hline Trabalho temporário & 7 & 3,85 \\
\hline Servidor Público & 5 & 2,75 \\
\hline Trabalhador avulso & 1 & 0,55 \\
\hline
\end{tabular}

De acordo com dados do Observatório Digital de Saúde e Segurança do Trabalho (2019), o sexo masculino é o mais envolvido em acidentes de trabalho graves, principalmente na faixa etária dos 18 aos 24 anos, o que difere dos resultados aqui encontrados. Além disso, os homens são o grupo populacional mais atingido por eventos de causas externas, das quais fazem parte a violência urbana e os acidentes de trânsito (DE LIMA, 2019). Cordeiro et. al (2017), em sua pesquisa para relacionar a violência urbana como maior causa de acidentes de trabalho fatais também observou a prevalência do sexo masculino nas mortes por causas externas, principalmente a violência no trânsito. Assim sendo, os indivíduos do sexo masculino são o grupo populacional mais vulnerável a acidentes de trabalho graves no trânsito e por isso políticas públicas de prevenção mais especificas a esta população seriam necessárias.

Apesar da maioria dos acidentados serem empregados com carteira assinada, 35,71\% dos trabalhadores envolvidos em acidentes de trânsito declararam ser autônomos ou empregados não registrados. 0 acidente além de trazer perda econômica para o empregador, no caso do trabalhador registrado, acarreta prejuizo econômico ao trabalhador autônomo e não registrado quando esse fica incapacidade para o trabalhar, devido a lesões corporais ou relacionadas ao veículo de transporte no qual o acidente ocorreu, pois este também pode ser sua ferramenta de trabalho.

Conforme pode ser visto na Tabela 2 houve uma prevalência dos acidentes de trajeto em relação aos acidentes de trabalho típicos. Além disso, os dados aqui analisados apontaram que a principal ocupação das vítimas eram condutores, dos quais 54,38\% eram autônomos e não registrados, e a motocicleta representou 73,08\% dos veículos envolvidos nos acidentes. Esses resultados foram semelhantes aos encontrados por Souto et al. (2016) em sua análise de perfil das vítimas de de acidentes de transporte em Pernambuco, onde $82,00 \%$ das vítimas eram condutores, sendo a motocicleta o principal meio de locomoção. Considerando que acidentes de trajeto podem ser as quedas e/ou escorregões do trabalhador no ônibus, atropelamento nas vias, colisões com outros veículos, etc.. Há de se considerar também que 
estes trabalhadores além de estarem expostos aos habituais riscos das atividades laborais como motorista, eles estão duplamente vulneráveis a acidentes relacionados diretamente ao trânsito.

Tabela 2. Frequência dos acidentes de trabalho graves no trânsito ocorridos de 2016 a 2018 em Santa Maria/RS segundo o tipo de acidente, veículo envolvido e evolução do caso.

\begin{tabular}{|l|c|c|}
\multicolumn{1}{|c|}{$\begin{array}{c}\text { Variáveis } \\
\text { Tipo de acidente }\end{array}$} \\
\hline Típico & 37 & 20,33 \\
\hline Trajeto & 144 & 79,12 \\
\hline Ignorado Veículo envolvido & 1 & 0,55 \\
\hline \multicolumn{2}{|c|}{ Motociclista } \\
\hline Carro & 133 & 73,08 \\
\hline Ciclista & 17 & 9,34 \\
\hline Atropelamento & 7 & 3,85 \\
\hline Veículo de transporte pesado & 13 & 7,14 \\
\hline Triciclo & 7 & 3,85 \\
\hline Não especificado & 2 & 1,10 \\
\hline \multicolumn{1}{|c|}{ Evolução do caso } & 3 & 1,65 \\
\hline Cura & 2 & 1,10 \\
\hline Ignorado & 4 & 2,20 \\
\hline Incapacidade Parcial & 9 & 4,95 \\
\hline Incapacidade Temporária & 146 & 80,22 \\
\hline Incapacidade Total Permanente & 1 & 0,55 \\
\hline Óbitos & 20 & 10,99 \\
\hline
\end{tabular}

O número elevado de acidentes de motocicletas observado no estudo pode ser explicado por recentes mudanças ecônomicas no país, onde houve um crescimento da frota devido ao baixo custo em relação a outros meios de transporte, além da possibilidade de sua utilização como uma fonte de trabalho, como no transporte de pessoas e produtos para entregas. Para mais, pode haver uma relação entre a baixa escolaridade, consequente baixa qualificação de mão-de-obra e a busca por alternativas de gerar renda (MIZIARA; MIZIARA; ROCHA, 2014). A média de anos de estudo da população acidentada foi de aproximadamente de 9 anos, ou seja, as vítimas tinham baixo nível de escolaridade. Um trabalho realizado na França por Fort et al. (2010), quando comparando condutores que haviam se acidentado com os que não se acidentaram para a avaliação do risco ocupacional, constatou que a baixa escolaridade foi um fator de risco.

Com relação à evolução dos casos registrados por este estudo, a maioria evoluiu para incapacidade temporária e apenas 20 casos resultaram em óbito, dos quais 14 foram em decorrência a um acidente de trajeto. Resultado semelhante foi visto por Cordeiro et al. em sua pesquisa sobre violência urbana e morte no trabalho, na qual 76,0\% dos trabalhadores que vieram a óbito por causas externas estavam no caminho de casa para o serviço, ou vice-versa. No entanto, os autores ressaltam que a categorização de um acidente como "de trajeto" é um ponto de muita discussão, principalmente no que tange as leis trabalhistas que estão atualmente analisadas e reavaliadas.

\section{CONCLUSÃO}

Novas formas de trabalho tem surgido como uma maneira de acompanhar as transformações do mercado ecônomico no Brasil e no Mundo, um setor que tem se destacado nos últimos anos é o de transporte. Essas inovações e novas situações de trabalho consequentemente trazem novos riscos a saúde do trabalhador, por isso, conhecer o perfil dos trabalhadores, e as condições dos acidentes nos quais estes se envolvem, no decorrer do exercício de sua atividade profissional, é essencial para elaborar e implementar politicas públicas de prevenção.

As estatísticas mostram que no Brasil o trânsito é uma das principais causas externas de morte, mesmo o país possuindo políticas de prenvenção de acidentes no trânsito. Pensando no trabalhador alocado no setor de transporte, a presente pesquisa visou contribuir para melhor entender a dinâmica dos acidentes de trabalho no trânsito, no contexto de Santa Maria. De fato, foi possível observar a predominância do sexo masculino, a baixa escolaridade e o predominio do envolvimento da motocicleta nos casos de acidentes de 
trabalho no trânsito do município. Além disso, a grande ocorrência de acidentes de trajeto aqui demonstrado, revela que pode existir uma deficiência, nas políticas de prevenção de acidentes de trânsito supracitadas, em Santa Maria.

Embora existam algumas limitações no estudo realizado, como a subnotificação, acredita-se que ele possa contribuir com informações que propiciam um melhor entendimento da dinâmica local dos acidentes de trabalho no trânsito e auxiliar na construção de estratégias específicas na prevenção dos mesmos para a população exposta.

\section{REFERÊNCIAS}

[1] BRASIL. Lei no 8.213, de 24 de julho de 1991. Diário da Oficial União. Poder Executivo. Brasília, DF. 24 jul. 1991.

[2] MINISTÉRIO DA FAZENDA (MF). Anuário Estatístico de Acidentes do Trabalho: AEAT 2017. vol. 1. Brasília: MF, 2017.

[3] MINISTÉRIO DA SAÚDE (MS). Departamento de informática do sus - DATASUS. Óbitos por causas externas Brasil. Jul. 2019. Disponível em: <http://tabnet.datasus.gov.br/cgi/tabcgi.exe?sim/cnv/ext10br.def>. Acesso em: 22 Ago. 2019.

[4] ORGANIZAÇÃO PAN-AMERICANA DE SAÚDE (OPAS). Folha informativa - Acidentes de trânsito. Fev. 2019. Disponível em: <https://www.paho.org/bra/index.php?option=com_content\&view=article\&id=5147:acidentes-detransito-folha-informativa\&Itemid=779>. Acesso em: 22 Ago. 2019.

[5] MINISTÉRIO DA FAZENDA (MF). Secretaria de Previdência. Acompanhamento Mensal dos Benefícios Auxílios-Doença Previdenciários Concedidos segundo os Códigos da CID-10 - Janeiro a Dezembro de 2017. Brásilia, DF. 01 mar. 2018. Disponível em:<http://sa.previdencia.gov.br/site/2018/03/Auxilio-Doen\%C3\%A7aPrevidenciario_2017_completo_CID.pdf>. Acesso em: 22 Ago. 2019.

[6] OBSERVATóRio Digital DE SAÚdE E SEGURANÇA Do TRABALHO. Perfil dos Casos - CAT. Acidentes de trabaho por idade e sexo. Disponível em: <https://smartlabbr.org/sst/localidade/0?dimensao=perfilCasosAcidentes>. Acesso em: 22 Ago. 2019.

[7] FORT, E. et al. Road accidents, an occupational risk. Safety science, v. 48, n. 10, p. 1412-1420, 2010.

[8] DE LIMA, T. F. et al. Análise epidemiológica dos acidentes de trânsito no Brasil. Encontro de Extensão, Docência e Iniciação Científica (EEDIC), v. 5, n. 1, 2019.

[9] CORDEIRO, R. et al. A violência urbana é a maior causa de acidente de trabalho fatal no Brasil. Revista de Saúde Pública, v. 51, p. 123-123, 2017.

[10] MIZIARA, I. D.; MIZIARA, C. S. M. G.; ROCHA, L. E. Acidentes de Motocicletas e sua relação com o trabalho: revisão da literatura. Saúde, Ética \& Justiça, v. 19, n. 2, p. 52-59, 2014.

[11] SOUTO, C. C. et al. Perfil das vítimas de acidentes de transporte terrestre relacionados ao trabalho em unidades de saúde sentinelas de Pernambuco, 2012-2014. Epidemiologia e Serviços de Saúde, v. 25, p. 351-361, 2016. 


\section{Capítulo 5}

\section{Vivência dos acadêmicos de Enfermagem nas unidades de urgência e emergência}

\section{Alisson Junior dos Santos}

\section{Gleida Maria Martins}

Resumo: Os serviços de urgência e emergência envolvem especificidades e articulações indispensáveis à gerência do cuidado a usuários com necessidades complexas, que requerem aprimoramento científico, manejo tecnológico e humanização, sendo assim, a formação do profissional de enfermagem demanda um ensino de qualidade, que lhe confira competência e habilidade na realização de atividades assistenciais. Este estudo consiste em um relato de experiência com acadêmicos de bacharelado em enfermagem que desenvolveram atividades de estágio curricular em unidades de urgência e emergência do município de Passos/MG no período de março a julho de 2016. A experiência possibilitou a efetiva inter-relação entre teoria e prática, assim como evidenciou o importante papel do profissional de enfermagem nestas unidades.

Palavras-chave: Estágios; Estudantes de enfermagem; Emergências. 


\section{INTRODUÇÃO}

As Unidades de Urgência e Emergência são ambientes de assistência à saúde onde é prestado o cuidado a pacientes em estado crítico que necessitam de cuidados individualizados e especializado, para os quais, se fazem necessários a monitorização rigorosa dos parâmetros vitais, cuidados intensivos, conhecimento teórico prático, habilidade e assistência de enfermagem contínua (MAIA; GUILHERME; SANTOS, 2016).

Como ambiente para o ensino da enfermagem juntos aos pacientes críticos, os serviços de urgência e emergência despertam grande interesse por parte dos acadêmicos, por ser uma unidade que possibilita o desenvolvimento de várias práticas básicas e específicas de enfermagem, além de sua complexidade e meios tecnológicos diferenciados como recursos para a sobrevida dos pacientes internados, e por consequência, favorecendo a aprendizagem neste campo de estágio.

De acordo com Silva et al (2014) o atendimento em urgência e emergência dado sua complexidade, requer que os profissionais de enfermagem estejam preparados para, a qualquer momento, prestar assistência a pacientes com alterações hemodinâmicas, sendo que, necessitam de conhecimentos e habilidades específicas para a tomada de decisões em tempo hábil, possibilitando uma intervenção eficaz.

A vivência nestas unidades nos leva a afirmar que estes são ambientes que possuem características próprias, quais sejam: a convivência dos profissionais com pacientes de risco, a ênfase do conhecimento e da tecnologia para o atendimento, a presença da morte, a ansiedade por parte de toda a equipe, pacientes e familiares e as rotinas de trabalho rígidas e desgastantes (SANTOS et al., 2013).

Este trabalho tem como objetivo reconhecer a vivência do estágio curricular em unidades de urgência e emergência do município de Passos/MG junto à acadêmicos de enfermagem.

\section{METODOLOGIA}

Trata-se de um estudo de relato de experiência através do desenvolvimento do estágio curricular com acadêmicos do 9o período do curso de bacharelado em enfermagem da Universidade do Estado de Minas Gerais - UEMG Unidade Passos, com vivência de 20 horas semanais de estágio curricular nas Unidades de Pronto Atendimento (UPA) e Unidade de Urgência e Emergência da Santa Casa de Misericórdia de Passos no período de março a julho de 2016.

De acordo com Oliveira (2012) o relato de experiência possibilita a descrição precisa de uma experiência vivenciada que possa contribuir de forma relevante para a área de atuação profissional, trazendo motivações, considerações e/ou impressões que a vivência trouxe àquele que a viveu.

Observou-se que, estes serviços de atendimento a pacientes críticos requerem atenção médica e de enfermagem permanente com dotação própria de pessoal técnico e profissionais especializados, com equipamentos específicos e demais recursos tecnológicos destinados ao diagnóstico, tratamento e estabilização dos pacientes atendidos.

\section{RESULTADOS}

Neste período, foi reconhecido o papel da equipe de enfermagem que atua em urgência e emergência, onde os profissionais devem ter um conhecimento amplo que vai desde a administração e efeitos das drogas utilizadas até o funcionamento, adequação dos equipamentos necessários, entremeando a consolidação do trabalho em equipe interdisciplinar e atividades diárias que integram a rotina de funcionamento das unidades.

Considera-se assim que os conhecimentos necessários podem ser construídos pelos profissionais de enfermagem por meio de estudos acadêmicos e no dia-a-dia, diante dos desafios que a realidade presente concede. O saber teórico é transformado em prática assistencial e este processo determinará as percepções e interpretações favorecendo o enfrentamento dos problemas do cotidiano. Essas premissas nos levam a compreender que a atividade prática poderá fortalecer este conhecimento e favorecer o desenvolvimento de competências necessárias para o trabalho em urgência e emergência.

De acordo com Dias et al (2015) os relatos e situações vivenciadas em unidades de urgência e emergência, contribuem para a capacitação dos futuros profissionais, garantindo uma assistência adequada e segura aos pacientes atendidos. 
Ao desenvolver o estágio curricular foi possível conhecer e vivenciar a rotina das unidades com mais intensidade, além de poder realizar funções e procedimentos delegados aos profissionais que atuam na unidade, interagindo com pacientes e demais membros da equipe interdisciplinar, colocando em prática conceitos aprendidos em campo teórico. Ao executar os procedimentos de enfermagem nas unidades foi possível aperfeiçoar destreza manual e habilidades técnicas de acordo com a demanda das unidades, fazendo dessa experiência complementação para a formação profissional e pessoal no que se refere à convivência com a equipe e conhecimentos adquiridos ao longo desse tempo.

Nesta vivência, foi possível unir a teoria com a prática no que se refere à importância do cuidado integral aos pacientes que se encontram ali devido ao estado grave de saúde, devendo-se estabelecer uma visão holística e humanizada.

Dessa forma, deve haver um propósito em assegurar a qualidade da formação dos profissionais de enfermagem, uma vez que cuidar de seres humanos requer profissionais capacitados para a realização das mais simples às mais complexas atividades, como no contexto do trabalho em urgência e emergência.

\section{CONSIDERAÇõES FINAIS}

$\mathrm{Na}$ formação dos profissionais de enfermagem deve-se ser estimulada a prática de estágios curriculares em unidades de urgência e emergência unindo os conteúdos teóricos à vivência prática encontrada nestes campos de atuação, favorecendo o espírito crítico dos acadêmicos.

Acreditamos que o caminho para uma maior autonomia e efetividade do exercício da enfermagem se fará com o domínio do conhecimento do seu campo, bem como da sua atuação prática e a utilização destes para o cuidado pleno em saúde. Por isso, reconhecemos a importância da vivência em urgência e emergência, pois foi possível fazer reflexões acerca da nossa prática no campo e conseguimos externar a contribuição para o nosso aprendizado, pautado em conhecimentos previamente discutidos e socializados em aulas teóricas do ensino de enfermagem.

Esta vivência é primordial e extremamente válida para a consolidação dos conhecimentos necessários para um bom desempenho e, portanto, para a formação profissional em enfermagem.

\section{REFERÊNCIAS}

[1] DIAS, R.A.; et al. Pet-Saúde/Rede Urgência e Emergência: relato de experiência em um hospital terciário do norte do Ceará. SANARE, Sobral, v.14, n.2, jan/jun. 2015. Disponível em: < https://sanare.emnuvens.com.br/sanare/article/viewFile/862/522>. Acesso em: 28 ago. 2016.

[2] MAIA, A.C.L.C.B.; GUILHERME, F.J.; SANTOS, M.S.S. Estágio extra-curricular na formação acadêmica do enfermeiro: relato de experiência. Revista Rede de Cuidados em Saúde, v.10, n.3, 2016. Disponível em: < http://publicacoes.unigranrio.edu.br/index.php/rcs/article/view/2772>. Acesso em: 19 ago. 2016.

[3] OLIVEIRA, A.R. Do relato de experiência ao artigo científico: questões sobre gênero, representações e letramento na formação de professores a distância. Revista Scripta, Belo Horizonte, v.16, n.30, 2012. Disponível em: < http://periodicos.pucminas.br/index.php/scripta/article/view/4253>. Acesso em: 28 ago. 2016.

[4] SANTOS, J.L.G.; et al. Práticas de enfermeiros na gerência do cuidado em enfermagem e saúde: revisão integrativa. Rev. bras. enferm., Brasília, v.66, n.2, mar/abr. $2013 . \quad$ Disponível em:<http://search.proquest.com/openview/216a1e83dfa94f02d5975e61460ff90f/1?pqorigsite=gscholar $>$. Acesso em: 19 ago. 2016.

[5] SILVA, D.; et al. A liderança do enfermeiro no contexto dos serviços de urgência e emergência. Rev. eletrônica enferm., Goiânia, v.16, n.1, jan/mar. $2014 . \quad$ Disponível em: < https://www.fen.ufg.br/fen_revista/v16/n1/pdf/v16n1a24.pdf>. Acesso em: 20 ago 2016. 


\section{Capítulo 6}

Violência obstétrica na percepção de enfermeiras e parturientes

\section{Naiara Almeida Guedes}

Resumo: INTRODUÇÃO: 0 termo violência obstétrica (VO) consiste em atos violentos cometidos contra gestantes, parturientes ou puérperas durante a assistência obstétrica e configura uma modalidade de violência contra a mulher. OBJETIVO: Elucidar sobre os fatores associados a ocorrência de violência obstétrica incluindo os principais aspectos geradores desse tipo de violência, além de ressaltar a responsabilidade do enfermeiro diante da bioética e a autonomia da parturiente no processo de gestar. METODOLOGIA: trata-se de uma revisão integrativa de abordagem qualitativa, os estudos foram coletados utilizando da BVS 4 bases de dados: MEDLINE, LILACS, BEDENF, IBECS, onde foram coletados artigos publicados em português entre os anos de (2015-2019), que estivessem disponíveis de forma completa e gratuita, sendo selecionados 12 artigos os quais comporão a estrutura do trabalho. RESULTADOS: De modo geral, os artigos definiram a Violência Obstétrica como um desrespeito à autonomia e aos direitos de escolha da mulher. É apresentado e discutido os resultados que emergiram do material de pesquisa onde constam relatos de enfermeiras e parturientes. CONCLUSÃO: 0 estudo contribuiu para uma melhor compreensão dos significados atribuídos à violência obstétrica e pode fornecer subsídios para que ações concretas relacionadas a essa questão possa ser considerada na elaboração de políticas públicas para enfrentamento deste fenômeno e melhoria da qualidade da assistência à parturiente.

Palavras-Chave: Violência obstétrica. Enfermeiras obstétricas. Parto humanizado. 


\section{INTRODUÇÃO}

O termo violência obstétrica consiste em atos violentos cometidos contra gestantes, parturientes ou puérperas durante a assistência obstétrica e configura uma modalidade de violência contra a mulher. (SANTOS; SOUZA; 2017).

A partir deste conceito surgiram questionamentos sobre um lugar no mundo, primeiramente como mulher e em segundo como futura profissional. Veio assim indagações: como pode um espaço e profissionais destinados ao cuidar, inverter seu papel e agredir e humilhar o próximo? Qual significado pode ser atribuído a esse tipo de agressão? A existência de atos violentos contra as parturientes é uma realidade, e diversos deles são relatados principalmente nas redes sociais, onde é nítido que tanto a população quanto os profissionais de saúde necessitam ter maior comprovação científica acerca da Violência Obstétrica (VO).

Uma vez despertado o interesse por esse tema tão complexo e que exige uma certa sensibilidade por quem o aborda, surgiram alguns questionamentos que levaram a reflexões mais amadurecidas para o delineamento do objetivo desta pesquisa, onde foi formulada a seguinte questão norteadora: qual a compreensão de enfermeiras e parturientes sobre a violência obstétrica?

Tendo em vista que uma grande porcentagem de mulheres relatou ter sofrido algum tipo de agressão durante a gestação, pré-natal ou no parto, a Organização Mundial da Saúde (OMS) em 2014, declarou a VO como uma violação dos direitos humanos fundamentais e a evidenciou como um problema global e disseminado. (SOUZA, et al. 2016).

Um ponto importante observado durante as pesquisas é que a identificação de fatores de riscos associados à ocorrência de VO possibilita intervenções de forma direcionada e é uma forma de incentivar tanto os gestores como instituições para a implementação de práticas de ensino humanizado desde a formação até as práticas dos profissionais, bem como melhorias nas condições de trabalho e na qualidade dos serviços de saúde pública. Sabendo que hoje o ensino está muito robotizado, e está formando profissionais direcionados a um problema e não ao cuidado ao ser humano, estão assim esquecendo de um ponto importante que é a humanização. Desta forma, o presente trabalho tem como objetivo elucidar sobre os fatores associados a ocorrência de violência obstétrica incluindo os principais aspectos geradores desse tipo de violência, além de ressaltar a responsabilidade do enfermeiro diante da bioética e a autonomia da parturiente no processo de gestar.

Em 2000, o MS lançou o Programa de Humanização do Pré-Natal e Nascimento com o objetivo de investir na "melhoria obstétrica e neonatal, universalização do acesso à assistência pré-natal e ao parto, exames de rotina e diminuição das taxas de cesárea desnecessária” (RODRIGUES, et al. 2018).

O que se observa hoje no nosso país é que ao mesmo tempo em que há melhorias de acesso das mulheres aos serviços de saúde e a disponibilização de tecnologias para o diagnóstico há também uma intensa medicalização do parto, com uma elevada taxa de morbimortalidade materna e perinatal. (BARBOSA; FABBRO; MACHADO, 2017). Isto mostra uma baixa qualidade da atenção ao pré-natal e ao parto.

A literatura e as redes sociais mostram que apesar de todos os movimentos já criados para diminuir os índices de ocorrência de práticas desnecessárias no parto e nascimento, observa-se que há muitos obstáculos dificultando os avanços na assistência ao pré-natal e ao parto, como por exemplo: a manutenção da medicalização do parto, o uso abusivo de tecnologias, a fragmentação das ações e dos serviços de saúde, a indiferença à presença de tratamentos hostis contra as mulheres, tanto em hospitais públicos quanto privados de todo país. (SÁ, et al. 2017).

0 tema aqui discutido tem grande relevância para a área da enfermagem e demais área da saúde envolvida bem como para toda população, pois a informação é poder, e nisso consiste a palavra empoderamento. As mulheres precisam conhecer o desconhecido para que possam fazer suas próprias escolhas. Precisam tomar para si o processo do parto e nascimento que hoje está muitas vezes entregue nas mãos apenas de profissionais. É de fundamental importância entender a priori, os direitos da mulher, a fim de não minimizar a problematização deste assunto. 


\section{METODOLOGIA}

Para alcançar o objetivo da pesquisa foi realizado uma pesquisa do tipo revisão integrativa com abordagem qualitativa, onde cada estudo investiga problemas iguais ou similares sobre determinado descritor, delineando uma conclusão a partir deles.

Revisão Integrativa é um método de pesquisa que busca proporcionar a síntese de conhecimento e a incorporação da aplicabilidade de resultados de estudos significativos na prática. (SOUZA; SILVA; CARVALHO; 2010).

O desenvolvimento desta pesquisa seguiu as seguintes etapas: identificação do tema e seleção do problema de pesquisa; definição dos critérios de inclusão e exclusão dos estudos; definição das informações a serem extraídas dos estudos primários; avaliação dos estudos primários incluídos na revisão; interpretação dos resultados e apresentação da revisão da síntese do conhecimento.

Os critérios de elegibilidade dos artigos foram: Os artigos devem responder à questão da pesquisa, sendo publicados em português nos últimos 5 anos (2015 - 2019), devem estar disponíveis de forma gratuita e completa. Estão excluídos os artigos que não respondem aos critérios de elegibilidade. Terceira etapa: A definição das informações a serem extraídas dos estudos primários: Os estudos primários foram adotados da BVS utilizando as bases de dados eletrônicas: MEDLINE, LILACS, BDENF e IBECS, a fim de reunir informações específicas relevantes para a condução da investigação e confiabilidade dos dados contidos nos artigos. Foram encontrados 111 artigos, destes foram excluídos os artigos incompletos e teses, e restaram 30 artigos, destes foram selecionados 12 artigos a partir da leitura dos resumos, os quais estão compondo a estrutura do trabalho. Esta pesquisa deve conter informações para que qualquer leitor possa identificar a relevância do estudo.

\section{DESENVOLVIMENTO}

A violência é um evento de caráter histórico que afeta todo o planeta, desde os primórdios, sendo considerada um problema de grande magnitude e complexidade. Sendo assim um fenômeno social intrínseco à civilização o qual se manifesta de várias formas: violência urbana, violência de gênero, violência física, sexual, entre outras. (BARUFALDI, et al. 2017).

Sabendo a amplitude do conceito de violência, faz-se necessário para fins desta pesquisa, em recorte específico da violência contra a mulher, aqui analisada como violência de gênero.

De acordo com os autores Barbosa, Fabbro, Machado, (2017) a violência contra a mulher é um grave problema de saúde pública, por ser uma das principais causas de mortalidade e morbidade, com impactos direto nos direitos à vida, à saúde e a integridade física e moral.

No que diz respeito a saúde pública, surgiu uma concepção de saúde da mulher, pautada na saúde sexual e reprodutiva como direito, o que impulsionou em 1984 pelo MS a elaboração do Programa de Assistência Integral à Saúde da Mulher (PAISM). Este programa compromete-se a atender todas as mulheres de forma integral, com respeito as especificidades do ciclo vital e valorização do contexto sociocultural e histórico. (MS, 2016).

Nesse contexto, faz-se necessário discutir uma outra forma de violência contra a mulher que, embora pouco abordada, tem ganhado notoriedade e motivado algumas mudanças nos sistemas de saúde: a violência obstétrica, sobre a qual iremos discorrer a seguir.

A violência obstétrica é qualquer ato ou intervenções consideradas desnecessárias realizadas à parturiente, praticada sem o consentimento da mulher e/ou em desrespeito à sua autonomia, integridade física ou psicológica, indo contra os seus desejos, sentimentos e opções. (SANTOS; SOUZA; 2017).

De acordo com Souza, et al. (2016), a violência obstétrica existe e caracteriza-se pela apropriação do corpo da mulher pelos profissionais de saúde, através do tratamento desumanizado, impactando negativamente na qualidade de vida das mulheres. Tal violência pode ser praticada por profissionais de saúde durante a gestação no momento das consultas de pré-natal, durante o parto, ou durante abortamentos.

Toda mulher tem direito a um pré-natal de qualidade, e este é um direito que visa à saúde e ao bem-estar não apenas da mulher, mas também da criança. A mulher também tem direito ao acompanhante durante todo seu trabalho de parto, parto e pós-parto, além de ser tratada com dignidade e ter garantida sua integridade física e psicológica. (SOUZA, et al. 2016). 
Dentre as características existentes de violência obstétrica durante a gestação podemos citar: Negar ou impor atendimento nos postos de saúde onde é realizado o acompanhamento de pré-natal; comentários constrangedores, por sua raça, cor, etnia, escolaridade, idade, religião, condição socioeconômica etc.; humilhar, ofender, xingar; negligenciar o atendimento; agendar cesárea sem recomendação, atendendo aos interesses e conveniência do médico. (SOUZA, et al. 2016; MS, 2016).

Já nas características existentes durante o trabalho de parto pode ser: Recusa do atendimento e admissão e impedimento da entrada do acompanhante escolhido pela gestante; procedimentos que incidam sobre o corpo da mulher, que interfiram, causem dor ou dano físico; toda ação verbal ou comportamental que cause sentimento de inferioridade, vulnerabilidade, medo e insegurança; cesariana sem nenhuma indicação clínica e sem consentimento da mulher; impedir ou retardar o contato da mulher com o bebê e impedir ou dificultar o aleitamento materno. (SOUZA, et al. 2016; TESSER, et al. 2015; ZANARDO, et al. 2017; OLIVEIRA; MERCES, 2017).

De acordo com os autores Tesser, et al. (2015) a violência obstétrica pode ser dividida em 7 categorias de desrespeito e abuso, são elas:

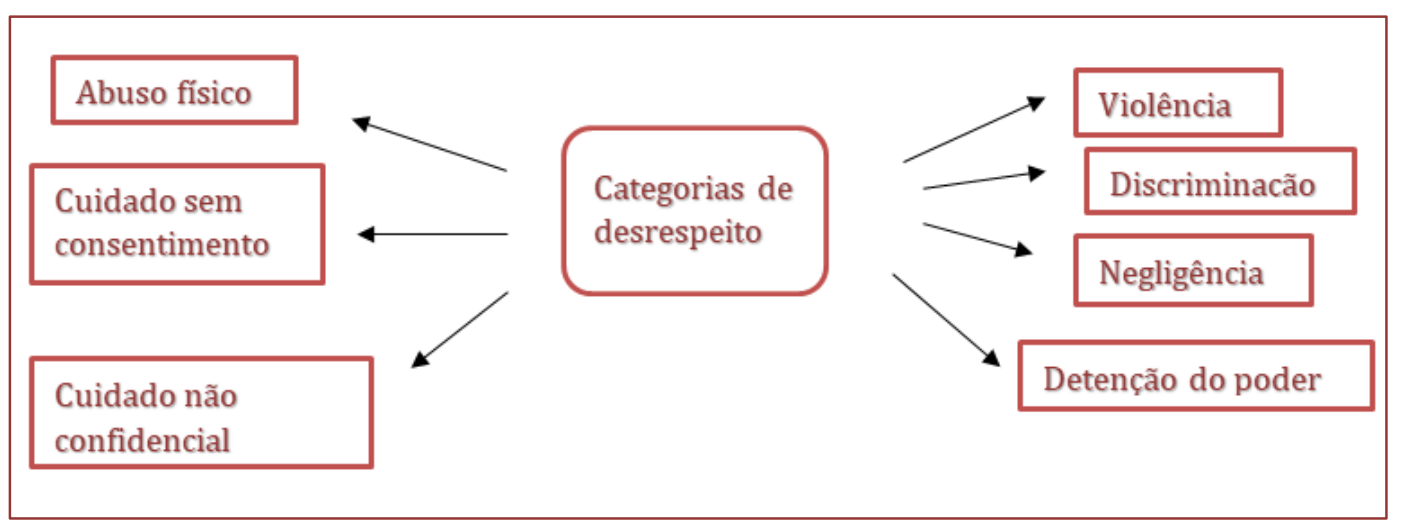

Cada uma destas categorias corresponde a um determinado direito da mulher: a mulher tem direito de estar livre de danos e maus tratos; de aceitar ou recusar qualquer procedimento após informação; ao acompanhante; a confidencialidade e privacidade; à dignidade e ao respeito; à igualdade e à equidade da atenção; ao cuidado à saúde em tempo oportuno; direito à liberdade e à autonomia. (DINIZ, et al. 2015; TESSER, et al. 2015).

Dessa forma, a violência obstétrica caracteriza-se por toda intervenção direcionado a gestante, parturiente ou puérpera de forma desnecessária e sem o consentimento prévio, ou com desrespeito a sua autonomia, integridade física ou emocional. No período pré-natal, parto e pós-parto a mulher precisa de apoio dos profissionais que estejam comprometidos com a fisiologia do nascimento e que respeitem a gestação, o nascimento, a amamentação como processos sociais e fisiológicos. No entanto, tais experiências são lembradas por muitas mulheres como momentos traumáticos, onde prevalece o sentimento do medo, da dor, da tristeza, aonde a mulher se sente agredida, desrespeitada e violentada por aqueles profissionais que deveriam prestar-lhe uma assistência de qualidade. (SOUZA, et al. 2016).

O Ministério da Saúde, em 2004, instituiu a Política Nacional de Assistência Integral à Saúde da Mulher (PNAISM), cujos princípios que norteiam o programa residem: na promoção da saúde, integralidade e no gênero, com foco na melhoria da atenção obstétrica, no planejamento familiar, na atenção ao abortamento inseguro e no combate à violência doméstica e sexual. Com esse foco de atuação, foi lançado ainda em 2004, o Pacto Nacional pela Redução da Mortalidade Materna e Neonatal, o qual consiste em ações programáticas em prol da qualificação de assistência obstétrica e neonatal (MS, 2016; OLIVEIRA, MERCES, 2017).

A Rede Cegonha foi organizada para garantir acesso, acolhimento, resolutividade e reduzir a mortalidade materna e infantil. (ZANARDO, et al. 2017). É definida como "uma rede de cuidados que assegura às mulheres o direito ao planejamento reprodutivo, à atenção humanizada à gravidez, parto e puerpério e às crianças o direito ao nascimento seguro, crescimento e desenvolvimento saudáveis". (ZANARDO, et al. 2017). 
Respaldadas em comprovações científicas, as diretrizes nacionais estabelecem recomendações para uma assistência focada na qualidade por meio da prática clínica baseada em evidências. Constituem, portanto, uma importante ferramenta de consulta e auxílio nas tomadas de decisões dos profissionais de saúde (MS, 2017). Apesar de poucas mudanças, entendemos que a normativa representa um avanço na tentativa de garantir os direitos e a autonomia das mulheres.

\section{RESULTADOS E DISCUSSÃO}

De modo geral, os resultados apontam que os artigos definiram a Violência Obstétrica como um desrespeito à autonomia e aos direitos de escolha da mulher. Sendo ainda mencionados como obstáculos à assistência qualificada ao parto: sobrecarga de serviço e falta de recursos financeiros e humanos. Alguns caminhos para a solução ou redução dessas barreiras puderam ser vistas em alguns artigos da pesquisa como: contratação de profissionais habilitados para atuação em partos humanizados e cursos de capacitação profissional voltados para a melhoria do atendimento à parturiente e família, tais como cursos voltados para todos os profissionais que fazem parte do atendimento a parturiente, e formulação da ótica dos graduandos de enfermagem.

Foi possível dentro dos estudos, identificar os fatores associados à ocorrência da VO onde tem-se como fator predominante, a formação da equipe de saúde responsável pelo atendimento da gestante, e o próprio ambiente de trabalho. Foi ainda observado e analisado as falas das enfermeiras e parturientes presentes nos artigos desta pesquisa, e em cima disto foi levantado argumentos e hipóteses.

As vivências dos profissionais de enfermagem a respeito da violência obstétrica emergiram de suas falas quando mencionaram desrespeito aos direitos da mulher, incluindo o direito à escolha do tipo de parto, e maus-tratos durante o atendimento. Citaram ainda algumas das principais manifestações da VO durante a rotina profissional, entre elas, abuso físico, cuidado indigno, demora no atendimento e falta de informação à gestante durante o pré-natal.

Nas falas dos profissionais entrevistados nos artigos, pode-se observar que, sob suas perspectivas, os principais desencadeantes da VO eram a ausência de informação da parturiente e do acompanhante, falta de capacitação e atualização do profissional, a falta de médicos e enfermeiros obstetras capacitados para a atuação no parto humanizado, e sobrecarga de trabalho.

Os profissionais de enfermagem também apontaram caminhos para o enfrentamento da VO, como por exemplo, abordagem do tema, e de como lidar com situações estressantes durante a formação profissional, que neste caso poderá ser feito por meio de treinamento e capacitação específicos para a realização de parto humanizado, além da sensibilização do profissional quanto ao tema.

As parturientes também deram o seu ponto de vista a respeito da violência obstétrica, relatando suas vivências nos ambientes hospitalares. Onde pode ser destacado como experiência de Vo, destacada por comprometer no âmbito psicológico dessas parturientes: intervenções insatisfatórias como o desrespeito na comunicação profissional-paciente, pouca autonomia sobre o próprio corpo, xingamentos e ofensas morais, submissão ao profissional de saúde, supressão de sentimentos como medo e ansiedade e momentos de solidão.

Ainda é visto mediante avaliação das falas das puérperas exame de toque excessivo, realização de manobra de Kristeller, episiotomia, esses procedimentos marcam a agressividade no processo de parturição.

A estas condutas expostas, posso correlacionar com a imposição de autoridade por parte dos profissionais de saúde, visto que no ambiente hospitalar são apontados como detentores do conhecimento. Muitas vezes os profissionais de saúde procurando agir de forma ágil no atendimento, acabam desconsiderando a assistência humanizada e integral a mulher e ao bebê.

Como consequência de tal atendimento as mulheres se sentem impotentes e reduzidas a simples objetos de trabalho, visto que deveriam ser consideradas personagem principal. Em conjunto a isso, elas também perdem a integridade biopsicossocial que podem gerar danos graves a mãe e ao bebê, como: estresse psicológico podendo esta levar a depressão pós-parto, complicações no processo de parto, traumas e até a morte por negligência, causando também um forte impacto negativo na qualidade de vida das mulheres e consequentemente na vida do bebê. 


\section{CARACTERIZAÇÃO DOS REFERENCIAIS TEÓRICOS}

Neste estudo foram analisados 12 artigos científicos, 3 livros do MS, um protocolo da OMS e o Código de Ética de Enfermagem, tais estudos cumpriram os critérios de elegibilidade previamente definidos.

Os artigos selecionados para a pesquisa encontram-se sumarizados no Quadro 1.

Quadro 1. Produção científica.

\begin{tabular}{|c|c|c|c|c|}
\hline Autor/Ano & Título & Objetivo & Metódo de Pesquisa & Resultados \\
\hline $\begin{array}{c}\text { BARBOSA, et al. } \\
2017\end{array}$ & $\begin{array}{l}\text { Violência } \\
\text { obstétrica: } \\
\text { revisão } \\
\text { integrativa de } \\
\text { pesquisas } \\
\text { qualitativas }\end{array}$ & $\begin{array}{l}\text { Descrever como os } \\
\text { fatores } \\
\text { intervencionistas } \\
\text { nas práticas de } \\
\text { assistência ao } \\
\text { parto interferem } \\
\text { na } \\
\text { vivência do parto e } \\
\text { nascimento. }\end{array}$ & $\begin{array}{l}\text { Trata-se de uma } \\
\text { revisão integrativa } \\
\text { de pesquisas } \\
\text { qualitativas. Sendo } \\
\text { utilizados na revisão } \\
54 \quad \text { artigos. } \\
\begin{array}{l}\text { Definindo-se quatro } \\
\text { categorias. }\end{array}\end{array}$ & $\begin{array}{l}\text { Os resultados apontaram } \\
\text { práticas de assistência ao parto } \\
\text { desatualizadas, } \\
\text { não recomendadas, vistas } \\
\text { como "normais", marcadas pelo } \\
\text { autoritarismo, desrespeito às } \\
\text { mulheres, caracterizando a } \\
\text { violência obstétrica. Já o modelo } \\
\text { humanizado, ao valorizar o } \\
\text { protagonismo da mulher, torna a } \\
\begin{array}{l}\text { experiência de parto mais } \\
\text { gratificante. }\end{array}\end{array}$ \\
\hline $\begin{array}{c}\text { BARUFALDI, et } \\
\text { al. } \\
2017\end{array}$ & $\begin{array}{l}\text { Violência de } \\
\text { gênero: } \\
\text { comparação da } \\
\text { mortalidade } \\
\text { por agressão } \\
\text { em mulheres } \\
\text { com e sem } \\
\text { notificação } \\
\text { prévia de } \\
\text { violência }\end{array}$ & $\begin{array}{lr}\text { Descrever } & \text { o perfil } \\
\text { de mortalidade por } \\
\text { agressão } & \text { em } \\
\text { mulheres } & \text { e } \\
\text { analisar se as } \\
\text { vítimas } & \text { de } \\
\text { violência } & \\
\text { apresentam taxas } \\
\text { de mortalidade } \\
\text { mais elevadas do } \\
\text { que a população } \\
\text { feminina geral. }\end{array}$ & $\begin{array}{lr}\text { Trata-se de } & \text { um } \\
\text { estudo descritivo da } \\
\text { mortalidade } \\
\text { agressão por } \\
\text { mulheres, a partir } \\
\text { do linkage de } \\
\text { bancos de dados. }\end{array}$ & $\begin{array}{l}\text { O risco de morte por agressão nas } \\
\text { mulheres notificadas por violência } \\
\text { foi maior do que na população } \\
\text { feminina geral, revelando assim } \\
\text { uma situação de vulnerabilidade. } \\
\text { Mulheres negras, de menor } \\
\text { escolaridade foram as principais } \\
\text { vítimas de violência e homicídios. }\end{array}$ \\
\hline $\begin{array}{c}\text { CARDOSO, et al. } \\
2017\end{array}$ & $\begin{array}{l}\text { Violência } \\
\text { obstétrica } \\
\text { institucional no } \\
\text { parto: } \\
\text { percepção de } \\
\text { profissionais } \\
\text { da saúde. }\end{array}$ & \begin{tabular}{lr}
\multicolumn{2}{l}{ Avaliar os saberes } \\
e práticas & sobre \\
violência & \\
obstétrica & na \\
percepção & dos \\
profissionais & da \\
saúde. &
\end{tabular} & $\begin{array}{l}\text { Estudo descritivo, } \\
\text { exploratório, de } \\
\text { abordagem } \\
\text { qualitativa, } \\
\text { realizado por meio } \\
\text { de entrevista com } \\
20 \text { profissionais da } \\
\text { saúde. A análise dos } \\
\text { dados ocorreu por } \\
\text { meio da técnica de } \\
\text { Análise de } \\
\text { Conteúdo. }\end{array}$ & $\begin{array}{l}\text { Apenas } 40 \% \text { dos profissionais da } \\
\text { saúde já tiveram ou ainda têm } \\
\text { contato com tema violência } \\
\text { obstétrica e apenas } 15 \% \text { relataram } \\
\text { ter cometido o ato da violência } \\
\text { obstétrica, demonstrando que o } \\
\text { tema violência obstétrica ainda é } \\
\text { desconhecido pelos profissionais da } \\
\text { saúde e vários são os motivos para } \\
\text { a existência desse problema, como } \\
\text { má estruturação das instituições de } \\
\text { saúde, carga horária excessiva e } \\
\text { falta de comunicação entre o } \\
\text { profissional e cliente }\end{array}$ \\
\hline $\begin{array}{l}\text { DINIZ, et al. } \\
\quad 2015\end{array}$ & $\begin{array}{l}\text { Violência } \\
\text { obstétrica } \\
\text { como questão } \\
\text { para saúde } \\
\text { pública no } \\
\text { Brasil: origens, } \\
\text { definições, } \\
\text { tipologia, } \\
\text { impactos sobre } \\
\text { a saúde } \\
\text { materna, e } \\
\text { propostas para } \\
\text { sua prevenção }\end{array}$ & $\begin{array}{l}\text { Realizar um } \\
\text { mapeamento de } \\
\text { suas origens, } \\
\text { definições, } \\
\text { tipologia, impactos } \\
\text { na saúde materna } \\
\text { e propostas de } \\
\text { prevenção } \\
\text { superação. e }\end{array}$ & $\begin{array}{l}\text { Revisão crítico- } \\
\text { narrativa sobre o } \\
\text { tema, abarcando } \\
\text { literatura } \\
\text { acadêmica, } \\
\text { produções dos } \\
\text { movimentos sociais } \\
\text { e documentos } \\
\text { institucionais, do } \\
\text { Brasil e exterior. }\end{array}$ & $\begin{array}{l}\text { Discute-se a complexa causalidade } \\
\text { destas formas de violência, } \\
\text { incluindo o papel da formação dos } \\
\text { profissionais e da organização dos } \\
\text { serviços de saúde e as implicações } \\
\text { na morbimortalidade materna. }\end{array}$ \\
\hline
\end{tabular}


Quadro 1. Produção científica. (Continuação)

\begin{tabular}{|c|c|c|c|c|}
\hline $\begin{array}{l}\text { Autor/ } \\
\text { Ano }\end{array}$ & Título & Objetivo & $\begin{array}{l}\text { Metódo de } \\
\text { Pesquisa }\end{array}$ & Resultados \\
\hline $\begin{array}{c}\text { OLIVEIRA; } \\
\text { MERCES, } 2017\end{array}$ & $\begin{array}{ll}\text { Percepções } & \\
\text { sobre } & \\
\text { violências } & \\
\text { obstétricas } & \text { na } \\
\text { ótica } & \text { de } \\
\text { puérperas } & \end{array}$ & $\begin{array}{lr}\text { Conhecer } & \text { a } \\
\text { percepção } & \text { das } \\
\text { puérperas } & \text { no } \\
\text { tocante } & \text { às } \\
\text { violências } & \\
\text { obstétricas. } & \end{array}$ & $\begin{array}{l}\text { Estudo descritivo, } \\
\text { de abordagem } \\
\text { qualitativa, com } 10 \\
\text { puérperas. Os } \\
\text { dados foram } \\
\text { produzidos por } \\
\text { meio de entrevista } \\
\text { semiestruturada }\end{array}$ & $\begin{array}{l}\text { Emergiram duas categorias após a } \\
\text { análise dos dados: Conhecimentos } \\
\text { de puérperas sobre violências } \\
\text { obstétricas e Antagonismo na hora } \\
\text { do parto: violências obstétricas }\end{array}$ \\
\hline $\begin{array}{c}\text { RAMOS, et al. } \\
2018\end{array}$ & $\begin{array}{l}\text { Contribuição } \\
\text { da enfermeira } \\
\text { obstétrica nas } \\
\text { boas práticas } \\
\text { da assistência } \\
\text { ao parto e } \\
\text { nascimento }\end{array}$ & $\begin{array}{l}\text { Identificar as boas } \\
\text { práticas } \\
\text { desenvolvidas pela } \\
\text { Enfermeira } \\
\text { Obstétrica em uma } \\
\text { Maternidade do } \\
\text { Rio de Janeiro e } \\
\text { analisar } \\
\text { assistência das } \\
\text { Enfermeiras } \\
\text { Obstétricas nas } \\
\text { Boas Práticas no } \\
\text { momento do parto. }\end{array}$ & $\begin{array}{l}\text { Estudo } \\
\text { documental, } \\
\text { realizado em } 1 \\
\text { maternidade } \\
\text { municipal da } \\
\text { cidade do Rio de } \\
\text { Janeiro no período } \\
\text { de janeiro a julho } \\
\text { de } 2015 \text {. }\end{array}$ & $\begin{array}{l}\text { Foi constatado que as Enfermeiras } \\
\text { Obstétricas ofereceram assistência } \\
\text { à } 367 \text { parturientes utilizando as } \\
\text { boas práticas de forma segura. O } \\
\text { estudo demonstrou que o uso das } \\
\text { boas práticas tem grande } \\
\text { influência na recuperação da } \\
\text { fisiologia materna, na adaptação do } \\
\text { recém-nascido e redução da } \\
\text { anemia na primeira infância. }\end{array}$ \\
\hline $\begin{array}{l}\text { RODRIGUES, et } \\
\text { al. } 2018\end{array}$ & $\begin{array}{lr}\text { A violência } \\
\text { obstétrica no } \\
\text { contexto } & \text { do } \\
\text { parto } & \text { e } \\
\text { nascimento } & \end{array}$ & $\begin{array}{l}\text { Analisar as } \\
\text { práticas } \\
\text { consideradas } \\
\text { violentas na } \\
\text { atenção obstétrica. }\end{array}$ & $\begin{array}{l}\text { Revisão } \\
\text { integrativa. }\end{array}$ & $\begin{array}{l}\text { Foram identificadas } 5 \text { categorias da } \\
\text { Violência obstétrica: tipologia, } \\
\text { definições, legislação; A violência } \\
\text { obstétrica na percepção da equipe } \\
\text { obstétrica; A violência obstétrica } \\
\text { na percepção das usuárias. }\end{array}$ \\
\hline SÁ, et al. 2017 & $\begin{array}{l}0 \text { direito ao } \\
\text { acesso } \\
\text { acompanhame } \\
\text { nto ao parto e } \\
\text { nascimento: a } \\
\text { ótica das } \\
\text { mulheres }\end{array}$ & $\begin{array}{lr}\text { Analisar } & \text { as } \\
\text { situações } & \text { de } \\
\text { violência } & \\
\text { obstétrica } & \\
\text { perpetrada } & \text { por } \\
\text { profissionais } & \text { de } \\
\text { saúde durante o } & \text { processo parto/ } \\
\text { nascimento sob a } \\
\text { percepção das } \\
\text { puérperas acerca } \\
\text { do direito ao } \\
\text { acesso à } \\
\text { maternidade e a } \\
\text { ter } \\
\text { acompanhante de } \\
\text { sua livre escolha. }\end{array}$ & $\begin{array}{l}\text { Estudo descritivo, } \\
\text { exploratório, de } \\
\text { abordagem } \\
\text { qualitativa, } \\
\text { realizado no } \\
\text { alojamento } \\
\text { conjunto de duas } \\
\text { maternidades } \\
\text { públicas. Foram } \\
\text { entrevistadas } 28 \\
\text { mulheres. }\end{array}$ & $\begin{array}{l}\text { O descumprimento dos direitos das } \\
\text { mulheres torna-se evidente com a } \\
\text { anulação simbólica de direitos } \\
\text { como o acesso ao serviço de saúde } \\
\text { e o descumprimento da Lei do } \\
\text { Acompanhante, que caracterizam a } \\
\text { violência obstétrica. Conclusão: o } \\
\text { apoio institucional à mulher é } \\
\text { imprescindível e deve estar } \\
\text { alicerçado na garantia do exercício } \\
\text { dos direitos legais que a amparam. }\end{array}$ \\
\hline
\end{tabular}


Quadro 1. Produção científica. (Continuação)

\begin{tabular}{|c|c|c|c|c|}
\hline $\begin{array}{c}\text { Autor/ } \\
\text { Ano }\end{array}$ & Título & Objetivo & $\begin{array}{l}\text { Metódo de } \\
\text { Pesquisa }\end{array}$ & Resultados \\
\hline $\begin{array}{c}\text { SANTOS, et al. } \\
2017\end{array}$ & $\begin{array}{l}\text { Elaboração de } \\
\text { novas } \\
\text { tecnologias em } \\
\text { enfermagem: } \\
\text { utilização de } \\
\text { uma cartilha } \\
\text { para prevenção }\end{array}$ & $\begin{array}{lr}\text { Elaborar cartilha } \\
\text { de orientações } \\
\text { para profissionais } \\
\text { de enfermagem } \\
\text { contendo } r \text { as } \\
\text { funções de cada } \\
\text { categoria e com } \\
\text { orientações sobre } \\
\text { os direitos da } \\
\text { mulher no pré- } \\
\text { natal, parto e pós- } \\
\text { parto. }\end{array}$ & $\begin{array}{l}\text { Estudo qualitativo, } \\
\text { que abrangeu sete } \\
\text { etapas, sendo } \\
\text { utilizando } \\
\text { diagrama teórico } \\
\text { como tecnologia } \\
\text { educativa. }\end{array}$ & $\begin{array}{l}\text { A Enfermagem pode incorporar, } \\
\text { em suas práticas de cuidado às } \\
\text { mulheres, ações de enfrentamento } \\
\text { e de prevenção dos agravos. } \\
\text { Elaborou-se uma cartilha intitulada } \\
\text { "Violência obstétrica é violência } \\
\text { contra a mulher - meu corpo, } \\
\text { minhas regras, meu parto, minhas } \\
\text { escolhas". }\end{array}$ \\
\hline $\begin{array}{c}\text { SOUZA, et al. } \\
2016\end{array}$ & $\begin{array}{l}\text { Fatores } \\
\text { associados a } \\
\text { ocorrência de } \\
\text { violência } \\
\text { obstétrica } \\
\text { institucional: } \\
\text { uma revisão } \\
\text { integrativa da } \\
\text { literatura }\end{array}$ & $\begin{array}{lr}\text { Realizar } & \text { revisão } \\
\text { integrativa } & \text { sobre } \\
\text { os } & \text { fatores } \\
\text { associados } & \text { à } \\
\text { ocorrência de } & \\
\text { violência } & \\
\text { obstétrica } & \\
\text { institucional } & \text { e } \\
\text { apresentar } & \text { as } \\
\text { principais } & \\
\text { evidências } & \\
\text { encontradas } & \text { nos } \\
\text { artigos } & \\
\text { selecionados. }\end{array}$ & $\begin{array}{l}\text { Revisão } \\
\text { integrativa. } \\
\text { amostra foi } \\
\text { composta por } 20 \\
\text { artigos publicados } \\
\text { entre os anos de } \\
2010 \text { e 2016. }\end{array}$ & $\begin{array}{l}\text { Diante da análise dos estudos, } \\
\text { constatou-se que os profissionais } \\
\text { descritos como promotores da } \\
\text { violência obstétrica foram os } \\
\text { médicos, equipe de enfermagem e } \\
\text { estudantes de medicina. Os } \\
\text { resultados encontrados foram } \\
\text { sistematizados e discutidos por } \\
\text { meio de } 5 \text { categorias. }\end{array}$ \\
\hline $\begin{array}{l}\text { TESSER, et al. } \\
2015\end{array}$ & $\begin{array}{l}\text { Violência } \\
\text { obstétrica } \\
\text { prevenção } \\
\text { quaternária: o } \\
\text { que é e o que } \\
\text { fazer }\end{array}$ & $\begin{array}{l}\text { Justificar } \\
\text { necessidade de } \\
\text { prevenção } \\
\text { quaternária frente } \\
\text { à violência } \\
\text { obstétrica. }\end{array}$ & $\begin{array}{l}\text { Revisão } \\
\text { bibliográfica. }\end{array}$ & $\begin{array}{l}\text { Destaca-se o excesso crônico de } \\
\text { cesarianas (55,6\% do total de } \\
\text { nascimentos) no Brasil, mais } \\
\text { prevalente no setor privado ( } 85 \%) \\
\text { do que no público }(40 \%) \text {. Ações de } \\
\text { prevenção quaternária dirigidas à } \\
\text { VO são propostas e discutidas. }\end{array}$ \\
\hline $\begin{array}{l}\text { ZANARDO, et al. } \\
2017\end{array}$ & $\begin{array}{ll}\text { Violência } & \\
\text { obstétrica no } \\
\text { Brasil: uma } \\
\text { revisão } & \\
\text { narrativa } & \end{array}$ & $\begin{array}{lr}\text { Realizar } & \text { uma } \\
\text { revisão narrativa } \\
\text { de estudos sobre } \\
\text { violência } \\
\text { obstétrica. }\end{array}$ & \begin{tabular}{lr}
\multicolumn{2}{l}{ Estudo narrativo } \\
que abordou o \\
histórico do parto \\
e & suas \\
intervenções, & o \\
conceito & de \\
violência & \\
obstétrica, \\
marcos legais & es o \\
panorama & \\
brasileiro & da \\
assistência & ao \\
parto. &
\end{tabular} & $\begin{array}{l}\text { Os dados apontam para a } \\
\text { necessidade de uma conceituação } \\
\text { de violência } \\
\text { obstétrica, preferencialmente em } \\
\text { documentos legais que a definam e } \\
\text { criminalizem. Tal conceituação } \\
\text { auxiliará na } \\
\text { identificação e enfrentamento } \\
\text { dessas situações. }\end{array}$ \\
\hline
\end{tabular}

Em relação ao ano de publicação, houve predominância dos artigos em 2017 (7) artigos, seguidos por artigos publicados em 2018 (2), 2015 (2) e 2016 (1).

Sobre a metodologia empregada, apresentaram estudos descritivos, exploratório, narrativo, documental, revisão integrativa e bibliográfica. Percebe-se que a abordagem qualitativa esteve presente em quase todos os artigos estudos.

Durante análise dos estudos foi possível identificar os fatores associados à ocorrência da VO, onde tem-se como fator predominante, a formação da equipe de saúde responsável pelo atendimento da gestante, e o próprio ambiente de trabalho. 


\section{CONCLUSÃO}

O estudo contribuiu para uma compreensão mais aprofundada dos significados atribuídos à violência obstétrica e pode fornecer subsídios para que ações concretas relacionadas a essa questão possa ser considerada na elaboração de políticas públicas para enfrentamento deste fenômeno e melhoria da qualidade da assistência à parturiente.

Posso afirmar que o significado da VO assume ampla configuração, contemplando todo o período gravídico-puerperal, o que remete a uma desvalorização da autonomia das parturientes, ao desrespeito aos seus direitos de escolha, incluindo o direito de decidir sobre a via de parto, e aos maus-tratos durante a assistência obstétrica. Vi que essa violência está pautada na intolerância ao próximo e na discriminação das mulheres que frequentam as maternidades públicas.

É fundamental o respeito aos Direitos Humanos e o enfrentamento da discriminação durante a assistência obstétrica. Mas para isso, é essencial a reorientação das intervenções focadas na autonomia e valorização da mulher enquanto sujeito ativo para que seja superado o modelo fragmentado de atenção ao parto. Com isto, acredito ser possível restabelecer e fortalecer a autonomia das mulheres, com vistas à qualidade ética e técnica nas relações entre parturientes e profissionais de saúde.

\section{REFERÊNCIAS}

[1] BARBOSA, L. C. B; FABBRO, M. R. C; MACHADO, G. P. R; Violência obstétrica: revisão integrativa de pesquisas qualitativas; Av. Enferm. 35 (2). 59637 p. 18. 2017. [citado 2019 fev. 19]. Disponível em: http://www.scielo.org.co/pdf/aven/v35n2/0121-4500-aven-35-02-00190.pdf

[2] BARUFALDI, L. A; SOUTO, R. M. C. V; CORREIA, R. S. B; MONTENEGRO, M. M. S; PINTO, I. V; SILVA, M. M. A; LIMA, C. M; Violência de gênero: comparação da mortalidade por agressão em mulheres com e sem notificação prévia de violência; Ciência\&Saúde Coletiva. Goiânia. 22 (9) 2929-2938, p. 10. 2017. [citado 2019 fev. 19]. Disponível em: http://www.scielo.br/pdf/csc/v22n9/1413-8123-csc-22-09-2929.pdf

[3] BRASIL. Ministério da Saúde. Protocolo de Atenção Básica: Saúde da Mulher/ Ministério da Saúde, Instituto Sírio-Libanês de Ensino e Pesquisa - Brasília: Ministério da Saúde, 2016. 230 p. [citado 2019 fev. 19]. Disponível em: http://portaldeboaspraticas.iff.fiocruz.br/biblioteca/protocolos-da-atencao-basica-saude-das-mulheres/

[4] BRASIL. Ministério da Saúde. Secretaria de Ciência, tecnologia e Insumos Estratégicos. Departamento de Gestão e Incorporação de Tecnologias em Saúde. Diretrizes nacionais de assistência ao parto normal/versão resumida. Brasília: Ministério da Saúde; 2017. 51 p. [citado em 2019 abril 04]. Disponível em: http://bvsms.saude.gov.br/bvs/publicacoes/diretrizes_nacionais_assistencia_parto_normal.pdf

[5] BRASIL. Ministério da Saúde. Humanização do parto e do nascimento/ Ministério da Saúde. Universidade Estadual do Ceará - Brasília: Ministério da Saúde, 2014. 465 p. (Caderno HumanizaSUS; v. 4). Disponível em: http://www.redehumanizasus.net/sites/default/files/caderno_humanizasus_v4_humanizacao_parto.pdf

[6] BRASIL. OMS - Organização Mundial de Saúde. Prevenção e eliminação de abusos, desrespeito e maus-tratos durante o parto em instituições de saúde. Genebra: OMS; 2014b. [citado 2019 mar. 10]. Disponível em: https://apps.who.int/iris/bitstream/handle/10665/134588/WHO_RHR_14.23_por.pdf?ua=1

[7] COFEN. Resolução № 564. Brasília. 2017. COFEN. [Citado 2019 fev. 19]. Disponível em: www.cofen.gov.br/resolução - cofen-no-5642017_59145.html

[8] CARDoso, F. J. C; COSTA, A. C. M; ALMEIDA, M. M.; SANTOS, T. S; OLIVEIRA, F. B. M; Violência obstétrica institucional no parto: percepção de profissionais da saúde. Rev enferm. UFPE On Line. Recife, 11 (9): 3346-53, set. 2017. [citado em 2019 fev. 19]. Disponível em: https://periodicos.ufpe.br/revistas/revistaenfermagem /article/viewFile/110232/22159

[9] DINIZ, S. G; SALGADO, H. O; ANDREZZO, H. F. A; CARVALHO, P. G. C; AGUIAR, C. A; NIY, D. Y; Violência obstétrica como questão para a saúde pública no Brasil: origens, definições, tipologia, impactos sobre a saúde materna, e propostas para sua prevenção. Journal of Human Growth and Development. São Paulo. 25 (3) 377-384 p. 8. 2015. [citado 2019 fev. 19]. Disponível em: http://pepsic.bvsalud.org/pdf/rbcdh/v25n3/pt_19.pdf

[10] OLIVEIRA, M. C; MERCES, M. C; Percepções sobre violências obstétricas na ótica de puérperas. Rev enferm. UFPE On Line. Recife, 11 (supl. 6): 2483-9, p. 7, jun., 2017. [citado em 2019 ab. 05]. Disponível em: https://periodicos.ufpe.br/revistas/revistaenfermagem/article/download/23415/19090

[11] RAMOS, W. M. A; AGUIAR, B. G. C; CONRAD, D; PINTO, C. B; MUSSUMECI, P. A; Contribuição da enfermeira obstétrica nas boas práticas da assistência ao parto e nascimento. Rev. Online de pesquisa. 10(1): 173-179 p. 7. 2018. [citado 2019 fev. 19]. Disponível em: www.seer.unirio.br/index.php/cuidadofundamental/article/ download/6019/pdf_1 
[12] RODRIGUES, D. P; ALVES, V. H; VIEIRA, R. S; LEÃO, D. C. M. R; PAULA, E; PIMENTEL, M. M; A violência obstétrica no contexto do parto e nascimento. Rev. Enferm. UFPE on line, Recife, v. 12 (1): 236-46, pg. 11, 2018. [Citado 2019 fev. 19]. Disponível em: https://periodicos.ufpe.br/revistas/revistaenfermagem/article/viewFile $/ 23523 / 26086$

[13] SÁ, A. M. P; ALVES, V. H; RODRIGUES, D. P; BRANCO, M. R. B. L; PAULA, E; MARCHIORI, G. R. S; O direito ao acesso e acompanhamento ao parto e nascimento: a ótica das mulheres. Rev enferm UFPE On Line, Recife, 11 (7): 2683-90 p. 8, jul., 2017. [citado 2019 fev. 19]. Disponível em: https://periodicos.ufpe.br/revistas/ revistaenfermagem/article/view/23440/19140

[14] SANTOS, A. L. M; SOUZA, M. H. T; Elaboração de novas tecnologias em enfermagem: utilização de uma cartilha para prevenção. Rev. Enferm. UFPE On Line, Recife, 11 (10): 3893-8, p. 6, Out., 2017. [Citado 2019 fev. 19]. Disponível em: https://periodicos.ufpe.br/revistas/revistaenfermagem/article/download/109105/24335

[15] SOUZA, A. B; SILVA, L. C; ALVES, R. N; ALARCÃO, A. C. J; Fatores associados à ocorrência de violência obstétrica institucional: uma revisão integrativa da literatura. Rev. Ciênc. Med., Campinas. 25 (3): 115-128 p. $14,2016$. [citado 2019 fev. 19]. Disponível em: http://www.scielo.org.co/pdf/aven/v35n2/0121-4500-aven-35-02-00190.pdf

[16] SOUZA, M. T; SILVA, M. D; CARVALHO, R; Revisão integrativa: o que é e como fazer; einstein. São Paulo.; 8 (1 Pt 1):102-6; 2010. [citado 2019 fev. 19]. Disponível em: http://www.scielo.br/pdf/eins/v8n1/pt_1679-4508-eins-81-0102.pdf

[17] TESSER, C. D; KNOBEL, R; ANDREZZO, H. F. A; DINIZ, S. G; Violência obstétrica e prevenção quaternária: o que é e o que fazer. Rev Bras Med Fam Comunidade. Rio de Janeiro, 10 (35) p. 12, 2015. [citado 2019 mar. 28]. Disponível em: https://www.rbmfc.org.br/rbmfc/article/download/1013/716

[18] ZANARDO, G. L. P; URIBE, M. C; NADAL, A. H. R; HABIGZANG, L. F; Violência obstétrica no Brasil: uma revisão narrativa. Psicologia\&Sociedade, Porto Alegre, 29: el5543 p. 11. 2017. [citado em 2019 fev. 19]. Disponível em: http://www.scielo.br/scielo.php?script=sci_arttext\&pid=S0102-71822017000100218 


\section{Capítulo 7}

Relato do aprender fazendo com educação em saúde: Grupo de gestantes de uma zona rural

\section{Bárbara Adrya Prestes da Silva \\ Andréa Timóteo dos Santos Dec \\ Mackelly Simionatto \\ Margarete Aparecida Salina Maciel}

Resumo: As oficinas em saúde para gestantes têm um papel de fortalecer o vínculo entre as gestantes e os profissionais de saúde. Este trabalho objetivou relatar a experiência das atividades de educação em saúde realizadas com grupos de gestantes da comunidade rural de Itaiacoca. Tratou-se de um estudo descritivo, do tipo relato de experiência, sobre as atividades de educação em saúde desenvolvidas durante o evento de extensão "Linha de Cuidado à gestantes da comunidade rural de Itaiacoca". As oficinas foram desenvolvidas nas USF do CRUTAC e do Biscaia, durante 2019, por profissionais e discentes da UEPG e com participação de profissionais da Prefeitura de Ponta Grossa. Utilizou-se de rodas de conversas e recursos que estimulassem a participação das gestantes. Um total de 15 gestantes com idades ente 14 e 43 anos foram beneficiadas. As oficinas atingiram as metas de construção do conhecimento e de proporcionar às gestantes o conhecimento e a autonomia para ao seu autocuidado e os cuidados com a criança. Para os discentes envolvidos foi uma experiência única do aprender fazendo proporcionado pela unificação do ensino, pesquisa e extensão.

Palavras-chave: Educação em Saúde. Grupos de Gestantes. Pré-natal. Zona rural. 


\section{INTRODUÇÃO}

A gravidez é um processo biológico mas que implica em constantes modificações biopsicossociais que atingem a vida da mulher. Desde o momento de sua descoberta podem surgir vários sentimentos contraditórios e até mesmo nunca experenciados (Leite et al., 2014).

A aceitação da gravidez depende de vários fatores que envolvem desde o apoio familiar, como aspectos emocionais e angústias que variam muito com a realidade de cada gestante (Leite et al., 2014; PAIVA et al., 2020). Neste contexto, as ações devem contemplar os aspectos negativos pelo impacto da descoberta da gravidez e dar suporte para que a gestante supere as dificuldades e ganhe satisfação com a maternidade (PAIVA et al., 2020).

As oficinas em saúde para gestantes têm um papel de fortalecer o vínculo entre as gestantes e os profissionais de saúde, por meio de um trabalho humanizado, que ultrapassa os aspectos biológicos e estimula o desenvolvimento do autocuidado e conhecimento sobre o processo gravídico-puerperal (QUENTAL et al., 2017). Garante-se deste modo, que no decorrer dos encontros, as gestantes tenham uma percepção positiva e crítica do seu autocuidado e dos cuidados com recém-nascido fortalecendo o vínculo mãe-filho (PAIVA et al., 2020).

Nesse âmbito, a Universidade Estadual de Ponta Grossa - UEPG por meio de seus professores do setor da saúde, atuantes no PROGRAMA CRUTAC, desenvolveu várias ações para promover a saúde de gestantes da região de Itaiacoca. Este trabalho aborda as oficinas educativas com gestantes, dado o potencial de impacto transformador nos cuidados que reduzem a morbimortalidade materno-infantil.

\section{OBJETIVOS}

Relatar a experiência das atividades de educação em saúde realizadas com grupos de gestantes da comunidade rural de Itaiacoca.

\section{METODOLOGIA}

Trata-se de um estudo descritivo, do tipo relato de experiência, sobre as atividades de educação em saúde desenvolvidas durante o evento de extensão "Linha de Cuidado à gestantes da comunidade rural de Itaiacoca", vinculado ao Programa Centro Rural Universitário de Treinamento e Ação Comunitária CRUTAC - 2 $2^{\text {a }}$ edição e proposto pelos projetos "Avaliação laboratorial na assistência à saúde e prevenção de doenças - Programa CRUTAC " e "Atuação dos pós-graduando de Odontologia (lato senso, stricto senso e residências) no Programa Centro Rural de Treinamento e Ação Comunitária - CRUTAC".

O evento ocorreu em duas Unidades Básicas com Estratégia de Saúde da Família (USF) da zona rural que abrangem várias microáreas do Distrito de Itaiacoca, zona rural do município de Ponta Grossa, Paraná. Portanto, o trabalho foi desenvolvido na USF do Centro Rural de Treinamento e Ação Comunitária CRUTAC, localizada no Cerrado Grande e na USF da localidade do Biscaia, ambas sob a responsabilidade da Prefeitura Municipal de Ponta Grossa, Secretaria Municipal de Saúde (PMPG-SMS). 0 período trabalhado compreendeu fevereiro a dezembro de 2019, com o envolvimento de profissionais e discentes dos cursos de Farmácia, Enfermagem e Odontologia da UEPG, além da participação de profissionais da PMPG-SMS.

As gestantes, bem como seus familiares e/ou acompanhantes, foram convidadas a participar dos grupos, que tiveram frequência mensal e ocorriam no mesmo dia da consulta do pré-natal.

Como critério de inclusão as gestantes deveriam estar vinculadas às USF citadas e aceitar participar do grupo de gestantes, independente do tempo de gestação ocorrido, sendo excluídas as gestantes que não atendiam a esses critérios.

Utilizou-se de rodas de conversa, recursos audiovisuais e atividades que estimulassem o dinamismo e a participação dos grupos e os temas eram referentes ao período gravídico-puerperal, aos cuidados gerais com a saúde e aos cuidados necessários desde o nascimento do bebê até os primeiros anos de vida da criança. Empregou-se, ainda, folhetos informativos. 


\section{RESULTADOS}

Participaram das ações educativas dez gestantes que frequentavam a USF do CRUTAC e cinco a USF do Biscaia, totalizando 15 gestantes com idades entre 14 e $43(27 \pm 9)$ anos que estavam no período gestacional, as vezes acompanhadas da mãe ou do companheiro, mas na maioria das vezes, sozinhas. Na figura 1 estão representadas as localidades atingidas neste trabalho e na figura 2, as principais características das gestantes participantes das atividades.

Figura 1 - Localidades abrangidas pela USF do CRUTAC e do Biscaia na Educação em Saúde para grupos de gestantes

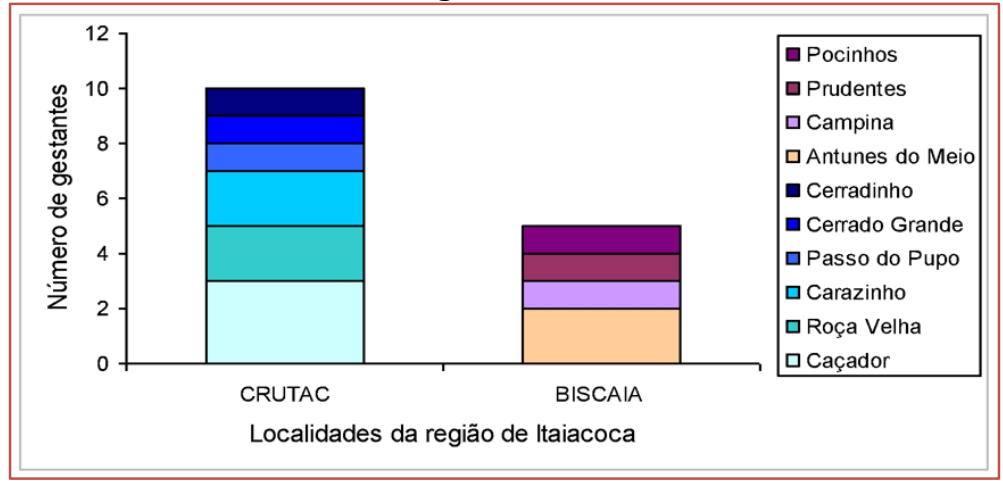

Fonte: Autoria própria (2019)

Figura 2 - Características demográficas e gestacionais das participantes dos grupo de gestantes de Itaiacoca

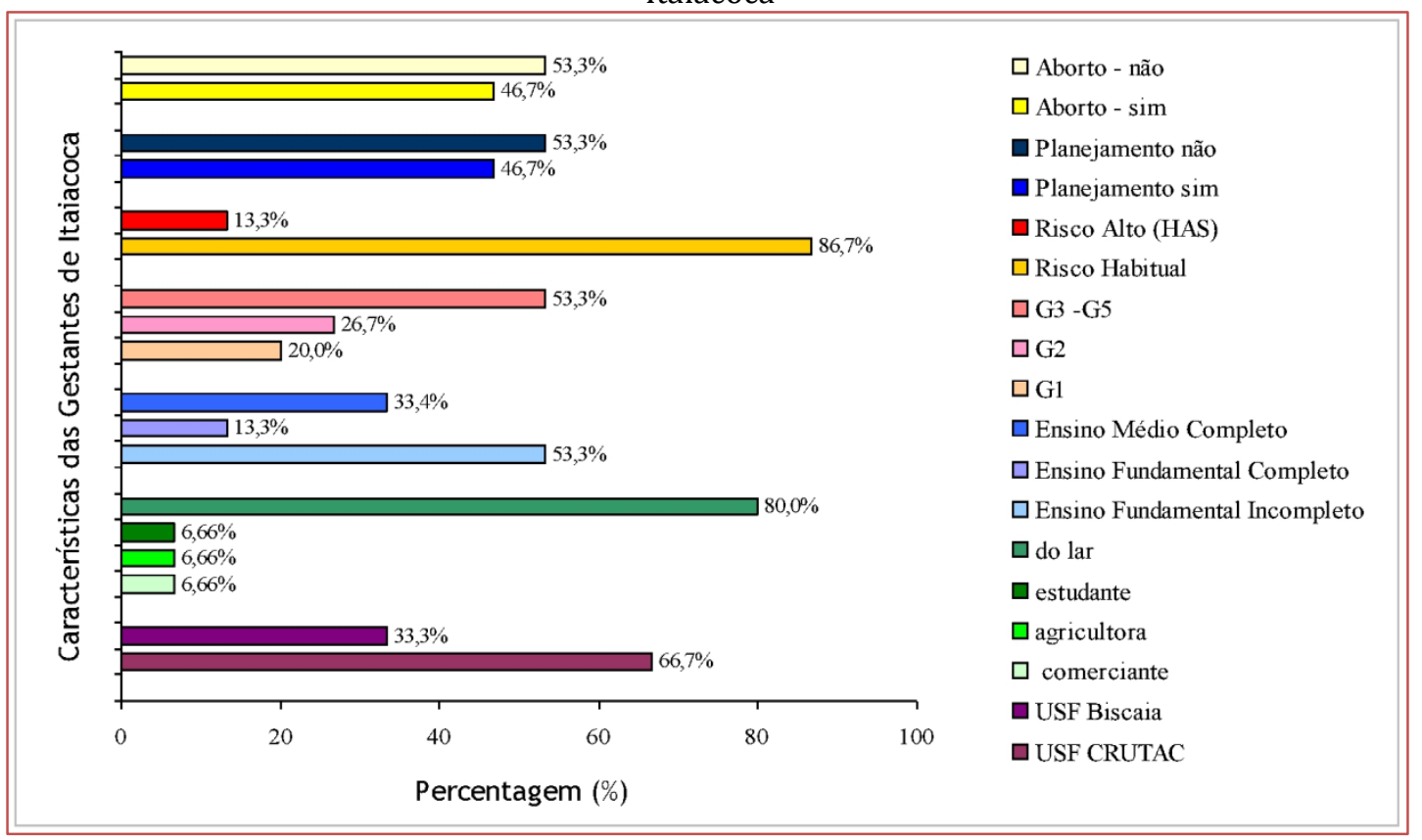

FONTE: Autoria própria (2019)

Pode se notar a predominância de gestantes que se dedicavam às atividades do lar $(80,0 \%)$ e com baixo nível de instrução escolar (53,3\%). Quanto à gestação, a maioria não havia planejado a gravidez $(n=8$; $53,3 \%)$ e três $(20,0 \%)$ eram primigestas, sendo uma de 14 anos. Sete $(46,7 \%)$ gestantes já haviam vivenciado um ou dois abortos anteriormente, o que lhes causava grande apreensão com a atual gestação. Na classificação de risco gestacional, duas mulheres (13,3\%) de 41 e 43 anos foram classificadas como gestantes de alto risco por apresentarem hipertensão arterial sistêmica, outro fator de grande preocupação quanto às complicações que poderiam acontecer. No entanto, tudo correu bem e ambas as gestações foram à termo. 
As oficinas trabalharam os temas que abordaram a importância da realização precoce do pré-natal, os exames laboratoriais no acompanhamento do período gestacional para prevenção e diagnóstico de doenças, o teste da mãezinha para o diagnóstico de hemoglobinopatias (bem como a realização do teste), pré-natal bucal, alimentação e exercícios físicos durante a gestação, autocuidados durante o período gestacional e puerperal, sexualidade na gravidez, direitos da gestante, parto e cesariana, aleitamento materno, cuidados com o recém-nascido e os primeiros mil dias da criança. A figura abaixo apresenta algumas atividades e produções que as discentes do curso de enfermagem utilizaram para tornar o ambiente mais acolhedor e para a fixação do tema discutido (Figura 3).

Figura 3 - Discentes atuando no evento "Linha do cuidado a gestantes da comunidade rural de Itaiacoca -

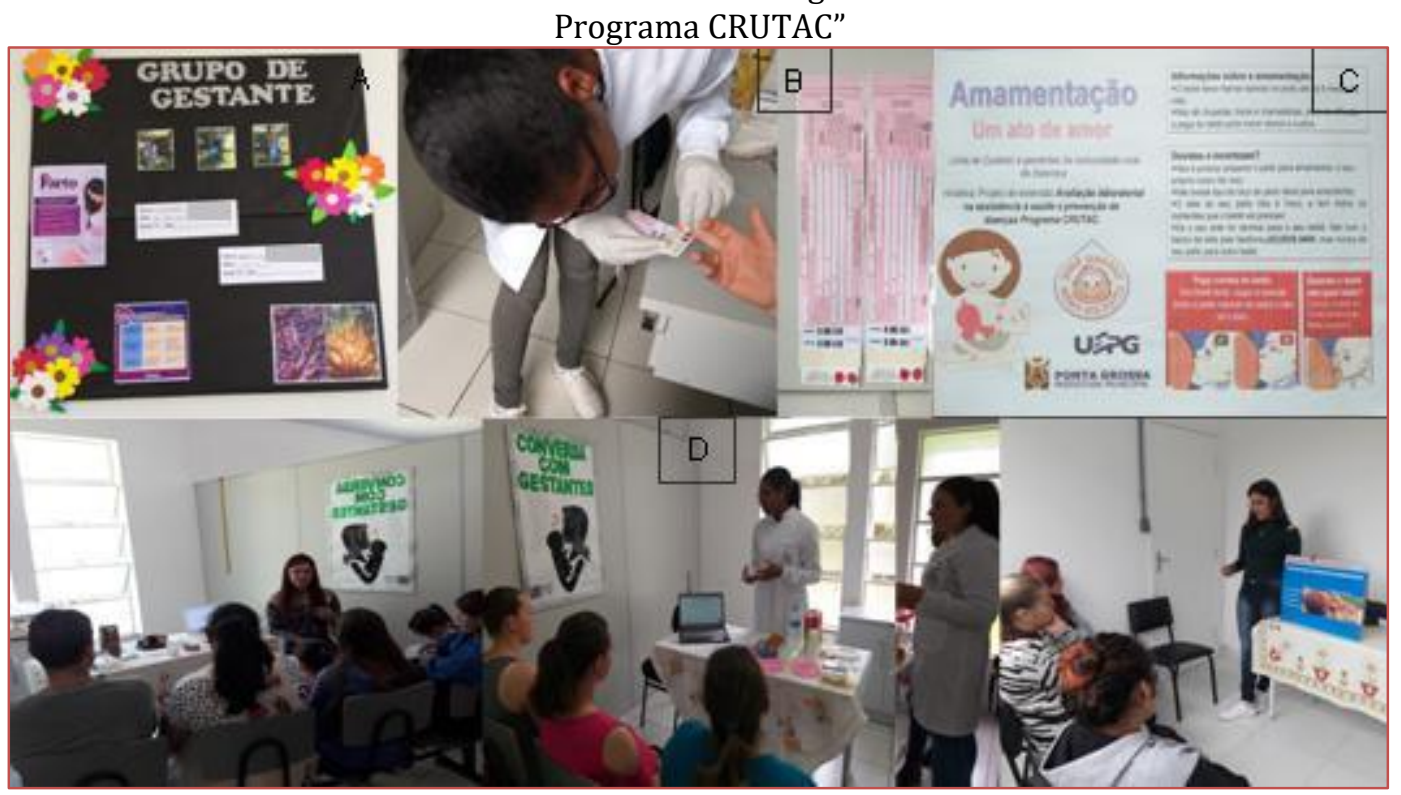

A: cartaz interativo; B: teste da mãezinha, C: folheto informativo e D: rodas de conversas.

As oficinas foram conduzidas de modo a incentivar a participação e a troca de experiências entre as gestantes, incorporando o saber científico ao saber popular. Foi perceptível a participação e satisfação das gestantes nos encontros. Com o decorrer do tempo, elas se tornaram mais comunicativas, falando e expondo seus sentimentos e dificuldades, além de compartilhar os momentos da descoberta da gravidez e o apoio recebido com a notícia. Pode-se perceber, ao longo das oficinas, a confiança que foram adquirindo em si mesmas e o comprometimento com as consultas periódicas e com os exames, tanto laboratoriais como os de ultrassonografia obstétrica.

\section{CONSIDERAÇÕES FINAIS}

0 acolhimento às gestantes, de forma simples e atenciosa e a escuta atenta são ferramentas para o sucesso das atividades educativas e para aproximação entre as participantes e os profissionais da saúde. As rodas de conversas estimulam o protagonismo das gestantes durante o processo educativo agregando maior segurança e estímulo para vivenciar este momento único, na vida de uma mulher. Os temas abordados nas oficinas educativas promovem as informações e orientações de autocuidados básicos para melhorar a saúde materno-infantil. 0 apoio de profissionais da saúde são imprescindíveis para segurança materna no processo de cuidar.

A atuação de discentes da área da saúde como os da enfermagem, frente a grupos de gestantes, proporciona a construção de conhecimentos mútuo entre discentes e grupos e contribui reciprocamente. Ocorre, visivelmente, um empoderamento das gestantes no processo do gestar e cuidar, enquanto as discentes aprendem a ensinar pela dinâmica aprender fazendo, proporcionado pela extensão aliada ao ensino e a pesquisa. 


\section{APOIO}

Pró- Reitoria de Extensão e Assuntos Culturais da UEPG - Programa Institucional de Bolsas Extensão Universitária - PROEX (Edital PROEX № 021/2019).

\section{REFERÊNCIAS}

[1] LEITE, M. G. et.al. Sentimentos Advindos da Maternidade: Revelações de um Grupo de Gestantes. Psicologia em Estudo, Maringá, v. 19, n. 1, p. 115-124, jan./mar. 2014.

[2] PAIVA, M. V. S. et al. Educação em saúde com gestantes e puérperas: um relato de experiência. Revista Científica de Enfermagem - RECIEN, São Paulo, v.10, n. 29, p.112-119, 2020.

[3] QUENTAL, L. L. C. et al. Práticas educativas com gestantes na atenção primária. Revista de Enfermagem UFPE on line, Recife, v. 11, supl. 12, p. 5370-81, dez., 2017. Disponível em: https://doi.org/10.5205/1981-8963v11i12a23138p5370-5381-2017. Acesso em: 28 set. 2020. 


\section{Capítulo 8}

\section{Atenção à saúde do recém-nascido prematuro: Uma revisão integrativa}

\section{Brenda Helen Freire Barbosa \\ José Deusvando Freire Campos \\ Josivan Felix da Silva \\ Assemcleves Aguiar da Silva \\ Alexandre Bezerra Silva}

Resumo: 0 nascimento prematuro é definido como sendo aquele que ocorre antes ou no final da $37^{a}$ semana de idade gestacional. Cerca de $10 \%$ dos partos no Brasil são prematuros e responsáveis por $75 \%$ das mortes neonatais. Objetivou-se identificar os principais cuidados de Enfermagem ao recém-nascido prematuro. Trata-se revisão integrativa da literatura. A busca ocorreu nas bases de dados eletrônicas: Literatura Latino-Americana e do Caribe em Ciências da Saúde (LILACS) e Scientific Eletronic Libraby Online (SCIELO). Os critérios de inclusão adotados foram: estudos publicados na língua portuguesa disponíveis de forma gratuita e online, e que compartilhassem da temática e do objetivo proposto. E quanto aos de exclusão, destaca-se artigos duplicados, em forma de resumos e carta ao editor. Os achados evidenciam que as causas dos partos prematuros são multifatoriais pode-se citar como exemplo: baixa estatura da mãe, gravidez na adolescência, cuidados pré-natais inadequados, condições socioeconômicas, consumo de drogas licitas e ilícitas. Constatou-se que muitos profissionais prestam assistência ao prematuro de forma empírica, por vários fatores, dentre eles a não institucionalização dos protocolos na sala de parto.

Palavras-chave: Enfermagem, Cuidados, Parto, Prematuridade, Neonatal 


\section{INTRODUÇÃO}

Segundo a Academia Americana de Pediatria (AAP) e o Colégio Americano de Obstetras e Ginecologistas definem o nascimento prematuro como sendo aquele que ocorre antes ou no final da $37 \underline{\text { a }}$ semana de idade gestacional (IG). Cerca de $10 \%$ dos partos no Brasil são prematuros e responsáveis por $75 \%$ das mortes neonatais (PONTES; CANTILLINO, 2014).

A predição do parto prematuro é associada a alguns fatores de riscos demográficos e obstétricos, tais como: idade materna menos que 21 ou maior que 36 anos, baixo nível socioeconômico, antecedente de parto pré-termo, estatura materna inferior a $1,52 \mathrm{~m}$, gestação gemelar, sangramento vaginal no $2^{\circ}$ trimestre, amadurecimento cervical e aumento da atividade uterina antes da $29^{a}$ semana de gestação (ANDRADE, 2009).

A criança prematura têm maior risco de desenvolver problemas graves ou de morrer durante o período neonatal. Sem tratamento adequado, aqueles que sobrevivem têm maior risco de deficiências ao longo da vida e pior qualidade de vida. As complicações decorrentes da prematuridade são a principal causa de morte neonatal e a segunda principal causa de morte entre crianças menores de 5 (cinco) anos (OMS, 2015).

A mortalidade infantil e a morbidade após o nascimento prematuro podem ser reduzidas através de intervenções voltadas para a mulher antes e durante a gestação e para o recém-nascido prematuro (OMS, 2015).

Entretanto, a hospitalização do recém-nascido prematuro (RNPT) na unidade de terapia intensiva neonatal (UTIN) está associada à sua submissão a um número excessivo de procedimentos como as punções venosas, as sondagens orogástricas e vesicais, as glicemias capilares, a realização de curativos, a aspiração de vias aéreas e a intubação endotraqueal dentre outros, o que pode gerar desconforto, estresse e dor (SANTOS; RIBEIRO; SANTANA, 2012).

A equipe de enfermagem pode e deve utilizar as medidas não farmacológicas de forma constante para o controle da dor nas unidades neonatais, já que são estratégias de cuidado que não necessitam da interferência de outros profissionais (SANTOS; RIBEIRO; SANTANA, 2012).

Nessa linha de reflexão, o Método Canguru representa uma proposta de assistência humanizada, com ênfase no paradigma da não separação entre o bebê e seus pais, especialmente a mãe. Assim, os pais se tornam parceiros nos cuidados com o bebê, o que possibilita a transformação da crise do nascimento prematuro e da internação em uma experiência mais gratificante para toda a família (SPEHAR; SEIDL, 2013).

Diante da intensidade da luz nas Unidades Neonatais, as ações de enfermagem devem ser dirigidas no sentido de reduzir a luminosidade ambiental, promovendo estratégias tais como, cobrir a incubadora com mantas, evitando desta forma, o excesso de estímulos, além de proporcionar o ciclo natural de sono e vigília do RNPT. 0 toque e o contato físico também acalmam. A estimulação sensorial poderá ser útil como, por exemplo, o uso da música, a fala suave, as massagens e o estímulo visual. Outra forma de acalmar o RNPT é a contenção do recém-nascido em um ninho, denominado útero artificial, o qual pode ser improvisado para promover a sua organização comportamental (SANTOS; RIBEIRO; SANTANA, 2012).

Nesse prisma, o estudo em tela ancora-se na seguinte questão de pesquisa: Quais os principais cuidados de Enfermagem ao recém-nascido pré-termo?

Nessa direção, este estudo tem como objetivo identificar os principais cuidados de Enfermagem ao recém-nascido pré-termo.

\section{METODOLOGIA}

Trata-se de uma Revisão integrativa da literatura que inclui a análise de pesquisas relevantes que dão suporte para a tomada de decisão e a melhoria da pratica clínica, possibilitando a síntese do estado do conhecimento de um determinado assunto, além de apontar lacunas do conhecimento que precisam ser preenchidas com a realização de novos estudos (MENDES, 2008).

Para construção dessa revisão de literatura foram utilizadas as seguintes etapas: seleção das questões temáticas; coleta de dados através da base de dados eletrônica, com alguns critérios de inclusão e exclusão; sua elaboração de instrumento de coleta como informações de interesses a serem extraídos dos estudos análise crítica da amostra, interpretação dos dados e apresentação dos resultados. 
A busca ocorreu por meio da Biblioteca Virtual em Saúde (BVS) nas seguintes bases de dados eletrônicas: Literatura Latino-Americana e do Caribe em Ciências da Saúde (LILACS) e Scientific Eletronic Libraby Online (SCIELO).

Os descritores em ciências da saúde (DeCS) utilizados para a pesquisa foram: Enfermagem, Cuidados e Prematuridade. Para refinamento do material utiliza-se o operador booleano and combinados na seguinte forma: Enfermagem and Cuidados, Enfermagem and Prematuridade, Cuidados and Prematuridade, Enfermagem and Cuidados and Prematuridade.

Os critérios de inclusão adotados foram: estudos publicados na língua portuguesa disponíveis de forma gratuita e online, e que compartilhassem da temática e do objetivo proposto. E quanto aos de exclusão, destaca-se artigos duplicados, em forma de resumos e carta ao editor.

Para análise crítica dos artigos realizou-se leitura completa com as respectivas sínteses. Os dados utilizados neste estudo foram devidamente referenciados, respeitando e identificando seus autores e demais fontes de pesquisa, observando rigor ético quanto à propriedade intelectual dos textos científicos que foram pesquisados, no que diz respeito ao uso do conteúdo e de citação das partes das obras consultadas.

Figura 1: Estratégia de busca e seleção dos artigos nas bases de dados SCIELO, LILACS Natal, 2018.

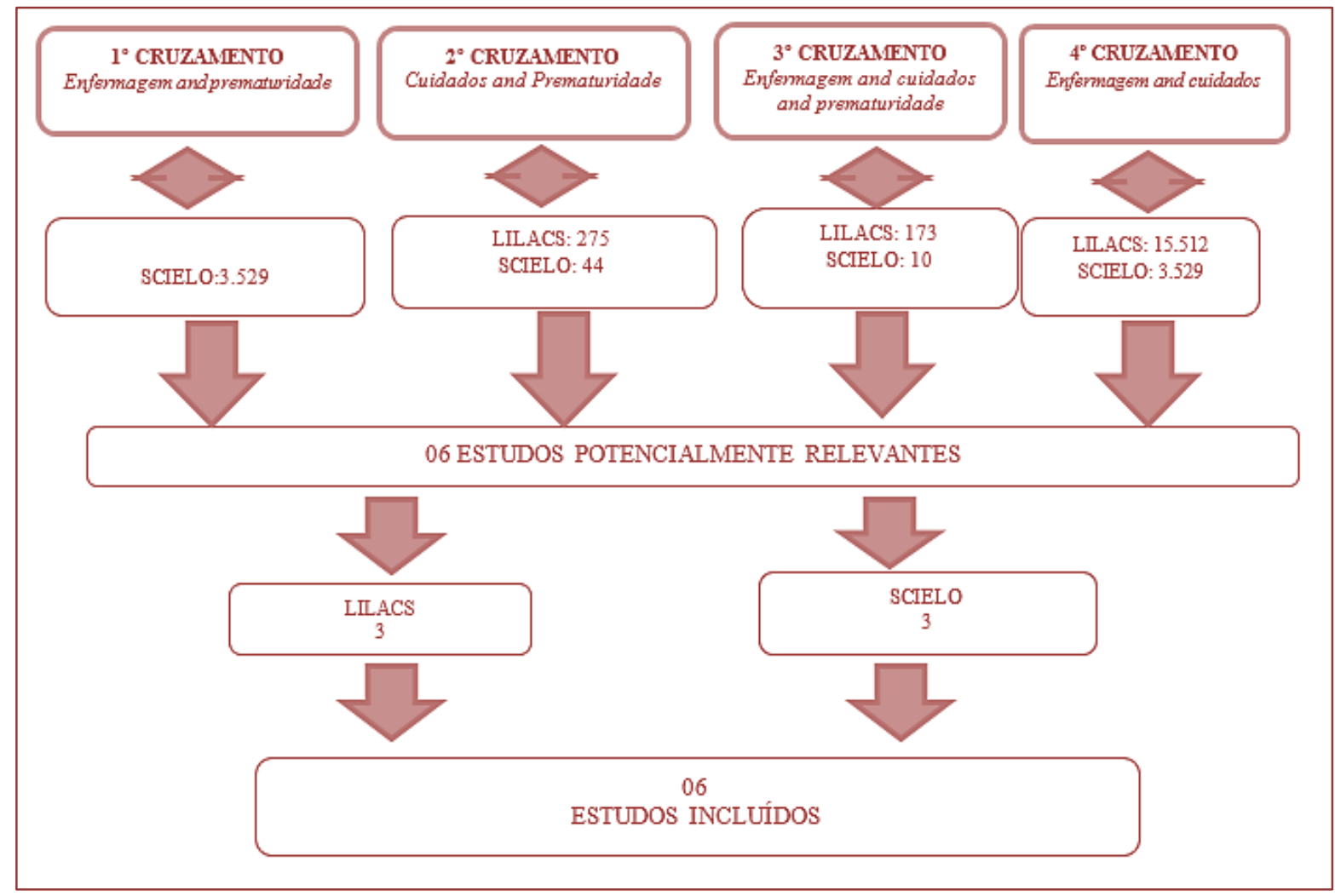

\section{RESULTADOS E DISCUSSÕES}

Quanto aos resultados, selecionou-se 06 (seis) estudos potencialmente relevantes, restando 06 estudos que atendiam aos critérios de elegibilidade e compondo o presente estudo. A seguir apresentar-se-á um panorama geral das publicações. 
Quadro 1. Distribuição dos dados analisados como título, autores, ano de publicação, objetivo, resultados principais e conclusão. Natal, 2018.

\begin{tabular}{|c|c|c|c|c|}
\hline Título & Autores e ano & Objetivo & $\begin{array}{l}\text { Resultados } \\
\text { principais }\end{array}$ & Conclusão \\
\hline $\begin{array}{l}\text { Análise dos fatores } \\
\text { obstétricos, } \\
\text { socioeconômicos e } \\
\text { comportamentais } \\
\text { que determinam a } \\
\text { frequência de } \\
\text { recém-nascidos } \\
\text { pré-termo em uti } \\
\text { neonatal. }\end{array}$ & $\begin{array}{l}\text { CHAGAS, } \\
\text { Rute. Et al } \\
2009\end{array}$ & $\begin{array}{l}\text { Analisar a prática de } \\
\text { educação adotada } \\
\text { pela equipe de saúde } \\
\text { junto às mães de } \\
\text { recém nascidos } \\
\text { internados na } \\
\text { Unidade de } \\
\text { Tratamento } \\
\text { Intensivo Neonatal. }\end{array}$ & $\begin{array}{l}\text { Há uma prevalência } \\
\text { de prematuros } \\
\text { associados a fatores } \\
\text { socioeconômicos. }\end{array}$ & $\begin{array}{l}\text { Dentre os fatores obstétricos, } \\
\text { predominaram a pré- } \\
\text { eclampsia ( } 30 \%) \text {; nos } \\
\text { socioeconômicos, } 21,4 \% \text { com } \\
\text { renda familiar inferior a } 1 \\
\text { salário mínimo; nos } \\
\text { comportamentais, } 81,4 \% \text { não } \\
\text { utilizaram álcool na gestação e } \\
2 \% \text { eram fumantes. }\end{array}$ \\
\hline $\begin{array}{l}\text { O crescimento e } \\
\text { desenvolvimento } \\
\text { frente à } \\
\text { prematuridade e } \\
\text { baixo peso ao } \\
\text { nascer }\end{array}$ & $\begin{array}{l}\text { PESSOA, } \\
\text { Tiara. Et al } \\
2015\end{array}$ & $\begin{array}{l}\text { Realizar um } \\
\text { levantamento } \\
\text { bibliográfico acerca } \\
\text { do crescimento e } \\
\text { desenvolvimento de } \\
\text { prematuros e/ou } \\
\text { com baixo peso ao } \\
\text { nascer. }\end{array}$ & $\begin{array}{l}\text { Aborda sobre: } \\
\text { fatores associados a } \\
\text { prematuridade e } \\
\text { baixo peso ao nascer. }\end{array}$ & $\begin{array}{l}\text { As crianças nascidas } \\
\text { prematuramente e com baixo } \\
\text { peso geralmente apresentam } \\
\text { déficit de desenvolvimento. } \\
\text { Um acompanhamento pós- } \\
\text { natal focado no crescimento e } \\
\text { desenvolvimento torna-se } \\
\text { essencial. }\end{array}$ \\
\hline $\begin{array}{l}\text { Parto prematuro: } \\
\text { abordagens } \\
\text { presentes na } \\
\text { produção científica } \\
\text { nacional e } \\
\text { internacional }\end{array}$ & $\begin{array}{l}\text { POHLMAAN, } \\
\text { Flavia. Et al } \\
2016\end{array}$ & $\begin{array}{l}\text { Conhecer a produção } \\
\text { científica acerca do } \\
\text { parto prematuro. }\end{array}$ & $\begin{array}{l}\text { Aponta que muitas } \\
\text { pesquisas estão } \\
\text { preocupadas com os } \\
\text { fatores de risco } \\
\text { relacionados à } \\
\text { prematuridade, } \\
\text { contribuindo para a } \\
\text { identificação } \\
\text { precoce e redução } \\
\text { nos índices desta } \\
\text { complicação. }\end{array}$ & $\begin{array}{l}\text { Percebe-se que poucos estudos } \\
\text { trazem contribuições para } \\
\text { enfermagem, deixando de } \\
\text { contribuir para o } \\
\text { conhecimento e processo de } \\
\text { trabalho desses profissionais, } \\
\text { também responsáveis por } \\
\text { produzir saúde neste momento } \\
\text { da vida de mulheres e famílias } \\
\text { que vivenciam a } \\
\text { prematuridade. }\end{array}$ \\
\hline $\begin{array}{l}\text { Humanização dos } \\
\text { cuidados ao } \\
\text { recém-nascido no } \\
\text { método canguru: } \\
\text { relato de } \\
\text { experiência }\end{array}$ & $\begin{array}{l}\text { LOPES, Thais. } \\
\text { Et al, } 2017\end{array}$ & $\begin{array}{l}\text { Relatar a vivência de } \\
\text { uma assistência } \\
\text { humanizada, por } \\
\text { meio de práticas } \\
\text { educativas no } \\
\text { Método Canguru, em } \\
\text { uma maternidade- } \\
\text { escola. }\end{array}$ & $\begin{array}{l}\text { Por meio das } \\
\text { práticas educativas, } \\
\text { as mães e os } \\
\text { familiares dos } \\
\text { recém-nascidos } \\
\text { prematuros } \\
\text { demonstraram-se } \\
\text { receptivos em } \\
\text { conhecer as } \\
\text { vantagens da } \\
\text { assistência } \\
\text { humanizada } \\
\text { realizada pela } \\
\text { prática do Método } \\
\text { Canguru. }\end{array}$ & $\begin{array}{l}\text { Percebeu-se, pela vivência nas } \\
\text { práticas educativas, a } \\
\text { importância das orientações } \\
\text { contínuas, de forma a } \\
\text { empoderar as mães e } \\
\text { familiares sobre os cuidados } \\
\text { neonatais, com vistas à } \\
\text { continuidade do método em } \\
\text { todas as fases que o } \\
\text { contemplam. Assim, deve-se } \\
\text { valorizar tais ações educativas, } \\
\text { nas práxis de Enfermagem, em } \\
\text { prol da melhoria da qualidade } \\
\text { de vida do recém-nascido e de } \\
\text { sua família }\end{array}$ \\
\hline
\end{tabular}


(Continuação ...)

Quadro 1. Distribuição dos dados analisados como título, autores, ano de publicação, objetivo, resultados principais e conclusão. Natal, 2018.

\begin{tabular}{|c|c|c|c|c|}
\hline Título & Autores e ano & Objetivo & $\begin{array}{l}\text { Resultados } \\
\text { principais }\end{array}$ & Conclusão \\
\hline $\begin{array}{l}\text { Cuidados com a pele } \\
\text { do recém-nascido } \\
\text { prematuro: revisão } \\
\text { integrativa }\end{array}$ & $\begin{array}{l}\text { AREDES, } \\
\text { Natalia; } \\
\text { SANTOS, } \\
\text { Raionara; } \\
\text { FONSECA, } \\
\text { Luciana. } \\
2017\end{array}$ & $\begin{array}{l}\text { Descrever e analisar } \\
\text { as evidências } \\
\text { científicas, em } \\
\text { estudos nacionais e } \\
\text { internacionais, sobre } \\
\text { os cuidados de } \\
\text { enfermagem para } \\
\text { integridade da pele } \\
\text { do recém-nascido } \\
\text { pré-termo na } \\
\text { Unidade de Terapia } \\
\text { Intensiva Neonatal. }\end{array}$ & $\begin{array}{l}\text { Apesar da variedade } \\
\text { de produtos } \\
\text { disponíveis, faltam } \\
\text { evidências para sua } \\
\text { aplicação na prática. } \\
\text { Periodicidade e } \\
\text { produtos do banho e } \\
\text { cuidados à lesão por } \\
\text { pressão foram } \\
\text { melhor abordados } \\
\text { pela literatura, } \\
\text { porém há lacunas na } \\
\text { prevenção de } \\
\text { infecções e agravos e } \\
\text { na utilização de } \\
\text { protocolos. }\end{array}$ & $\begin{array}{l}\text { Os resultados permitiram } \\
\text { constatar que apesar da } \\
\text { variedade de produtos } \\
\text { disponíveis, faltam evidências } \\
\text { para sua aplicação na prática. } \\
\text { Periodicidade produtos do } \\
\text { banho e cuidados à lesão por } \\
\text { pressão foram melhor } \\
\text { abordados pela literatura, } \\
\text { porém há lacunas na } \\
\text { prevenção de infecções e } \\
\text { agravos e na utilização de } \\
\text { protocolos. }\end{array}$ \\
\hline $\begin{array}{l}\text { Conhecimento da } \\
\text { equipe de } \\
\text { enfermagem sobre a } \\
\text { dor no recém- } \\
\text { nascido prematuro }\end{array}$ & $\begin{array}{l}\text { MARCOND } \\
\text { ES, Camila. } \\
\text { Et al, } 2017\end{array}$ & $\begin{array}{l}\text { Identificar o } \\
\text { conhecimento da } \\
\text { equipe de } \\
\text { Enfermagem sobre a } \\
\text { dor no recém- } \\
\text { nascido prematuro }\end{array}$ & $\begin{array}{l}\text { Evidenciariam que } \\
100 \% \text { dos } \\
\text { entrevistados } \\
\text { identificam a dor de } \\
\text { forma empírica, } \\
\text { demonstrando a } \\
\text { necessidade do uso e } \\
\text { implementação da } \\
\text { SAE pelas equipes. }\end{array}$ & $\begin{array}{l}\text { É necessária a capacitação da } \\
\text { equipe multidisciplinar para a } \\
\text { identificação da dor no } \\
\text { neonato e sistematização da } \\
\text { assistência da Enfermagem } \\
\text { para propiciar intervenções } \\
\text { efetivas para a dor. }\end{array}$ \\
\hline
\end{tabular}

Fonte: Os autores

Os nascimentos prematuros na população brasileira têm se mantido constante nos últimos anos, com média de 6,6\%, sendo variáveis de Estado para Estado, podendo atingir taxas de até $9 \%$ e com tendência à elevação em algumas metrópoles (CHAGAS, et al., 2009).

Os estudos apontam a prevalência da prematuridade em países desenvolvidos e em desenvolvimento, como o Brasil. A sua causa é multifatorial pode-se citar como exemplo baixa estatura, gravidez na adolescência, cuidados pré-natais inadequados, condições socioeconômicas, consumo de drogas licitas e ilícitas; um dos principais fatores obstétricos para prematuridade é a pré-eclâmpsia (CHAGAS, et al., 2009).

Ainda se destaca que a maior prevalência é o baixo nível socioeconômico materno, pois elas se submetem a precárias condições de vida tendo como consequência uma alimentação não adequada, prejudicando o crescimento intrauterino. Além das condições socioeconômicas outro fator é a idade materna, que maior de 35 anos está relacionada a nascimentos pré-termo; relacionado também quando não há um considerável intervalo entre uma gestação e outra (menor que 18 meses) (PESSOA, et al., 2015).

Diante do exposto, tendo em vista que há um prevalência de partos prematuros, se faz necessário a capacitação do profissional da saúde e que fiquem atentos para orientar as mulheres em relação a realização do pré-natal, observar as características das gestantes e a partir disso, poderem planejar uma adequada assistência ao binômio mãe-filho direcionado a um cuidado integral e na prevenção do parto prematuro (PP) (POHLMAAN, et al., 2016)

Em 1978, na Colômbia foi criado o Método Canguru (MC) , que tinha como objetivo diminuir as unidades hospitalares por meio da alta hospitalar dos recém-nascidos pré-termo (RNPT). Esse método é um dos principais cuidados com o RNPT por meios não farmacológico, que estabelece o vínculo do RNPT com o seu familiar, dessa forma mantém o recém-nascido (RN) sobre o seu peito, na posição vertical e decúbito ventral, o RN com a menor quantidade de roupa para estabelecer o contato pele a pele. Nessa perspectiva, os profissionais de enfermagem devem enfatizar a importância do MC para o vínculo familiar, após a alta hospitalar (LOPES, 2017). 
No RNPT as funções da pele se encontram limitada devido à baixa quantidade de estrato córneo, diminuindo a quantidade de fibras de colágeno e de elastina entre as camadas, a sua imaturidade aumenta sua permeabilidade, diminuindo a sua função protetora, aumentando a absorção de substancias aplicadas, podendo levar a uma infecção; quando no Recém-nascido a termo onde temos o estrato córneo completamente formado, sendo assim enfatiza que os cuidados ao prematuro deve ser diferenciado. Os cuidados de Enfermagem com a pele do RN incluem: evitar exposição ao ambiente, manutenção da temperatura, banho; aplicação de óleos emolientes e outros produtos aplicados sobre a pele (AREDES; SANTOS; FONSECA, 2017).

Em relação à intervenção de enfermagem ou seu tratamento para o alivio da dor, constatou-se que os profissionais usam a massagem e ofertam um leito confortável para o RN. Notou-se que pouco é utilizada a Sistematização da Assistência de Enfermagem (SAE), sabendo-se que ela é uma importante ferramenta para direcionar as intervenções conforme a necessidade do RN, como também facilita os cuidados de Enfermagem, garantindo uma qualidade e organização da assistência para promover uma maior sobrevida e menor tempo na Unidade de Terapia Intensiva Neonatal (UTIN) (MARCONDES, et al., 2017).

Para o enfermeiro prestar a devida assistência, é necessário evidencias cientificas que contribuam para essa tomada de decisões de produtos, métodos, técnicas, materiais e procedimentos, apesar do avanço na área neonatal, ainda é limitado ao prematuro, que apresenta especificidades pela sua imaturidade fisiológica. Onde em sua pratica há uma grande dificuldade, por não existir uma padronização de protocolos assistenciais (AREDES; SANTOS; FONSECA, 2017).

\section{CONCLUSÃO}

O estudo permitiu analisar as produções cientificas a respeito da prematuridade, onde a sua maioria mostra os principais fatores de risco. Dentre eles os mais citados foram: síndrome hipertensiva gestacional; baixa idade materna, baixo nível socioeconômico, números de consultas pré-natais insuficiente, gestação gemelar, sangramento vaginal no $2^{\circ}$ trimestre, amadurecimento cervical e aumento da atividade uterina antes da 29aㅗ semana de gestação.

Ressalta-se que foi possível aprofundar o conhecimento a respeito dos cuidados ao RNPT, onde enfatiza-se por meios não farmacológicos os principais cuidados prestados, onde destaca-se o método canguru, onde a enfermagem possui um papel impar para concretizar esse método, pois favorece a tríade pai-mãe e filho.

Ainda existe uma lacuna a respeito da prematuridade, onde se constatou que muitos profissionais prestam a assistência de forma empírica, por ainda não ter protocolos padronizados nas instituições que prestam assistência ao recém-nascido durante o parto.

\section{REFERÊNCIAS}

[1] Aredes NDA, Santos RCA, Fonseca LMM. Cuidados com a pele do recém-nascido prematuro: revisão integrativa. Rev. Eletr. Enf. [Internet]. 2017. 19-59 p. Disponível em: <http://doi.org/10.5216/ree.v19.43331> Acesso em: 17 de Outubro. 2018.

[2] Araújo BBM, Rodrigues BMRD. Vivências e perspectivas maternas na internação do filho prematuro em Unidade de Tratamento Intensivo Neonatal. São Paulo: Rev Esc Enferm, 2009. 865-872 p. disponível em: <file:///E:/TCC/02.pdf> Acessado em: 20 de Abril. 2018.

[3] Chagas RIA, et al. Análise dos fatores obstétricos, socioeconômicos e comportamentais que determinam a frequência de recém-nascidos pré-termos em uti neonatal: 1984/1986. São Paulo: IBICT, 2009. 7-11 p. v. 9. Disponível em: <file:///E:/TCC/v.9_n.1-art1.pesq-analise-dos-fatores-obstetricos-socioeconomicos.pdf> Acesso em: 20 de Abril. 2018.

[4] Santos LM, Ribeiro IS,Santana RCB. Identificação e tratamento da dor no recém-nascido prematuro na Unidade de Terapia Intensiva: 1984/1986. Brasília: IBICT, 2012. 269-275 p. Disponível em: <file:///E:/TCC/267028449011.pdf> Acessado em: 24 de Abril. 2018.

[5] Lopes TRG et al. humanização dos cuidados ao recém-nascido no método canguru: relato de experiência. Recife: Rev enferm UFPE on line, 2017. 4492-7. Disponível em: <file:///C:/Users/Brenda/Downloads/25089-726251-PB\%20(2).pdf> Acesso em: 17 de Outubro. 2018

[6] Medes KS, Silveira RCCP, Galvão CM. Revisão integrativa: método de pesquisa para a incorporação de evidências na saúde e na enfermagem. florianópolis: texto contexto enfermagem, 1987. 758-764 p. 
[7] Pessoa TAO et al. 0 crescimento e desenvolvimento frente à prematuridade e baixo peso ao nascer. Av Enferm. 2015;33(3):401-411. Disponível em: <http://www.scielo.org.co/pdf/aven/v33n3/v33n3a08.pdf> Acesso em: 25 de Setembro.2018.

[8] Pohlmann FC. et al. Parto prematuro: abordagens presentes na produção científica nacional e interna cional. Enfermería Global, 2016. 398-409 p.Disponível em: < http://scielo.isciii.es/pdf/eg/v15n42/pt_revision1.pdf> Acesso em: 17 de Outubro. 2018

[9] Spehar MC, Seildl EMF. Percepções maternas no método canguru: contato pele a pele, amamentação e autoeficácia. Maringá: Psicologia Em Estudo, 2013. 647-656 p. v. 18. Disponível em: <file:///E:/TCC/07.pdf> Acesso em: 25 de Abril. 2018

[10] Marcondes C. et al. conhecimento da equipe de enfermagem sobre a dor no recém-nascido prematuro. Recife: Rev enferm UFPE on line ,2017. 3354-9 p. Disponível em: < file:///C:/Users/Brenda/Documents/11023359471-1-PB\%20(2).pdf> Acesso: 25 de Outubro. 2018. 


\title{
Capitulo 9
}

Relação entre qualidade de vida, transtornos mentais menores e resiliência entre profissionais de enfermagem

\author{
Emerson Roberto dos Santos \\ Daniela Comelis Bertolin \\ Loiane Letícia dos Santos \\ Patrícia da Silva Fucuta \\ Daniele Alcalá Pompeo \\ Júlio César André
}

Resumo : Objetivos: Avaliar a qualidade de vida, transtornos mentais menores e o nível de resiliência entre profissionais de Enfermagem de unidades de internação e setores de emergência e realizar análise comparativa de acordo com variáveis sociodemográficas e profissionais. Métodos: Estudo quantitativo, descritivo, correlacional e transversal, realizado em unidades de internação de um hospital escola, Hospital de Base, e setores de emergência que incluíram todas as Unidades de Pronto Atendimento do município de São José do Rio Preto/SP e dois setores de emergência do Hospital de Base. População do estudo composta por todos os auxiliares e técnicos de Enfermagem e enfermeiros dos locais definidos; estimados 444 profissionais. Excluídos os que estavam de férias e/ou afastados das atividades profissionais por qualquer motivo e aqueles que não aceitaram participar da pesquisa. Dados coletados, após agendamento com gerentes dos setores, aos quais os pesquisadores explicaram os objetivos do estudo e entregaram os instrumentos de coleta de dados e o Termo de Consentimento Livre e Esclarecido, que repassaram aos profissionais sob sua gerência e os recolheram em envelopes separados e lacrados, no período de agosto a outubro de 2019. Amostra final de 203 participantes. Utilizados quatro instrumentos autoaplicáveis: questionário de variáveis sociodemográficas e profissionais, instrumento de Avaliação de Qualidade de Vida (WHOQOL-BREF), Self-Report Questionnaire (SRQ-20) e Escala de Resiliência de Wagnild \& Young. Os dados das escalas foram analisados em função do cálculo dos escores, adequados à análise dos instrumentos e sofreram tratamento estatístico apropriado, de forma a responder os objetivos do estudo, considerando nível de significância de 95\%. Resultados: Um total de 165 (81,3\%) profissionais do sexo feminino e 119 (58,6\%) com até 39 anos de idade, 99 (48,8\%) técnicos, 79 (38,9\%) enfermeiros e 25 (12,3\%) auxiliares de enfermagem. Níveis de qualidade de vida indicando insatisfação com a mesma; sem diferença entre as categorias e a análise inferencial dos escores revelou diferença significante quanto à idade (maior em profissionais mais velhos), sexo (maior no sexo masculino) e na renda familiar (maior para a faixa entre 1.001 e 3.000 reais). Prevalência global de transtornos mentais menores entre os participantes do estudo de 31\%, menores em profissionais mais velhos e no sexo masculino. Altos índices de resiliência, maiores entre profissionais mais velhos e entre profissionais dos setores de emergência. Todos sem diferença significante entre as três categorias de profissionais. Conclusões: Baixos escores de qualidade de vida entre os profissionais de Enfermagem. Resiliência aumentou com a idade e foi maior entre os profissionais do setor de emergência. Quanto maior a resiliência, maiores os escores de qualidade de vida e associação consistente da resiliência como fator de proteção aos transtornos mentais menores. Os resultados sugerem que a resiliência desempenha um papel importante na promoção da saúde e bem-estar psicológico, melhorando a qualidade de vida e diminuindo os riscos de transtornos mentais menores. Desta forma, apontam caminhos para intervenções individuais e institucionais, tanto no nível da prevenção e promoção, como na recuperação da saúde dos indivíduos.

Palavras-chave: Equipe de Enfermagem; Saúde Mental; Qualidade de Vida; Transtornos Mentais; Resiliência Psicológica. 


\section{INTRODUÇÃO}

\subsection{QUALIDADE DE VIDA}

O conceito de qualidade de vida (QV) está centrado na avaliação subjetiva do indivíduo, incluindo uma variedade de condições que podem afetar sua percepção, seus sentimentos e comportamentos relacionados ao seu dia a dia e não só à condição de saúde. A literatura é clara sobre a QV dos profissionais de Enfermagem (PE). A prática laboral é realizada muitas vezes em condições inadequadas. As relações hierárquicas são conflituosas, favorecendo o estresse ${ }^{1,2}$. Estes fatores somados às cargas horárias excessivas resultam em elevados índices de absenteísmo, desgastes físicos e emocionais. Os profissionais mais acometidos são os técnicos de Enfermagem (TE), tendo em vista que realizam os cuidados diretos aos pacientes No entanto, os enfermeiros (E) também são susceptíveis à alteração da QV, pois são os que menos se afastam das atividades laborais e, além, de ser a única categoria que realiza o gerenciamento da assistência de Enfermagem ${ }^{3-5}$.

Existem vários instrumentos que têm sido utilizados para mensurar a QV, a maioria deles desenvolvidos principalmente na Europa e Estados Unidos da América (EUA), o que requer tradução e adaptação transcultural. Sobre a sua aplicação, podem ser divididos em dois grandes grupos. Os genéricos, desenvolvidos com a finalidade de refletir o impacto de uma doença sobre a vida do paciente, e podem ser aplicados a várias populações. Avaliam o perfil de saúde e as medidas que indicam a preferência do paciente por determinado estado de saúde, tratamento ou intervenção. Instrumentos genéricos como World Health Organization to Access Quality of Life-100 (WHOQOL-100), Medical Outcomes Study ShortForm Health Survey (SF-36), Quality of Life Index - Ferrans and Powers foram traduzidos e adaptados para a cultura brasileira e têm sido utilizados para a avaliação da QV da população em geral6,7. Instrumentos específicos permitem avaliar de forma pontual determinados aspectos da QV, proporcionando uma maior sensibilidade na detecção de melhora ou piora do aspecto em estudo. Importante ter clareza na utilização destes instrumentos de medida e considerar suas propriedades psicométricas, que lhes conferem confiabilidade e validade. 0 pesquisador precisa ter de forma clara o conceito que está sendo medido para fazer a escolha assertiva do instrumento a ser utilizado. Uma análise realizada pelo Grupo de Qualidade de Vida da Organização Mundial de Saúde (OMS) demonstrou que é possível desenvolver uma medida de qualidade de vida aplicável e válida para uso em diversas culturas ${ }^{8}$ e devido à necessidade de instrumentos curtos e de rápida aplicação, surgiu a versão abreviada do WHOQOL completo (WHOQOL100 ), o WHOQOL-Bref, cuja versão final ficou composta por 26 questões 9 .

Em relação à QV os avanços nas pesquisas poderão resultar em mudanças nas práticas assistências e na solidificação de novos paradigmas no processo saúde/doença. Vai contribuir para a superação do modelo eminentemente biomédico, que desconsidera os aspectos socioeconômicos, psicológicos e culturais nas ações de promoção, tratamento e reabilitação da saúde ${ }^{6,7}$.

\subsection{TRANSTORNOS MENTAIS MENORES}

Os Transtornos Mentais Menores (TMM) são uma síndrome ou padrão comportamental ou psicológico que ocorre em um indivíduo, que reflete numa disfunção psicológica subjacente. Está associado à presença de sofrimento ou incapacidade, e não é apenas uma resposta esperada a estressores e perdas comuns, uma resposta culturalmente sancionada a um evento particular e muito menos é o resultado primário de desvio social ou conflitos com a sociedade $10-12$. Os TMM alteram o modo como a mente funciona e atrapalha o desenvolvimento da vida social, familiar e do trabalho, induzindo negativamente nas relações interpessoais ${ }^{13}$.

Segundo Schmidt et al. ${ }^{14}$, os TMM são entendidos como condições clinicamente significativas, caracterizadas por alterações no humor, nas emoções, no pensamento e no comportamento, que surgem associadas com angústia pessoal e/ou funcionamento deficiente. São características de TMM, o esquecimento, fadiga, depressão, falta de concentração, irritabilidade, insônia e queixas somáticas, e sendo estes os transtornos mais prevalentes na população, imperceptível, de várias formas e de difícil identificação ${ }^{15}$.

O Instituto Nacional do Seguro Social (INSS) revela que os TMM estão entre as principais doenças relacionadas ao trabalho, ficando na terceira posição entre as doenças responsáveis por extensos períodos de afastamento de trabalhadores por incapacidade laborativa temporária e permanente no Brasil.14,16,17 
A equipe de Enfermagem tem maior risco de adoecimento por TMM, uma vez que dos seis cargos com maior prevalência, quatro deles são de PEs: auxiliar de Enfermagem (AE) com 14,92\%, auxiliar de saúde com 13,33\%, E com 11,83\% e o TE com 10,42\%, com um risco de afastamento 2,5 vezes maior. ${ }^{14,18-20}$

As matrizes sobre intensidade do trabalho revelam a posição distinta que cada profissional da equipe de Enfermagem ocupa no processo de trabalho. Para AEs e TEs as variáveis relacionadas com a assistência direta ao usuário são as que se constituem em maior carga fatorial, tornando esses profissionais propensos ao adoecimento por alta carga de trabalho, bem como, a cometerem erros assistências. ${ }^{3,21}$

Para os enfermeiros as variáveis refletem a posição gerencial-assistencial que esses ocupam no processo de trabalho em Enfermagem. Sobretudo, a intensidade do trabalho causa impacto na tomada de decisão, comprometendo a parte gerencial de seu trabalho acrescendo o fato de que a execução de atividades assistenciais e gerenciais ao mesmo tempo faz com que percebam, em maior proporção, a intensidade do seu trabalho. ${ }^{22-24}$

Os instrumentos de rastreio são ferramentas importantes para a identificação precoce, permitindo a detenção e prevenção de comportamentos prejudiciais à saúde física e mental, sua aplicação deve ter boa aceitabilidade, baixo custo e um bom rigor. Para rastrear TMM o instrumento mais usado no Brasil é o SelfReport Questionnaire-20 (SRQ-20), desenvolvido pela Organização Mundial da Saúde (OMS). É apropriado para estudos em populações, amplamente utilizado em diversos países apresentando bons resultados de validade preditiva e correlação forte com a entrevista diagnóstica, tendo sido adaptado e validado para a população brasileira, em 1985.25-29

\subsection{RESILIÊNCIA}

O setor de emergência (SE) é descrito como uma área física e psicologicamente avassaladora para profissionais de saúde, incluindo a equipe de Enfermagem. Pode torna-los mais suscetíveis à exaustão emocional e com um risco maior de desenvolver estresse traumático, impondo-lhes a necessidade de estar cientes de fatores que contribuam para manter seu bem-estar, os fatores de proteção.

Nesse sentido, a resiliência (R) pode ser entendida como fator de proteção. Os fatores de risco reduzem a possibilidade de superação diante das necessidades impostas, mas seu impacto é diminuído pelos fatores de proteção.

As experiências positivas ou negativas vivenciadas no trabalho podem impactar o desempenho do indivíduo e a qualidade da assistência por ele prestada. A preocupação com a satisfação da equipe de Enfermagem no trabalho tem tornado cada vez mais necessária a sua avaliação entre profissionais e organizações, a fim de fomentar a qualidade da assistência e eficiência da organização. Esse investimento pode repercutir em melhoria contínua da satisfação de funcionários e retenção de profissionais qualificados e experientes. ${ }^{30-32}$

Experiências de trabalho que permitem ao indivíduo o pleno uso das suas habilidades, a expressão da sua criatividade e o significativo controle sobre as suas atividades são entendidas como promotores de realização, prazer, saúde e satisfação ${ }^{33}$. Contudo, o trabalho realizado sob condições que oferecem baixo controle sobre a própria tarefa, altas demandas psicológicas, estigmatização por relações sociais conflituosas ou caracterizadas por constante isolamento, podem estimular o adoecimento mental ${ }^{34-36}$.

Etimologicamente derivada do latim resilio, a palavra resiliência (R) em ciências humanas é usada para descrever o potencial de uma pessoa ou grupo de pessoas de se construir ou se reconstruir positivamente mesmo em um ambiente adverso e desfavorável. ${ }^{37-39}$

No contexto do trabalho, a resiliência é um processo constante, marcado pelo crescimento pessoal e o desenvolvimento das potencialidades que as pessoas apresentam para a promoção da saúde do trabalhador. Ao identificar e reconhecer suas limitações o profissional pode minimizar, parcial ou totalmente, os estressores desnecessários criando habilidades e sugestões para a melhoria da sua qualidade de vida e atuação profissional. Nesse contexto, o trabalhador que utiliza suas características pessoais e seu equilíbrio físico e mental tem mais possibilidade para suportar o ritmo de trabalho desgastante, a pressão e as responsabilidades, tornando-se um profissional resiliente. ${ }^{37-42}$ 


\subsection{CATEGORIAS PROFISSIONAIS NA ENFERMAGEM}

Ao redor do mundo existem diversas maneiras de se categorizar o profissional que exerce a Enfermagem, ficando a critério de cada país regulamentar. No Brasil, regulamenta-se através da Lei no 7.498, de 25 de junho de 198643. Define-se: [...] A Enfermagem é exercida privativamente pelo Enfermeiro, pelo Técnico de Enfermagem, pelo Auxiliar de Enfermagem e pela Parteira, respeitados os respectivos graus de habilitação $[\ldots] .43-48$

Às categorias da lei cabem atividades que consideram o nível de formação. Ao Enfermeiro (nível superior) atividades de maior complexidade e conhecimento teórico/prática; ao Técnico (curso técnico) atividades de auxílio; ao Auxiliar (AE) (certificado de Enfermagem conferido por uma instituição de ensino) atividades de natureza repetitiva. ${ }^{47}$

Diante da importância e escassa produção científica desta temática, principalmente na literatura de enfermagem, sua discussão torna-se relevante, pois seu conceito nas reflexões sobre o processo de trabalho em saúde apresenta-se operativo, inovador e atual.

\section{OBJETIVOS}

\subsection{OBJETIVO GERAL}

Avaliar QV, presença de TMM e nível de R entre PEs de Unidades de Internação (UI) e SEs, da Rede Pública (RP) e Hospital de Base (HB) de São José do Rio Preto, um município de grande porte do interior paulista.

\subsection{OBJETIVOS ESPECÍFICOS}

[1]. Descrever o perfil sociodemográfico e profissional de auxiliares (AE), técnicos de Enfermagem (TE) e enfermeiros (E) de UIs do HB e SEs da RP e HB;

[2]. Avaliar qualidade de vida (QV), transtornos mentais menores (TMN) e resiliência (R) entre os participantes do estudo;

[3]. Comparar QV, TMN e R entre as três categorias profissionais;

[4]. Realizar análise comparativa de QV, TMN e R, de acordo com variáveis sociodemográficas e profissionais;

[5]. Analisar correlação entre QV, TMN e R dentre os participantes do estudo.

\section{CASUÍSTICA E MÉTODOS}

\subsection{TIPO DE ESTUDO}

Trata-se de estudo quantitativo, descritivo, correlacional e transversal, realizado entre os auxiliares (AE), técnicos de Enfermagem (TE) e enfermeiros (E) de UIs do HB e SEs da RP e HB do município de São José do Rio Preto, São Paulo, no ano de 2019.

\subsection{LOCAL DO ESTUDO}

0 município de São José do Rio Preto situa-se ao norte do estado de São Paulo (Figura 1), a $452 \mathrm{~km} \mathrm{da}$ Capital do Estado de São Paulo e 600 km de Brasília; possui população estimada, em 1 de julho de 2019, de 460.671 habitantes. ${ }^{49}$ É reconhecido como centro de referência na área da saúde e sede da maior região de Saúde do estado de São Paulo e de estados vizinhos que utilizam os serviços de saúde do município. 
Figura 1. Localização geográfica do município de São José do Rio Preto. ${ }^{49}$

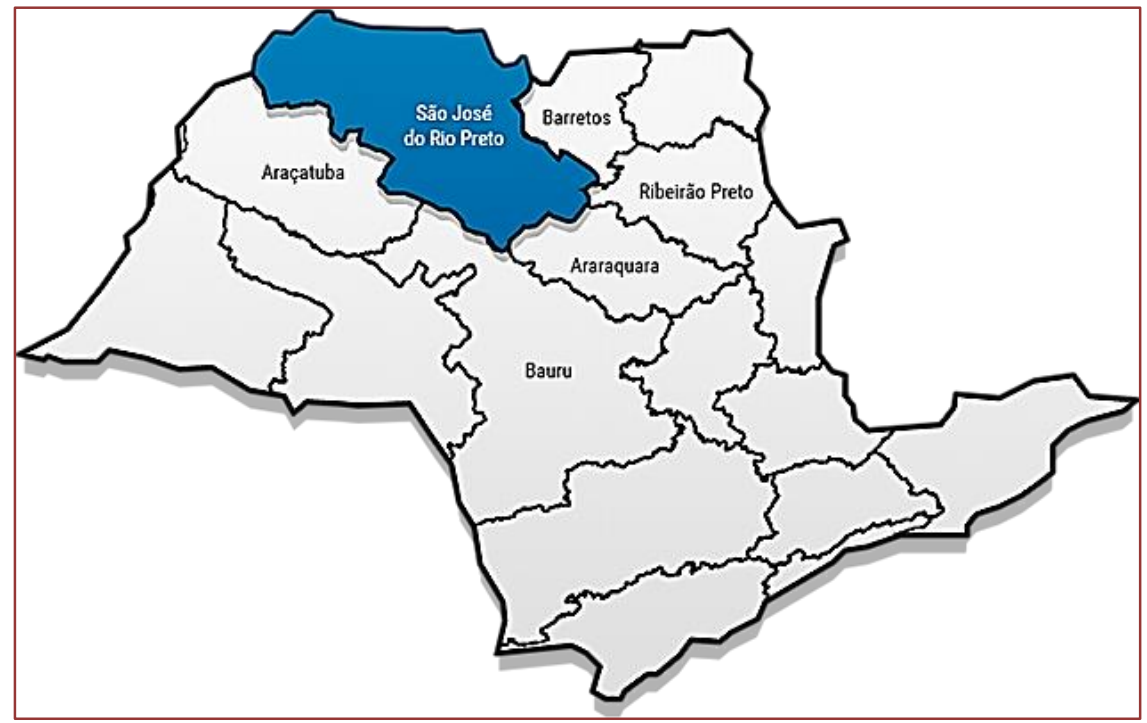

Na estruturação do modelo de saúde local, o Sistema Municipal possui cinco Distritos de Saúde e as Unidades de Saúde estão distribuídas em 10 regiões. Em 05 (cinco) delas (Região Bosque, Região CEU Santo Antônio e Parque Nova Esperança, Região HB, Região Pinheirinho e Região Vila Toninho) há Unidades de Pronto Atendimento (UPAs) - UPA Jaguaré, UPA Santo Antônio, UPA Tangará/Estoril, UPA Região Norte e UPA Vila Toninho - totalizando cinco (Figura 2). ${ }^{50}$

Figura 2. Distribuição das Unidades de Pronto Atendimento nos Distritos de Saúde de São José do Rio

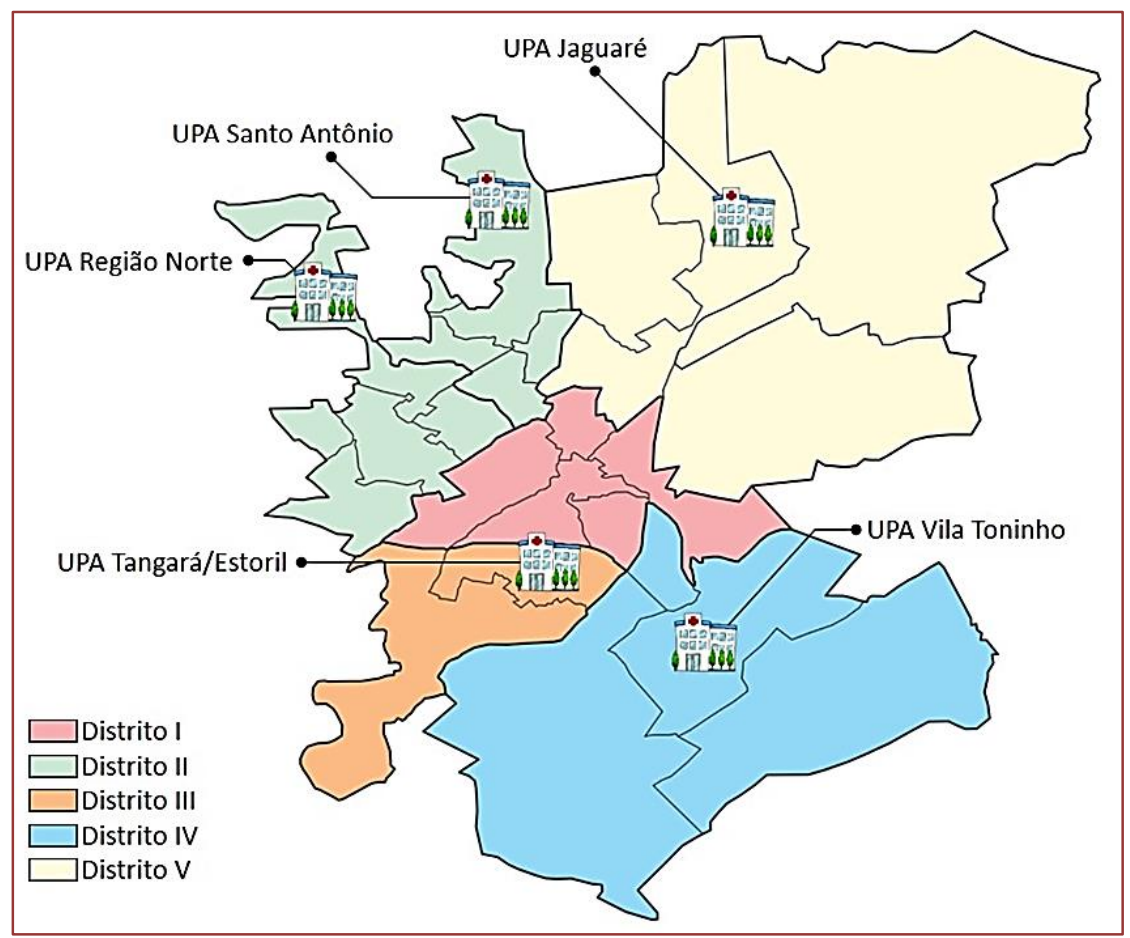

Preto.

O HB de São José do Rio Preto é um dos maiores e mais importantes complexos hospitalares do Estado de São Paulo. É um hospital-escola, ligado à Faculdade de Medicina de São José do Rio Preto (FAMERP), que atende $85 \%$ de seus pacientes pelo Sistema Único de Saúde (SUS). É o centro médico de referência para o 
atendimento de mais de dois milhões de habitantes dos 102 municípios pertencentes à Divisão Regional de Saúde de Rio Preto - 15 (DRS-15), e atrai pessoas de todas as regiões do Brasil e até da América Latina. Possui 708 leitos de internação e Unidades de Terapia Intensiva (UTI) e possui ainda uma das maiores emergências do interior paulista, com 12.000 atendimentos por mês, divididos em dois setores: Emergência Convênio (EC) e Emergência SUS (E-SUS). ${ }^{51}$

\subsection{POPULAÇÃO DO ESTUDO}

A população do estudo foi composta por todos os AEs, TEs e Es das UPAs do município de São José do Rio

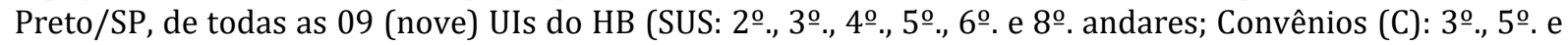
6‥ andares) e dos 02 (dois) setores de emergência do HB, EC e E-SUS, sendo estimados 444 (quatrocentos e quarenta e quatro) profissionais.

Figura 3. Distribuição dos setores do Hospital de Base de São José do Rio Preto onde houve coleta de da dados. ${ }^{5}$

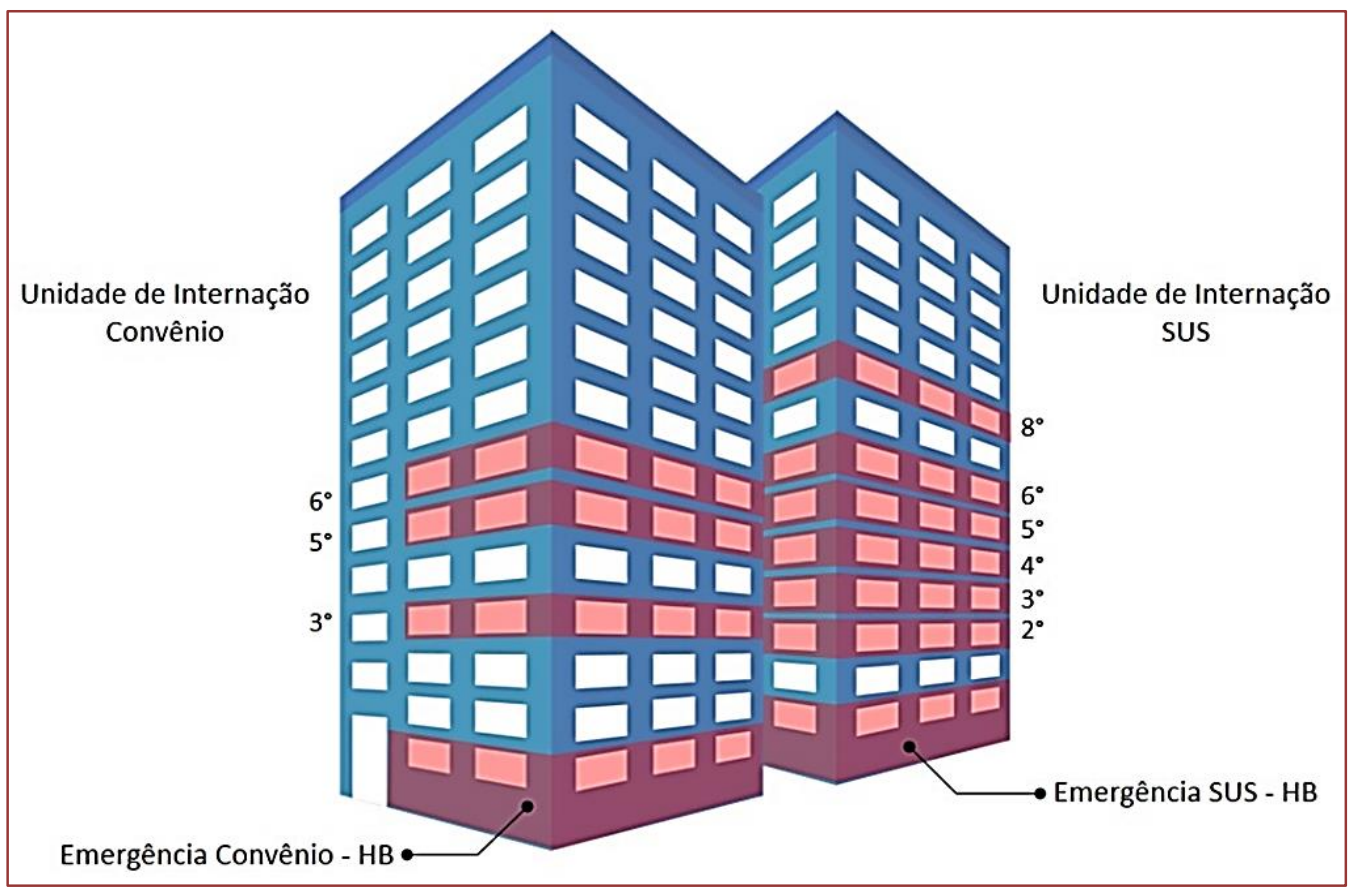

Elaborado pelo autor

Foram excluídos os AEs, TEs e Es que estavam de férias e/ou afastados das atividades profissionais por qualquer motivo e aqueles que não aceitaram participar da pesquisa, seja se furtando já na entrega do TCLE e ICDs pelo seu gerente de enfermagem ou não os devolvendo depois. A amostra foi constituída por 25 (vinte e cinco) AEs, 99 (noventa e nove) TEs e 79 (setenta e nove) Es, correspondendo a uma taxa de resposta de $45,7 \%$.

\subsection{INSTRUMENTOS, PROCEDIMENTOS DE COLETA E ANÁLISE DOS DADOS}

Para a coleta dos dados foram utilizados quatro instrumentos autoaplicáveis (Instrumentos de Coleta de Dados - ICD):

Instrumento 1: Questionário de Variáveis Sociodemográficas e Profissionais: foi elaborado pelos pesquisadores, contendo questões fechadas sobre sexo, idade, estado conjugal, número de filhos e renda familiar, no quesito variáveis sociodemográficas, e categoria profissional, setor de trabalho, instituição de trabalho, número de horas trabalhadas, número de vínculos empregatícios, motivação para o acúmulo de vínculo empregatício, em caso de, turno de trabalho e formação acadêmica, este último aplicável apenas aos Es; 
- Instrumento 2: Instrumento de Avaliação de Qualidade de Vida (The World Health Organization Quality of Life - WHOQOL-Bref): Uma análise realizada pelo Grupo de Qualidade de Vida da OMS demonstrou que é possível desenvolver uma medida de qualidade de vida aplicável e válida para uso em diversas culturas ${ }^{8}$. Assim, num projeto colaborativo em 15 centros surgiu o World Health Organization Quality of Life-100 (WHOQOL-100 ${ }^{8,9,52}$. Devido à necessidade de instrumentos curtos e de rápida aplicação, foi, então, desenvolvida a versão abreviada do WHOQOL-100, o WHOQOL-Bref, cuja versão final ficou composta por 26 questões $^{9}$. A primeira questão refere-se à qualidade de vida de modo geral e a segunda, à satisfação com a própria saúde ${ }^{8}$. As outras 24 estão divididas nos domínios físico, psicológico, das relações sociais e meio ambiente, sendo um instrumento que pode ser utilizado tanto para populações saudáveis como para populações acometidas por agravos e doenças crônicas ${ }^{53.54}$. Além do caráter transcultural, os instrumentos WHOQOL valorizam a percepção individual da pessoa, podendo avaliar qualidade de vida em diversos grupos e situações. Tal instrumento reúne informações em quatro âmbitos ou domínios:

- Domínio Físico - dor, desconforto, energia, fadiga, sono, repouso, atividades da vida cotidiana, dependência de medicação ou de tratamentos, mobilidade, capacidade de trabalho;

- Domínio Psicológico - sentimentos positivos, pensamento, aprendizagem, memória, concentração, autoestima, imagem corporal, aparência, sentimentos negativos, espiritualidade, religião, crenças pessoais;

- $\quad$ Relações Sociais - relações pessoais, suporte/apoio social, atividade sexual;

- Domínio do Ambiente - segurança física, proteção, ambiente no lar, recursos financeiros, cuidados de saúde e sociais/disponibilidade e qualidade, oportunidades de adquirir novas informações e habilidades, participação em oportunidades de recreação e lazer, ambiente físico (quanto à poluição, ruído, trânsito, clima) e transporte.

No total, o WHOQOL-BREF inclui 26 questões. As respostas a essas questões geram pontuações que variam de 1 a 5 conforme o grau de satisfação, indo de "nada satisfeito" a "muito satisfeito". Para análise da qualidade de vida por meio do WHOQOL-BREF, inicialmente, é calculado um Escore Bruto (EB) mediante a soma das pontuações de cada questão e posteriormente é gerado um Escore Transformado 4-20 (ET 420), cujos valores variam de 4 a 20. Na sequência, calcula-se o Escore Transformado 0-100 (ET 0-100), onde os valores variam de 0 a 100. Para a análise dos dados de QV dos quatro domínios estudados, utilizase uma escala adaptada ${ }^{55}$. Essa escala é categorizada da seguinte maneira: valores entre 0 e 40 são considerados região de insatisfação; de 41 a 69, correspondem à região de indefinição; e, acima de 70, como tendo atingido a região de sucesso. Para o presente estudo, no sentido de facilitar os cálculos, foi considerado como ponto de corte o valor abaixo de 70 e igual ou maior que 70, no qual os níveis abaixo de 70 são considerados como insatisfação com a QV e níveis acima como satisfação com a mesma (Quadro 1).

Quadro 1. Modelo para interpretação dos valores dos escores médios (Média) do WHOQOL-Bref.

\begin{tabular}{|c|c|}
\hline $\mathrm{e}$ & AVALIAÇÃO DA QV \\
\hline$<70$ & Insatisfação \\
\hline$\geq 70$ & Satisfação \\
\hline
\end{tabular}

Elaborado pelo autor

Instrumento 3: Instrumento Para Rastreamento de Transtornos Mentais Menores (Self-Report Questionnaire - SRQ-20): Constitui-se numa versão de 20 itens utilizados para rastreamento de transtornos mentais menores (TMM), desenvolvido pela Organização Mundial de Saúde (OMS) e validado no Brasil25,26. As respostas utilizadas no questionário são apenas sim ou não e cada resposta positiva corresponde ao valor 1 para compor o escore final por meio da soma total destes valores. Os escores obtidos são referentes à probabilidade de presença de TMM, variando de 0 que corresponde a nenhuma probabilidade e 20 que significa a extrema probabilidade de apresentar $\mathrm{TMM}^{26}$. Os sintomas são agrupados em categorias, e é utilizada uma classificação que estabelece quatro subdivisões de sintomas que são o humor depressivo/ansioso (itens 4,6, 9 e 10), sintomas somáticos (itens 1, 2, 3, 5, 7 e 19), 
redução de energia vital (itens 8, 11,12,13, 18 e 20) e pensamentos depressivos (itens 14, 15, 16 e 17) ${ }^{56}$ (Quadro 2).

Quadro 2. Modelo para interpretação dos valores dos escores médios (Média) do SRQ-20

\begin{tabular}{|c|c|c|c|}
\hline CATEGORIA & ITENS & ESCORE 0 & ESCORE 20 \\
\hline Escore final & Todos & \multirow{5}{*}{$\begin{array}{c}\text { Nenhuma } \\
\text { probabilidade } \\
\text { de apresentar }\end{array}$} & \multirow{5}{*}{$\begin{array}{c}\text { Extrema } \\
\text { probabilidade } \\
\text { de apresentar }\end{array}$} \\
\hline Humor depressivo/ansioso & $4,6,9$ e 10 & & \\
\hline Sintomas somáticos & $1,2,3,5,7$ e 19 & & \\
\hline Redução da energia vital & $8,11,12,13,18$ e 20 & & \\
\hline Pensamentos depressivos & $14,15,16$ e 17 & & \\
\hline
\end{tabular}

Elaborado pelo autor

Instrumento 4: Escala de Resiliência de Wagnild \& Young: A escala de resiliência desenvolvida por Wagnild \& Young57 é um dos poucos instrumentos usados para medir níveis de adaptação psicossocial positiva em face de eventos de vida importantes. Possui 25 itens descritos de forma positiva com resposta tipo Likert variando de 1 (discordo totalmente) a 7 (concordo totalmente). Os escores da escala oscilam de 25 a 175 pontos, com valores altos indicando elevada resiliência.

Os dados foram coletados, após agendamento com as gerentes das UPAs do município de São José do Rio

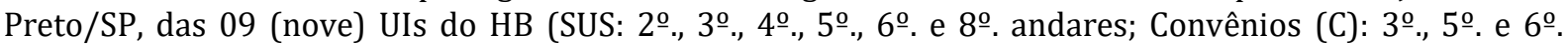
andares) e dos 02 (dois) setores de emergência do HB: EC e E-SUS, para quem os pesquisadores explicaram os objetivos do estudo e entregaram os quatro ICDs e os Termos de Consentimento Livre e Esclarecidos (TCLEs) em duas versões (versão para o respondente, que permanecia com o mesmo, e versão para o pesquisador, que entregaram aos profissionais sob sua gerência e recolheram os mesmos (ICDs e TCLE versão para o pesquisador) em envelopes separados e lacrados, para preservar o anonimato dos participantes do estudo, e entregaram para os pesquisadores, no período de agosto a outubro de 2019.

As variáveis sociodemográficas e profissionais foram utilizadas para caracterizar a população do estudo. A análise exploratória dos dados incluiu média, mediana, desvio-padrão e variação para variáveis contínuas e número e proporção para variáveis categóricas. A distribuição normal das variáveis contínuas foi analisada pela assimetria, curtose e teste de Kolmogorov-Smirnov.

Comparação de variáveis ordinais entre dois grupos foi realizada pelo teste de Mann-Whitney e entre três grupos pelo teste de Kruskal-Wallis. Análise de correlação entre qualidade de vida e resiliência, bem como entre transtornos mentais menores e resiliência foi realizada pelo coeficiente de correlação de Spearman. Análise estatística foi realizada mediante o software IBM-SPSS Statistics versão 24 (IBM Corporation, NY, USA). Todos os testes foram bicaudais e valores de $\mathrm{p}<0,05$ foram considerados significantes.

\subsection{ASPECTOS ÉTICOS}

Este estudo é parte do projeto-mãe “Grau de Resiliência entre Profissionais de Enfermagem dos Setores de Emergência do Hospital de Base de São José do Rio Preto: Fator Preditivo da Qualidade do Atendimento Prestado", submetido à apreciação do Comitê de Ética em Pesquisa (CEP) da Faculdade de Medicina de São José do Rio Preto (FAMERP), sob Certificado de apresentação para Apreciação Ética (CAAE) n. 89714418.0.0000.5415, e aprovado em 02 de julho de 2018, com parecer n. 2.748.173.

\section{RESULTADOS}

\subsection{DADOS SOCIODEMOGRÁFICOS E PROFISSIONAIS}

Foram incluídos 203 profissionais no estudo, sendo 165 (81,3\%) do sexo feminino e 119 (58,6\%) com até 39 anos de idade. Os dados sociodemográficos dos participantes estão descritos na Tabela 1. 
Tabela 1. Dados sociodemográficos dos 203 dos participantes do estudo

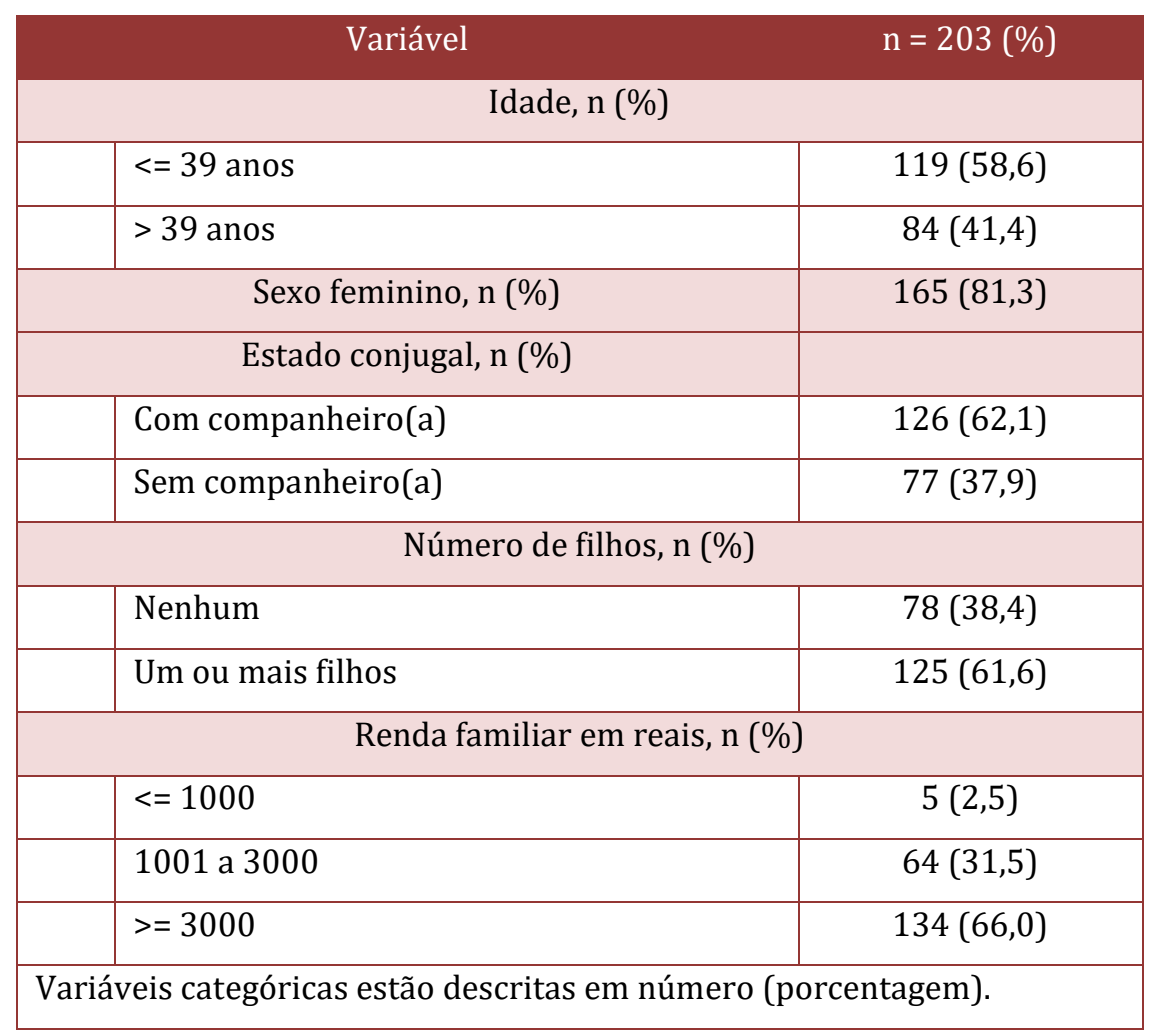

Quanto à categoria profissional, 99 (48,8\%) participantes eram TE, 79 (38,9\%) E e 25 (12,3\%) AE. Quanto à formação acadêmica, 132 (65\%) participantes não responderam este questionamento. Entre os 71 respondentes, $64(90,1 \%)$ participantes possuíam especialização (sendo 42 participantes com uma especialização e 22 com duas ou mais especializações), seis possuíam mestrado e um possuía doutorado. As variáveis profissionais estão relatadas na Tabela 2.

Tabela 2. Dados profissionais dos 203 participantes do estudo

\begin{tabular}{|c|c|}
\hline Variável & $n=203(\%)$ \\
\hline \multicolumn{2}{|l|}{ Categoria profissional, n (\%) } \\
\hline Técnico de enfermagem & $99(48,8)$ \\
\hline Enfermeiro & $79(38,9)$ \\
\hline Auxiliar de enfermagem & $25(12,3)$ \\
\hline \multicolumn{2}{|l|}{ Formação profissional, n (\%) } \\
\hline $\begin{array}{l}\text { Sem discrepância entre a formação atual e } \\
\text { o cargo que ocupa }\end{array}$ & $200(98,5)$ \\
\hline Auxiliar e técnico de enfermagem & $1(0,5)$ \\
\hline Técnico de enfermagem e enfermeiro & $2(1,0)$ \\
\hline
\end{tabular}


Tabela 2. Dados profissionais dos 203 participantes do estudo (continuação)

\begin{tabular}{|c|c|}
\hline Variável & $n=203(\%)$ \\
\hline \multicolumn{2}{|c|}{ Setor de trabalho, n (\%) } \\
\hline Unidade de internação - HB & $59(29,1)$ \\
\hline \multicolumn{2}{|c|}{ Emergência, n(\%) } \\
\hline UPAs & $89(43,8)$ \\
\hline Emergência SUS - HB & $39(19,2)$ \\
\hline Emergência Convênio - HB & $16(7,9)$ \\
\hline \multicolumn{2}{|c|}{ Instituição de trabalho, n (\%) } \\
\hline Hospital de Base & $114(56,2)$ \\
\hline UPA Tangará & $25(12,3)$ \\
\hline UPA Jaguaré & $22(10,8)$ \\
\hline UPA Sto Antonio & $16(7,9)$ \\
\hline UPA Norte & $16(7,9)$ \\
\hline UPA Vila Toninho & $10(4,3)$ \\
\hline \multicolumn{2}{|c|}{ Horas de trabalho, n (\%) } \\
\hline 30 horas semanais & $42(20,7)$ \\
\hline 31 a 44 horas semanais & $136(67,0)$ \\
\hline Mais que 44 horas semanais & $25(12,3)$ \\
\hline \multicolumn{2}{|c|}{ Turno de trabalho, n (\%) } \\
\hline Diurno & $102(50,2)$ \\
\hline Noturno & $60(29,6)$ \\
\hline Mais de um turno & $41(20,2)$ \\
\hline \multicolumn{2}{|c|}{ Formação acadêmica, n (\%) } \\
\hline Especialização & $64 / 79(81,0)$ \\
\hline Mestrado & $6 / 79(7,6)$ \\
\hline Doutorado & $1 / 79(1,3)$ \\
\hline Não reponderam & $8 / 79(10,1)$ \\
\hline
\end{tabular}

Variáveis categóricas estão descritas em número (porcentagem).

Ainda em dados profissionais, os participantes foram inqueridos sobre mais de um vínculo empregatício e a motivação para acúmulo de vínculos. Os resultados estão na Tabela 3. 
Tabela 3. Dados relativos a vínculo empregatício adicional entre os 203 participantes do estudo

\begin{tabular}{|c|c|}
\hline Variável & $n=203(\%)$ \\
\hline \multicolumn{2}{|c|}{ Número de vínculos empregatícios, n (\%) } \\
\hline $\mathrm{Um}$ & $157(77,3)$ \\
\hline Dois & $42(20,7)$ \\
\hline Três & $4(2,0)$ \\
\hline \multicolumn{2}{|c|}{ Instituição de trabalho adicional, n (\%) } \\
\hline Um único vínculo empregatício & $163(80,3)$ \\
\hline Dois vínculos, sem especificar & $25(12,3)$ \\
\hline Três vínculos, sem especificar & $5(2,5)$ \\
\hline Santa Casa & $4(2,0)$ \\
\hline Austa & $2(1,0)$ \\
\hline Unimed & $3(1,5)$ \\
\hline Beneficência Portuguesa & $1(0,5)$ \\
\hline \multicolumn{2}{|c|}{ Motivação para acúmulo de vínculos empregatícios, n (\%) } \\
\hline Não acumula & $161(79,3)$ \\
\hline Necessidade financeira & $30(14,8)$ \\
\hline Busca melhor remuneração & $12(5,9)$ \\
\hline
\end{tabular}

Variáveis categóricas estão descritas em número (porcentagem).

\subsection{ANÁLISE DESCRITIVA DE QV (WHOQOL-BREF)}

A análise da QV dos participantes da pesquisa revelou níveis que indicam insatisfação com a mesma, como demonstrado na Tabela 4. Dentre os quatro domínios, aquele que apresentou menor escore (ET 0-100) foi o físico e o maior foi o domínio relações sociais.

Tabela 4. Qualidade de Vida de 203 participantes do estudo, segundo os domínios do WHOQOL-Bref (ET 0$100)$.

\begin{tabular}{|l|c|c|c|c|c|c|}
\hline \multicolumn{1}{|c}{ Domínios de QV } & \multicolumn{1}{c|}{ Média } & Mediana & DP & Mínimo & Máximo & Amplitude \\
\hline Físico & 55,3 & 53,6 & 10,4 & 21,4 & 85,7 & 64,3 \\
\hline Psicológico & 62,3 & 62,5 & 12,8 & 25,0 & 95,8 & 70,8 \\
\hline Relações sociais & 65,3 & 66,7 & 19,8 & 0,0 & 100,0 & 100,0 \\
\hline Ambiente & 62,2 & 62,5 & 13,8 & 18,8 & 93,8 & 75,0 \\
\hline
\end{tabular}

WHOQOL-Bref, World Health Organization Quality of Life - Bref; QV, qualidade de vida; DP, desvio-padrão. 
Tabela 5. Questionamentos adicionais do WHOQOL-Bref

\begin{tabular}{|l|l|c|}
\hline \multicolumn{2}{|c|}{ Questionamentos } & n/total (\%) \\
\hline \multirow{2}{*}{$\begin{array}{l}\text { Alguém lhe ajudou a preencher este } \\
\text { questionário?, n (\%) }\end{array}$} & Não & $195 / 201(97,0)$ \\
\cline { 2 - 3 } & Sim & $6 / 201(3,0)$ \\
\hline \multirow{2}{*}{$\begin{array}{l}\text { Quanto tempo você levou para preencher } \\
\text { este questionário?, n (\%) }\end{array}$} & Menos de 5 minutos & $44 / 200(22,0)$ \\
\cline { 2 - 3 } & Entre 5 e 10 minutos & $66 / 200(33,0)$ \\
\cline { 2 - 3 } & Entre 11 e 20 minutos & $45 / 200(22,5)$ \\
\cline { 2 - 3 } & Mais de 20 minutos & $45 / 200(22,5)$ \\
\hline
\end{tabular}

Variáveis categóricas estão descritas em número (porcentagem).

Quanto ao questionamento do WHOQOL-Bref "Você tem algum comentário sobre este questionário?", 12 participantes pronunciaram-se e os relatos estão transcritos no Quadro 3.

Quadro 3. Transcrição de respostas para o questionamento final do WHOQOL-Bref: "Você tem algum comentário sobre este questionário?"

\begin{tabular}{|c|c|}
\hline Comentário 1 & Muito bom. \\
\hline Comentário 2 & Muito interessante. \\
\hline Comentário 3 & Atual. \\
\hline Comentário 4 & Útil. \\
\hline Comentário 5 & Devia ter a opção “às vezes”, pois mudamos de acordo com a situação. \\
\hline Comentário 6 & Muito grande. \\
\hline Comentário 7 & Não foi muito satisfatório. \\
\hline Comentário 8 & Pensando por que não consigo estar satisfeita. \\
\hline Comentário 9 & $\begin{array}{l}\text { Na página 1, questão 17, já tive momentos de me sentir inútil e depressiva, mas já faz tempo que } \\
\text { não tenho mais! }\end{array}$ \\
\hline Comentário 10 & $\begin{array}{l}\text { Na questão saudável é seu ambiente físico deveria estar separado do trabalho e família, teria } \\
\text { pontuação diferente no meu caso. }\end{array}$ \\
\hline Comentário 11 & Perguntas sem algum significado; sem algum esclarecimento, \\
\hline Comentário 12 & $\begin{array}{l}\text { Se tivesse mais apoio no trabalho talvez nossa vida seria outra. Pois algumas perguntas só é uma } \\
\text { dúvida. Falta apoio. }\end{array}$ \\
\hline
\end{tabular}




\subsection{ANÁLISE DESCRITIVA DE TMM, SEGUNDO O SRQ (SELF-REPORT QUESTIONNAIRE).}

$\mathrm{Na}$ análise de possíveis transtornos mentais menores, observou-se baixa probabilidade de ocorrência destes transtornos de maneira global entre os participantes do estudo, como demonstrado na Tabela 6.

Tabela 6. Rastreamento de Transtornos Mentais Menores, segundo SRQ-20 (n=203).

\begin{tabular}{|c|c|c|c|c|c|c|}
\hline$S R Q-20$ & Média & Mediana & DP & Mínimo & Máximo & Amplitude \\
\hline Escore final & 5,12 & 4,0 & 4,6 & 0 & 17 & 17 \\
\hline Humor depressivo/ansioso & 1,33 & 1,0 & 1,3 & 0 & 4 & 4 \\
\hline Sintomas somáticos & 1,63 & 1,0 & 1,6 & 0 & 7 & 7 \\
\hline Redução da energia vital & 1,77 & 1,0 & 1,9 & 0 & 6 & 6 \\
\hline Pensamentos depressivos & 0,39 & 0,0 & 0,8 & 0 & 4 & 4 \\
\hline
\end{tabular}

SRQ-20, Self-Report Questionnaire; DP, desvio-padrão.

0 cálculo da prevalência global de TMM em nossa amostra pode ser visto na Tabela 7 e corresponde a 31\%.

Tabela 7. Distribuição dos 203 participantes do estudo, quanto ao diagnóstico de Transtornos Mentais Menores, segundo o $S R Q-20$.

\begin{tabular}{|c|c|}
\hline $\mathrm{TMM}^{*}$ & $n(\%)$ \\
\hline Não & $140(69,0)$ \\
\hline Sim & $63(31,0)$ \\
\hline
\end{tabular}

Variáveis categóricas estão descritas em número (porcentagem).

*Presente se escore $S R Q-20 \geq 8$ pontos. ${ }^{58}$

TMM, transtorno mental menor. SRQ-20, Self-Report Questionnaire.

\subsection{ANÁLISE DESCRITIVA DE R (ESCALA DE RESILIÊNCIA DE WAGNILD E YOUNG)}

Quando analisada a R entre os participantes da pesquisa, observou-se altos índices (vale lembrar que, na escala de Wagnild e Young, a pontuação varia de 25 a 175, sendo que valores altos indicam elevada resiliência). Os resultados podem ser vistos na Tabela 8 e Figura 5.

Tabela 8. Resiliência entre os 203 participantes do estudo, segundo a Escala de Resiliência de Wagnild e Young.

\begin{tabular}{|c|c|}
\hline Escore & $n=203$ \\
\hline Média & 136,4 \\
\hline Mediana & 139,0 \\
\hline Desvio-padrão & 20,1 \\
\hline Mínimo & 79 \\
\hline Máximo & 175 \\
\hline Amplitude & 96 \\
\hline
\end{tabular}


Figura 5. Resiliência entre os participantes do estudo, segundo a escala de Resiliência de Wagnild e Young.

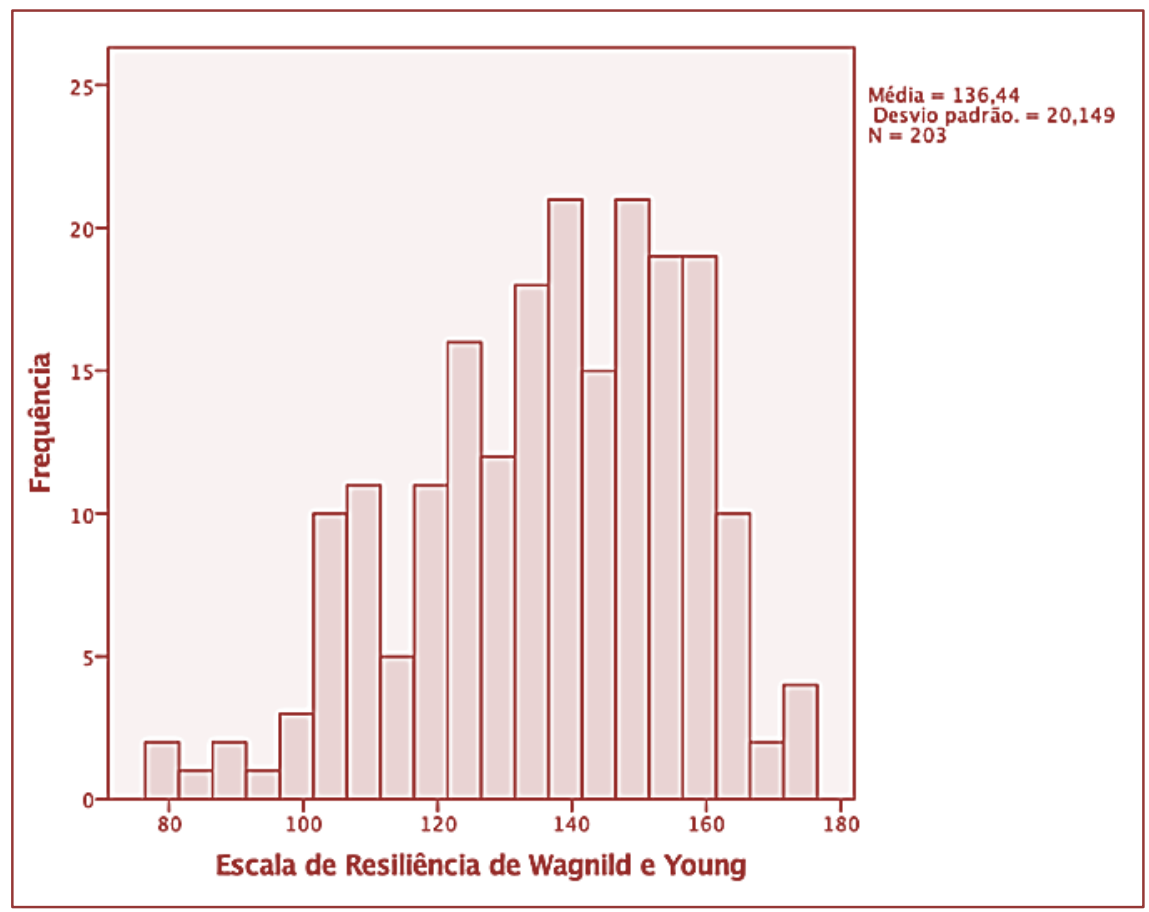

\subsection{ANÁLISE COMPARATIVA DE QV, TMN E R ENTRE E, TE E AE}

Procedeu-se a análise comparativa de QV, TMN e R entre as três categorias de profissionais e não houve diferença significante entre elas (Tabelas 9 a 11 e Figura 6).

Tabela 9. Análise comparativa da Qualidade de Vida entre as três categorias profissionais.

\begin{tabular}{|c|c|c|c|c|}
\hline Domínio do WHOQOL-Bref & $\begin{array}{c}\text { Auxiliar de } \\
\text { enfermagem } \\
(n=25)\end{array}$ & $\begin{array}{c}\text { Técnico de } \\
\text { enfermagem }(\mathrm{n}= \\
\text { 99) }\end{array}$ & $\begin{array}{l}\text { Enfermeiro } \\
\quad(\mathrm{n}=79)\end{array}$ & Valor $\mathrm{p}^{*}$ \\
\hline Físico & 67,9 & 71,4 & 71,4 & 0,761 \\
\hline Psicológico & 70,8 & 66,7 & 66,7 & 0,607 \\
\hline Social & 66,7 & 66,7 & 66,7 & 0,410 \\
\hline Ambiente & 59,4 & 62,5 & 65,6 & 0,321 \\
\hline
\end{tabular}

Tabela 10. Análise comparativa de Transtornos Mentais Menores entre as três categorias profissionais.

\begin{tabular}{|l|c|c|c|c|}
\multicolumn{1}{|c}{ SRQ } & $\begin{array}{c}\text { Auxiliar de } \\
\text { enfermagem } \\
(\mathrm{n}=25)\end{array}$ & $\begin{array}{c}\text { Técnico de } \\
\text { enfermagem }(\mathrm{n}=99)\end{array}$ & $\begin{array}{c}\text { Enfermeiro } \\
(\mathrm{n}=79)\end{array}$ & Valor $\mathrm{p}^{*}$ \\
\hline SRQ escore total & 3,0 & 4,0 & 5,0 & 0,079 \\
\hline Humor depressivo/ansioso & 1,0 & 1,0 & 1,0 & 0,212 \\
\hline Sintomas somáticos & 1,0 & 1,0 & 2,0 & 0,171 \\
\hline Redução da energia vital & 0,0 & 1,0 & 2,0 & 0,236 \\
\hline Pensamentos depressivos & 0,0 & 0,0 & 0,0 & 0,359 \\
\hline
\end{tabular}

Variáveis estão descritas em mediana.

*Teste de Kruskall-Wallis. 
Tabela 11. Análise comparativa da Resiliência entre as três categorias profissionais

\begin{tabular}{|c|c|c|c|c|}
\hline Categoria & Média & Mediana & Variação & Valor p* \\
\hline Enfermeiro $(\mathrm{N}=79)$ & 133,1 & 135,0 & $80-166$ & \multirow{3}{*}{0,211} \\
\hline Técnico de enfermagem $(\mathrm{N}=99)$ & 138,8 & 141,0 & $91-175$ & \\
\hline Auxiliar de enfermagem $(\mathrm{N}=25)$ & 137,6 & 144,0 & $79-175$ & \\
\hline
\end{tabular}

*Teste de Kruskall-Wallis.

Resiliência entre os participantes do estudo, de acordo com a categoria profissional, segundo a escala de Resiliência de Wagnild e Young.

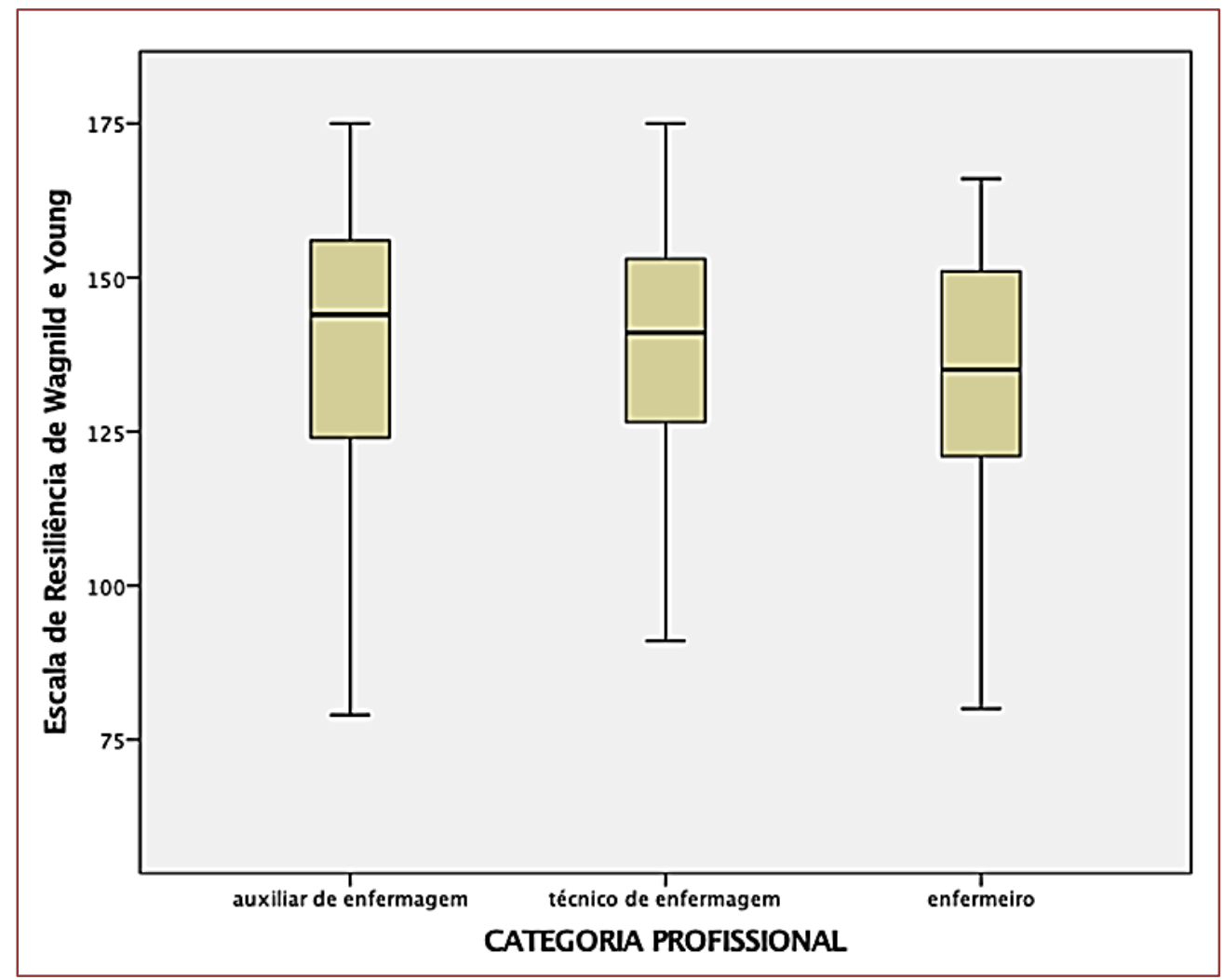

\subsection{ANÁLISE COMPARATIVA DE QV, TMM E R DE ACORDO COM VARIÁVEIS SOCIODEMOGRÁFICAS E PROFISSIONAIS.}

Uma vez que não houve diferença nos escores de QV, TMM e R entre as três categorias profissionais, procedeu-se a análise da amostra como um todo, na busca de possíveis associações com dados sociodemográficos e profissionais.

\subsubsection{QV E VARIÁVEIS SOCIODEMOGRÁFICAS E PROFISSIONAIS}

A análise inferencial dos escores de QV entre os participantes da pesquisa revelou diferença significante apenas para:

- $\quad$ idade (maior em profissionais mais velhos) nos domínios psicológico $(\mathrm{p}=0,026)$ e relações sociais $(\mathrm{p}=0,004)$;

- $\quad$ sexo (maior qualidade de vida no sexo masculino) nos domínios físico $(\mathrm{p}=0,049)$, psicológico $(p=0,007)$ e relações sociais $(p=0,005)$; 
- renda familiar (maior para a faixa entre 1001 e 3000 reais), no domínio psicológico $(\mathrm{p}=0,026)$;

- horas de trabalho (maior para os que trabalham 30 horas semanais) no domínio ambiente $(p=0,021)$;

- número de vínculos empregatícios (maior para quem tem apenas 1 vínculo), no domínio físico $(p=0,025)$.

\subsubsection{TMM E VARIÁVEIS SOCIODEMOGRÁFICAS E PROFISSIONAIS}

A análise inferencial da presença de TMM entre os participantes da pesquisa revelou diferença significante quanto à idade (menor em profissionais mais velhos) no escore final $(\mathrm{p}=0,012)$ e nas categorias humor depressivo/ansioso $(p=0,009)$ e redução da energia vital $(p=0,017)$, e sexo (menor no sexo masculino) no escore final $(p=0,023)$ e nas categorias humor depressivo/ansioso $(p=0,009)$ e sintomas somáticos $(p=0,041)$. Não houve diferenças significantes para as demais variáveis.

\subsubsection{R E VARIÁVEIS SOCIODEMOGRÁFICAS E PROFISSIONAIS}

Como pode ser visto na Tabela 12, a análise inferencial dos escores de resiliência entre os participantes da pesquisa revelou diferença significante quanto à idade (maior em profissionais mais velhos) e quanto ao setor de trabalho (maior resiliência entre profissionais do setor de emergência).

Tabela 12. Análise comparativa de Resiliência de acordo com os dados sociodemográficos e profissionais dos 203 participantes do estudo.

\begin{tabular}{|c|c|c|}
\hline Variável & Resiliência & Valor $\mathrm{p}$ \\
\hline \multicolumn{3}{|c|}{ Idade, n (\%) } \\
\hline$<=39$ anos & 137,0 & \multirow{2}{*}{0,034} \\
\hline$>39$ anos & 143,0 & \\
\hline \multicolumn{3}{|c|}{ Sexo, n (\%) } \\
\hline Feminino & 138,0 & \multirow{2}{*}{0,292} \\
\hline Masculino & 140,5 & \\
\hline \multicolumn{3}{|c|}{ Estado conjugal, n (\%) } \\
\hline Com companheiro & 137,5 & \multirow{2}{*}{0,516} \\
\hline Sem companheiro & 140,0 & \\
\hline \multicolumn{3}{|c|}{ Número de filhos, n (\%) } \\
\hline Nenhum & 138,5 & \multirow{2}{*}{0,761} \\
\hline Um ou mais filhos & 139,0 & \\
\hline \multicolumn{3}{|c|}{ Renda familiar em reais, $\mathrm{n}(\%)$} \\
\hline$<=1000$ & 107,0 & \multirow{3}{*}{0,212} \\
\hline 1001 a 3000 & 144,0 & \\
\hline$>=3000$ & 137,0 & \\
\hline
\end{tabular}


Tabela 12. Análise comparativa de Resiliência de acordo com os dados sociodemográficos e profissionais dos 203 participantes do estudo. (continuação)

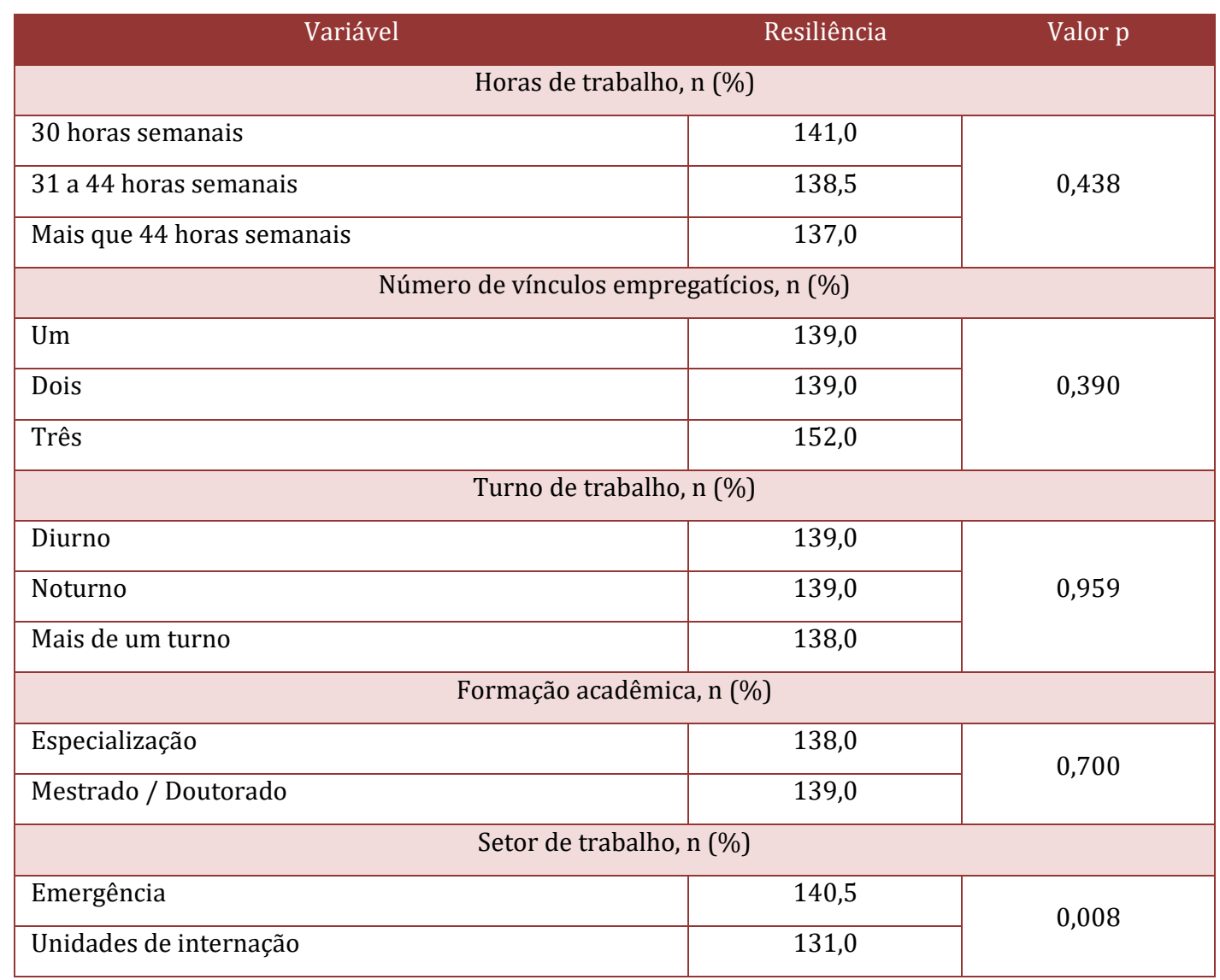

Variáveis categóricas estão descritas em mediana.

\subsection{ANÁLISE DE CORRELAÇÃO ENTRE QV, TMM E R DE E, TE E AE.}

Procedeu-se, a seguir, análise na busca de possíveis correlações entre QV e R, bem como, entre TMM e R. Pode-se observar correlação positiva, estatisticamente significante, entre todos os domínios de QV, segundo o WHOQOL-Bref, e R, como demonstrado na Tabela 13. Além disso, houve correlação inversa, estatisticamente significante, entre TMM e R, tanto no escore total, quanto nas quatro subdivisões de sintomas, denotando que, quanto maior a possibilidade de transtorno, menor a resiliência. (Tabela 13).

Tabela 13. Análise de correlação entre Qualidade de Vida e Resiliência, bem como Transtornos Mentais Menores e Resiliência dos participantes do estudo $(n=203)$.

\begin{tabular}{|l|c|c|}
\hline \multicolumn{2}{|c|}{ Resiliência, segundo a escala de Wagnild e Young } \\
Coeficiente $r^{*}$ & Valor $\mathrm{p}$ \\
\hline \multicolumn{2}{|c|}{ Qualidade de vida, domínios do WHOQOL-Bref } \\
\hline Físico & 0,453 & $<0,001$ \\
\hline Psicológico & 0,559 & $<0,001$ \\
\hline Relações sociais & 0,414 & $<0,001$ \\
\hline Ambiente & 0,395 & $<0,001$ \\
\hline
\end{tabular}


Tabela 13. Análise de correlação entre Qualidade de Vida e Resiliência, bem como Transtornos Mentais Menores e Resiliência dos participantes do estudo $(n=203)$ (continuação).

\begin{tabular}{|l|c|c|}
\hline \multicolumn{2}{|c|}{ Resiliência, segundo a escala de Wagnild e Young } & Valor p \\
\hline \multicolumn{2}{|c|}{ Transtornos mentais menores, segundo SRQ-20 } \\
\hline Escore total SRQ & $-0,427$ & $<0,001$ \\
\hline Humor depressivo/ansioso & $-0,326$ & $<0,001$ \\
\hline Sintomas somáticos & $-0,337$ & $<0,001$ \\
\hline Redução da energia vital & $-0,443$ & $<0,001$ \\
\hline Pensamentos depressivos & $-0,213$ & 0,002 \\
\hline
\end{tabular}

\section{DISCUSSÃO}

Considerando que os trabalhadores de Enfermagem enfrentam mais sofrimento psicológico do que a população em geral, estando expostos a uma variedade de elementos geradores de desgaste, a QV relacionada ao trabalho é um tema que vem despertando crescente interesse, dada a importância de fatores pessoais, ambientais e organizacionais envolvidos no contexto laboral ${ }^{38}$.

Os resultados dos dados sociodemográficos nesta amostra são endossados por outras pesquisas ${ }^{59,60}$. Não há predomínio importante no que se refere à faixa etária; também o predomínio do sexo feminino remete a própria origem histórica da Enfermagem que é por essência um trabalho feminino e que perdura ainda nos dias de hoje 61.

O estado conjugal com companheiro e a presença de filhos ficaram marcados entre os sujeitos da pesquisa, o que é um resultado comum ${ }^{59,60}$, embora preocupante já que fica implícita a sobrecarga com dupla jornada, no trabalho e em casa com afazeres domésticos e no cuidado com os filhos ${ }^{61}$. A renda familiar também se mostrou dentro de uma faixa compatível com a profissão no Brasil ${ }^{62}$.

A quantidade predominante de horas trabalhadas, de 31 a 44 horas semanais, deve-se à realidade atual do mercado e à sociedade capitalista. Ocorre trabalho em excesso e em horários não usuais, embora a maioria dos sujeitos da pesquisa não ultrapassa o limite máximo de horas trabalhadas para os profissionais de Enfermagem, tendo teoricamente tempo para desenvolver outras atividades no âmbito da vida pessoal, como atividades de lazer que promovam saúde e qualidade de vida ${ }^{61}$.

A insatisfação com relação à QV dos profissionais da amostra está de acordo com esta temática na literatura, onde os profissionais de Enfermagem via de regra têm a qualidade de vida severamente comprometida por conta da sua opção de trabalho e os trabalhadores de saúde têm sido constantemente apontados como um grupo de risco para o adoecimento físico e mental. No seu cotidiano de trabalho, os profissionais de saúde deparam-se com pessoas ou grupos que estão em situações limites e complexas, por exemplo, violência sexual, fome, abandono, miséria, entre outras, o que pode gerar angústia e contribuir para o aparecimento de doenças funcionais ${ }^{63}$.

A não diferença nos escores de QV entre as três categorias profissionais pode ser explicada pelo fato de que, embora com diferentes graus de envolvimento e responsabilidade resultando em diferentes níveis de exposição ${ }^{64}$, todas as três categorias estão expostas aos mesmos fatores estressores do ambiente de trabalho, já que o compartilham. Uma das dimensões mais estressantes está relacionada principalmente ao enfrentamento da realidade do sofrimento humano, sobretudo, antes do processo de morrer, do que de fato a própria morte. Isso se dá devido às expectativas não atendidas e arrependimento por não ser capaz de impedir uma morte inevitável, o que se torna uma grande fonte de estresse, afetando a capacidade do profissional de atuar. Um segundo fator de maior estresse deve-se aos pacientes e suas famílias. A interação contínua, a falta de cooperação e compreensão e o sentimento de despreparo do profissional para lidar com as diferentes necessidades emocionais de pacientes e seus familiares criam sentimentos de raiva, medo e decepção na equipe de Enfermagem, conduzindo a níveis elevados de estresse. A revisão da 
literatura revela que o risco de violência física e psicológica por pacientes abusivos e familiares é altamente estressor 65,66 .

0 menor nível de insatisfação com a QV foi com o domínio Relações Sociais. As grandes jornadas de trabalho, trabalho aos fins de semana e no período noturno, fazem com que a vida social acabe por ser relegada a segundo plano devido à dificuldade de compatibilidade de horários com as pessoas de seu círculo social, além de não terem muito tempo para a prática de lazer e de atividades junto à família ${ }^{67} 0$ maior nível de insatisfação com a QV foi com o domínio Físico. Sabe-se que a Enfermagem é uma profissão que necessita de grande esforço físico como ficar em pé por longos períodos, uso repetido das mãos, andar com frequência e realizar esforço braçal e há alta prevalência de dor osteomuscular, principalmente nas regiões de ombro, pescoço e lombar. Fatores influenciados pelo ritmo de trabalho, pressão temporal e a pouca quantidade de funcionários necessários para a demanda, sendo esses fatores relacionados à organização do trabalho ${ }^{68-70}$.

A maior QV, nos domínios Psicológico e Relações Sociais, entre os profissionais mais velhos pode ser o resultado da experiência profissional e das conquistas decorrentes do trabalho, tais como cargo, renda e satisfação profissional. Os profissionais de Enfermagem mais jovens podem possuir uma rede mais vasta de relações sociais e interpessoais em relação aos profissionais mais velhos da área, o que, em tese, poderia lhes conferir a manutenção dos preditores de $\mathrm{QV}^{71}$. Em contrapartida os profissionais de Enfermagem de maior idade, que provavelmente têm rede social menos vasta de relações sociais em virtude das responsabilidades cumulativas ao longo da vida e pelo cansaço físico e mental do dia a dia e de sorte que suas relações sociais passam a ser quase restritas ao ambiente familiar, têm relações sociais mais duradouras e satisfatórias e então se beneficiam da influência positiva das mesmas na QV.

Com uma amostra predominante de profissionais do sexo feminino, com companheiro e filhos, ainda que com jornada de até 30 horas semanais e turno de trabalho predominantemente diurno, a associação dos afazeres domésticos conjunto com os afazeres domésticos podem ser exaustivos, acarretando problemas tanto de ordem física quanto mental ${ }^{61}$; em consequência, uma menor insatisfação com a QV, nos domínios Físico, Psicológico e Relações Sociais, entre os profissionais do sexo masculino, já que afazeres domésticos e cuidados com os filhos ainda são predominantemente atribuições femininas.

A remuneração é um aspecto responsável pelo desempenho, motivação e satisfação no trabalho, sendo citada como causadora de preocupação e insatisfação no trabalho, caso a mesma esteja aquém da capacidade de atender às necessidades pessoais ${ }^{72}$. Em Silva et al. ${ }^{60}$, a remuneração foi o componente de maior satisfação profissional atribuída para auxiliares e técnicos de Enfermagem, tal como encontrado para outras equipes de técnicos e enfermeiros gerenciais ${ }^{73}$. Uma QV com escore menos insatisfatório, no domínio Psicológico, entre os profissionais com renda familiar entre 1.001 e 3.000 reais pode calcar-se no fato de que a faixa salarial do E, a categoria com maior remuneração dentre as 3, é de R\$3.139,69 (média do piso salarial 2020 de acordos, convenções coletivas e dissídios), sendo R $\$ 3.152,00$ o salário mediano da pesquisa, levando-se em conta profissionais de todo o Brasil ${ }^{62}$.

Para grandes jornadas semanais de trabalho, aliadas ao estresse emocional, soma-se ainda o desgaste físico devido às rotatividades de turnos, plantão noturno, jornada de trabalho de 12 horas, plantão durante os finais de semana e feriados, a ausência de regularidade durante as refeições e sobrecarga física $^{74}$, o que explica um escore de QV menos distante do nível de satisfação, no domínio Ambiente, entre os profissionais que trabalham 30 horas semanais.

Embora a pesquisa que vincule $\mathrm{R}$ aos ambientes ocupacionais ainda tenha escopo limitado, a $\mathrm{R}$ é frequentemente mencionada no contexto da prática de Enfermagem. Existem evidências crescentes de que a resiliência não é uma característica estática ou inata, mas um processo contextual e dinâmico ${ }^{75}$. 0 termo resiliência é comumente usado para descrever a capacidade de transformar desafios em oportunidades e aprender com situações exigentes ${ }^{76}$.

Num sistema de saúde orientado para o déficit, com numerosos estressores, pode ser desafiador assumir uma abordagem de resiliência baseada em forças para as adversidades individuais e estruturais. Eles podem parecer intransponíveis. No entanto, há poder e eficácia em uma abordagem coletiva e proativa. Se quisermos fazer a diferença na saúde e no bem-estar dos consumidores, prestadores de cuidados e força de trabalho, precisamos trabalhar juntos para realizar mudanças positivas em todos os níveis - individual, organizacional e profissional. Podemos, assim como Braithwaite et al. ${ }^{77}$ afirmam, não apenas procurar o que deu errado e corrigi-lo, mas também adotar uma abordagem proativa para criar pontos fortes e garantir que as coisas corram bem desde o início ${ }^{78}$. 
Os altos índices de R, sem diferença significante entre as três categorias de profissionais, podem estar diretamente relacionados à paixão e o interesse dos profissionais de enfermagem que os motivam a lidar com as adversidades no local de trabalho, o orgulho e valor em seu papel profissional e satisfação com sua escolha de carreira. 0 senso de valor na profissão de Enfermagem influencia significativamente os profissionais a lidarem com as adversidades no local de trabalho ${ }^{79}$.

Escores de R podem diferir de acordo com os anos de experiência profissional. Mills et al. ${ }^{80}$ sugerem que os escores de R são mais altos no primeiro ano após a graduação, mas diminuem ligeiramente até estabilizar em torno de três a cinco anos, o que está de acordo com os nossos dados de maiores índices de R entre os profissionais mais velhos.

$\mathrm{O}$ fator tempo proporcionando aumento do índice de $\mathrm{R}$, favorece o desenvolvimento de atributos individuais que podem ser usados para criar resiliência, dentre eles: organização do trabalho e equilíbrio trabalho-vida como estratégias conscientes, mecanismo de auto-suficiência, pensamento positivo, inteligência emocional e paixão e interesse, como estratégias de autoeficácia ${ }^{80}$.

Foco em uma experiência que ocorre no presente de maneira não julgadora é o que se pode chamar de atenção plena, que é importante principalmente quando os profissionais de Enfermagem organizam-se e se afastam de situações emocionais altamente carregadas e refletem, aprendem e seguem em frente. Deste modo profissionais de Enfermagem atentos podem se organizar e recuar mentalmente e pensar sobre o que está acontecendo e o que pode ser feito ${ }^{81}$. A organização do trabalho é , então, usada como estratégia consciente pelos profissionais de Enfermagem para melhorar sua resiliência no trabalho, assumindo a forma de horários de trabalho flexíveis (reduzindo o horário de trabalho ou recusando-se a trabalhar em turnos duplos ou horas extras, menor demandas de trabalho (mudança para uma enfermagem fisicamente mais leve, limitando a exposição a trabalhos físicos difíceis e descanso e relaxamento deliberados para se recuperar quando estiver fora de serviço, maior autonomia pessoal (maior controle sobre o trabalho), trabalho em funções interessantes e especializadas, maiores recursos de enfrentamento e insights sobre capacidade de reconhecer estressores ${ }^{82,83}$. É importante ressaltar que menores demandas de trabalho e maiores recursos de enfrentamento têm a capacidade de melhorar a saúde psicológica ${ }^{84}$, enquanto a autonomia pessoal melhora a competência e o controle sobre o trabalho ${ }^{82}$. Os profissionais de enfermagem que têm autonomia pessoal em relação ao seu trabalho são capazes de se concentrar em fornecer assistência centrada na pessoa e em um envolvimento profissional significativo com seus pacientes e, posteriormente, alcançar níveis mais altos de confiança, eficácia e satisfação no trabalho ${ }^{82}$.

O equilíbrio entre vida profissional e pessoal como uma estratégia consciente pode ser empregado para reduzir o estresse no local de trabalho entre os profissionais de Enfermagem ${ }^{80}$ e a capacidade de manter 0 equilíbrio entre vida profissional e pessoal ajuda a prevenir sentimentos de sofrimento emocional e promove o bem-estar 85,86 .

De modo geral, a identificação dos principais fatores ocupacionais estressores em Enfermagem está relacionada às unidades ou contextos específicos de trabalho, tais como as UTIs ${ }^{87}$, as Es ${ }^{87}$, os Serviços Especializados, como os Serviços Psiquiátricos ou a Atenção Primária ${ }^{88}$. Se por um lado as UTIs podem ser consideradas um ambiente de trabalho estressante para os profissionais ${ }^{89}$, por outro lado, UTI e SEs são os setores que dispõem de maior quantidade de profissionais de Enfermagem, seja na rede pública ou em uma unidade hospitalar, pois é percebida como o setor de maior criticidade, o que possibilita melhor aporte quantitativo e qualitativo de profissionais. É significativa a atuação desses profissionais de Enfermagem que, em meio às adversidades de seus postos de trabalho e exigências físicas e mentais acentuadas, executam suas atividades laborais por afinidade/satisfação pessoal e profissional. Isto que se converte em benefícios para os pacientes, para a empresa e para si próprios, pois uma vez que o profissional identifica-se com a sua atuação profissional e se reconhece satisfeito pessoal e profissionalmente, aumenta sua $\mathrm{R}$ reduz-se o risco de comprometimento de sua $\mathrm{QV}^{90}$, o que explica a correlação positiva de QV e R, ou seja, quanto maior a R maiores os escores de QV.

Destaca-se que o cuidar é o cerne da Enfermagem e o enfermeiro é o responsável por proporcionar o cuidado adequado, resolutivo, ético e humanístico ao paciente. Quando as consequências desse trabalho se tornam sofrimento, diminui-se o desempenho de ações necessárias e eficazes para a qualidade desse cuidado $68-70$.

O adoecimento físico perpassa inúmeras dimensões, desde a forma como está organizado o serviço, quantidade de profissionais e infraestrutura, até a forma como o profissional atua com o paciente. É notório, não raramente, que enfermeiros, técnicos e auxiliares de Enfermagem, estudantes de Enfermagem e Medicina, médicos e serviços de apoio podem não possuir competências para a condição que o paciente exige e que muitas vezes não se sentem preparados para tal ${ }^{68-70}$. 
Assim é necessário repensar a formação contínua dos profissionais da saúde, tendo em vista que esse campo é amplo, com diversas áreas específicas. Cabe ao profissional estar atento para o desenvolvimento de competências e habilidades que possa lhe ajudar na atuação onde for requisitado. Um primeiro passo para transformar esse insight em diretrizes para educar profissionais e futuros profissionais de Enfermagem que estejam em condições de cuidar deve ser focado numa cultura de aprendizado de confiabilidade, no ambiente de trabalho e de aprendizagem ${ }^{91}$. Isso poderia facilitar o que Rusthon et al. ${ }^{92}$ descrevem como passar da vitimização para o empoderamento. Ao seguir esse caminho, os profissionais e estudantes de Enfermagem podem amadurecer e ganhar a capacidade de cuidar de si mesmos e de seus pacientes em um processo contínuo de aprendizado e construção de resiliência.

Resiliência não é simplesmente responsabilidade de um indivíduo; é uma responsabilidade social compartilhada93. Além de criar recursos individuais e ambientais em situações de adversidade, também é necessário abordar os fatores estruturais e sistêmicos que causam o estresse e a adversidade ${ }^{94}$. Indiscutivelmente, este é um desafio muito maior; no entanto, resiliência não é esperar que as pessoas lidem com situações cada vez mais difíceis. As causas do estresse e da adversidade precisam ser reduzidas ou removidas sempre que possível. Encontrar maneiras de superar as adversidades nos cuidados de saúde é uma responsabilidade compartilhada ${ }^{91}$.

Nossos resultados apontaram que a prevalência global de TMM nos profissionais que compuseram a amostra foi de $31 \%$, apoiando outros estudos $29,95,96$. À beira do leito, 6, 12 ou 24 horas por dia, seis ou sete dias por semana, os profissionais de Enfermagem apresentam níveis bastante elevados de estresse ocupacional e sofrimento psíquico quando comparados a outros grupos. Estudos evidenciam índices aumentados de autopercepção de estresse, ansiedade e depressão em profissionais de Enfermagem; manifestações que compõem, isoladamente ou associadas, os TMM96. Ademais, constata-se taxas alarmantes de suicídio e tentativa de suicídio nessa categoria profissional ${ }^{95}$.

Não houve diferença estatística na prevalência dos TMM e as três categorias da equipe de Enfermagem. A literatura tem identificado que profissionais de nível técnico são mais sensíveis aos TMM, já que são submetidos, diariamente, à realização de tarefas repetitivas, desgastantes, que exigem maior esforço físico e contato mais próximo com os pacientes e, consequentemente, com o seu sofrimento ${ }^{97}$. Esse resultado conflitante pode estar relacionado ao estresse advindo da intensa atividade cognitiva do enfermeiro e do cuidado direto oferecido pelo enfermeiro assistencial.

No que concerne ao local de trabalho, a literatura é controversa, apontando elevadas prevalências de TMM em profissionais que atuam tanto em SEs ${ }^{98}$ como em ambulatórios ${ }^{99}$ e UIs ${ }^{97}$. Em nosso estudo o local de trabalho não foi associado com maior prevalência de TMM.

Indivíduos mais velhos têm menores probabilidades de TMM, tanto no escore final como nas categorias humor depressivo/ansioso e redução da energia vital. Alguns estudos mostram maiores riscos de TMM na faixa etária mais avançada ${ }^{97,100}$, particularmente, os transtornos ansiosos ${ }^{97}$. A literatura ainda faz referência a possibilidade do cenário estar aumentado em face da maior prevalência de doenças crônicas nas pessoas mais velhas ${ }^{96}$. A presença de doenças crônicas não foi investigada nesse estudo.

Por outro lado, as pessoas de idade mais avançada apresentaram maior resiliência, fator que pode ter contribuído para o baixo risco de transtornos emocionais nesses profissionais. Estudos evidenciam que a resiliência está fortemente associada a maior saúde mental ${ }^{101-103}$, pois sugerem que esses indivíduos possuem maior aptidão em suportar adversidades e demonstram atitude positiva diante dos problemas ${ }^{103}$.

Tomando por premissa o sexo como variável biológica fundamental para compreender a ampla gama de consequências fisiológicas, neurobiológicas e comportamentais ${ }^{104}$ as menores probabilidades de TMM em profissionais de Enfermagem do sexo masculino, no escore final e nas categorias humor depressivo/ansioso e sintomas somáticos, podem ter uma relação direta com a ausência da dupla jornada que, via de regra, se impõe aos profissionais do sexo feminino em qualquer área e favorece o desenvolvimento de TMM97,105.

0 apontamento para a categoria sintomas somáticos, tal como aparece aqui, parece corroborar isso e está diretamente ligada à categoria humor depressivo/ansioso e, portanto, ao escore final. As menores probabilidades de TMM em profissionais do sexo masculino na categoria humor depressivo/ansioso contraria dados da literatura que colocam os indivíduos do sexo masculino como mais afetados pela ansiedade e depressão ${ }^{97,106}$. Contudo, alerta-se que há necessidade de maior esclarecimento desse fenômeno, já que uma infinidade de outros sinais podem gerar diferenças no desenvolvimento do cérebro masculino e feminino e alterarem a resposta a sinais intrínsecos e extrínsecos ${ }^{104}$. 
Embora a renda tenha sido descrita como associada aos TMM em trabalhadores em geral ${ }^{107}$, isto não se replicou em nossos dados $(p=0,146)$, talvez pela especificidade da amostra. Níveis menores de risco de TMM também foram associados aos menores níveis de formação acadêmica ${ }^{100}$, o que também não foi encontrado neste estudo $(\mathrm{p}=0,628)$.

Embora o papel gerencial, oportunidades de desenvolvimento de carreira, relacionamento conjugal, mais anos de trabalho no hospital, melhor estado de saúde física e relacionamento e ambiente de trabalho harmonioso tenham sido associados a menores taxas e gravidade de transtornos mentais autorreferidos ${ }^{96}$; nenhum estudo faz a correlação direta da resiliência como fator de proteção aos TMM.

Os índices elevados de resiliência verificados em nossos dados contrariam alguns dados da literatura ${ }^{108,109}$ e corroboram outros ${ }^{110,111}$. Contudo, a ausência de diferença entre as três categorias de profissionais $(p=$ 0,211) pode estar diretamente relacionada à paixão e ao interesse dos profissionais de Enfermagem, independente da categoria, que os motivam a lidar com as adversidades no local de trabalho; o orgulho e valor em seu papel profissional e satisfação com sua escolha de carreira, já que o senso de valor na profissão de Enfermagem influencia significativamente os profissionais para lidar com as adversidades no local de trabalho ${ }^{79,112}$.

É patente a constatação de que maior idade, estabilidade no trabalho e períodos mais longos de trabalho no mesmo local ajudam os profissionais a ganharem mais experiência profissional e de vida, mais oportunidades de desenvolvimento de carreira, como treinamento e promoção, maior segurança no emprego e níveis mais altos de satisfação ${ }^{113,114}$. Todos associados à estabilidade na vida pessoal como boa saúde geral, relacionamento conjugal estável ${ }^{83,115}$, melhor renda ${ }^{116}$, podem favorecer o desenvolvimento da resiliência. Nossos dados estão de acordo e reforçam a associação entre idade $(p=0,034)$ e local de trabalho $(\mathrm{p}=0,008)$, porém não no que se refere ao relacionamento estável $(\mathrm{p}=0,516)$ ou renda $(\mathrm{p}=$ $0,212)$.

0 avanço da idade como fator de desenvolvimento de resiliência pode estar associado ao envelhecimento bem-sucedido, em que um nível mais alto de qualidade de vida relacionado à idade tem sido relacionado às adversidades prévias, inclusive do início da vida ${ }^{117}$, mediando significativamente a relação dessa resiliência com a saúde mental.

Nossos resultados mostraram maior resiliência dos profissionais que atuam em unidades de emergência, quando comparados com aqueles locados em unidades de internação clínica e cirúrgica, resultados esses corroborados pela literatura ${ }^{110,111}$.

Dados de correlação negativa da Resiliência (sugerindo que possa atuar como fator de proteção) foram demonstrados em relação à carga de cuidado. Também, os resultados de ajuste de angústia e aspectos positivos do cuidado entre cuidadores primários de crianças e adolescentes com esquizofrenia ${ }^{100}$, compatíveis com os dados aqui mostrados em que a resiliência teve um efeito de mediação / fator de proteção. Desta forma, os profissionais e seus empregadores devem se concentrar em intervenções baseadas na resiliência; o que pode incluir: oferecer apoio, proporcionar um maior senso de desenvoltura, incentivar a utilização proativa do suporte e aprimorar habilidades de enfrentamento resilientes para desenvolver a R, reduzir o sofrimento e diminuir os riscos de desenvolver TMM.

Mas, tratar a resiliência como uma característica individual é visto como "deixando as organizações fora do gancho"118, ainda que muitas vezes tenha sido o foco das estratégias organizacionais até o momento. Mas isso não funciona assim e certamente não é apropriado; uma vez que as evidências sugerem que a resiliência da equipe parece estar "mais relacionada aos laços entre os membros da equipe do que à composição psicológica ou aos estilos de enfrentamento de qualquer indivíduo"119. Sobretudo, do ponto de vista sócioecológico, esse processo envolve interação ativa entre os recursos de uma pessoa e os de seu ambiente, ou seja, para aumentar a resiliência de uma pessoa, é preciso haver acesso adequado e disponibilidade de recursos e apoios relevantes ao seu redor ${ }^{120}$, em que recursos pessoais (por exemplo, características pessoais como otimismo, senso de autoeficácia e empatia) e recursos ecológicos (por exemplo, apoio emocional e prático de outras pessoas, incluindo organizações) são necessários ${ }^{78,121,122}$.

E, embora inexista um processo emocional único que explique processo de construção da Resiliência, esse processo pode girar em torno do sentimento de desamparo, da presença de emoções positivas ou a percepção do controle sobre a situação, que poderia estar diretamente relacionada ao sentimento de impotência ${ }^{123}$. Deste modo as perspectivas atuais sobre a Resiliência são de que não é simplesmente responsabilidade de um indivíduo, mas sim uma responsabilidade social compartilhada ${ }^{78,93,121 .}$ 
Os fatores de proteção, incluindo a Resiliência, podem afetar o desempenho e a qualidade da assistência prestada pelos profissionais de Enfermagem, o que corrobora a correlação inversa de TMM e Resiliência aqui relatada $(r=-0,427)$, dados esses que não aparecem na literatura.

Os profissionais de Enfermagem sentem-se repetidamente ignorados por seus empregadores quando levantam preocupações sobre a sua saúde mental ${ }^{95}$. Portanto, seria produtivo que esses empregadores tivessem um foco na responsabilidade organizacional pela saúde e bem-estar psicológico de seus colaboradores ao invés de simplesmente dar uma ênfase excessiva na procura por profissionais que "já são resilientes" como uma alternativa em face da falta de pessoal ou da constatação de que o mesmo requer um trabalho emocional intenso ${ }^{118}$.

Importante enfatizar a importância do apoio de colegas e equipes para permitir uma recuperação positiva, após experiências estressantes emocionalmente e que gerentes, organizações e líderes podem servir de apoio aos profissionais até nos momentos mais críticos. A Resiliência nunca deve ser vista como uma responsabilidade individual, mas sim como uma responsabilidade coletiva e organizacional ${ }^{78,93}$, e impensável deixar que esses profissionais possam "se sentir culpados" por não serem "suficientemente resilientes" ou não terem "treinado a resiliência"124.

No que tange à futura força de trabalho de Enfermagem, a preparação dos alunos para a prática e sua Resiliência são áreas emergentes de investigação em Enfermagem e o treinamento em inteligência emocional pode ajudar a construir a Resiliência dos estudantes de Enfermagem e melhorar sua prontidão para a prática ${ }^{125}$, já que esse constructo pode ser "treinado"123.

\section{CONCLUSÕES}

Os baixos escores em todos os domínios da QV neste trabalho revelam que a QV geral dos profissionais de Enfermagem é influenciada pelos fatores físicos e psicoemocionais que envolvem as complexas relações de trabalho a que todas as categorias estão expostas durante o desenvolvimento de suas práticas assistenciais e gerenciais. Isto evidencia a centralidade que o trabalho ocupa em suas vidas e o quanto é importante no processo de autorrealização pessoal e profissional.

A resiliência contribui para a prontidão dos profissionais de Enfermagem em cuidar. Uma cultura de aprendizado educacional de confiabilidade promove o desenvolvimento da resiliência, de modo que os educadores de Enfermagem possam apoiar o desenvolvimento da resiliência de seus alunos, futuros profissionais de Enfermagem nos três níveis.

A prevalência global dos TMM entre os participantes foi elevada, sendo menor em profissionais de idade mais avançada e do sexo masculino. Identificou-se correlação negativa da resiliência com os TMM, indicando que essa habilidade pode ser considerada fator de proteção à saúde mental de trabalhadores de Enfermagem. A resiliência aumentou com a idade e foi maior entre os profissionais do setor de emergência.

Os resultados sugerem que a resiliência desempenha um papel importante na promoção da saúde e bemestar psicológico, diminuindo os riscos de TMM. Desta forma, aponta caminhos para intervenções individuais e institucionais, tanto no nível da prevenção e promoção, como na recuperação da saúde dos indivíduos.

Considerando-se que o comprometimento organizacional está associado à satisfação no trabalho e ao ambiente de trabalho profissional, os gerentes organizacionais e de unidades podem aumentar a participação dos funcionários na tomada de decisões e lhes dar a oportunidade de realizar seu valor. Em outras palavras, dar uma mão mais forte aos profissionais de Enfermagem, propiciando acesso a recursos e criando novas perspectivas sobre estratégias para aumentar sua qualidade de vida, compromisso organizacional e satisfação no trabalho. A melhoria da comunicação e cooperação; o estabelecimento de gestão participativa e o aprimoramento dos pontos fortes / qualificações dos trabalhadores também serão complementares à manutenção de uma estrutura organizacional saudável. 


\section{REFERÊNCIAS BIBLIOGRÁFICAS}

[1] Arnetz J, Hamblin LE, Sudan S, Arnetz B. Organizational Determinants of Workplace Violence Against Hospital Workers. J Occup Environ Med. 2018;60(8):693-9.

[2] Crawford CL, Chu F, Judson LH, Cuenca E, Jadalla AA, Tze-Polo L. An Integrative Review of Nurse-to-Nurse Incivility, Hostility, and Workplace Violence: A GPS for Nurse Leaders. Nurs Adm Q. 2019;43(2):138-56.

[3] Souza LA, Ikegami EM, Walsh IAP, Bertoncelli D. Associação do nível de atividade física com a capacidade para o trabalho e sintomas osteomusculares em profissionais de enfermagem do âmbito hospitalar Saúde (Sta. Maria). 2019:45(3):1-12

[4] Ozanam MAQ, Santos SVM, Silva LA, Darli RCMB, Bardaquim VA, Robazzi MLCC. Satisfação e insatisfação no trabalho dos profissionais de enfermagem. Braz J Develop. 2019;5(6):6156-78.

[5] Silva LNS, Azevedo CAS, Silva WC, Mendez RC, Perreira TJS, Souza BM, et al. Aspectos físicos e socioeconômicos que interferem na qualidade de vida do profissional de enfermagem. Res Soc Develop.2019;9(1):1 22.

[6] Mendonça RB, Sarni ROS, Len C, Solé D. (2018). Tradução para o português (cultura brasileira) e adaptação cultural de questionários para avaliação da qualidade de vida de crianças com alergia alimentar e de seus pais. Braz J Allergy Immunol. 2018;2(3):364-72.

[7] Mizuno M, Sugimoto K, Mayers T, Ferrans CE. Ensuring Cultural and Cognitive Integrity in Instrument Translation: Quality of Life Index for Japanese Cancer Patients. Asia Pac J Oncol Nurs. 2019;6(1):64-71.

[8] The Whoqol Group. World Health Organization quality of life assessment (WHOQOL): development and general psychometric properties. Soc Sci Med. 1998;46(12):1569-85.

[9] Fleck MP, Louzada S, Xavier M, Chachamovich E, Vieira G, Santos L, et al. Aplicação da versão em português do instrumento abreviado de avaliação da qualidade de vida WHOQOL-bref. Rev Saúde Publica. 2000;34(2):178-83.

[10] Alcântara AC. Trabalho, adoecimento e saúde mental na Universidade de São Paulo [dissertação]. São Paulo: Faculdade de Odontologia da Universidade de São Paulo; 2018.

[11] Cardoso MCB, Araújo TM. Atenção aos transtornos mentais relacionados ao trabalho nas regiões do Brasil. Psicol Soc. 2018; 30:e163746.

[12] Conselho Federal de Psicologia. Saúde do trabalhador no âmbito da saúde pública: referências para atuação da(o) psicóloga(o). 2ª ed. Brasília (DF): CFP; 2019.

[13] Oliveira AMN, Araújo MT. Situações de desequilíbrio entre esforço recompensa e transtorno mentais comuns em trabalhadores da atenção básica de saúde. Trab Educ Saúde. 2018;16(1):243-62.

[14] Schimidht MLG, Barbosa WF, Rotoli LUM. Prevalência de transtornos mentais entre auxiliares e técnicos de enfermagem readaptados no trabalho. Rev Saúde Ciênc Online. 2018;7(3):23-31.

[15] Pereira SS, Teixeira CB, Reisdorfer E, Vieira MV, Gherardi-Donato ECS, Cardoso L. The relationship between occupational stressors and coping strategies in nursing technicians. Texto \& Contexto Enferm [periódico na Internet]. 2016 Dez [acesso 2019 Nov 30];25(4): [aproximadamente 8 p.]. Disponível em: http://www.scielo.br/pdf/tce/v25n4/0104-0707-tce-25-04-2920014.pdf

[16] Cordeiro TMSC, Araújo TM. Prevalência da capacidade para o trabalho inadequada entre trabalhadores de enfermagem da atenção básica à saúde. Rev Bras Med Trab. 2017;15(2):150-7.

[17] Jaracz M, Rosiak I, Bertrand-Bucińska A, Jaskulski M, Nieżurawska J, Borkowska A. Affective temperament, job stress and professional burnout in nurses and civil servants. PloS one. 2017;12(6):e0176698.

[18] Silva SM, Borges E, Abreu M, Queirós C, Baptista PCP, Felli, VEA. Relação entre resiliência e burnout: Promoção da saúde mental e ocupacional dos enfermeiros. Rev Port Enferm Saúde Mental. 2016;(16):41-8.

[19] Sousa KH, Lopes DP, Nogueira ML, Tracera GM, Moraes KG, Zeitoune RC. Risk of illness and human cost at work in a psychiatric hospital. Esc Anna Nery. 2018;22(2)::e20170288

[20] World Helath Organization [homepage na Internet]. Geneva: WHO; 2019 [acesso em 2020 Ago 24]. World Health Statistics 2019: Monitoring health for the SDGs, sustainable development goals; [aproximadamente 132 p.]. Disponível em: https://apps.who.int/iris/bitstream/handle/10665/324835/9789241565707eng.pdf?sequence=9\&isAllowed=y

[21] Mendes JR, Lopes MCB, Vancini-Campanharo CR, Okuno MFP, Batista REA. Types and frequency of errors in the preparation and administration of drugs. Einstein (São Paulo) [periódico na Internet]. 2018 [acesso em 2020 Ago 24;16(3):[aproximadamente 6 p.]. Disponível em: https://www.scielo.br/pdf/eins/v16n3/2317-6385-eins-16-03eA04146.pdf 
[22] Steege LM, Pinekenstein BJ, Rainbow JG, Arsenault Knudsen E. Addressing Occupational Fatigue in Nurses: Current State of Fatigue Risk Management in Hospitals. J Nurs Adm. 2017;47(9):426-33.

[23] Udod SA, Cummings G, Care WD, Jenkins M. Impact of Role Stressors on the Health of Nurse Managers: A Western Canadian Context. J Nurs Adm. 2017;47(3):159-64.

[24] Santos TA, Santos HS, Sampaio ES, Melo CMM, Souza EA, Pires CGS. Intensity of nursing work in public hospitals. Rev Latinoam Enferm [periódico na Internet]. 2020 [acesso em 2020 Ago 24];28:[aproximadamente 8 p.]. Disponível em: https://www.scielo.br/pdf/rlae/v28/0104-1169-rlae-28-e3267.pdf

[25] Mari, JJ, Williams PA. A validity study of a psychiatric screening questionnaire (SRQ-20) in primary care in the city of São Paulo. Br J Psychiatry. 1986;148(1):23-6.

[26] Gonçalves DM, Stein AT, Kapczinski F. Avaliação de desempenho do SelfReporting Questionnaire como instrumento de rastreamento psiquiátrico: um estudo comparativo com o Structured Clinical Interview for DSMIV-TR. Cad Saúde Pública. 2008;24(2):380-90.

[27] Bolsoni LM, Zuardi AW. Estudos psicométricos de instrumentos breves de rastreio para múltiplos transtornos mentais. J Bras Psiquiatr. 2015;64(1):63-9.

[28] Moreira IJB, Horta JA, Duro LN, Borges DT, Cristofari AB, Chaves J, et al. Perfil sociodemográfico, ocupacional e avaliação das condições de saúde mental dos trabalhadores da Estratégia Saúde da Família em um município do Rio Grande do Sul, RS. Rev Bras Med Fam Comunidade. 2016;11(38):1-12

[29] Jacinto A, Tolfo SR. Fatores psicossociais de risco no trabalho e Transtorno Mental Comum: uma revisão sistemática de estudos que utilizaram os instrumentos JCQ, JSS e SRQ-20. Rev Psicol IMED. 2017;9(2):107-24.

[30] Seo H-S, Kim H, Hwang S-M, Hong SH, Lee I-Y. Predictors of job satisfaction and burnout among tuberculosis management nurses and physicians. Epidemiology and health. Epidemiol Health. 2016;38:e2016008.

[31] Majidi A, Mahmoodi S, Adineh VH. An Epidemiologic Study of Emergency Department Visits before and after Executing Health Sector Evolution Plan; a Brief Report. Iran J Emerg Med. 2017;4(3):130-4.

[32] Farah BF, Dutra HS, Ramos ACTM, Friedrich DBC. Percepções de enfermeiras sobre supervisão em enfermagem na Atenção Primária à Saúde. Rev Rene. 2017;17(6):804-11.

[33] Neme GGS, Limongi JE. Prevalência e fatores relacionados à transtornos mentais comuns entre professores universitários de uma Universidade Federal Brasileira. Hygeia. 2019;15(31):112-20.

[34] Alves AP, Pedrosa LAK, Coimbra MAR, Miranzi MAS, Hass VJ. Prevalência de transtornos Mentais comuns entre profissionais de saúde. Rev Enferm UERJ. 2015;23(1):64-9.

[35] Ansoleaga E. Indicadores de salud mental asociados a riesgo psicosocial laboral en un hospital público. Rev Med Chile. 2015;143(1):47-55.

[36] Alves KR, Alves MS, Almeida CPB. Mental health care: values, concepts and philosophies present in the everyday care. Rev Enferm UFPI. 2017;6(2):4-9.

[37] Farias SNP, Zeitoune RCG. A Qualidade de Vida no Trabalho de Enfermagem. Esc Anna Nery. 2007;11(3):48793.

[38] Azevedo BDS, Nery AA, Cardoso JP. Occupational stress and dissatisfaction with quality of work life in nursing. Texto \& Contexto Enferm [periódico na Internet]. 2017 Mar. [acesso em 2019 Dez 02];26(1):[aproximadamente 11 p.]. Disponível em: http://www.scielo.br/pdf/tce/v26n1/1980-265X-tce-26-01e3940015.pdf

[39] Corrêa RZA, Souza MSS, Baptista AMN. Vulnerabilidade ao estresse no trabalho e qualidade de vida de enfermeiros. Psicol Argum. 2017;31(75):599-606.

[40] Khamisa N, Oldenburg B, Peltzer KD. Work related stress, burnout, job satisfaction and general health of nurses. Int J Environ Res Public Health. 2015;12(1):652-66.

[41] Maroco J, Maroco AL, Leite E, Bastos C, Vazão MJ, Campos J. Burnout em profissionais da saúde portugueses: Uma análise a nível nacional. Acta Med Port. 2016;29(1):24-30.

[42] Cruz EJER, Souza NVDO, Amorim LKA, Pires AS, Gonçalves FGA, Cunha LP. Resiliência como objeto de estudo da saúde do trabalhador: uma revisão narrativa. Rev Pesqui Cuid Fundam (Online). 2018;10(1):283-8.

[43] Brasil. Lei no 7.489, de 25 de junho de 1986. Dispõe sobre a regulamentação do exercício da Enfermagem e dá outras providências. Diário Oficial da União, 26 jun. 1986. Seção 1:9273. [aproximadamente 7 telas]. Disponível em: http://www.cofen.gov.br/lei-n-749886-de-25-de-junho-de-1986_4161.html

[44] Brasil. Decreto no 94.406, de 8 de Junho de 1987. Regulamenta a Lei no 7.498, de 25 de junho de 1986, que dispõe sobre o exercício da enfermagem, e dá outras providências. Diário Oficial da União, 09 jun. 1987. Seção 1:88538855. 
[45] Fracolli LA, Granja GF. A utilização da categoria processo de trabalho pela enfermagem brasileira: uma análise bibliográfica. Rev Esc Enferm USP. 2005;39(Spec):597-602.

[46] Stolarski CV, Teston V, Kolhs M. Conhecimento da equipe de enfermagem sobre suas atribuições legais. REME Rev Min Enferm. 2009;13(3):321-6.

[47] Leal JAL, Melo CMM. The nurses' work process in different countries: an integrative review. Rev Bras Enferm. 2018;71(2):413-23.

[48] COFEN, 2020 Conselho Federal de Enfermagem. (2020). Pesquisa de Dados Estatísticos [Statistical Data Research]. Retrieved from http://www.portalcofen.com.br/_novoportal/section008.asp /lnfoID=\&editionSectionID=8\&SectionParentID

[49] Agência IBGE Notícias [Internet]. Rio de Janeiro: IBGE; 2019 [acesso em 2019 Nov 28]. Estimativas da população residente no Brasil e Unidades da Federação com data de referência em 1o de julho de 2019; [aproximadamente 119 p.]. Disponível em: https://agenciadenoticias.ibge.gov.br/media/com_mediaibge/arquivos/7d410669a4ae85faf4e8c3a0a0c649c7.pdf

[50] São José do Rio Preto (Município) [homepage na Internet]. São José do Rio Preto: Secretaria Municipal de Saúde; 2019 [acesso em 2019 Nov 29]. Prefeitura de Rio Preto inaugura Centro Clínico de Pesquisas; [aproximadamente 1 tela]. Disponível em: http://www.saude.riopreto.sp.gov.br/transparencia/

[51] Hospital de Base [homepage na Internet]. São José do Rio Preto: Hospital de Base; C 2019 [acesso em 2019 Nov 28]. 0 Hospital; [aproximadamente 4 telas]. Disponível em: http://www.hospitaldebase.com.br/o-hospital

[52] The Whoqol Group. World Health Organization quality of life assessment (WHOQOL): position paper from World Health Organization. Soc Sci Med. 1995;41(10):1403-9.

[53] Berlim MT, Fleck MP. Quality of life: a brand new concept for research and practice in psychiatry. Rev Bras Psiquiatr. 2003; 25(4):249-52.

[54] Gonçalves A, Vilarta R. Qualidade de vida: identidades e indicadores. In: Gonçalves A, Vilarta R, organizadores. Qualidade de vida e atividade física - explorando teorias e práticas. Barueri: Manole; 2004. p. 3-25.

[55] Saupe R, Nietche EA, Cestari ME, Giorgi MDM, Krahl M. Qualidade de vida dos acadêmicos de enfermagem. Rev Latinoam Enferm. 2004; 12(4): 636-42.

[56] Iacoponi E, Mari JJ. Reability and fator strucuture of the Portuguese version of Self-Reporting Questionnaire. Int J Soc Psychiatry. 1989;35(3):213-22.

[57] Pesce RP, Assis SG, Avanci JQ, Santos NC, Malaquias JV, Carvalhaes R. Adaptação transcultural, confiabilidade e validade da escala de resiliência. Cad Saúde Pública. 2005;21(2):436-48.

[58] Gonçalves DM, Stein AT, Kapczinski F. Avaliação de desempenho do SelfReporting Questionnaire como instrumento de rastreamento psiquiátrico: um estudo comparativo com o Structured Clinical Interview for DSMIV-TR. Cad Saúde Pública. 2008;24(2):380-90.

[59] Rigue A, Dalmolin G, Speroni K, Bresolin J, Rigue A. (2016). Work satisfaction: perception of nurses of a university hospital. Cogitare Enferm [periodico na Internet]. 2016 [acesso em 2020 Ago 24];21(3):[aproximadamente 8 p.]. Disponível em: https://revistas.ufpr.br/cogitare/article/download/46199/pdf_en

[60] Silva VR, Velasque LS, Tonini T. Job satisfaction in an oncology nursing team. Rev Bras Enferm. 2017;70(5):988-95.

[61] Maciel MED, Oliveira FN. Qualidade de vida do profissional técnico de enfermagem: a realidade de um hospital filantrópico em Dourados-MS. Rev Psicol Saúde. 2014;6(1):83-9.

[62] Salário [homepage na Internet]. 2020 [acesso em 2020 Ago 24]. Enfermeiro - Salário 2020 e Mercado de Trabalho [aproximadamente 11 telas]. Disponível em: https://www.salario.com.br/profissao/enfermeiro-cbo$223505 /$

[63] Brolese DF, Lessa G, Santos JLG, Mendes JS, Cunha KS, Rodrigues J. Resilience of the health team in caring for people with mental disorders in a psychiatric hospital. Rev Esc Enferm USP [periódico na Internet]. 2017 Ago [acesso em 2019 Dez 02];51:e03230:[aproximadamente 8 p.]. Disponível em: http://www.scielo.br/pdf/reeusp/v51/1980220X-reeusp-51-e03230.pdf

[64] Puerto JC, Soler LM, Montesinos MJL, Marcos AP, Chorda VMG. A new contribution to the classification of stressors affecting nursing professionals. Rev Latinoam. Enferm [periódico na Internet. 2017 Maio [acesso em 2019 Dez 02];25:[aproximadamente 7 p.]. Disponível em: http://www.scielo.br/pdf/rlae/v25/0104-1169-rlae-25e2895.pdf

[65] Arnetz J, Hamblin LE, Sudan S, Arnetz B. Organizational Determinants of Workplace Violence Against Hospital Workers. J Occup Environ Med. 2018;60(8):693-9. 
[66] Crawford CL, Chu F, Judson LH, Cuenca E, Jadalla AA, Tze-Polo L, et al. An Integrative Review of Nurse-toNurse Incivility, Hostility, and Workplace Violence: A GPS for Nurse Leaders. Nurs Adm Q. 2019;43(2):138-56.

[67] Mendes SS, De Martino MMF. Shift work: overall health state related to sleep in nursing workers. Rev Esc Enferm USP. 2012;46(6):1471-6.

[68] Boustanipour L, Saberi H, Soheili A. Prediction of Level of Aggression and Interpersonal Problems in ED nurses based on their Occupational Stress. J Urmia Nurs Midwifery Fac. 2017;15(6):478-87.

[69] Sangaletti J, Ceretta LB, Soratto MT. Ansiedade dos enfermeiros da estratégia saúde da família. Rev Interdisciplin Estud Saúde. 2018;7(1):234-48.

[70] Lopes FP, Paiano M, Miguel MEGB, Salci MA. Percepção dos enfermeiros sobre estratificação de risco em saúde mental e as ações de enfermagem. R Saúde Públ. 2019;2(1):68-79.

[71] Paschoa S, Zanei SSV, Whitaker IY. Qualidade de vida dos trabalhadores de enfermagem de unidades de terapia intensiva. Acta Paul Enferm. 2007;20(3):305-14.

[72] Siqueira VTA, Kurcgant P. Job satisfaction: a quality indicator in nursing human resource management. Rev Esc Enferm USP. 2012;46(1):151-7.

[73] Tenani MNF, Vannuchi MTO, Haddad MCL, Matsuda LM, Pissinati PSC. Work satisfaction of newly hired nursing workers in a public hospital. REME Rev Min Enferm. 2014;18(3):585-91. doi:

[74] Paschoa S, Zanei SSV, Whitaker IY. Qualidade de vida dos trabalhadores de enfermagem de unidades de terapia intensiva. Acta Paul Enferm. 2007;20(3):305-14.

[75] Aburn G, Gott M, Hoare K. What is resilience? An Integrative Review of the empirical literature. J Adv Nurs. 2016;72(5):980-1000.

[76] Delgado C, Upton D, Ranse K, Furness T, Foster K. Nurses' resilience and the emotional labour of nursing work: an intergrative review of empirical literature. Int J Nurs Stud. 2017;70:71-88.

[77] Braithwaite J, Wears RL, Hollnagel E. Resilient health care: Turning patient safety on its head. Int J Qual Health Care. 2015;27(5):418-20.

[78] Foster, K. Resilience in the face of adversity: A shared responsibility. Int J Ment Health Nurs. 2020;29(1):3-4.

[79] Cope V, Jones B, Hendricks J. Residential aged care nurses: portraits of resilience. Contemp Nurse. 2016;52(6):736-52.

[80] Mills J, Woods C, Harrison H, Chamberlain-Salaun J, Spencer B. Retention of early career registered nurses: The influence of self-concept, practice environment and resilience in the first five years postgraduation. J Res Nurs. 2017;22(5):372-85

[81] Cusack L, Smith M, Hegney D, Rees CS, Breen LJ, Witt RR, et al. Exploring environmental factors in nursing workplaces that promote psychological resilience: constructing a unified theoretical model. Front Psychol. 2016;7:600.

[82] McDonald G, Jackson D, Vickers, MH, Wilkes L. Surviving workplace adversity: a qualitative study of nurses and midwives and their strategies to increase personal resilience. J Nurs Manag. 2016;24(1):123-31.

[83] Perry L, Nicholls R, Duffield C, Gallagher R. Building expert agreement on the importance and feasibility of workplace health promotion interventions for nurses and midwives: A modified Delphi consultation. J Adv Nurs. 2017;73(11):2587-99.

[84] Gao F, Newcombe P, Tilse C, Wilson J, Tuckett A. Models for predicting turnover of residential aged care nurses: a structural equation modelling analysis of secondary data. Int J Nurs Stud. 2014;51(9):1258-70.

[85] Rose J, Glass N. Enhancing emotional well-being through self-care: the experiences of community health nurses in Australia. Holist Nurs Pract. 2008;22(6):336-47.

[86] Cameron F, Brownie S. Enhancing resilience in registered aged care nurses. Australas J Ageing. 2010;29(2):66-71.

[87] Yang J, Tang S, Zhou W. Effect of mindfulness-based stress reduction therapy on work stress and mental health of psychiatric nurses. Psychiatr Danub. 2018;30(2):189-96.

[88] Braga LC, Carvalho LR, Binder MCP. Condições de trabalho e transtornos mentais comuns em trabalhadores da rede básica de saúde de Botucatu (SP). Ciênc Saúde Coletiva. 2010;15(Supl. 1):1585-96.

[89] Karanikola M, Giannakopoulou M, Mpouzika M, Kaite CP, Tsiaousis GZ, Papathanassoglou EDE. Dysfunctional psychological responses among Intensive Care Unit nurses: a systematic review of the literature. Rev Esc Enferm USP. 2015;49(5):847-57. 
[90] Queiroz DL, Souza JC. Qualidade de vida e capacidade para o trabalho de profissionais de enfermagem. Psicol Inf. 2012;16(16):103-26.

[91] Amsrud K, Lyberg A, Severinsson E. Development of resilience in nursing students: A systematic qualitative review and thematic synthesis. Nurse Educ Pract. 2019;41:102621.

[92] Rusthon CH, Caldwell M, Kurtz M. CE: Moral Distress: A Catalyst in Building Moral Resilience. Am J Nurs. 2016;116(7):40-9.

[93] McAllister M, Brien DL. Resilience in nursing. In: McAllister M, Brien DL, editors. Empowerment Strategies for Nurses: Developing Resilience in Practice, 2nd ed. New York: Springer Publishing Company; 2020. p. 1-28.

[94] Masten A, Obradovic J. Competence and resilience in development. Ann N Y Acad Sci. 2006;1094:13-27.

[95] Mitchell G. Figures spark call for inquiry into 'alarming' levels of nurse suicide [homepage na Internet]. 2019 [acesso em 2020 Ago 24]. Disponível em: https://www.nursingtimes.net/news/workforce/figures-spark-call-forinquiry-into-alarming-levels-of-nurse-suicide-29-04-2019/

[96] Tran TTT, Nguyen NB, Luong MA, Bui THA, Phan TD, Tran VO, et al. Stress, anxiety and depression in clinical nurses in Vietnam: a cross-sectional survey and cluster analysis. Int J Ment Health Syst. 2019;13:3.

[97] Oliveira DM, Alencar NMBM, Costa JP, Fernandes MA, Gouveia MTO, Santos JDM. Afastamento do trabalho por transtornos mentais e comportamentais entre profissionais de enfermagem. Rev Cuid. 2019;10(2):e631.

[98] Ratrout HF, Ayman M. Hamdan-Mansour AM. Factors Associated with Secondary Traumatic Stress among Emergency Nurses: An Integrative Review. Open J Nurs [periodic na Internet]. 2017 [acesso em 2020 Ago 24];7(11):[aproximadamente 10 telas]. Disponível em: https://m.scirp.org/papers/80234

[99] Marques DO, Pereira MS, Souza ACS, Vila VSC, Almeida CCOF, Oliveira EC. Absenteeism - illness of the nursing staff of a university hospital. Rev Bras Enferm. 2015;68(5):76-82.

[100] Wang Y, Di Y, Ye J, Wei W. Study on the public psychological states and its related factors during the outbreak of coronavirus disease 2019 (COVID-19) in some regions of China. Psychol Health Med. 2020;1-10.

[101] Hildebrand NA, Celeri EHRV, Morcillo AM, Zanolli ML. Resilience and mental health problems in children and adolescents who have been victims of violence. Rev Saude Publica [peródico na Internet]. 2019 [acesso em 2020 Ago 24];53:[aproximadamente 14 p.]. Disponível em: https://www.scielo.br/pdf/rsp/v53/1518-8787-rsp-53-17.pdf

[102] Melo JO, Romani PF. Resiliência de imigrantes haitianos frente ao processo de adaptação no novo país: impactos na saúde mental. Psicol Argum. 2019;37(96):184-206.

[103] Sakuma TH, Vitalle MSS. Programa de resiliência: práticas educativas para a prevenção de bullying e promoção da saúde mental na adolescência. Rev Educ. 2020;15(1):53-64.

[104] Bath KG. . Synthesizing Views to Understand Sex Differences in Response to Early Life Adversity. Trends Neurosci. 2020;43(5):300-10.

[105] Silva DSD, Tavares NVS, Alexandre ARG, Freitas DA, Brêdas MZ, Albuquerque MCS, et al. Depression and suicide risk among nursing professionals: an integrative review. Rev Esc Enferm USP. 2015; 49(6):1023-31.

[106] Godin I, Kittel F, Coppieters Y, Siegrist J. A prospective study of cumulative job stress in relation to mental health. BMC Public Health. 2005;5:67.

[107] Feitosa CDA, Fernandes MA. Leave of absence due to depression. Rev Latinoam Enferm [periodic na Internet]. 2020 [acesso em 2020 Ago 24];28:[aproximadamente 10 p.]. Disponível em: https://www.scielo.br/pdf/rlae/v28/0104-1169-rlae-28-e3274.pdf

[108] Hayes B, Douglas C. Bonner A. Predicting emotional exhaustion among haemodialysis nurses: a structural equation model using Kanter's structural empowerment theory. J Adv Nurs. 2014;70(12):2897-909.

[109] Abraham LJ, Thom O, Greenslade JH, Wallis M, Johnston AN, Carlström E, et al. Morale, stress and coping strategies of staff working in the emergency department: A comparison of two differentsized departments. Emerg Med Australas. 2018;30(3):375-381.

[110] Cunha S, Queirós C, Fonseca S, Campos. Resiliência como Preditor do Impacto Traumático em Técnicos de Emergência Pré-Hospitalar. Int J Work Cond. 2017;(13):51-67.

[111] Shakespeare-Finch JE, Daley E. Workplace belongingness, distress, and resilience in emergency service workers. Psychol Trauma. 2017;9(1):32-5.

[112] Cope V, Jones B, Hendricks J. Why nurses chose to remain in the workforce: Portraits of resilience. Collegian. 2016;23(1):87-95.

[113] Lee KJ, Kim JI. Relating factors for depression in korean working women: secondary analysis of the fifth Korean national health and nutrition examination survey (KNHANES V). Asian Nurs Res. 2015;9(3):265-70. 
[114] Goh YS, Lee A, Chan SWC, Chan MF. Profiling nurses' job satisfaction, acculturation, work environment, stress, cultural values and coping abilities: a cluster analysis. Int J Nurs Pract. 2015;21(4):443-52.

[115] Cheung T, Yip PSF. Depression, anxiety and symptoms of stress among Hong Kong nurses: a cross-sectional study. Int J Environ Res Public Health. 2015;12(9):11072-100.

[116] Aboalshamat K, Hou XY, Strodl E. The impact of a self-development coaching programme on medical and dental students' psychological health and academic performance: a randomised controlled trial. BMC Med Educ. $2015 ; 15: 134$.

[117] Höltge J, Gee SLM, Thoma MV. The curvilinear relationship of early-life adversity and successful aging: the mediating role of mental health. Aging Ment Health. 2019;23(5):608-17.

[118] Traynor M. Guest editorial: What's wrong with Resilience? J Res Nurs. 2018;23(10):5-8.

[119] Greenberg N, Wessely S, Wykes T. Potential mental health consequences for workers in the Ebola Regions of West Africa- a lesson for all challenging environments. J Ment Health. 2015;24(1):1-3.

[120] Ungar M. The social ecology of resilience: Addressing contextual and cultural ambiguity of a nascent construct. Am J Orthopsychiatry. 2011;81(1):1-17.

[121] Badu E, O’Brien P, Mitchell R, Rubin M, James C, McNeil K, et al. Workplace stress and resilience in the Australian nursing workforce: A comprehensive integrative review. Int J Ment Health Nurs. 2020;29(1):5-34.

[122] Cooper AL, Brown JA, Rees CS, Leslie GD.Nurse resilience: A concept analysis. Int J Ment Health Nurs. 2020;29(4):553-575.

[123] Rolin H, Fossion P, Kotsou I, Leys C. Perspectives on resilience : trait or aptitude ? Rev Med Brux. 2018;39(1):22-28

[124] Maben J, Bridges J.Covid-19: Supporting nurses' psychological and mental health. J Clin Nurs. 2020;29(1516):2742-50.

[125] Hurley J, Hutchinson M, Kozlowski D, Gadd M, van Vorst S. Emotional intelligence as a mechanism to build resilience and non-technical skills in undergraduate nurses undertaking clinical placement. Int J Ment Health Nurs. 2020;29(1):47-55. 


\section{Capítulo 10}

Características associadas à depressão senil em idosos na Atenção Primária à Saúde: Scoping Review

\section{Edith Monteiro de Oliveira}

Davi Pereira Coelho

Flávia Reis da Silva

Taciely Campana Colli

Thainá Ribeiro Rezende de Morais

Daniele Knopp Ribeiro

Fabiola Lisboa da Silveira Fortes

Denise Barbosa de Castro Friedrich

Resumo: Objetivo: Identificar nas produções científicas acerca da depressão senil e os fatores associados no contexto da Atenção Primária à Saúde. Metodologia: Revisão Integrativa realizadas nas bases de dados da Base de Dados de Enfermagem BDENF, Índice Bibliográfico Espanhol de Ciências da Saúde - IBECS, Literatura LatinoAmericana e do Caribe em Ciências da Saúde - LILACS e Scientific Electronic Library Online - SCIELO, entre os meses de abril e maio de 2019, sendo analisados cinco artigos. Resultados: Emergiu a categoria a seguir - Depressão Senil: dos fatores associados à prática de promoção da saúde. Finais: Conclui-se que os principais fatores associados aos casos de depressão tratam-se de: idosos usuários da APS do sexo feminino, idosos em inatividade sexual ou sem vínculo afetivo seja por divórcio, separação ou viuvez, sem escolaridade, que não participam de atividades comunitárias ou que não possuem uma religião, idosos com mais comorbidades e com autopercepção negativa de saúde.

Palavras Chave: Atenção primária à saúde; Depressão; Idoso. 


\section{INTRODUÇ̃̃O}

No Brasil, o perfil demográfico iniciou sua transformação, a partir de 1970, quando a população predominantemente rural, com famílias numerosas e elevado risco de mortalidade infantil, passou a uma população urbana, com redução do número de filhos e uma nova estrutura familiar brasileira (1). Nessa perspectiva, observa-se que uma população notavelmente jovem em um passado recente, tem atualmente sido superposta gradativamente por um contingente expressivo de pessoas com 60 anos de idade ou mais (2).

A transição demográfica desencadeou com a redução das taxas de mortalidade e, posteriormente, com a diminuição das taxas de natalidade, ocasionando alterações consideráveis na estrutura etária populacional (3). Tais alterações têm se dado de forma célere, sem a correspondente modificação das condições de vida da população idosa (4).

No ano de 2004, as pessoas com 60 anos ou mais representavam 9,7\% da população brasileira (5), passando para 12,8\% em 2012 e 15,4\% em 2018 (6). Projeções realizadas pelo Instituto Brasileiro de Geografia e Estatística (IBGE) apontam um aumento expressivo na proporção de idosos: em 2030 corresponderão 18,6\% e, em 2060, cerca de 34,0\% da população brasileira (5).

Associado ao crescimento da população idosa está o surgimento de complicações econômicas, físicas e mentais. Pesquisas revelam que ao longo das últimas décadas houve o aumento da prevalência de doenças crônico-degenerativas na população idosa, entre elas a depressão (7). A depressão pode ser suscitada por fatores biológicos, sendo a genética um fator relevante no desenvolvimento de um quadro depressivo. Ademais, fatores psicológicos acarretam perda da autonomia e deterioramento de condições patológicas preexistentes no idoso, tal como fatores sociais que acometem na capacidade funcional, das relações sociais e do autocuidado (8).

Para tanto, a Política Nacional de Saúde da Pessoa Idosa (PNSPI, Portaria GM no 2.528, de 19 de outubro de 2006, que tem como meta a atenção à saúde de qualidade e digna para os idosos, além da recuperação e promoção da autonomia e independência, em conformidade com os princípios do Sistema Único de Saúde (SUS). Destaca-se que essa portaria define que a atenção à saúde da pessoa idosa terá como porta de entrada a Atenção Primária à Saúde (APS) (9).

Ratifica a necessidade de atenção a população idosa na APS, o Estudo Longitudinal da Saúde dos Idosos Brasileiros (ELSI - Brasil), rede internacional para pesquisas sobre envelhecimento, que avaliou que $75,3 \%$ dos idosos brasileiros dependem exclusivamente do SUS (10).

Diante disso, esta pesquisa justifica-se em função da relevância de se prevenir precedentemente a população idosa com depressão, em virtude dos dispêndios no âmbito individual e organizacional, tornando-se de suma importância a pesquisa pertinente ao assunto e seus fatores associados, ao se considerar a importância de informações acerca da depressão no contexto da APS, corroborando no processo de conhecimento da temática e na prevenção da doença e atenuação das nocividades. Portanto, objetivou-se identificar nas produções científicas acerca da depressão senil e os fatores associados no contexto da APS.

\section{METODOLOGIA}

Realizou-se uma busca online da literatura no mês de abril e maio do ano de 2019. O levantamento das informações se deu no ambiente virtual nas seguintes bases científicas: Base de Dados de Enfermagem BDENF, Índice Bibliográfico Espanhol de Ciências da Saúde - IBECS, Literatura Latino-Americana e do Caribe em Ciências da Saúde - LILACS e Scientific Electronic Library Online - SCIELO. Realizou-se a busca na BDENF, IBECS E LILACS através do portal da Biblioteca Virtual em Saúde - BVS. Os descritores foram utilizados de acordo com os Decs - Descritores em Ciências da Saúde: "Atenção Primária à Saúde", "Depressão", "Idoso". Para a realização da pesquisa avançada, os descritores citados foram cruzados e combinados utilizando o operador booleano AND, sendo assim pesquisou-se por atenção primária à saúde AND depressão AND idoso.

Os artigos foram selecionados a partir dos seguintes critérios de inclusão: ser artigo escrito por pelo menos um profissional enfermeiro; estar publicado em um dos periódicos encontrados para o estudo; estar o artigo disponível na íntegra no banco de dados online, publicados nos idiomas inglês, português e espanhol e que foram propagados nos últimos 5 anos (2015 - 2019). Foram exclusos deste estudo publicações que não possuíam relação com o tema e anuários repetidos. 
Em consonância com os descritores, na primeira seleção dos artigos nas bases de dados foi encontrado um total de 103 artigos, sendo 09 da BDENF,63 da LILACS,11 do IBECS e 20 da Scielo. Destes, foi realizada uma segunda seleção por meio da leitura dos títulos e resumos, sendo excluídos do estudo 95 artigos por não estarem em conformidade com os critérios de inclusão. Numa terceira seleção, após a leitura e análise dos artigos evidenciou-se que: 03 destes eram duplicados. Portanto, 05 artigos foram selecionados para compor a amostra deste estudo.

Para a extração dos dados, foi confeccionado um instrumento para coleta dos dados relevantes acerca de cada artigo selecionado, objetivando facilitar e coordenar a pesquisa. Este compreende a compilação dos seguintes dados: base de dados, ano de publicação, periódico, nome do Artigo/Autores, os objetivos e a metodologia utilizada para a elaboração do artigo. A avaliação dos artigos foi realizada de maneira independente por meio da observação da consistência textuais, da coerência, coesão e do método, possibilitando a elaboração da categoria: Depressão Senil: dos fatores associados à prática de promoção da saúde.

\section{RESULTADOS}

Dentre os artigos selecionados em conformidade com os critérios de inclusão e exclusão previamente estabelecidos para a revisão deste estudo, constatou-se que 60\% foram publicados em Minas Gerais (MG), $20 \%$ no Rio de Janeiro (RJ) e 20\% no Rio Grande do Sul (RS). Em relação ao ano de publicação, 60\% dos artigos foram publicados no ano de 2017, 20\% no ano de 2016 e 20\% em 2015.

No que diz respeito às bases de dados, $80 \%$ foram indexados na LILACS e $20 \%$ na BDENF, prevalecendo o método de pesquisa quantitativo (100\%).Em relação a temática dos estudos $80 \%$ analisaram a prevalência de sintomas depressivos e fatores associados em idosos atendidos na APS e $20 \%$ realizaram uma associação entre a depressão e a qualidade de vida em idosos da APS.

A seguir, apresentaremos um quadro sinóptico dos artigos estudados (Quadro 1), explanando os títulos e os principais resultados:

Quadro 1: Descrição dos artigos selecionados para o referido estudo

\begin{tabular}{|c|c|}
\hline Título & Principais Resultados \\
\hline $\begin{array}{l}\text { Sintomas depressivos } \\
\text { e fatores associados } \\
\text { em idosos na Atenção } \\
\text { Primária à Saúde }\end{array}$ & $\begin{array}{l}\text { O estudo avaliou que os sintomas depressivos estavam associados à } \\
\text { inatividade física e comorbidades. Além disso, o relato de diagnóstico de } \\
\text { depressão foi superior ao indicativo de depressão grave e cerca de menos da } \\
\text { metade dos idosos com indício de depressão grave faziam uso de } \\
\text { antidepressivo. }\end{array}$ \\
\hline $\begin{array}{l}\text { Associação entre } \\
\text { depressão e qualidade } \\
\text { de vida em idosos: } \\
\text { atenção primária à } \\
\text { saúde }\end{array}$ & $\begin{array}{l}\text { Verificou maior associação significativa para o desfecho de depressão as } \\
\text { variáveis qualidade de vida, depressão autorreferida, sexo feminino, consumo } \\
\text { de álcool e renda familiar menor que três salários mínimos. Os autores } \\
\text { salientaram que é crítico o subdiagnóstico de depressão em pessoas idosas e } \\
\text { que é fundamental um maior investimento em políticas públicas relacionadas } \\
\text { à saúde mental e bem-estar nas faixas etárias mais avançadas e capacitação } \\
\text { dos profissionais de saúde para o rastreamento precoce da depressão. }\end{array}$ \\
\hline $\begin{array}{l}\text { Prevalência de } \\
\text { sintomas de depressão } \\
\text { em idosos assistidos } \\
\text { pela estratégia de } \\
\text { saúde da família }\end{array}$ & $\begin{array}{l}\text { O estudo identificou maior prevalência de sintomas de depressão em idosos } \\
\text { do sexo feminino, divorciadas, sem religião e com doença crônica. Salientando } \\
\text { a importância da prática de consultas com uma avaliação holística e de } \\
\text { qualidade a pessoa idosa na atenção primária. }\end{array}$ \\
\hline
\end{tabular}


Quadro 1: Descrição dos artigos selecionados para o referido estudo (continuação)

\begin{tabular}{|c|c|}
\hline Título & Principais Resultados \\
\hline $\begin{array}{l}\text { Depressão em idosos } \\
\text { na estratégia saúde da } \\
\text { família: uma } \\
\text { contribuição para a } \\
\text { atenção primária }\end{array}$ & $\begin{array}{l}\text { Constatou-se maior incidência de depressão em mulheres, idosos entre } 70 \text { e } \\
79 \text { anos, viúvos, aposentados sem escolaridade ou com ensino fundamental } \\
\text { incompleto e que não participam de atividades comunitárias. Revelando um } \\
\text { alto índice de idosos com quadro depressivo que, grande parte não utilizam } \\
\text { de medicação antidepressiva }\end{array}$ \\
\hline $\begin{array}{l}\text { Sintomas depressivos } \\
\text { em idosos residentes } \\
\text { em áreas de } \\
\text { abrangência das } \\
\text { Unidades Básicas de } \\
\text { Saúde da zona urbana } \\
\text { de Bagé, RS }\end{array}$ & $\begin{array}{l}\text { Analisou que os sintomas depressivos associavam aos idosos do sexo } \\
\text { feminino, cor da pele amarela, parda ou indígena, classificação econômica } \\
\text { inferior, aposentados, histórico de problemas cardíacos, incapacidade para } \\
\text { atividades básicas da vida diária, autopercepção de saúde prejudicada e } \\
\text { insatisfação geral em sua vida. }\end{array}$ \\
\hline
\end{tabular}

Fonte: Elaborado pelos pesquisadores, 2019.

\section{DISCUSSÃO}

Depressão Senil: dos fatores associados à prática de promoção da saúde

A depressão é uma doença grave, comum em idosos, mas que constantemente é subdiagnosticada e até mesmo desprezada. 0 diagnóstico da depressão é fundamentalmente clínico, embora as evidências de constatação dos sintomas depressivos e consecutivamente o estabelecimento de um tratamento eficaz são ínfimos, em especial na atenção primária a saúde. Dado que, muitos profissionais de saúde veem os sintomas depressivos como manifestações naturais do processo de envelhecimento, confundindo com ansiedade e tristeza; entretanto, os lapsos relacionados a depressão senil, podem determinar um pior prognóstico e custos excessivos relacionados aos idosos, suas famílias, sociedade e sistema de saúde $(11,12)$.

Nesse estudo foram observadas importantes associações da sintomatologia depressiva com alguns fatores como: sexo feminino, vida sexual ativa, divórcio, ocupação, escolaridade, atividades comunitárias, religião, alcoolismo, comorbidades e autopercepção. A literatura evidencia que associações refletidas nas desigualdades sociais influem diretamente nas condições de vida e de saúde e podem corroborar para o surgimento de sintomas depressivos ou acentuar os preexistentes (11).

Uma associação encontrada entre sintomas depressivos e sexo feminino foi notória, implicando cerca de 3,33 vezes maior em relação ao sexo masculino (13), consistente com outros achados(11,14). A literatura documenta que a maior prevalência de sintomas depressivos em idosas pode ser explicada pelo fato que as mesmas vivem, em média, mais do que os idosos e idades mais avançadas são acompanhadas por uma maior incidência de doenças crônicas, entre elas a depressão $(11,14)$.

Além disso, as idosas devido alterações hormonais ocorridas no climatério, a privação do estrogênio, a irritabilidade, a redução da concentração, da libido e da memória, as questões sociais às quais estão expostas, assim como, a violência doméstica, o isolamento social, a discriminação no acesso à educação, renda, alimentação, trabalho e seguridade social, a maior chance de admitirem e se queixarem mais dos sentimentos depressivos que os idosos, podem contribuir para que as mulheres sejam mais vulneráveis ao desenvolvimento de transtornos mentais na velhice $(11,12,14,15)$.

Um estudo evidenciou que idosos que relataram vida sexual ativa apresentaram menor proporção de sintomas depressivos se comparado aos inativos, tendo estes chances 2,42 vezes maiores de apresentarem sintomatologia depressiva (13). Nessa perspectiva, a literatura aponta que idosos separados, divorciados ou viúvos tendem a maior prevalência de sintomas depressivos, enfatizando que a solidão pode ser um fator de risco para o desenvolvimento desses sintomas $(11,12)$. Estudos corroboram que a perda do companheiro tem sido associada a declínio mental e físico, transcorrendo sintomas depressivos cerca de dois a seis meses após a perda, representando um evento de sobrecarga, intensificando a vulnerabilidade para acometimentos à saúde (11).]

Em relação a aposentadoria, um estudo identificou que os aposentados apresentaram maiores índices de quadros depressivos (12), entretanto, outro estudo salientou que a aposentadoria demonstrou ser um 
fator de proteção contra a depressão, mantendo uma relação positiva mesmo com o ajuste para possíveis fatores de confusão (15).

A ocupação do idoso é um fator importante para o surgimento de depressão, visto que envolve fatores psicossociais, emocionais e econômicos. Os idosos que se mantêm no mercado de trabalho continuam se sentindo úteis à comunidade, entretanto não desconsideram que há possibilidade de causa reversa nessa associação, uma vez que tanto a ausência de trabalho quanto o inverso, podem levar a sintomatologia depressiva (12).

Cabe destacar a importância da renda para a preservação da autonomia e, o quanto a inatividade econômica pode inviabilizar o acesso ao cuidado de qualidade e a aquisição de medicamento para a manutenção do tratamento de doenças crônicas e incapacitantes, afligindo diretamente a qualidade de vida do idoso (15).

Idosos sem escolaridade estão mais propícios a apresentarem quadros depressivos (12), ratifica uma pesquisa realizada em Unidades Básicas de Saúde do município de Uberaba, em Minas Gerais, que identificou que idosos com escolaridade de até três anos apresentam chances de 2,24 vezes maiores de desenvolver sintomas depressivos (13), sendo considerada a escolaridade mais alta um fator protetor importante para a ocorrência de sintomas depressivos, seja pelo maior conhecimento sobre o assunto ou até mesmo pelo acesso a medidas preventivas que melhoram a situação econômica e a qualidade de vida dos idosos $(12,13)$.

Segundo a literatura, a não participação de idosos em atividades comunitárias, revelou que esses não tinham exames normais, sendo a maioria entre os portadores de depressão (12). Nessa perspectiva, idosos que não possuem religião têm maior prevalência de sintomas depressivos, condição essa que evidencia que a vivência da espiritualidade pode cooperar no enfrentamento de momentos desafiadores, perdas do envelhecer e no processo saúde-doença, ofertando um suporte social e viabilizando melhor saúde e qualidade de vida (11).

Numa pesquisa que envolveu 593 usuários da Atenção Primária a Saúde de Belo Horizonte, Minas Gerais, relatou que idosos com rastreamento positivo para alcoolismo, estimado pelo AUDIT-C, tiveram 80 vezes menos possibilidades de ter sintomas depressivos se comparado aos que fazem uso de bebida alcóolica. Todavia, o English Longitudinal Study of Ageing (ELSA) apontou que, em idosos o consumo de níveis moderados de álcool correlaciona com uma melhor saúde cognitiva e bem-estar, sintomatologia reduzida de depressão, do que se mantivesse abstinência (14).

A presença de sintomas depressivos foi 2,75 vezes maior para idosos com quatro ou mais patologias (13), ratificando estudos que apresentam maior associação entre o maior número de comorbidades e os sintomas depressivos $(11,15)$. No que diz respeito à associação entre depressão e doenças crônicas, evidenciou maior correlação entre as doenças musculoesqueléticas e um maior impacto na qualidade de vida do que a hipertensão arterial sistêmica e a diabetes mellitus (11), outro estudo apontou que a presença de incapacidades funcionais dobrou a suscetibilidade de ocorrência de sintomas depressivos (15).

Diante o exposto, ao se considerar as comorbidades supracitadas e as alterações mínimas na coordenação e destreza para as atividades da vida diária (AVD) e atividades instrumentais da vida diária (AIVD), que levam a perda da autonomia e o consequente isolamento social, nota-se que além do desenvolvimento de alguma doença, sentimentos de ansiedade e insegurança, podem surgir e desencadear um processo depressivo, trazendo prejuízos à qualidade de vida dos idosos $(11,15)$.

A autopercepção de saúde tem se destacado como um eficiente indicador de saúde, uma vez que está associado a doenças crônicas e mortalidade, sendo considerado este um preditor de sobrevida abarcando aspectos da saúde física e psíquica, evidenciando o real estado de saúde do idoso e vertendo as representações objetivas de saúde. Em um estudo realizado na zona urbana de Bagé, no Rio Grande do Sul, constatou-se por meio da Escala de Depressão Geriátrica, que a autopercepção de saúde estava diretamente relacionada à presença de sintomas depressivos, triplicando sua prevalência entre os indivíduos que a avaliaram como ruim ou péssima se comparado àqueles com autopercepção boa ou ótima. Outro quesito importante, foi a insatisfação com a vida que também demonstrou forte associação com sintomas depressivos. Todavia, a pergunta é de fácil aplicabilidade na rotina, podendo esta servir de marcador no rastreamento de sintomas depressivos (15).

0 tratamento da depressão senil busca a redução do sofrimento psíquico ocasionado por esse transtorno e do risco de suicídio, a melhoria do estado geral do paciente e da qualidade de vida desses. Contudo, o 
tratamento em idosos constitui um desafio que abarca intervenção especializada e estratégias como o uso de psicofarmacologia ou até mesmo eletroconvulsoterapia $(12,13)$.

Uma alternativa de tratamento não farmacológica também utilizada no tratamento da depressão em idosos, trata da atividade física regular, que apresenta a vantagem de não apresentar efeitos colaterais e resultar na melhoria da autoestima e autoconfiança, uma vez que demanda comprometimento ativo por parte do usuário, ao contrário de uma ação relativamente passiva de tomar a pílula $(12,13)$.

0 conhecimento dos fatores associados aos sintomas depressivos na população idosa apontam que há necessidade de esforços sistemáticos com vistas a promoção de práticas que estimulem o envelhecimento ativo e reduzam a incapacidade funcional, assim como um maior investimento em políticas públicas direcionadas à saúde mental e bem-estar dos idosos $(13,14,15)$, treinamento dos profissionais da APS para a redução de subdiagnóstico, rastreamento precoce e manejo da depressão $(13,14)$ e utilização na rotina dos serviços da APS da EDG que apoiará na intervenção dos profissionais de saúde, evitando o agravamento do problema e promovendo a qualidade de vida dos idosos(15).

Apresenta-se como limitação do estudo a escassez de produções científicas relacionadas a depressão em idosos e fatores associados no contexto da APS, recomendando-se novos estudos mais abrangentes no cenário brasileiro.

As contribuições para a área da enfermagem, saúde ou política pública desse estudo trata de que o conhecimento acerca dos fatores associados aos sintomas depressivos poderá servir de subsídio para gestores e demais profissionais de saúde no enfrentamento do desafio de garantir um envelhecimento saudável à população, fortalecendo a prioridade da saúde mental de idosos usuários dos serviços básicos de saúde, ressaltando estratégias voltadas para a prevenção, intervenção em fatores de risco, diagnóstico precoce e tratamento da depressão, além da manutenção da independência física, autonomia, condições econômicas e o suporte social.

\section{CONSIDERAÇÕES FINAIS}

Constatou-se por meio da análise das produções científicas da enfermagem, um significativo índice de depressão senil em usuários da APS. Os fatores apresentados evidenciaram a relevância de uma investigação mais acurada na consulta do idoso na APS, buscando detectar prováveis fatores de risco para a depressão, uma vez que as produções apontam maior incidência de casos de depressão em usuários do sexo feminino, em idosos em inatividade sexual, ou sem vínculo afetivo seja por divórcio, separação ou viuvez, sem escolaridade, que não participam de atividades comunitárias ou que não possuem uma religião, idosos com mais comorbidades e com autopercepção negativa da saúde.

\section{REFERÊNCIAS}

[1] Leone ET, Maia AG, Baltar PE. Mudanças na composição das famílias e impactos sobre a re- dução da pobreza no Brasil. Economia e Sociedade. $2010 \quad 04 ; 19: 59$ - 77 . Available from: http://www.scielo.br/scieloOrg/php/articleXML.php?lang=enpid=S0104-06182010000100003.

[2] Vasconcelos Ana Maria Nogales, Gomes Marília Miranda Forte. Transição demográfica: a experiência brasileira. Epidemiol. Serv. Saúde [Internet]. 2012 Dez [citado 2019 Jun 29] ; 21( 4 ): 539-548. Disponível em: http://scielo.iec.gov.br/scielo.php?script=sci_arttext\&pid=S1679$49742012000400003 \& \operatorname{lng}=$ pt. http://dx.doi.org/10.5123/S1679-49742012000400003.

[3] Alves JED. A transição demográfica e a janela de oportunidade. São Paulo: Instituto Fernand Braudel de Economia Mundial; 2008.

[4] Bezerra FC, de Almeida MI, Nóbrega-Therrien SM. Estudos sobre Envelhecimento no Brasil: Revisão Bibliográfica. Revista Brasileira de Geriatria e Gerontologia. 2012;15(1):155 - 167.]

[5] IBGE, Instituto Brasileiro de Geografia e Estatística. Mudança Demográfica no Brasil no início do Século XXI: Subsídios para as projeções da população. Rio de Janeiro; 2015. Available from: https://biblioteca.ibge.gov.br/visualizacao/livros/liv93322.pdf.

[6] IBGE. INSTITUTO BRASILEIRO DE GEOGRAFIA E ESTATÍSTICA. 2019 IBGE; 2019. Available from: https://sidra.ibge.gov.br/tabela/5457resultado.

[7] Gullich Inês, Duro Suele Manjourani Silva, Cesar Juraci Almeida. Depressão entre idosos: um estudo de base populacional no Sul do Brasil. Rev. bras. epidemiol. [Internet]. 2016 Dec [cited 2019 June 29] ; 19 ( 4 ): 691-701. Available from: http://www.scielo.br/pdf/rbepid/v19n4/1980-5497-rbepid-19-04-00691.pdf 
[8] Nóbrega Isabelle Rayanne Alves Pimentel da, Leal Márcia Carréra Campos, Marques Ana Paula de Oliveira, Vieira Júlia de Cássia Miguel. Fatores associados à depressão em idosos institucionalizados: revisão integrativa. Saúde debate [Internet]. 2015 June [cited 2019 June 29] ; 39( 105 ): 536-550. Available from: http://www.scielo.br/pdf/sdeb/v39n105/0103-1104-sdeb-39-105-00536.pdf

[9] Brasil. PORTARIA No 2.528 DE 19 DE OUTUBRO DE 2006. Aprova a Política Nacional de Saúde da Pessoa Idosa. 2006 Outubro;Available from: http://bvsms.saude.gov.br/bvs/saudelegis/gm/2006/prt252819102006.html.

[10] Lima-Costa Maria Fernanda. Envelhecimento e saúde coletiva: Estudo Longitudinal da Saúde dos Idosos Brasileiros (ELSI-Brasil). Rev. Saúde Pública [Internet]. 2018 [cited 2019 June 29] ; 52( Suppl 2 ): 2s. Available from: $\quad$ http://www.scielo.br/scielo.php?script=sci_arttext\&pid=S003489102018000300200\&lng=en.\%20Epub\%200ct\%2025,\%202018.\%20http://dx.doi.org/10.11606/s15188787.201805200supl2ap.

[11] de Sousa KA, Freitas FFQ, de Castro AP, Oliveira CDB, de Almeida AAB, de Sousa KA. Prevalência de Sintomas de Depressão em Idosos assistidos pela Estratégia de Saúde da Família. Revista Mineira de Enfermagem. 2017;2(1):1 7 .

[12] Magalhães JM, de Melo Brito Carvalho A, Carvalho SM, de Carvalho Alencar D, Moreira WC, da Cunha Menezes Parente A. Depressão em Idosos na Estratégia Saúde da Família: uma contribuição para a Atenção Primária. Revista Mineira de Enfermagem. 2016;20.

[13] Hajjar R, Nardelli GG, Gaudenci EM, da Silva Santos1 A. Sintomas depressivos e fatores associados em idosos na Atenção Primária à Saúde. Revista da Rede de Enfermagem do Nordeste. 2017;18(6):727 - 733.

[14] Soares SM, Silva PAB, Santos JFG, Silva LB. Associação entre Depressão e Qualidade de vida em idosos: Atenção Primária à Saúde. Revista Enfermagem UERJ. 2017;25.

[15] Bretanha Andréia Ferreira, Facchini Luiz Augusto, Nunes Bruno Pereira, Munhoz Tiago N., Tomasi Elaine, Thumé Elaine. Sintomas depressivos em idosos residentes em áreas de abrangência das Unidades Básicas de Saúde da zona urbana de Bagé, RS. Rev. bras. epidemiol. [Internet]. 2015 Mar [cited 2019 June 29] ; 18( 1 ): 1-12. Available from: http://www.scielo.br/scielo.php?script=sci_arttext\&pid=S1415-790X2015000100001 


\section{Capítulo 11}

Programa UEPG Abraça: Práticas Integrativas Complementares em Saúde (PICS) na promoção de Saúde Mental

Anna Laura Martinelli

Lara Simone Messias Floriano

Thais Fernanda Chelsk

Guilherme Arcar

Alessandra Rodrigues Martin

Milena Dzazio de Oliveira

Jussany Cristine Miranda

Suellen Vienscoski Skupien

Resumo: As Práticas Integrativas Complementares em Saúde possuem o intuito de ampliar a integralidade da atenção do processo saúde-doença, atuando na prevenção, promoção e recuperação da saúde. Nesse sentido, o Programa de Extensão: UEPG Abraça oferece algumas destas abordagens terapêuticas para acadêmicos e servidores que estão em acompanhamento psicossocial no referido Programa. Objetivo: Discorrer sobre a inserção de Práticas Integrativas Complementares como a yoga, massagem e auriculoterapia oferecidos pelo Programa de Extensão UEPG Abraça sob a ótica de apoio psicossocial a acadêmicos, docentes e técnicos da UEPG. Metodologia: Foram disponibilizadas vagas para a comunidade universitária e elaborada uma lista com os interessados, que deveriam primeiramente comparecer ao ambulatório de saúde para a avaliação médica de atividade física, para dar início as práticas integrativas complementares. Resultados: O Programa UEPG Abraça proporcionou aos servidores e acadêmicos benefícios para a saúde física e mental com as atividadesrealizadas, entre eles, redução do estresse, ansiedade, fortalecimento do sistema imunológico, melhora do sono, do funcionamento do sistema respiratório e comportamento cardiovascular. Conclusão: Diante do exposto, torna-se claro a necessidade do olhar interdisciplinar às Práticas Integrativas Complementares em Saúde como uma forma de manejo alternativo ao tratamento medicamentoso, estendendo-se estas ações a comunidade universitária.

Palavras-chave: Serviços de Saúde Mental; Terapias Complementares; Serviços de Saúde para Estudantes. 


\section{INTRODUÇÃO}

De acordo com o Ministério da Saúde as Práticas Integrativas Complementares em Saúde (PICS) são tratamentos que utilizam recursos terapêuticos baseados em conhecimentos tradicionais, voltados para prevenir diversas doenças como depressão e hipertensão, e em alguns casos, também utilizadas como coadjuvante em tratamentos paliativos. Em resumo, as PICS consistem em um conjunto heterogêneo de práticas, produtos e saberes, agrupados pela característica comum de não pertencerem ao escopo dos saberes ou práticas consagradas na medicina convencional (MEDEIROS, 2017).

A Política Nacional de Práticas Integrativas, implementada em 2006, legitimou as práticas da fitoterapia, da homeopatia, da medicina tradicional chinesa, medicina antroposófica e do termalismo social, mas também significou um impulso no reconhecimento e crescimento de todas as demais PICS no SUS (MATOS et al., 2018).

Nessa perspectiva emerge a Saúde Mental como um importante campo para aplicação de PICS tanto para prevenção, quanto manejo de transtornos mentais, a fim de fugir dos padrões biologicistas e tratamentos convencionais baseados unicamente em tratamento medicamentoso. Além disso, estudos ressaltam a importância de possuir hábitos de vida saudável para manutenção da saúde fisica e mental, ao exemplo de alimentação adequada e prática de atividades que promovam o bem-estar (TELESI JÚNIOR, 2016).

O Yoga por sua vez, apresenta benefícios como aumento da imunidade, redução da pressão arterial, e significante redução nos sintomas de depressão em indivíduos que faziam ou não uso de antidepressivos. Está associada à atividade física, exercícios respiratórios, meditação e a religiosidade, sofrendo hibridismo mais tarde, após sua antiga origem sânscrita (MEDEIROS, 2017).

Consciente do problema público que os transtornos mentais se tornaram, e da sua demanda crescente, o Programa de Extensão UEPG Abraça, atuando como promoção e prevenção de Saúde Mental, oferta desde 2018 acompanhamento psicossocial para a comunidade universitária e externa e propõe viabilizar formas de tratamentos acessíveis a população para enfrentamento as condições adversas de Saúde Mental.

Ainda referente ao Programa, este conta com uma equipe multidisciplinar formada por assistente social, enfermeiro, psicólogo e psiquiatra, podendo encaminhar para outros serviços de saúde especializados quando necessário. Além do atendimento individual, o Programa oferece cursos e eventos de extensão, rodas de conversa, grupos de apoio e práticas integrativas complementares bem como pesquisas na área de Saúde Mental.

\section{OBJETIVO}

0 presente estudo tem como objetivo discorrer sobre a inserção de Práticas Integrativas Complementares como a yoga, massagem e auriculoterapia oferecidos pelo Programa de Extensão UEPG Abraça sob a ótica de apoio psicossocial a acadêmicos, docentes e técnicos da UEPG.

\section{METODOLOGIA}

O presente estudo foi desenvolvido através de um estudo observacional transversal. Com intuito de diversificar os tipos de atendimentos em Saúde Mental, o Programa UEPG Abraça em parceria com o Departamento de Educação Física, com proposta de projeto de extensão sob a coordenação de uma docente do referido Departamento, proporcionaram, desde fevereiro de 2019, Yoga, e outras vagas para a prática de atividades integrativas complementares a estudantes e profissionais em acompanhamento psicossocial, também foram disponibilizadas, sendo a massagem terapêutica com pedras quentes e auriculoterapia, estes dois últimos por profissionais residentes em saúde da Universidade. 0 número de vagas oferecidas variou de acordo com prática de escolha, sendo 20 vagas por semestre para yoga e 5 vagas por semana para massagem terapêutica com pedras quentes. A auriculoterapia não apresentou quantidade de vagas especifica, uma vez que sua realização e periodicidade foi estabelecida em comum acordo entre o usuário e psicólogo.

O projeto de pesquisa foi aprovado pelo Comitê de Ética mediante Parecer no 3.604.737. A amostra foi atribuída por conveniência de acordo com a participação dos alunos nas atividades integrativas, de 2019 a 2020. As práticas integrativas oferecidas foram amplamente divulgadas, bem como todos os serviços oferecidos pele Programa, sendo selecionados a participar aqueles que manifestaram interesse e possuíam disponibilidade de horário para participação. Além disso, os que optaram por prática que envolve 
atividade fisica, foram convocados a comparecer ao ambulatório de saúde da UEPG para realizar avaliação médica de atividade física, quando aptos foram autorizados a participar das aulas.

Em caso de duas faltas nas aulas, os indivíduos eram automaticamente desligados da atividade e informados ao próximo interessado a oferta de vaga. Todas as práticas integrativas foram ofertadas de forma gratuita durante o semestre vigente e após esse período foi informado queos participantes interessados poderiam continuar com a prática mediante uma taxa mensal simbólica para manutenção do local e equipamentos e em comum acordo de ambas as partes.

\section{RESULTADOS}

Durante o ano de 2019, ao todo cerca de 50 integrantes da UEPG informaram interesse em participar das Práticas Integrativas e Complementares em Saúde (PICS), os quais procuraram o serviço de atenção psicossocial e informaram sua disponibilidade para realização de tais práticas, sendo esses técnicos, discentes e docentes da Universidade, em sua maioria composta por mulheres (aproximadamente 92\%). No que tange as práticas oferecidas, foram ofertadas sessões de auriculoterapia, massagem terapêutica com pedras quentes e aulas práticas de Yoga.

As sessões de massagem terapêutica foram realizadas de maneira voluntária por profissional de enfermagem que já atuava profissionalmente no ramo durante o primeiro semestre de 2019 nas dependências do ambulatório de saúde e seguindo as normas técnicas e recomendações da prática difundidas na literatura; sendo beneficiados aqueles que procuravam atendimento e após triagem apresentavam somatização de transtornos psicológicos, com o intuito de reduzir a tensão muscular por meio do trabalho manual (CARVALHO; ALMEIDA, 2018).

Além disso, os usuários que estiveram em acompanhamento psicológico com a equipe do Programa puderam usufruir também da prática de auriculoterapia como prática complementar a sessão de psicoterapia, com a instituição de protocolos específicos voltados principalmente ao controle de ansiedade, depressão, fobia e dores crônicas (CÔRREA et al., 2019).

A despeito da prática de Yoga, a mesma consistiu em harmonizar o corpo com a mente e a respiração, através de técnicas de respiração, postura e meditação, com a finalidade de trazer equilibrio integral ao individuo (MEDEIROS, 2017). Cerca de 20 pessoas participaram dessa prática, que ocorria duas vezes na semana com duração de uma hora por dia, ministrada por profissionais e acadêmicos de Educação Física aos usuários que apresentassem algum comprometimento psicossocial.

Contudo as práticas integrativas e complementares oferecidas pelo Programa não se restringiram somente ao âmbito universitário da UEPG, sendo também realizadas oficinas terapêuticas de relaxamento e controle do estresse para servidores do Hospital Universitário da UEPG (HU/UEPG) e no 37ํ Seminário de Extensão Universitária da Região Sul (SEURS) realizado em julho de 2019 na Universidade Federal de Santa Catarina, como observados nas imagens abaixo:

Foto 01 - Técnicas de alongamento e relaxamento realizada com profissionais do HU/UEPG

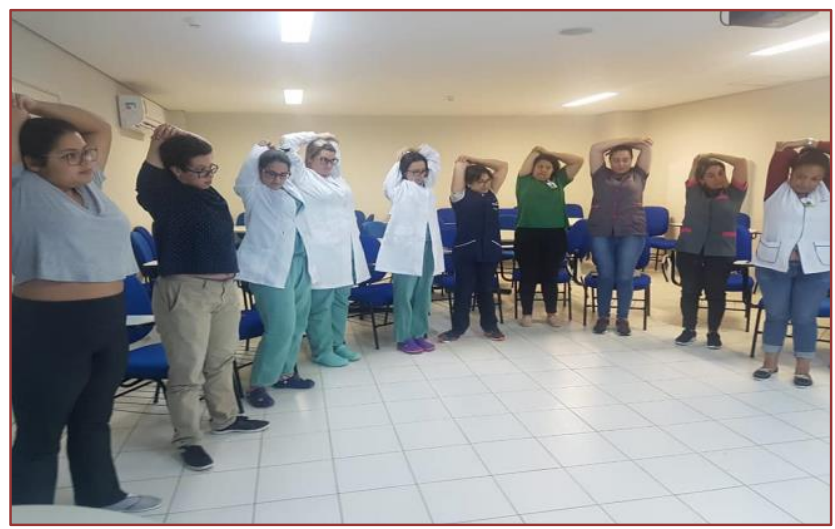

Fonte: Arquivo do Programa UEPG Abraça 
Foto 02 - Oficina terapeutica para controle de ansiedade e estresse - 37은 SEURS/UFSC

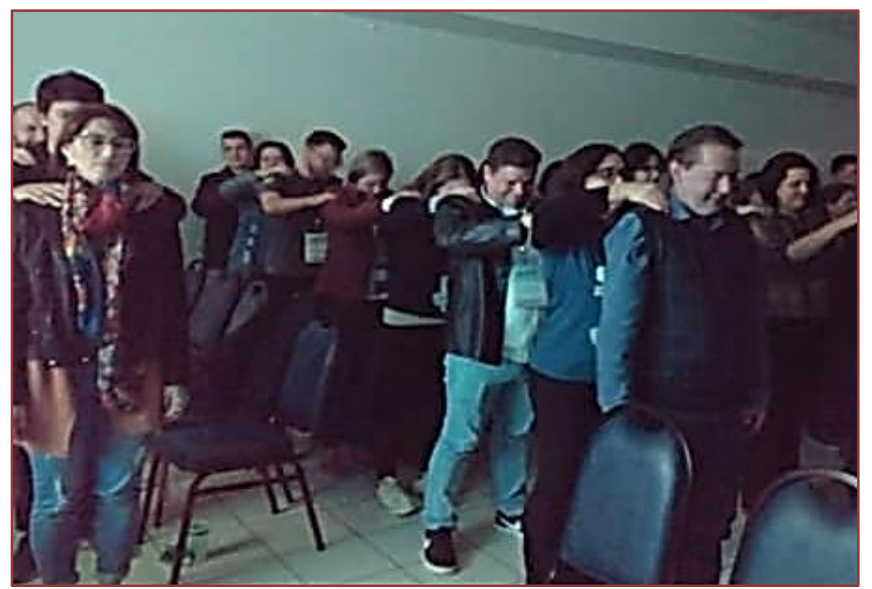

Fonte: Arquivo do Programa UEPG Abraça

\section{DISCUSSÃO}

As Praticas Integrativas Complementares em Saúde (PICS) concernem em medidas terapêuticas de grande relevância no manejo de condições crônicas no âmbito da Saúde Mental. Surgindo com o intuito de romper com a hegemonia do modelo biomédico que tende a ignorar práticas alternativas e tradicionais de prevenção e tratamento, e estabelecer medidas que consideram a visão integral e holistica do indivíduo, tendo em vista os fatores biopsissociais e subjetividades (MEDEIROS, 2017).

Sabe-se que o cotidiano é repleto de situações estressoras que são gatilhos para ansiedade e depressão, causando variadas respostas fisiológicas ou psicológicas nos indivíduos, isso impulsiona na procura de manejos como a auriculoterapia, uma técnica atóxica, que não causa a dependêcia, possui mínimas contraindicaçoes e eventos adversos, é de baixo custo erápida aplicação. Sua ação ocorre pela função somatotrópica, já que a orelha possui células pluripotentes e tem rica inervção e irrigação sanguínea (CÔRREA et al., 2019).

Isso também é evidenciado em um ensaio clinico randomizado realizado com profissionais de saúde com o intuito de verificar a efetividade de protocolo auricular para redução de ansiedade e dor entre os profissionais, sendo neste evidenciado a redução dos níveis de ansiedade e melhora da qualidade de vida no quesito Saúde Mental após dez sessões dessa terapia (KUREBAYASHI et al., 2017).

Outra PICS é a massagem, um recurso manual e não invasivo que além de promover relaxamento, realiza controle no estresse, ansiedade, tensão e dores musculares. Estudos apontam que o contato entre a pele do paciente e do massagista coordena uma série de reações no organismo que são responsáveis pela sensação de bem-estar (CEZIMBRA, 2009). Além disso, a massagem atua na imunidade, funções vitais, alívio de dores e melhora na circulação sanguínea (CARVALHO; ALMEIDA, 2018).

A Yoga, evidenciada como uma prática de grande potencial terapêutico, traz inúmeros benefícios para o bem estar fisico e mental por meio de meditação, levando a redução de estresse, sintomas depressivos e dores, concernindo em melhora da qualidade de vida (MEDEIROS, 2017).

Como verifica Streeter e colaboradores (2017), em seu estudo comprova o uso de Yoga e intervenção respiratória como tratamento para aliviar sintomas de depressão profunda, diminuindo a pressão arterial e agindo nos sistemas cardiovascular e nervoso. Tais aspectos também foram observados em uma revisão sistemática da literatura com objetivo de verificar o impacto da prática de Yoga em indivíduos com ansiedade e depressão, sendo possível constatar resultados positivos, como redução de níveis de ansiedade e depressão, principalmente entre pessoas do sexo feminino e idosos, com evidente melhora na qualidade de vida após inserção dessa atividade (LUQUINE JUNIOR et al., 2019).

Kohut etal (2005) constataram a diminuição da depressão, após dez meses de exercício físico, com alterações no sistema imunológico. A liberação de hormônios como epinefrina, norepinefrina, somatrofina, âendorfina e cortisol, que atingem receptores específicos situados nos linfócitos e macrófagos, promovendo um aumento na concentração dessas células, pode ser uma possível explicação para esses resultados. 
Sabe-se que o principal local para implantação e fornecimento de Práticas Integrativas Complementares em Saúde é a Atenção Básica, de modo que comumente sua aplicação se restringe somente ao ambiente da Estratégia Saúde da Família, resultando em um desafio no âmbito de Saúde Mental, principalmente no meio universitário. Isso mostra a necessidade de pensarmos em alternativas de acessibilidade. As PICS são valiosas formas de manejo, visto que são recursos menos estressantes, utilizam meios naturais, demandam maior envolvimento entre profissional e paciente aumentando assim o vínculo terapêutico e autocuidado. Entretanto, ainda enfrentamos a escassez de estudos e aceitabilidade diante da comunidade terapêutica. (RODRIGUES; ARILO, 2020).

Limitação da pesquisa: com o encerramento do ano letivo de 2019, as aulas de Yoga, bem como atendimento de psicoterapia presencial foram suspensas, com previsão de retorno no início do período letivo de 2020. No entanto, diante da situação pandêmica causada pelo novo coronavírus em março de 2020, não foi possível retornar as atividades presenciais, mantendo-se suspensas até a presente data.

\section{CONSIDERAÇÕESFINAIS}

Ao ofertar Práticas Integrativas Complementares em Saúde (PICS) aos usuários do Programa UEPG Abraça, espera-se implementar conhecimentos e práticas terapêuticas desvencilhadas da medicina tradicional, sem uso de fármacos como forma de tratamento.

Diante da importância que as PICS vem adquirindo no âmbito da saúde, programas ou serviços que atuam na promoção da Saúde Mental, como o Programa UEPG Abraça, tornam-se cada vez mais importantes, preocupando-se com o bem-estar físico e mental de seus acadêmicos, docentes e agentes universitários.

\section{REFERÊNCIAS}

[1] CARVAlHO, R. J.; ALMEIDA, M. A. P. T. Efeitos da massoterapia sobre o sistema imunológico. Revista Multidisciplinar e de Psicologia, v. 12, n. 40, 2018. Disponível em: https://idonline.emnuvens.com.br/id/article/view/1118. DOI: https://doi.org/10.14295/idonline.v12i40.1118. Acesso em: 4 mar. 2021.

[2] CEZIMBRA, M. Bem-Estar na Palma das Mãos: a cultura da massagem do oriente ao ocidente. Rio de Janeiro: Senac Nacional, 2009. 160 p.

[3] CORREA, Hérica Pinheiro et al . Efeitos da auriculoterapia sobre o estresse, ansiedade e depressão em adultos e idosos: revisão sistemática. Rev. esc. enferm. USP, São Paulo , v. 54, e03626, 2020 . Disponível em: <http://www.scielo.br/scielo.php?script=sci_arttext\&pid=S0080-2342020000100808\&lng=en\&nrm=iso >. Acesso em 04 Mar. 2021. https://doi.org/10.1590/s1980-220x2019006703626.

[4] GUlletTEE. C. D. ; BlumenthalJ. A. Exercise Therapy for the Prevention and Treatmentos Depression. Journal of Practice Psychology and Healthy, 5:263-271,1996.

[5] KOHUTM. L. et al.The exercise-induced enhancement of influenza immunity is mediated in part by improvements in psychosocial factors in older adults. Brain Behav Immun. 2005; 19(4):357-66.

[6] KUREBAYASHI, Leonice Fumiko Sato et al. Auriculoterapia para redução da ansiedade e dor em profissionais de enfermagem: ensaio clínico randomizado. Rev. Latino-Am. Enfermagem, Ribeirão Preto, v. 25, e2843, 2017. Disponível em: <http://www.scielo.br/scielo.php?script=sci_arttext\&pid=S0104$11692017000100320 \& \operatorname{lng}=$ en\&nrm=iso $>$. Acesso em 04 mar. 2021.

[7] LUQUINE JÚNIOR, Cézar Donizetti et al. Yoga para tratamento de ansiedade ou depressão em adultos e idosos: Qual a eficácia/efetividade e segurança da yoga para o tratamento da ansiedade ou depressão em adultos e idosos? Fiocruz Brasília Instituto de Saúde, Brasília, 33-33 p. ilus.dez. 2019. Disponível em: <https://pesquisa.bvsalud.org/portal/resource/pt/biblio-1102350>. Acesso em 04 mar. 2021.

[8] MATOS, Pollyane da Costa et al . PRÁTICAS INTEGRATIVAS COMPLEMENTARES NA ATENÇÃO PRIMÁRIA À SAÚDE. Cogitare enferm., Curitiba ， v. 23, n. 2, e54781, 2018 . Disponível em <http://www.revenf.bvs.br/scielo.php?script=sci_arttext\&pid=S1414-85362018000200321\&lng=pt\&nrm=iso>. Acesso em 04 mar. 2021. Epub 21-Jan-2019. http://dx.doi.org/10.5380/ce.v23i2.54781.

[9] MEDEIROS, A. M. Práticas integrativas e complementares no SUS: os benefícios doYoga e da Meditação para a saúde do corpo e da alma. Revista Eletrônica Correlatio, v.16, n. 2, dez. 2017. Disponível em:<https://www.metodista.br/revistas/revistas-ims/index.php/COR/article/viewFile/8369/6145>. Acesso em: 04 mar. 2021. 
[10] MINISTÉRIO DA SAÚDE. Práticas Integrativas e Complementares (PICS): quais são e para que servem. Disponível em: <www.saude.gov.br/saude-de-a-z/praticas-integrativas-e-complementares>. Acesso em: 04 mar. 2021.

[11] MORAES, Helena et al . O exercício físico no tratamento da depressão em idosos: revisão sistemática. Rev. psiquiatr. Rio Gd. Sul, Porto Alegre , v. 29, n. 1, p. 70-79, Apr. 2007 . Disponível em: <http://www.scielo.br/scielo.php?script=sci_arttext\&pid=S0101-81082007000100014\&lng=en\&nrm=iso>. Acesso em 04 mar. 2021. http://dx.doi.org/10.1590/S0101-81082007000100014.

[12] RODRIGUES I. S. ; ARILO L. M. C. AS PRÁTICAS INTEGRATIVAS E COMPLEMENTARES EM SAÚDE COMO ESTRATÉGIA DE INTERVENÇÃO PARA O CUIDADO EM SAÚDE MENTAL DO MUNICÍPIO DE BARROQUINHA-CE. UnaSUS. Disponível em: <https://ares.unasus.gov.br/acervo/handle/ARES/14743>. Acesso em 04 mar. 2021.

[13] STREETER C.C. et al. Treatment of Major Depressive Disorder with Iyengar Yoga and Coherent Breathing: A Randomized Controlled Dosing Study. J Atern Complement Med. 2017 Mar; 23(3):201-207.

[14] TELESI JUNIOR, Emílio. Práticas integrativas e complementares em saúde, uma nova eficácia para o SUS.Estud. av., São Paulo , v. 30, n. 86, p. 99-112, Apr. 2016 . Disponível em: <http://www.scielo.br/scielo.php?script=sci_arttext\&pid=S0103-40142016000100099\&lng=en\&nrm=iso>. Acesso em 04 mar. 2021.

[15] UNIVERSIDADE FEDERAL DE SANTA CATARINA. Formação em auriculoterapia para profissionais de saúde da atenção básica. Santa Catarina, 2018. 


\section{Capítulo 12}

\section{Programa UEPG Abraça: Eventos de extensão que compartilham Saúde Mental para a comunidade}

\section{Millena Dzazio de Oliveira}

Lara Simone Messias Floriano

Jussany Cristine Miranda

Suellen Vienscoski Skupien

Anna Laura Martinelli

Thais Fernanda Chelsk

Guilherme Arcaro

Alessandra Rodrigues Martins

Resumo: Objetivou-se divulgar os resultados de eventos de extensão realizados pelo Programa UEPG Abraça, que realiza atendimento psicossocial à comunidade universitária da Universidade Estadual de Ponta Grossa e comunidade externa, para contribuir com o compartilhamento de conhecimento no campo da Saúde Mental. Foram realizadas palestras, debates e mesas redondas em eventos de extensão no ano de 2019 e 2020, por pesquisadores, professores e profissionais especializados no campo da Saúde Mental. Os principais temas abordados foram: Programa UEPG Abraça; Saúde Mental dos Universitários; Programa de Acolhimento Relacionado ao Uso de Álcool e Outras Drogas; Ações em Saúde Mental na Comunidade; Experiências e Projetos para a qualidade de vida da Comunidade Universitária; Contribuição dos Programas de Residência Multiprofissional; Rede de Atenção Psicossocial de Ponta Grossa; Ações de Prevenção e Acolhimento ao Suicídio, Conscientização do Setembro Amarelo dentro da Comunidade Universitária. Os resultados apontam que participaram dos eventos 1.109 pessoas, dentre ouvintes e equipe organizadora nos eventos intitulados: Programa UEPG Abraça na prevenção do suicídio; Saúde Mental: Vida, Arte e Terapia; A Saúde Mental e a Comunidade UEPG: Ações de Prevenção e Acolhimento Programa UEPG Abraça; Liga de Psiquiatria e Saúde Mental: Setembro Amarelo e a Prevenção ao Suicídio; Programa UEPG Abraça e Centro Acadêmico de Enfermagem Sandra Bastos: Jornada Amarela, Conversando sobre o que Importa. Conclui-se que os eventos de extensão contribuíram com a sensibilização e discussão de políticas públicas de Saúde Mental e a atuação da universidade diante da problemática do uso de álcool e outras drogas, enfrentamento de transtornos mentais e prevenção do suicídio. Ressalta-se a importância da Saúde Mental e o seu potencial na contribuição e no desenvolvimento científico dentro da área da Saúde, bem como no compartilhamento do conhecimento para a comunidade.

Palavras-chave: Saúde Mental. Universidade. Estudante Universitário. Educação em Saúde. 


\section{INTRODUÇÃO}

As universidades têm uma grande importância na Saúde Mental dos discentes, visto que, é uma etapa de grandes mudanças e adaptações onde as cobranças e obrigações serão maiores, a competitividade aparece com maior vigor, é marcado por decisões sobre o futuro, profissão, e entrar para a vida adulta, onde você precisa administrar seu tempo, suas relações familiares, com amigos e afetivas, além de precisar aprender o ofício de ser um aluno. Todas essas mudanças pode causar sofrimento para esses estudantes. ${ }^{[1,2]}$

Neste contexto, um dos fatores que dificulta o tratamento e prevenção de transtornos mentais nos estudantes é a comunicação deficitária entre diferentes serviços de suporte e alunos. As universidades precisam aumentar os investimentos em serviços e programas relacionados à orientação, acompanhamento, aconselhamento e encaminhamento de estudantes, identificando quais as necessidades dentro de suas políticas atuais relacionadas.[3]

Atualmente, nota-se a importância dada à organização de serviços/eventos que oferecem cuidados frente à Saúde Mental da comunidade universitária. A difusão desses serviços de Saúde Mental deve-se a Primeira Conferência Internacional sobre Saúde Mental Estudantil, que teve como finalidade elaborar programas e projetos que pudessem servir de modelo às universidades de todos os países. ${ }^{[4]}$

Nesta perspectiva e como forma de contribuir com a Saúde Mental da comunidade universitária, uma docente do Departamento de Enfermagem e Saúde Pública (DENSP) iniciou junto a colegas professores e equipe técnica, a criação de um Programa de Extensão denominado Programa UEPG Abraça, serviço destinado ao atendimento psicossocial de docentes, discentes e agentes universitários da Universidade Estadual de Ponta Grossa (UEPG).[5]

O Programa UEPG Abraça vêm ao encontro da necessidade em disseminar o conhecimento, bem como sensibilizar a população em relação à problemática do uso/abuso de álcool e outras drogas; prevenção do suicídio; e enfrentamento dos transtornos mentais, como ansiedade e depressão no âmbito das universidades.

Ainda referente ao Programa[5], este conta com uma equipe multidisciplinar formada por assistente social, enfermeiro, psicólogo e psiquiatra, podendo encaminhar para outros serviços de saúde especializados quando necessário. Além do atendimento individual, o Programa oferece cursos e eventos de extensão, rodas de conversa, grupos de apoio e práticas integrativas complementares bem como pesquisas na área de Saúde Mental.

\section{OBJETIVO}

Objetivou-se divulgar os resultados de eventos de extensão realizados pelo Programa UEPG Abraça, que realiza atendimento psicossocial à comunidade universitária da Universidade Estadual de Ponta Grossa e comunidade externa, para contribuir com o compartilhamento de conhecimento no campo da Saúde Mental.

\section{METODOLOGIA}

Trata-se da apresentação dos eventos de extensão intitulados: A Saúde Mental e a Comunidade UEPG: Programa UEPG Abraça na prevenção do suicídio - 1aa Edição; Saúde Mental: Vida, Arte e Terapia - 1a Edição; A Saúde Mental e a Comunidade UEPG: Ações de Prevenção e Acolhimento Programa UEPG Abraça - 1 Edição; Liga de Psiquiatria e Saúde Mental: Setembro Amarelo e a Prevenção ao Suicídio - 1a Edição; Programa UEPG Abraça e Centro Acadêmico de Enfermagem Sandra Bastos: Jornada Amarela, Conversando sobre o que Importa - 1a Edição.

Realizado no dia 20 de agosto de 2019, teve como local a Universidade Estadual de Ponta Grossa o evento de extensão intitulado "Programa UEPG Abraça na Prevenção do Suicídio - 1a Edição". A metodologia utilizada foi uma série de cinco palestras ministradas por profissionais da área de Saúde Mental, com o objetivo de debater sobre práticas de prevenção do suicídio na sociedade atual e sobre cuidados de saúde na prevenção do suicídio. Todos os participantes responderam um questionário de avaliação do evento ao término das palestras. 
O evento de extensão intitulado de "Saúde Mental: Vida, Arte e Terapia - 1a Edição" foi realizado dia 30 de outubro de 2019 às 14 horas, no Museu Campos Gerais, na cidade de Ponta Grossa. Como metodologia, foram expostas as obras de arte confeccionadas pelos usuários do Sistema de Saúde Mental de Ponta Grossa, bem como a exibido o documentário "Loucura em Ponta Grossa", sendo este um dos objetivos do projeto de extensão "Compartilhando Saúde Mental com a Comunidade”, vinculado ao Programa UEPG Abraça.

O evento de extensão intitulado de "A Saúde Mental e a Comunidade UEPG: Ações de Prevenção e Acolhimento Programa UEPG Abraça - 1aㅡ Edição” foi realizado nos dias 28 e 29 de novembro de 2019, nas dependências do Teatro PAX. Foi utilizado como metodologia: três mesas redondas que abordaram a Saúde Mental dos universitários e comunidade e quatro palestras que abordaram os programas e projetos referentes à qualidade de vida e saúde no âmbito da UEPG e instituições parceiras. Com o término do evento, um questionário foi entregue aos ouvintes participantes, com a finalidade de avaliar o impacto e a qualidade do mesmo.

O evento de extensão intitulado de "Liga de Psiquiatria e Saúde Mental: Setembro Amarelo e a prevenção ao suicídio - 1a Edição" foi realizado de 01 à 09 de setembro de 2020 de forma online, através de lives pela plataforma YouTube. Foram abordados como metodologia: nove palestras apresentadas, abordando temas referentes à temática do Setembro Amarelo na conscientização e prevenção ao suicídio, na prevenção da autolesão não suicida, no comportamento suicida dentre a comunidade e também entre os acadêmicos universitários.

Intitulado de "Programa UEPG Abraça e Centro Acadêmico de Enfermagem Sandra Bastos: Jornada Amarela - Conversando sobre o que Importa - 1a Edição", foi um evento desenvolvido de 07 à 29 setembro de 2020. Realizado através do Centro Acadêmico de Enfermagem Sandra Bastos juntamente com o Programa UEPG Abraça. Contou com quatro palestras relacionadas ao tema prevenção do suicídio. Nelas foram abordados temas como: abuso infantil, pessoas com deficiência, População LGBTQIA+ e questões referentes à pressão estética nos dias atuais. Todo o evento foi realizado de maneira online através da plataforma Google Meet.

Todos os eventos foram compostos por pesquisadores, professores, profissionais especializados no campo da Saúde Mental da UEPG e parceiros externos, sendo destinado aos docentes, discentes, agentes universitários, profissionais de saúde, educadores, comunidade externa, e demais interessados na temática de Saúde Mental.

\section{RESULTADOS E DISCUSSÃO}

Todos os cinco eventos foram realizados pelo Departamento de Enfermagem e Saúde Pública da Universidade Estadual de Ponta Grossa, tendo como coordenadora da proposta uma professora do respectivo Departamento. Tiveram um total de 1.109 participantes, dentre estes: discentes, docentes, agentes universitários, profissionais da saúde e demais interessados pelas temáticas abordadas. Acumulando um total de 67 horas contabilizando todos os eventos em sua decorrência, ofertando ao público o compartilhamento do conhecimento científico nos âmbitos da Saúde Mental e afins, bem como sua importância dentro da comunidade como um todo. ${ }^{[5-9]}$

O evento intitulado "Programa UEPG Abraça na Prevenção do Suicídio - 1a Edição" foi realizado no dia 20 de agosto de 2019 e teve como local a Universidade Estadual de Ponta Grossa. Dentre os participantes: 5 ministrantes, 311 ouvintes, 1 docente, 1 técnico e 13 discentes. Com uma carga horária contabilizada em 4 horas de atividades, a proposta surgiu devido à preocupação tanto da Reitoria (gestão 2018-2022) da Universidade Estadual de Ponta Grossa, quanto do Programa UEPG Abraça a respeito da temática no século XXI e sua importância dentro da Saúde Mental.[8]

Do cronograma, seguiu-se a apresentação de cinco palestras ministradas por profissionais da área de Saúde Mental: Palestra 1 - "Inspiração: Intervenções para prevenção e Pósvenção do suicídio"; Palestra 2 "A prevenção do suicídio sob o olhar da psiquiatria"; Palestra 3 - "Por que temos que falar sobre a saúde mental dos acadêmicos?"; Palestra 4 - "Atuação do assistente social no enfrentamento à violência autoprovocada em urgência e emergência"; Palestra 5 - "O Programa UEPG Abraça na prevenção do suicídio". O evento teve um total de 331 participantes e ocorreu de acordo com a programação, não havendo nenhuma alteração. 0 público participante demonstrou-se bastante interessado, respondeu a um questionário, onde a principal sugestão apontada foi à realização de um próximo evento com dois dias. Todas as apresentações tiveram como objetivo debater sobre práticas de prevenção do suicídio na sociedade atual e sobre cuidados de saúde em casos de prevenção do suicídio.[8] 
O evento intitulado de "Saúde Mental: Vida, Arte e Terapia - 1a Edição" foi realizado dia 30 de outubro de 2019 às 14 horas, no Museu Campos Gerais, na cidade de Ponta Grossa. Contabilizou uma carga horária de 6 horas, e dentre os ouvintes participantes estão: 61 ouvintes, 2 docentes, 1 técnico e 4 discentes. ${ }^{[9]}$

Na exibição foram expostas as obras de arte confeccionadas pelos usuários do Sistema de Saúde Mental de Ponta Grossa, bem como a exibido o documentário "Loucura em Ponta Grossa" retratando a rotina dos mesmos. Com um total de 68 participantes, o evento teve como objetivo trazer visibilidade aos trabalhos desenvolvidos pelo Ambulatório de Saúde Mental de Ponta Grossa junto aos usuários desse serviço, ressaltando sua importância e contribuindo para a luta antimanicomial, sendo estes, um dos objetivos do projeto de extensão "Compartilhando Saúde Mental com a Comunidade”, vinculado ao Programa UEPG Abraça. ${ }^{[9]}$

O evento intitulado de "A Saúde Mental e a Comunidade UEPG: Ações de Prevenção e Acolhimento Programa UEPG Abraça - 1a Edição" teve como período de inscrição período de 28 até 29 de novembro de 2019, e foi realizado nas dependências do Teatro PAX, na cidade de Ponta Grossa. A carga horária prevista das atividades foi de 6 horas, mas contou com uma carga horária total de 8 horas. Em relação ao número de participantes foram: 7 ministrantes e 64 ouvintes, 3 docentes e 15 discentes. [5]

O evento contou com a fala inicial da Coordenadora, e em sua programação, sucederam-se quatro mesas redondas com os seguintes temas: Mesa 1 - "A Saúde Mental dos Universitários"; Mesa 2 - "Acolhe USP: Programa de Acolhimento Relacionado ao Uso de Álcool e outras Drogas da Universidade de São Paulo"; Mesa 3 - "Ações de Saúde Mental na Comunidade"; Mesa 4 - Experiencias e Projetos para a qualidade de vida da comunidade UEPG". Após o encerramento dessas, iniciou-se três palestras, intituladas: Palestra 1 "Projeto VIVENCIARTE: Arteterapia na UEPG"; Palestra 2 - "Elaboração e Aplicação de Sistema Online para a avaliação do estado emocional de acadêmicos da UEPG"; Palestra 3 - "Projeto Pró Servidor"; Palestra 4 "A contribuição dos Programas de Residência Multiprofissional do HURCG/UEPG". Finalizadas por mais duas mesas redondas na sequência: "Mesa 5 - "Rede de Atenção Psicossocial de Ponta Grossa" e Mesa 6 "Me deixe em Paz (?)". Todas as interações abordaram os programas e projetos referentes à qualidade de vida e saúde no âmbito da UEPG, instituições parceiras e da comunidade acadêmica como um todo. Com um total de 89 participantes, foi um evento direcionado a profissionais de saúde, educação, assistência social, psicologia, entre outros, e demais interessados na temática.[5]

O evento, intitulado de "Liga de Psiquiatria e Saúde Mental: Setembro Amarelo e a prevenção ao suicídio 1a Edição" foi realizado pela Liga de Psiquiatria e Saúde Mental (LSPM) da Universidade Estadual de Ponta Grossa, com orientação e coordenação do Programa UEPG Abraça. Realizado de forma online através do sistema "Ao Vivo de lives" pela plataforma YouTube, durante o período de 01 à 09 de setembro de 2020. Contou com um total de 30 horas de carga horária prevista, porém foi realizado em 40 horas. Teve um total de participantes: 8 ministrantes, 537 ouvintes, 1 docente e 8 discentes. ${ }^{[6]}$

Da programação, foram realizadas sete palestras: Abertura e Palestra 1 no dia 01/09/2020 - "Ações estratégicas para a prevenção do suicídio"; Palestra 2 no dia 02/09/2019 - "Prevenção da autolesão não suicida (Automutilação)"; Palestra 3 no dia 03/09/20 - "Comportamento suicida nas redes sociais virtuais"; Palestra 4 no dia 04/09/20 - "Suicídio na adolescência; ambas Palestra 5 - "Suicídio entre os universitários" e Palestra 6 - "Programa UEPG Abraça: Estratégia de Enfrentamento da COVID-19 e Prevenção do Suicídio no Ambiente Universitário" no dia 08/09/20; e Palestra 7 no dia 09/09/20 "Posvenção, o cuidado de quem ficou". Não houve nenhuma alteração no cronograma estabelecido previamente.

As dificuldades encontradas foram com relação a transmissão no meio online, pois devido ao conhecimento da tecnologia computacional distinto de cada palestrante, encontraram-se dificuldades com a transmissão do áudio, vídeo e conexão da internet. Entretanto, todos os problemas foram totalmente resolvidos com orientação e cooperação da equipe do evento. Houveram novas propostas de parcerias entre os palestrantes e a LPSM, além de programação de futuros novos eventos online e presenciais com os mesmos palestrantes. Contabilizando um total de 554 participantes, o evento teve como objetivo desenvolver e propagar o conhecimento no que tange a Saúde Mental na prevenção ao suicídio no mês de setembro.[6]

O evento intitulado de "Programa UEPG Abraça e Centro Acadêmico de Enfermagem Sandra Bastos: Jornada Amarela - Conversando sobre o que Importa - 1a Edição" foi realizado do dia 07 à 29 setembro de 2020. Contou com uma carga horária prevista de 10 horas, em uma série de quatro palestras relacionadas ao tema "prevenção do suicídio". Dentre todos os participantes contabilizaram-se: 5 ministrantes, 49 ouvintes, 1 docente e 12 discentes.[7] 
No cronograma inicializou-se com: Palestra 1 no dia 07/09 - "A pressão estética nos dias atuais e suas influências"; Palestra 2 no dia 14/09 - "População LGBTQIA+"; Palestra 3 no dia 21/09 - "A pessoa com deficiência"; e Palestra 4 do dia 29/09 - "O Abuso Infantil". Todo o evento foi realizado de maneira online através da plataforma Google Meet, inicialmente estava previsto para ser realizado na plataforma Stream Yard, mas devido à quantidade de inscrições e a necessidade de haver maior articulação do palestrante com o público, houve a necessidade de mudança.

O evento contou com um total de 67 participantes e mostrou aos alunos da graduação da área da saúde e a população em geral como abordar e realizar o acolhimento de pessoas em situação de risco e sobre a importância de campanhas para a prevenção do suicídio, além de possibilitar o diálogo em diversas esferas da sociedade sobre o tema grupos abordados em questão. ${ }^{[7]}$

Com relação à carga horária de todos os eventos, estimavam-se 56 horas de atividades. No entanto realizou-se um total de 67 horas. Com relação aos participantes, 25 são ministrantes, enquanto que 1022 são ouvintes. Quanto às equipes de coordenação, somam-se 8 docentes, 52 discentes e 2 técnicos.

Todos os eventos foram apresentados por profissionais da área e destinados a comunidade UEPG e demais interessados, abordando temas relevantes como: Programas de Atenção Psicossocial à comunidade, Saúde Mental dos universitários, Programas de Acolhimento relacionados ao uso de álcool e drogas, Redes de Atenção Psicossocial de Ponta Grossa, Ações em Saúde Mental de prevenção e acolhimento dentro da comunidade, assim como experiências e projetos para a qualidade de vida da mesma, entre outros assuntos relevantes. ${ }^{[5-9]}$

O público ouvinte teve mútuo conhecimento adquirido a respeito das temáticas dos eventos citados, pois foram abordados assuntos de suma importância para toda a comunidade acadêmica, profissional e social, auxiliando em vários tópicos relacionados aos campos da Saúde Mental, além de todo ensino técnico que foi abordado nos eventos, refletindo na aplicação clínica dos acadêmicos ouvintes da área da saúde. As informações passadas através das interações por meio das palestras, rodas de conversas, entre outras ministradas por médicos, enfermeiras, psicólogos e especialistas na área - buscaram esclarecer ao público, com relação aos temas abordados, orientações corretas de prevenção, cuidados e ações que devem ser tomadas para cuidar dos diferentes campos da Saúde Mental.[5-9]

Por fim, o Quadro 1 a apresenta os dados de carga horária de cada evento, e o Quadro 2 apresenta a discriminação de participantes e membros da coordenação de cada evento.

Quadro 1: Dados de carga horária dos eventos de extensão propostos pela coordenação do Programa de Extensão UEPG Abraça.

\begin{tabular}{|c|c|c|}
\hline & Proposta & Realizada \\
\hline Programa UEPG Abraça na prevenção do suicídio (1ª Edição) & 4 & 4 \\
\hline Saúde Mental: Vida, Arte e Terapia (1ª Edição) & 6 & 5 \\
\hline $\begin{array}{l}\text { A Saúde Mental e a Comunidade UEPG: Ações de Prevenção e Acolhimento Programa } \\
\text { UEPG Abraça ( } 1 \text { a Edição) }\end{array}$ & 6 & 8 \\
\hline $\begin{array}{l}\text { Liga de Psiquiatria e Saúde Mental: Setembro Amarelo e a Prevenção ao Suicídio (1ª } \\
\text { Edição) }\end{array}$ & 30 & 40 \\
\hline $\begin{array}{l}\text { Programa UEPG Abraça e Centro Acadêmico de Enfermagem Sandra Bastos: Jornada } \\
\text { Amarela - Conversando sobre o que Importa (1 } \text { ( } \text { a Edição) }^{\text {a }}\end{array}$ & 10 & 10 \\
\hline TOTAL & 56 & 67 \\
\hline
\end{tabular}

Fonte: Coordenação do Programa UEPG Abraça, 2021. 
Quadro 2: Dados dos participantes e das equipes de coordenação dos eventos de extensão propostos pela coordenação do Programa de Extensão UEPG Abraça.

\begin{tabular}{|c|c|c|c|c|c|c|}
\hline \multirow[b]{2}{*}{ TÍTULO DO EVENTO } & \multicolumn{2}{|c|}{ PARTICIPANTES } & \multicolumn{3}{|c|}{ COORDENAÇÃO } & \multirow{2}{*}{ 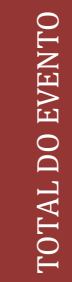 } \\
\hline & 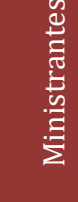 & 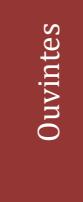 & 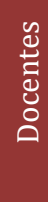 & 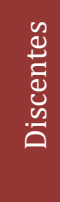 & 导 & \\
\hline $\begin{array}{l}\text { Programa UEPG Abraça na prevenção do } \\
\text { suicídio (1ํ- Edição) }\end{array}$ & 5 & 311 & 1 & 13 & 1 & 331 \\
\hline Saúde Mental: Vida, Arte e Terapia (1 ${ }^{\mathrm{a}}$ Edição) & 0 & 61 & 2 & 4 & 1 & 68 \\
\hline $\begin{array}{l}\text { A Saúde Mental e a Comunidade UEPG: Ações } \\
\text { de Prevenção e Acolhimento Programa UEPG } \\
\text { Abraça (1 }{ }^{a} \text { Edição) }\end{array}$ & 7 & 64 & 3 & 15 & 0 & 89 \\
\hline $\begin{array}{l}\text { Liga de Psiquiatria e Saúde Mental: Setembro } \\
\text { Amarelo e a Prevenção ao Suicídio (1 } 1 \text { a Edição) }\end{array}$ & 8 & 537 & 1 & 8 & 0 & 554 \\
\hline $\begin{array}{l}\text { Programa UEPG Abraça e Centro Acadêmico } \\
\text { de Enfermagem Sandra Bastos: Jornada } \\
\text { Amarela - Conversando sobre o que Importa } \\
\text { (1ª Edição) }\end{array}$ & 5 & 49 & 1 & 12 & 0 & 67 \\
\hline TOTAL & 25 & 1022 & 8 & 52 & 2 & 1109 \\
\hline
\end{tabular}

Fonte: Coordenação do Programa UEPG Abraça, 2021.

\section{CONCLUSÃO}

Conclui-se que os eventos de extensão contribuíram com a sensibilização e discussão de políticas públicas de Saúde Mental e a atuação da universidade diante das problemáticas do uso de álcool e outras drogas; enfrentamento de transtornos mentais; e prevenção do suicídio.

Destaca-se que os resultados deste estudo servem de subsídios não apenas para a constituição de ações dedicadas ao cuidado de saúde mental e qualidade de vida dos universitários e comunidade externa, mas também para direcionar as discussões sobre suporte e serviços a estas populações.

Ressalta-se a importância da Saúde Mental e o seu potencial na contribuição e no desenvolvimento científico dentro da área da saúde, bem como no compartilhamento do conhecimento para a comunidade.

\section{REFERÊNCIAS}

[1] PINHO, R. Caracterização da clientela de um programa de atendimento psicológico a estudantes universitários. Psicol. Conoc. Soc., Montevideo , v. 6, n. 1, p. 114-130, maio 2016 . Disponível em: $<$ http://www.scielo.edu.uy/scielo.php?script=sci_arttext\&pid=S1688-70262016000100006\&lng=es\&nrm=iso >. Acessado em 20 jul 2020.

[2] LEAL, K. S.; OLIVEIRA, P. D. S.; RODRIGUES, P. R. G., \& FOGAÇA, F. F. S. Desafios enfrentados na universidade pública e a saúde mental dos estudantes. Revista Humanidades e Inovação, 6(8), 59-69. Palmas v.6, n,8. Jun, 2019. Disponível

em:

<https://revista.unitins.br/index.php/humanidadeseinovacao/article/view/1149\#: :text=0s\%20resultados\%20de monstram\%20que\%20os,mental\%2C\%20inclusive\%20depress\%C3\%A3o\%20e\%20suic\%C3\%ADdio.> Acessado em 20 jul 2020.

[3] CERCHIARI, E.A.N. et al. Utilização do serviço de saúde mental em uma universidade pública. Psicologia: Ciência e Profissão, Brasília, v.25, n.2, p.252-65, $2005 . \quad$ Disponível em: http://www.scielo.br/pdf/pcp/v25n2/v25n2a08.pdf. Acessado em 04 de julho de 2020.

[4] CASTRO, V.R. Reflexões sobre a saúde mental do estudante universitário: estudo empírico com estudantes de uma instituição pública de ensino superior. Revista Gestão em Foco, São Paulo, v.9, n.1, p.380-401, 2017. Disponível em: http://portal.unisepe.com.br/unifia/wp-content/uploads/sites/10001/2018/06/043_sau de_mental.pdf. Acessado em 06 de julho de 2020.

[5] A SAÚDE MENTAL E A COMUNIDADE UEPG: AÇÕES DE PREVENÇÃO E ACOLHIMENTO 1ª EDIÇÃO. Programa UEPG Abraça. Ponta Grossa. 5 p. 2019.

[6] LIGA DE PSIQUIATRIA E SAÚDE MENTAL: SETEMBRO AMARELO E A PREVENÇÃO AO SUICÍDIO 1aㅡ EDIÇÃO. Programa UEPG Abraça. Ponta Grossa. 4 p. 2020. 
[7] PROGRAMA UEPG ABRAÇA E CENTRO ACADÊMICO DE ENFERMAGEM SANDRA BASTOS: JORNADA AMARELA - CONVERSANDO SOBRE O QUE IMPORTA 1a EDIÇÃO. Programa UEPG Abraça. Ponta Grossa. 4 p. 2020.

[8] PROGRAMA UEPG ABRAÇA NA PREVENÇÃO DO SUICÍDIO 1ª EDIÇÃO. Programa UEPG Abraça. Ponta Grossa. 3 p. 2019.

[9] SAÚDE MENTAL - VIDA, ARTE E TERAPIA 1a EDIÇÃO. Programa UEPG Abraça. Ponta Grossa. 3 p. 2019. 


\section{Capitulo 13}

\section{Desafios frente ao cuidado à pessoa usuária de álcool e outras drogas}

\section{Laíse Ávila de Siqueira}

Camila Andriele Nunes Martins Lopes

Mariana Kristosch dos Santos

Karen Brião da Costa

Juliana da Rosa Marinho

Priscilla La Flor Duarte

Bruna Rodrigues Maziero

Resumo: 0 presente artigo tem por objetivo discorrer sobre o cotidiano de trabalho em uma unidade de internação psiquiátrica de um hospital geral, envolvendo uma discussão acerca da Rede de Atenção Psicossocial em um município do interior do Rio Grande do Sul. A natureza desta pesquisa é qualitativa, do tipo descritivo, e trata-se de um relato de experiência. Para a discussão deste trabalho, foi enfatizada, de forma mais específica, a finalidade da internação para os usuários de álcool e outras drogas, que, neste espaço pesquisado, ocorre somente para a desintoxicação. A maior dificuldade enfrentada pelos profissionais no local refere-se às internações feitas de maneira compulsória, que acontecem via judicial. Ressalta-se a importância de lutar pela consolidação das políticas públicas que buscam, no âmbito da saúde, proporcionar uma atenção integral e novas possibilidades de cuidado pautadas no respeito às singularidades de cada sujeito no que se refere às suas dificuldades e necessidades.

Palavras-chave: Internação psiquiátrica; Drogas; Políticas Públicas. 


\section{INTRODUÇÃO}

O presente artigo tem por objetivo discorrer sobre o cotidiano de trabalho em uma unidade de internação psiquiátrica de um hospital geral, sob os múltiplos olhares de uma equipe de residentes em saúde mental, composta por duas assistentes sociais, duas psicólogas e duas terapeutas ocupacionais. A discussão direcionar-se-á para a Rede de Atenção Psicossocial em um município do interior do Rio Grande do Sul, voltando-se mais detalhadamente para os dispositivos de atenção e cuidado à saúde de pessoas que demandam acompanhamento devido às necessidades pelo uso abusivo de álcool e outras drogas. A proposta do trabalho surgiu a partir da compreensão da relevância da temática, bem como pelo aprofundamento a respeito do assunto em uma disciplina que propôs o repensar da prática profissional e as estratégias para o trato dispensado aos usuários. Para uma melhor compreensão do tema abordado e, também, para o entendimento dos fatores que impulsionaram essa reflexão, faz-se necessário buscar um embasamento teórico sobre a política de atenção integral aos usuários de álcool e outras drogas, suas garantias, sua real efetivação e os maiores desafios, perpassando pelo conhecimento da realidade que a instituição apresenta e por uma reflexão crítica daquilo que será possível questionar e buscar compreender melhor essa complexidade.

No Brasil, foi o advento do Sistema Único de Saúde (SUS), instituído pela Lei º 8080, de 1990, que permitiu repensar os modos de atentar à saúde das pessoas e de proporcionar estratégias de cuidado. 0 SUS envolve ações e serviços de saúde que têm o objetivo de promover maior qualidade de vida para toda a população do país, garantindo o acesso de todos a uma assistência integral e equitativa à saúde. Destacase a importância deste sistema para buscar a consolidação de uma rede de cuidados que funcione de forma regionalizada, hierarquizada e integrada (BRASIL, 1990).

A Reforma Psiquiátrica, também, teve papel fundamental, apresentando várias possibilidades terapêuticas e posicionando-se contrária aos espaços manicomiais e de enclausuramento. A internação psiquiátrica torna-se o último recurso, considerada apenas se outras abordagens terapêuticas não se mostram suficientes. Destaca-se que, em relação aos tipos de internação, na forma do artigo 6o da Lei no 10.216/01, que garante a Reforma Psiquiátrica, são considerados: internação voluntária, internação involuntária e internação compulsória.

Diante dessa nova perspectiva que possibilita o cuidado integral, surge, em 2001, a Rede de Atenção Psicossocial (RAPS), que estabelece, dentre outros, os pontos de atenção ao atendimento a pessoas com transtornos mentais e que apresentam necessidades devido ao uso nocivo de crack, álcool e outras drogas. Fazem parte da teia de dispositivos os Centros de Atenção Psicossocial (CAPS), os Serviços Residenciais Terapêuticos (SRT), os Centros de Convivência e Cultura, as Unidade de Acolhimento (UAs), e os leitos de atenção integral (hospitais gerais; CAPS III) (BRASIL, 2001).

É neste cenário de SUS e RAPS que serão discutidas as vivências na unidade de internação psiquiátrica, visto que, após alguns anos de leis em vigor, ainda são encontradas dificuldades e limitações para se consolidar aquilo que é proposto. Serão expostas, ainda, algumas inquietações, através de discussões e reflexões acerca das barreiras judiciais e possibilidades de internação psiquiátrica, levando em consideração a importância de repensar as práticas nos serviços como estratégias para efetivação de uma política de atendimento às pessoas em situação de risco e vulnerabilidade social, para que não se perpetue um segmento de população historicamente excluída e estigmatizada.

\section{REVISÃO DE LITERATURA}

A partir da lei do SUS, a constituição de redes assistenciais tornou-se tema de fundamental relevância para que fossem estimuladas as novas formas de atenção à saúde. De acordo com Ferla, Leal e Pinheiro (2006), um primeiro passo importante para a formação de redes deu-se pela descentralização da saúde no Brasil, possibilitando a realização de ações locais, de território, aspecto que trouxe resultados positivos no âmbito da saúde de modo geral, considerando todos os níveis de atenção.

Para Merhy (1997), é o projeto terapêutico, pensado para cada sujeito, que é o disparador dessa rede, e é dentro desta lógica de cuidado singular e voltado às pessoas de forma integral que se tece a rede, pois, de acordo com cada demanda, estabelece-se a articulação entre serviços e dispositivos de saúde. Assim, as equipes voltam-se ao o sujeito, validando suas particularidades e potencializando novas formas de lidar com suas demandas e enfrentar as situações cotidianas. 
No que se refere ao cuidado da pessoa usuária de drogas, é importante, primeiramente, compreender, de forma histórica, a questão do uso abusivo de substâncias. Predominantemente, a temática tem sido abordada por uma perspectiva médica, de modo que outros aspectos, como questões político-sociais, psicológicas e econômicas ficam em segundo plano.

Além disso, o uso de substâncias também é facilmente relacionado à criminalidade, de modo que há uma grande oferta de tratamentos inspirados em modelos de exclusão dos usuários do convívio social (BRASIL, 2003).

Diante deste cenário, grande parte das estratégias de cuidado costuma apresentar caráter total, fechado e tendo a abstinência como principal objetivo a ser alcançado. Entretanto, é importante reconhecer que o consumo abusivo de drogas tem como característica a heterogeneidade, ou seja, está presente na vida das pessoas em contextos diferentes, afetando-as de modos diversos. Dessa forma, muitos consumidores de drogas não compartilham a expectativa e o desejo de abstinência dos profissionais de saúde e abandonam os serviços ou não aderem aos tratamentos (BRASIL, 2003).

Foi considerando a necessidade de ampliar e diversificar os serviços do SUS para a atenção às pessoas com necessidades decorrentes do consumo de álcool, crack e outras drogas que, na política da RAPS, pensou-se como eixo uma série de ações de prevenção e de redução de danos (BRASIL, 2011). Essa política tem como objetivos específicos, no âmbito do álcool e outras drogas, a prevenção do consumo e da dependência, a redução de danos provocados pelo consumo de substâncias, bem como a promoção da reabilitação e da reinserção social dos indivíduos com necessidades decorrentes do uso de drogas, por meio do acesso ao trabalho, renda e moradia solidária.

Destaca-se a criação do Plano Integrado de Enfrentamento ao Crack e outras Drogas, que tem alguns objetivos como, por exemplo, estruturar, integrar, articular e ampliar as ações voltadas à prevenção do uso, tratamento e reinserção social de usuários de crack e outras drogas, contemplando a participação dos familiares e a atenção aos públicos vulneráveis, entre outros, crianças, adolescentes e população em situação de rua (BRASIL, 2010).

Na busca por dispositivos de cuidado, apontamos, também, a necessidade de implementar os Centros de Apoio Psicossocial para usuários de drogas, os CAPS AD, além dos CAPS AD III, que proporcionam atendimento a adultos, crianças e adolescentes com necessidades de cuidados clínicos contínuos. O CAPS AD III, especificamente, é um serviço com até doze leitos para observação e monitoramento, de funcionamento 24 horas, incluindo feriados e finais de semana, e tem indicação para ser construído em municípios ou regiões com população acima de duzentos mil habitantes. (BRASIL, 2011)

\section{METODOLOGIA}

A natureza desta pesquisa é definida como qualitativa, do tipo descritivo, constituindo-se através de um relato de experiência. Segundo Minayo (2007), o estudo qualitativo caracteriza-se pela busca de um aprofundamento da compreensão do tema pesquisado. Ainda, a pesquisa, com enfoque qualitativo, requer como atitudes fundamentais a abertura, a flexibilidade, a capacidade de observação e de interação com o grupo de investigadores e com os atores sociais envolvidos.

0 método utilizado foi relato de experiência, trazendo conceitos que partem de vivências que são significativas à área a ser estudada, trazendo considerações a fim de descrever uma conjuntura. É esperado que tais experiências possam contribuir com outros pesquisadores da área, ampliando o efeito da sua experiência e potencializando-se para ser exemplo a outros estudos e vivências.

Para concretizar este trabalho, são consideras as experiências de campo em uma unidade de internação psiquiátrica. Dentre os objetivos do local, tem-se a internação de usuários de substâncias psicoativas ao processo de desintoxicação. Concomitantemente a esse acompanhamento no cotidiano da unidade psiquiátrica, houve a busca teórica por materiais que pudessem auxiliar na fundamentação da realidade constatada, a fim de relacionar os conceitos teóricos com as práticas observadas e realizadas. 


\section{RESULTADOS E DISCUSSÕES}

De acordo com o contexto nas políticas de saúde, torna-se necessário refletir sobre a realidade da unidade de internação psiquiátrica de um hospital geral, que, atualmente, conta com 24 leitos divididos em ala feminina e ala masculina, onde há atendimento às demandas de saúde mental para adolescentes e adultos. As internações no local podem ser realizadas de forma voluntária - que se dá com o consentimento do usuário - involuntária, que se dá sem o consentimento do usuário e a pedido de terceiro; e de maneira compulsória, determinada pela justiça, (Brasil, 2001).

Para a discussão deste trabalho, é importante considerar, de forma pontual, a finalidade da internação para os usuários de álcool e outras drogas que, neste espaço, ocorre somente para a desintoxicação, sendo um período relativamente curto de permanência na instituição, aproximadamente três semanas, dependendo do caso.

Durante este tempo, são realizados contatos com os serviços e profissionais dos dispositivos de saúde mental da rede, a fim de que sejam colhidas informações relevantes que possam contribuir para as intervenções da equipe no local, bem como para que seja definida uma continuidade de acompanhamento no pós-alta.

É preciso, também, refletir a respeito da estrutura e das peculiaridades do cotidiano do serviço, dentre elas, o fato de que muitos usuários residem em localidades afastadas, a não disponibilidade de veículos para transporte dos profissionais a fim de realizar visitas, de modo que o serviço se configura a partir de contatos telefônicos e via email, além de atendimentos junto aos profissionais, de acordo com a disponibilidade do serviço que dará continuidade ao acompanhamento, o que limita muitas intervenções.

A maior dificuldade enfrentada pelos profissionais no local refere-se às internações feitas de maneira compulsória, que acontecem via judicial. Partes significativas destes pacientes internados compulsoriamente chegam à unidade sem a intenção de realizar tratamento, ou seja, não desejam estar naquele local e não têm a finalidade de parar o uso de substâncias. Ademais, muitas vezes, o contexto social e a história do sujeito são os fatores determinantes para escolher como estratégia de enfrentamento o uso de drogas, de modo que a desintoxicação, como apenas uma parte do processo de tratamento na dependência química, não definirá uma evolução clínica na saúde do sujeito que está sendo internado sem ter feito tal escolha. Outro fator relevante é a dificuldade na comunicação e nos encaminhamentos pósalta, o que pode indicar uma falha na rede, visto que, em determinadas situações, não existem opções de locais para que o sujeito continue o tratamento e/ou cuidado necessário após o período de internação.

Outro ponto importante, visualizado através da experiência no local em questão, é a ausência de ações de prevenção e de redução de danos (que são parte do eixo da RAPS que trata das questões sobre álcool e outras drogas), de modo que a internação torna-se um dos principais recursos utilizados para o acompanhamento das pessoas usuárias de substâncias psicoativas. Nesse sentido, visualizamos uma distorção na finalidade da internação, que se torna a primeira e, muitas vezes, a única possibilidade de trabalhar uma demanda que, pelas políticas de saúde atuais, deveria ser coberta desde a atenção primária, no território.

As dificuldades enfrentadas pelo elevado número de internações para desintoxicação e a permanência do usuário durante um tempo superior ao que é necessário e orientado, ocorrem devido à superlotação dos serviços de saúde mental, bem como pela ausência de dispositivos propostos pela lei da RAPS, o que é o caso do CAPS AD III, dos consultórios de rua, etc. Além disso, serviços de saúde mental nem sempre seguem uma mesma linha de cuidado pautada na redução de danos, de modo que não se consegue fazer um acompanhamento longitudinal e coerente com a lógica antimanicomial e de cuidado integral.

Constata-se, ainda, a importância de enxergar, também, o profissional envolvido neste tipo de serviço que, muitas vezes, se vê sobrecarregado, sem recursos e sem suporte para definir os encaminhamentos mais adequados e que contemplem as reais necessidades do usuário. As fragilidades da rede refletem, de alguma forma, na saúde do trabalhador que está envolvido nos cuidados das pessoas que demandam atenção integral. Nesse sentido, torna-se relevante desenvolver uma visão crítica e sistêmica acerca dos serviços de saúde, que influenciam as necessidades dos usuários destes dispositivos e refletem, também, na equipe de profissionais, em sua saúde e, consequentemente, em sua dinâmica e na forma de atuar no local de trabalho. 


\section{CONCLUSÃO}

Diante do exposto e considerando o papel dos profissionais residentes dentro dos serviços de saúde, ressalta-se a importância de lutar pela consolidação das políticas públicas que buscam, no âmbito da saúde, proporcionar uma atenção integral e novas possibilidades de cuidado pautadas em respeito às singularidades de cada sujeito no que se refere às suas dificuldades e necessidades. Trata-se de efetivar na prática o que já está definido em teoria e lei.

O Brasil tem avançado significativamente nas políticas de saúde desde a implementação do SUS, entretanto, ainda não são observadas nos campos de trabalho as diretrizes que são apresentadas em legislações e resoluções que estão em vigor atualmente. Apesar da criação de CAPS AD III estar amparada em lei, por exemplo, a cidade onde se dá o serviço de internação e acompanhamento psiquiátrico aqui discutida não apresenta projeto de criação desse tipo de dispositivo, o que pode ser um dos fatores que resultam em superlotação de outros serviços que não têm exatamente a função de receber usuários de álcool e outras drogas que necessitam de cuidado e acompanhamento.

Entende-se, também, que os dispositivos de saúde mental em muitos casos não tecem uma rede, pois existem significativas limitações, como por exemplo, a dificuldade de comunicação (seja por falta de recursos quanto pela falta de disponibilidade e interesse de alguns serviços), as diferentes visões adotadas pelos profissionais para pensar estratégias de cuidado para usuários de drogas (ou abstinência ou redução de danos), a lotação excessiva nos locais de atendimento e impossibilidade de novos encaminhamentos, dentre outras.

Por conseguinte, conclui-se que existem diferentes aspectos nos serviços de saúde que resultam ao não cumprimento de certos pontos das leis e diretrizes apresentadas anteriormente, sendo importante que as equipes de saúde se empoderem do que está sendo articulado na legislação no âmbito da saúde, a fim de desenvolver um olhar mais crítico diante da realidade e buscar novas estratégias de efetivar essas formas de cuidado.

\section{REFERÊNCIAS:}

[1] BRASIL. Lei n. 8.080, de 19 de setembro de 1990. Dispõe sobre as condições para promoção, proteção e recuperação da saúde, a organização e o funcionamento dos serviços correspondentes, e dá outras providências. Diário Oficial da União, Brasília, DF, 20 set. 1990.

[2] BRASIL. Lei n. 10.216, de 06 de abril de 2001. Dispõe sobre a proteção e os direitos das pessoas portadoras de transtornos mentais e redireciona o modelo assistencial em saúde mental. Diário Oficial da União, Brasília, DF, 06 abr. 2001.

[3] BRASIL. Ministério da Saúde. Secretaria Executiva. Coordenação Nacional de DST/AIDS. A Política do Ministério da Saúde para atenção integral a usuários de álcool e outras drogas / Ministério da Saúde, Secretaria Executiva, Coordenação Nacional de DST e AIDS. Brasília: Ministério da Saúde, 2003.

[4] BRASIL. Decreto n. 7.179 de 20 de maio de 2010. Institui Plano Integrado de Enfrentamento ao Crack e outras Drogas, criam o seu Comitê Gestor, e dá outras providências. Diário Oficial da União; 20 de maio 2010.

[5] BRASIL. Portaria n. 3.088, de 23 de dezembro de 2011. Institui a Rede de Atenção Psicossocial para pessoas com sofrimento ou transtorno mental e com necessidades decorrentes do uso de crack, álcool e outras drogas, no âmbito do Sistema Único de Saúde. Diário Oficial da União, Brasília, DF, 23 dez. 2011.

[6] FERLA, A. A., LEAL, M. B.; PINHEIRO, R. Um olhar sobre as práticas avaliativas em descentralização do sistema de saúde: construindo uma abordagem analítica para atuação em rede. In: Pinheiro, R.; Mattos, R. A. (Orgs.). Gestão em redes: práticas de avaliação, formação e participação em saúde. Rio de Janeiro: IMS/UERJ: Abrasco, 2006.

[7] MERHY, E. E. Em busca do tempo perdido: a micropolítica do trabalho vivo em saúde. In MERHY, E. E.; ONOCKO, R. (Orgs.). Agir em saúde: um desafio para o público. São Paulo: Hucitec, 1997. P. 71-112.

[8] MINAYO, M. C. S. O desafio do conhecimento: pesquisa qualitativa em saúde. Ed. São Paulo: Hucitec, 2007. 


\section{Capítulo 14}

\section{Vitamina D: Deficiência e suplementação relacionada à cirurgia Bariátrica}

\section{Elisa Clerici Lütdke \\ Eduarda Flores de Lima \\ Camila Franco}

Resumo: 0 objetivo da presente pesquisa é investigar a literatura quanto ao acompanhamento pré e pós-cirúrgico de pacientes submetidos a cirurgia bariátrica, considerando as concentrações séricas de vitamina D e sua suplementação. Para tal, empregou-se um estudo exploratório, por meio de revisão bibliográfica, buscando informações referentes a "Deficiência de Vitamina D x Cirurgias Bariátricas". Os resultados inferem a necessidade de controle dos níveis de vitamina D no período pré e pós-operatório, visto que o organismo não consegue absorver as quantidades normais de nutrientes, necessitando suplementação. Conclui-se que a maioria dos pacientes possui essa deficiência vitamínica por não exporem-se ao sol ou apresentarem dieta inadequada. Ressalta-se a importância da presença de um acompanhamento farmacêutico e multidisciplinar, pois podem haver patologias associadas que exijam ajuste de prescrição para obter um uso racional de medicamentos e tratamentos com dosagens menores possíveis.

Palavras-chave: Obesidade, Carência de Vitamina D, Reposição Vitamínica. 


\section{INTRODUÇÃO}

A obesidade é uma doença crônica crescente nas últimas décadas no Brasil e no mundo, atingindo a maior parte da população acima de 35 anos de idade. Segundo a Vigilância de Fatores de Risco de Doenças Crônicas Não Transmissíveis (DCNT) do Ministério da Saúde (BRASIL, 2014), 52,2\% dos brasileiros estão acima do peso, sendo que os homens são maioria em número (56,5\%). Entretanto, as mulheres apresentam os maiores índices de obesidades, atingindo 18,2\% (homens, 17,6\%) (ABESO, 2014).

Fandiño (2004) observa que segundo a Organização Mundial de Saúde, o Índice de Massa Corporal (IMC) pode ser classificado em níveis de obesidade. Grau I envolve IMC entre 30 e 34,9 Kg/m², Grau II entre 35 e $39,9 \mathrm{Kg} / \mathrm{m}^{2}$ e Grau III acima de $40 \mathrm{Kg} / \mathrm{m}^{2}$, sendo que nesse estágio é fundamental estar atendo a saúde do paciente pois considera-se fator de risco de vida e indica obesidade mórbida, podendo gerar complicações físicas.

Muitos obesos buscam como tratamento a cirurgia bariátrica, conhecida como gastroplastia ou cirurgia de redução de estômago e, como o próprio nome indica, é uma plástica no estômago que objetiva reduzir o peso das pessoas com IMC muito elevado. Segundo a Sociedade Brasileira de Cirurgia Bariátrica e Metabólica (2016), o Brasil tem realizado a cada ano um maior número de procedimentos sendo que em 2003 houveram 16.000 casos e em 2015 foram 93.500 cirurgias. Uma vez que o paciente pretende se submeter a esse procedimento são exigidos exames de acompanhamento de suas condições, que compreendem exames laboratoriais ou de imagem, entre outros. Nessa etapa, é comum observar pacientes que apresentam déficit de vitamina D no sangue antes da execução da cirurgia, bem como irão necessitar acompanhamento após a bariátrica pois o processo cirúrgico pode acarretar maior deficiência.

Em vista do aumento da obesidade no mundo atual e do número de cirurgias bariátricas que vem sendo realizadas, faz-se importante o levantamento bibliográfico a respeito do controle da deficiência de vitamina $\mathrm{D}$, da necessidade de suplementação desta e do acompanhamento dos pacientes submetidos a este procedimento.

\section{REVISÃO DE LITERATURA}

A vitamina D é conhecida como calciferol, é uma vitamina lipossolúvel da classe dos esteroides, sendo obtida por meio da ingestão de alguns alimentos e também por meio da transformação do colesterol pelas radiações solares, tendo influência sobre a homeostase do cálcio e fosforo, tem ações conhecidas como extra ósseas, protegendo o tecido cardíaco e nervoso a sinalização de recrutadores inflamatórios (BORDALO, MOURÃO E BRESSAN, 2011; SMITH, 2007, p. 648). A vitamina D é absorvida dos alimentos sob a forma de ergocalciferol ou vitamina D2. A vitamina D2 será submetida as rotas de metabolismo hepático e renal, sendo transformada em 1,25-diidroxicolecalciferol (1,25- $\left.(\mathrm{OH})_{2} \mathrm{D} 3\right)$. Estudos publicados no Banco de Dados dos Medicamentos da Agência Nacional de Vigilância Sanitária (ANVISA) sob a autoria de Freitas e Melado (2000) citam que a vitamina D é:

“[...] a vitamina provém da conversão endógena de colesterol em 7deidrocolesterol pela ação solar. 0 7-deidrocolesterol é sintetizado pela pele, constituindo a principal pró-vitamina encontrada nos tecidos animais. A exposição da pele à luz ultravioleta converte essa pró-vitamina em colecalciferol (ou vitamina D3) que será hidrolisada pelo fígado (25hidroxivitamina D) e, posteriormente pelos rins, a calcitriol $\left(1,25-(\mathrm{OH})_{2} \mathrm{D} 3\right)$, a forma mais ativa da vitamina D, considerada um hormônio (FREITAS, MELADO, 2000, p.1).

A etapa inicial no processo de síntese endógena das moléculas do grupo vitamina D se inicia nas camadas profundas da epiderme (estrato espinhoso e camada basal), onde está armazenada a substância precursora, o 7-deidrocolesterol (7-DHC, Figura 1), o qual é exposto a radiação ultravioleta B $(\lambda=290$-315 nm) (MORRIS, 1999 apud CASTRO, 2011, p. 1). Essa transformação envolve a quebra da ligação entre C9C10, abrindo o anel B da molécula. Abaixo na Figura 1, encontram-se as estruturas moleculares do precursor e da vitamina D. 
Figura 1. Estrutura molecular do 7-deidrocolesterol (A) e vitamina D3 (B).

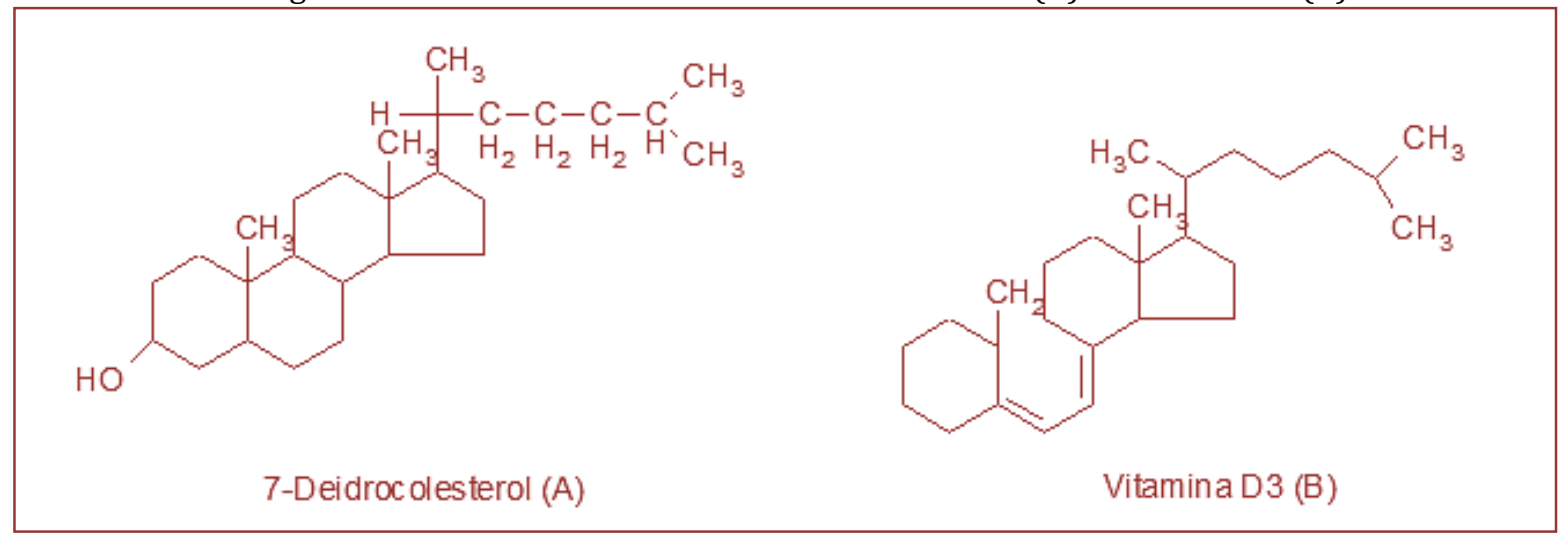

Para produzir vitamina D sob exposição ao sol, é necessário atingir um índice ultravioleta superior a 3, sendo que no Brasil esse índice varia de 4 a 9 durante o ano e, conforme o especialista Michael Holick, o melhor horário para a síntese de vitamina D é das 10 horas da manhã às 16 horas da tarde, devido ao ângulo de incidência dos raios solares. É aconselhado permanecer de 5 a 20 minutos sob exposição solar, com periodicidade de 3 vezes por semana, sem o uso de protetor solar em braços, pernas, abdômen ou costas, mas, indispensável o uso de protetor solar no rosto (HOLICK apud TÔRRES, 2013). Embora esse horário seja o melhor para a síntese de vitamina D, ressalta-se a importância de cuidados com a exposição demasiada a fim de prevenir ocorrência de câncer de pele, pois esse é o horário de maior incidência de radiação. Estima-se que uma pessoa de pele clara submetida de 20 a 30 minutos de exposição solar no rosto e antebraços no horário do meio-dia gere o equivalente a 2000 UI de vitamina D (GUPTA, 2012 apud BRAGA, 2014, p. 8).

Já a deficiência de vitamina D no organismo é causada por alimentação inadequada e falta de absorção de raios UVB pela pele. A perda de vitamina D ocorre porque o organismo após a cirurgia bariátrica, não consegue mais absorver a mesma quantia de vitamina. Deficiências nutricionais ocorrem como resultado da má alimentação, absorção ou utilização diminuídas, ou ainda, da necessidade aumentada ou excreção aumentada (MINER, 2007).

Conforme Bordalo, Mourão e Bressan (2011, p. 1026):

Os doentes submetidos à cirurgia bariátrica, principalmente pelas técnicas do by-pass gástrico em Y-de-Roux (BGYR) ou derivação biliopancreática/Duodenal Switch (DBP) apresentam um maior risco de desenvolver deficiências nutricionais devido, principalmente, à exclusão de partes do trato gastrointestinal prejudicando a absorção eficiente dos nutrientes evidenciando que, as técnicas cirúrgicas com características disabsortivas exercem um maior impacto na absorção de vitaminas e minerais e, frequentemente, resultam em deficiências nutricionais. Desta forma é fundamental o acompanhamento clínico nutricional de todos os doentes submetidos à cirurgia bariátrica a fim de garantir a manutenção da perda de peso de forma saudável.

Sendo que, segundo Bittar (2009, p. 34) a falta de vitamina D após a cirurgia bariátrica pode causar alterações esqueléticas, deficiência de cálcio e de vitamina $\mathrm{D}$, aumentando o risco de malignidades (de cólon, mama e próstata) e, doenças inflamatórias crônicas ou autoimunes, alterações metabólicas, doença vascular periférica, fraqueza muscular e, osteoporose ou osteomalácia. Ainda, Smith (2007) refere que o calcitriol $\left(1,25-(\mathrm{OH})_{2} \mathrm{D} 3\right.$, forma ativa) só é produzido mediante níveis séricos baixos de cálcio (estimulados pelo paratormônio ou PTH), já níveis altos de cálcio formam a 24,25- $(\mathrm{OH})_{2} \mathrm{D} 3$ (forma inativa da vitamina D). A principal função da vitamina D é estimular a absorção de cálcio pela mucosa intestinal, em nível de duodeno e jejuno. 
Dentre os exames clínicos exigidos no pré-operatório, é corriqueiro a solicitação do exame 25hidroxivitamina $\mathrm{D}$, que em níveis de até $20 \mathrm{ng} / \mathrm{mL}$ indicam deficiência, de 21-29 ng/mL correspondem a insuficiência e, de 30-100 ng/mL são considerados suficientes (SEARLEMAN, 2012). Em casos nos quais se detecte deficiência ou insuficiência pré ou pós-operatória, é necessário acompanhamento das dosagens de vitamina D, cálcio e fósforo e, de sua suplementação. A suplementação pode ser realizada por meio da ingestão de atum, sardinha, salmão, ovos, cogumelos, entre outros alimentos ou pode ser realizada via oral ou injetável.

Logo, a presente pesquisa justifica-se pela relevância do tema, como meio de divulgação aos pacientes e aos profissionais da saúde que atendem pessoas obesas que desejam se submeter a cirurgia bariátrica ou que foram submetidos a este procedimento e ressalta os cuidados do acompanhamento da saúde destes indivíduos no que se refere a suplementação de vitamina D.

\section{METODOLOGIA}

O estudo desenvolvido seguiu os preceitos metodológicos de um estudo exploratório, por meio de revisão bibliográfica, buscando descrever e reunir informações referentes ao assunto "Deficiência de Vitamina D x Cirurgias Bariátricas" e "sua suplementação antes e após a cirurgia", atendendo o objetivo de investigar o acompanhamento pré e pós-cirúrgico, formas de suplementação e atenção farmacêutica. Para tal, realizouse um levantamento de dados no período de 2010 a 2016 nas bases Scielo, Web of Science, Science Direct, Medline, Medline Pharmacist, American Chemical Society, sites da ANVISA e Ministério da Saúde, além de literatura impressa. Foram utilizadas as palavras-chaves de pesquisa: "Vitamina D", "Dosagem de Vitamina D", “Cirurgia Bariátrica”, "Déficit de Vitamina D” e "Obesidade”.

\section{RESULTADOS E DISCUSSÕES}

Em fase pré-operatória é necessária uma consulta nutricional do paciente que inclua anamnese alimentar detalhada (quantidade, qualidade, paladar, apetite, nível de saciedade, intolerâncias, alergias alimentares, consumo de bebidas alcóolicas ou drogas, hábito intestinal, mastigação e preparo de alimentos) (BITTAR, 2009, p. 34). Também se exigem exames laboratoriais como hemograma, uréia, creatinina, glicemia em jejum, insulinemia, proteínas totais, albumina, ferro sérico, ferritina, vitaminas B12 e D, ácido fólico, colesterol total e frações, triglicerídeos, aminotransferases (TGO e TGP), fosfatase alcalina, gamaglutamiltransferase (GGT) e bilirrubinas total e frações (ABREU, 2015).

Ainda, indica-se a realização de radiografia de tórax, ultrassonografia de abdômen, avaliação cardiológica, endoscopia digestiva para Helicobacter pylori e avaliação da função respiratória, parecer de um endocrinologista, psiquiatra e/ou psicólogo e fisioterapeuta. A partir daí, realizam-se reuniões multidisciplinares prévias a cirurgia. Se o paciente apresentar qualquer patologia esta deverá ser tratada antes da realização do procedimento cirúrgico, e este somente será realizado com uma condição clínica perfeita.

Araújo (2013) relata que um estudo em 123 pacientes os quais passaram por cirurgia bariátrica foram avaliados quanto aos níveis de vitamina D e PTH antes e após um ano da cirurgia, apresentando deficiência de vitamina D em 86\% dos casos antes da cirurgia e, em 70\% após a cirurgia.

A conduta terapêutica indicada antes e após a cirurgia bariátrica, conforme Ybarra et al. (2005) apud Mustafa (2014, p. 27-28), indica que o paciente candidato à cirurgia de obesidade apresenta dois riscos associados ao desenvolvimento de deficiência de vitamina D: relacionado à obesidade e relacionado à disabsorção provocada pela cirurgia. Encontrou-se a prevalência de 81,3\% de hipovitaminose D antes da cirurgia e 77,3\% após (SÁNCHESZHERNÁNDEZ et al., 2005 apud MUSTAFA, 2014, p. 27-28). A prescrição de vitamina D no pré-operatório é indicada no caso de apresentar dosagem inferior a $30 \mathrm{ng} / \mathrm{mL}$ quando detectado no exame 25-hidroxivitamina D, sendo recomendado o uso de 50.000 UI de colecalciferol oral por semana, durante seis a oito semanas (FLANCBAUM, 2006 apud BORDALO, 2011, p. 118). Já no pósoperatório, segundo a ANVISA (2000), a suplementação pode ser realizada via oral ou intravenosa, conforme a Tabela 1 . 
Tabela 1. Prescrição de vitamina D em adultos e crianças. Fonte: Adaptado de ANVISA (2000). Banco de Dados de Medicamentos.

\begin{tabular}{|c|c|}
\hline PACIENTES & SEM PATOLOGIA ASSOCIADA \\
\hline Vitamina D - Via Oral & $\begin{array}{l}\text { Adultos: } 400 \text { UI/dia associar a dieta e exposição solar } \\
\text { Gestantes: } 400 \mathrm{UI} / \text { dia } \\
\text { Lactentes: predispostos ao raquitismo } 30.000 \mathrm{UI} / \text { dia } \\
\text { Prematuros ou lactentes: } 400 \mathrm{UI} / \text { dia }\end{array}$ \\
\hline PACIENTES & COM PATOLOGIA ASSOCIADA \\
\hline \multirow{6}{*}{$\begin{array}{l}\text { Vitamina D - Via } \\
\text { Intravenosa }\end{array}$} & $\begin{array}{l}\text { Hipoparatireoidismo: } \\
\text { Adultos e crianças maiores de } 8 \text { anos: iniciar com } 50.000 \text { a } 200.000 \text { UI/dia e } \\
\text { manutenção de } 25.000 \text { a } 100.000 \text { UI/dia. } \\
\text { Crianças de } 1-8 \text { anos: } 10.000 \text { a } 25.000 \text { UI/dia. }\end{array}$ \\
\hline & $\begin{array}{l}\qquad \text { Osteomalácia ou raquitismo: } \\
\text { Adultos e crianças maiores de } 8 \text { anos: } 10.000 \text { a } 25.000 \mathrm{UI} / \text { dia. } \\
\text { Crianças de } 1-8 \text { anos: } 5.000 \text { a } 50.000 \mathrm{UI} / \text { dia. }\end{array}$ \\
\hline & $\begin{array}{l}\text { Má-absorção - predisposto ao raquitismo: } \\
\text { Adultos e crianças maiores de } 8 \text { anos: } 1.000 \text { a } 2.000 \text { UI/dia e manutenção de } 400 \\
\text { UI/dia. } \\
\text { Crianças de 1-8 anos: } 10.000 \text { a } 25.000 \text { UI/dia. }\end{array}$ \\
\hline & $\begin{array}{l}\text { Hipofosfatemia: } \\
\text { Crianças de 1-8 anos: } 25.000 \text { a } 100.000 \text { UI/dia, associar a elevada ingesta de fosfato } \\
\text { e suplementar cálcio. }\end{array}$ \\
\hline & $\begin{array}{l}\text { Osteoporose: } \\
\text { Adultos e crianças maiores de } 8 \text { anos: } 300 \mathrm{UI} / \text { dia. } \\
\text { Idosos: } 700 \mathrm{UI} / \text { dia. }\end{array}$ \\
\hline & $\begin{array}{l}\text { Doença Hepatobiliar (hepatite viral, fígado gordo, colecistite, colelitíase): } \\
\text { Adultos e crianças maiores de } 8 \text { anos: } 10.000 \text { a } 40.000 \text { UI/dia. Associado a } \\
\text { anticonvulsivantes: } 1.000 \text { UI/dia. } \\
\text { Crianças de } 1-8 \text { anos: } 1.000 \text { UI/dia. }\end{array}$ \\
\hline
\end{tabular}

Na literatura há inúmeras informações sobre a suplementação da vitamina D mas, a maioria das orientações recaem sobre a dosagem exposta na Tabela 1. 0 importante é fazer com que o paciente saiba da necessidade de reposição e do tempo de duração dessa reposição, até que os níveis sejam estabilizados. Em relação a pacientes que apresentem patologias associadas, as dosagens variam conforme as Sociedades. 0 Instituto de Medicina recomenda 600 UI para pessoas entre 51-70 anos de idade e 800 UI para pacientes acima de 70 anos. A Sociedade Americana de Geriatria recomenda 800 UI para todas as pessoas em risco de queda (LICHTENSTEIN et al., 2013) e a ANVISA (2000) recomenda para adultos e crianças maiores de 8 anos, $300 \mathrm{UI} /$ dia enquanto para idosos a dose seria de $700 \mathrm{UI} / \mathrm{dia}$.

Quanto a condição de gestante, a ANVISA dispões de um padrão de 400 UI/dia, contudo Pereira e Solé (2015) demonstraram em um estudo randomizado uma suplementação de 4000 UI/dia durante a gravidez reduz o risco de morbidades combinadas como infecções maternas, parto cesáreo e prematuro.

Bordalo (2011, p. 118) refere-se que a suplementação após a cirurgia bariátrica depende do tipo de cirurgia aplicada, sugerindo que não há uma dosagem que seja apropriada a todos os pacientes, por isso a necessidade do monitoramento por meio de exames periódicos. Ele relata ainda que uma suplementação de 2000 UI/dia no pós-operatório deverá ser utilizada inicialmente, observando cuidados de politerapia, como pacientes que utilizam anticonvulsivantes, glicocorticoides, heparina ou colestiramina, pois apresentam maior risco de doença óssea. Em torno de $50 \%$ ou mais dos pacientes pós-operatório com deficiência de vitamina D suplementam com 400-800 UI/dia de vitamina D (COATES, 2004; NEWBURY, 2003; YBARRA, 2005 apud BORDALO, 2011). Entretanto Torezan (2013) aponta que é necessário em caso de deficiência severa de vitamina D a reposição de 50.000 a 100.000 UI/semana, por 6 a 8 semanas. 
Conforme discutido, pode existir variações individuais de resposta aos diferentes tratamentos, logo, uma reavaliação dos valores plasmáticos após cada ciclo mostra-se ideal, especialmente em deficiências graves. Após esse período de estabilização, uma dose de manutenção deve ser instituída, variando com a faixa etária do paciente e suas condições. Para adultos, as doses de manutenção podem variar de 400-2.000 UI, dependendo da alimentação e exposição solar. Para idosos, recomenda-se de 1.000 a $2.000 \mathrm{UI} / \mathrm{dia}$ ou 7.000 a 14.000 UI/semana. É necessária muita cautela na reposição de vitamina D uma vez que o excesso é prejudicial à saúde, acarretando em desmineralização metaplásica de tecidos moles e intoxicação de vitamina D. Este estudo demonstra que é necessária a assistência e atenção farmacêuticas ao paciente bariátrico, observando sinergismos e antagonismos de ação entre medicamentos administrados concomitantemente, ajustando dosagens e formas ou horários da administração em vistas do uso racional de medicamentos e do cuidado integral do paciente.

\section{CONCLUSÃO}

A obesidade se tornou uma epidemia mundial devido a problemas físicos e emocionais, ingestão inadequada ou captação aumentada da vitamina D pelo tecido adiposo, o que elevou enormemente o número de procedimentos bariátricos realizados nos últimos anos. 0 acompanhamento de dosagens séricas de vitamina D pré e pós-operatória é ponto crucial à manutenção da saúde do paciente.

Indica-se que o cuidado ao paciente envolva o trabalho de equipes multiprofissionais em saúde para a orientação e reposição de vitamina D, por meio do ajuste de uma dieta adequada, recomendação de exposição solar adequada e suplementação vitamínica constante até atingirem-se níveis sanguíneos estáveis. Não existe conduta apropriada a todos os pacientes, pois cada indivíduo possui metabolismos específicos e condições associadas diferenciadas. Entretanto, a presente pesquisa conduz a conclusão de que existem alguns protocolos mais empregados para a suplementação pré e pós-operatória e, que estão de acordo com o protocolo da ANVISA. A suplementação deverá ser selecionada pelos profissionais que integram a equipe cuidadora e deverá ter ajustes de dosagens e administração, conforme a necessidade do paciente, sendo observado o uso de medicamentos concomitantes destinados a condições associadas.

\section{REFERÊNCIAS}

[1] ABESO, Associação Brasileira para o Estudo da Obesidade e da Síndrome Metabólica. Vigilância de fatores de risco e proteção para doenças crônicas para inquérito telefônico. 2014. Disponível em: http://www.abeso.org.br/uploads/downloads/80/553a243c4b9f3.pdf. Acesso em: 11 dez. 2016.

[2] ABREU, Issac Walker de. Tipos de Cirurgia Bariátrica. 2015. Disponível em: < http://drisaacwalker.site.med.br/index.asp?PageName=Tipos-20de-20Cirurgia-20Bari-E1trica>. Acessado em 18 out. 2015.

[3] ARAÚJO, Leila. Deficiência de vitamina D em obesos e cirurgia bariátrica. 2013. Disponível em: http://www.abeso.org.br/pdf/revista 61/artigo_vitaminad.pdf. Acesso em: 15 ago. 2015.

[4] BITTAR, Thalita; MORAES, Aline; BENCHIMOL, Alexander. Avaliação clínica pré e pós-operatórias na cirurgia bariátrica. ltapevi, SP : AC Farmacêutica, 2009.

[5] BORDALO, Lívia A.; MOURÃO, Denise Machado; BRESSAN, Josefina. Deficiências nutricionais após cirurgia bariátrica: Por Que Ocorrem? Acta Med Port 2011; v. 24 n. S4, p. 1021-1028.

[6] BRAGA, Lucas Souza. Uso de protetor solar e deficiência de vitamina D na infância e adolescência: uma revisão sistemática. Monografia, como exigência parcial e obrigatória para conclusão do Curso de Medicina da Faculdade de Medicina da Bahia (FMB), da Universidade Federal da Bahia (UFBA), Salvador, 2014.

[7] BRASIL. Ministério da Saúde. Secretaria de Vigilância em Saúde. Departamento de Vigilância de Doenças e Agravos não Transmissíveis e Promoção da Saúde. Vigitel Brasil 2014: vigilância de fatores de risco e proteção para doenças crônicas por inquérito telefônico. Brasília : Ministério da Saúde, 2015. Disponível em: <http://bvsms.saude.gov.br/bvs/publicacoes/vigitel_brasil_2014.pdf>. Acesso em: 15 ago. 2015.

[8] CASTRO, Luiz Claudio Gonçalves de. O sistema endocrinológico vitamina D. Arq. Bras. Endocrinol. Metab., v..55, n. 8, São Paulo. 2011. Disponível em:< http://www.scielo.br/scielo.php?script=sci_arttext\&pid=S0004$27302011000800010>$. Acesso em: 15 set. 2016.

[9] FANDIÑO, Julia; BENCHIMOL,Alexander K.; COUTINHO, Walmir F.; APPOLINÁRIO, José C.. Cirurgia Bariátrica: aspectos clínico-cirúrgicos e psiquiátricos. Rev. psiquiatr., v. 26, n. 1, p.47-51, 2004.

[10] FREITAS, Aline Matias de; MELADO, Viviane Fernandes. Calciferol, Colecalciferol, calcitriol, alfacalcidol in: FÁRMACOS UTILIZADOS EM NUTRIÇÃO E ANEMIA. ANVISA (Agência Nacional de Vigilância Sanitária). 2000. 
Disponível em: <http://www.anvisa.gov.br/divulga/public/livro_eletronico/Nutricao.html\#_Toc24800723>. Acesso em 30 ago. 2015.

[11] LICHTENSTEIN, Arnaldo; FERREIRA-JÚNIOR, Mario; SALES, Maria Mirtes; AGUIAR, Francisco Bueno de; FONSECA, Luiz Augusto M.; SUMITA, Nairo M.; DUARTE, Alberto J. S. Vitamina D: ações extraósseas e uso racional. Rev. Assoc. Med. Bras., v. 59, n. 5, p.495-506, São Paulo, 2013.

[12] MINER, J. Boné. Fotossíntese de Vitamina D3 pela pele: uma forma sustentável e eficiente de produção. 2007. Disponível em: http://www.dermagenetica.com.br/m17307/destaques/fotossintese_de_vitamina_d3_pela_pele_uma_forma_sustentavel_e_eficiente_de_producao. Acesso em: 05 set. 2015.

[13] MUSTAFA, Sumaia. A cirurgia bariátrica e a perda óssea. Int. J. Nutrology, v. 7, n. 1, p. 22-30. 2014.

[14] PEREIRA, Marilyn U.; SOLÉ, Dirceu. Deficiência de vitamina D na gravidez e o seu impacto sobre o feto, o recém-nascido e na infância. Revista Paulista de Pediatria, v. 33, n. 1, p. 104-113. march 2015.

[15] SBCBM - Sociedade Brasileira de Cirurgia Bariátrica e Metabólica. Evolução das cirurgias bariátricas no Brasil. 2016. Disponível em: http://www.sbcbm.org.br/wordpress/imprensa-2/releases/evolucao-das-cirurgiasbariatricas-no-brasil/. Acesso em: 14 set. 2016.

[16] SEARLEMAN, Eric. Exame de 25-hidroxivitamina D. (Artigo), 2012 . Disponível em: <http://pt.healthline.com/health/exame-de-25-hidroxivitamina-d\#Panoramageral1>. .Acesso em: 06 set. 2015.

[17] SMITH, Collen; MARKS, Allan D.; LIEBERMAN, Michael. Bioquímica Médica básica de Marks. Tradução Ângela de Mattos Dutra...[et al.]. 2. ed.. Porto Alegre: Artmed. 2007.

[18] TOREZAN, Erika F. G. Revisão das principais deficiências de micronutrientes no pós-operatório do Bypass Gástrico em Y de Roux. Int. J. Nutrology, v. 6, n. 1, p. 37-42, jan/abr 2013.

[19] TÔRRES, Renata. Vitamina D: tempo ideal de exposição ao sol depende do tom de pele. 2013. Disponível em: <http://www.ebc.com.br/noticias/saude/2013/11/vitamina-d-tempo-ideal-de-exposicao-ao-sol-depende-do-tomde-pele>. Acesso em: 14 set. 2016. 


\section{Capítulo 15}

Percepções de idosos sobre prevenção de quedas em domicílios

\section{Morgana Cristina Leôncio de Lima}

Elaine Cristina dos Santos Oliveira Holanda

Monica Rita da Silva Simplicio

Elidiane Lira da Silva Pereira

Rebeca Bezerra Bonfim de Oliveira

Ana Priscila Duarte de Aguiar

Laryssa Grazielle Feitosa Lopes

Resumo: Objetivou-se descrever as percepções de idosos sobre a prevenção de quedas em domicílios. Estudo descritivo, exploratório, com abordagem qualitativa, cuja amostra foi constituída por 10 idosas que desenvolviam atividades em pastoral da saúde do estado de Pernambuco, Brasil. Utilizou-se da entrevista para obtenção dos dados, sendo analisados com auxílio do software IRAMUTEQ, por meio da técnica da Classificação Hierárquica Desentende e da nuvem de palavras. Emergiram do estudo duas categorias: Fatores de risco extrínsecos que predispõem às quedas no ambiente domiciliar $\mathrm{e}$ Envelhecimento saudável relacionado à prevenção de quedas em domicílios. 0 estudo revelou a importância de medidas preventivas no âmbito domiciliar, relacionadas aos fatores extrínsecos que causam quedas, reforçando estratégias de promoção e saúde no cuidado integral, no processo de envelhecimento.

Palavras-chave: Idosos; Fatores de Risco; Prevenção de Acidentes; Promoção da Saúde. 


\section{INTRODUÇÃO}

0 processo de envelhecimento populacional no Brasil segue a tendência mundial, estima-se que a população idosa corresponde a, aproximadamente, 23 milhões de indivíduos. 0 fenômeno é acompanhado por mudanças na estrutura demográfica, em que se verifica o alargamento da pirâmide etária no país e o aumento da expectativa de vida para 74 anos. Devido ao envelhecimento acelerado e intenso, mensura-se que, em 2050, a população idosa mundial atingirá dois bilhões de pessoas (PEREIRA et al., 2017; IBGE, 2019; BRASIL, 2017; VIEIRA et al., 2016).

Associado ao processo de envelhecimento, evidencia-se maior incidência de quedas em idosos em domicílios, especialmente relacionadas à inadequação do ambiente (CRUVINEL et al., 2020). Nesta perspectiva, as medidas preventivas contribuem para diminuição dos acidentes domésticos, deste modo, repercute na redução dos custos hospitalares e efeitos desfavoráveis pertinentes à ocorrência de queda (LUZARDO et al., 2018). Assim, readequação e modificação do ambiente são fundamentais para remoção e redução de risco de quedas evitáveis.

As medidas preventivas auxiliam nas práticas e atividades cotidianas de idosos e familiares, a implantação de estratégias preventivas perpassa vários níveis de prevenção, a saber: educação em saúde, promoção do estilo de vida saudável, prática de exercício físico, controle da dor, adequação do ambiente, prevenção de quedas, as quais possibilitam a manutenção da autonomia e do autocuidado do idoso (LUZARDO et al., 2018; XIMENES et al., 2019).

Diante do exposto, verifica-se a importância de medidas preventivas, por meio de adaptações e remoções dos fatores de riscos evitáveis que causam quedas em idosos, uma vez que a incidência destas, ainda, é elevada e responsável por alto número de internamentos e complicações. Assim, objetivou-se descrever as percepções de idosos sobre a prevenção de quedas em domicílios.

\section{METODOLOGIA}

Trata-se de estudo descritivo, exploratório, com abordagem qualitativa, realizado nas arquidioceses de Recife e Olinda, por meio da Pastoral da Saúde do estado de Pernambuco, Brasil. Os critérios de inclusão dos participantes da pesquisa foram: a) Agentes da Pastoral da Saúde; b) Ambos os sexos; c) Idade igual ou maior que 60 anos. Critérios de exclusão: a) Idosos com comprometimento cognitivo; b) Idosos ou cuidadores com dificuldades no uso de recursos como videochamadas; c) Idosos ou cuidadores com dificuldades no manuseio de questionários eletrônicos.

A coleta de dados foi conduzida de agosto de 2020 a setembro de 2020, em dois momentos: no primeiro momento, utilizou-se de questionário sociodemográfico eletrônico, contendo as seguintes variáveis: idade, estado civil e escolaridade, visando à caracterização do perfil dos participantes; e o segundo momento foi guiado por um roteiro de entrevista semiestruturado, que versou sobre fatores de risco extrínsecos que predispõem os idosos às quedas no ambiente domiciliar, considerando cômodos do domićlio, fatores de risco e medidas preventivas.

As entrevistas foram realizadas por videochamada ou ligação telefônica gravadas pelo celular, justificada pelo cenário de pandemia pela COVID-19 para não exposição desse grupo de risco. Tempo médio de duração de 40 minutos, por meio de prévio agendamento com idoso ou cuidador.

A interpretação dos dados qualitativos e subjetivos inerentes da interação humana foi realizada por meio da análise de conteúdo de Bardin, método sob rigor científico que une um conjunto de técnicas de análise das comunicações baseada na inferência. A operacionalização do processo da análise de dados é organizada em três fases: pré-análise, exploração do material e tratamento dos resultados obtidos e interpretação dos dados (BARDIN, 2011).

Quanto à análise dos dados, utilizou-se do software Interface de R pour lês Analyses Multidimensionnelles de Textes et de Questionnaires (IRAMUTEQ). Dentre os variados cenários analíticos ofertados pelo programa, decidiram-se pela utilização da técnica da Classificação Hierárquica Descendente (CHD), a qual está inserida no método de Reinert (CAMARGO; JUSTOS, 2013), e pelos recursos técnicos de análise lexical, como a técnica da nuvem de palavras (SOUZA et al., 2018; CAMARGO; JUSTOS, 2013). As falas dos participantes estão identificadas pela palavra "idoso", seguida pela ordem da entrevista (Exemplo: Idoso 01, ..., Idoso 10).

Respeitaram-se os preceitos éticos da Resolução no 466/2012, do Conselho Nacional de Saúde, do Ministério da Saúde, referente a estudos com seres humanos, sendo a pesquisa aprovada pelo Comitê de 
Ética em Pesquisa, conforme Certificado de Apresentação para Apreciação Ética n. 35434920.2.0000.5192 e parecer n. 4.216.570.

\section{RESULTADOS}

A amostra do estudo foi constituída por 10 idosos que desenvolviam atividades em pastoral da saúde, com idades entre 60 e 92 anos, destes, 50\% eram casados e 30\% concluíram o ensino superior.

A técnica da nuvem de palavras agrupa as palavras e as organiza graficamente em função da frequência, no presente estudo, destacaram-se as palavras: casa (26), queda (14) tapete de tecido (14), banheiro (13), cair (10), barras de segurança (10). Na imagem, apresentam-se as citações dos participantes, conforme a frequência com que apareceram nas entrevistas (Figura 1).

Figura 1 - Nuvem de palavras sobre prevenção de quedas de idosos em domicílios. Recife, Pernambuco, Brasil, 2020.

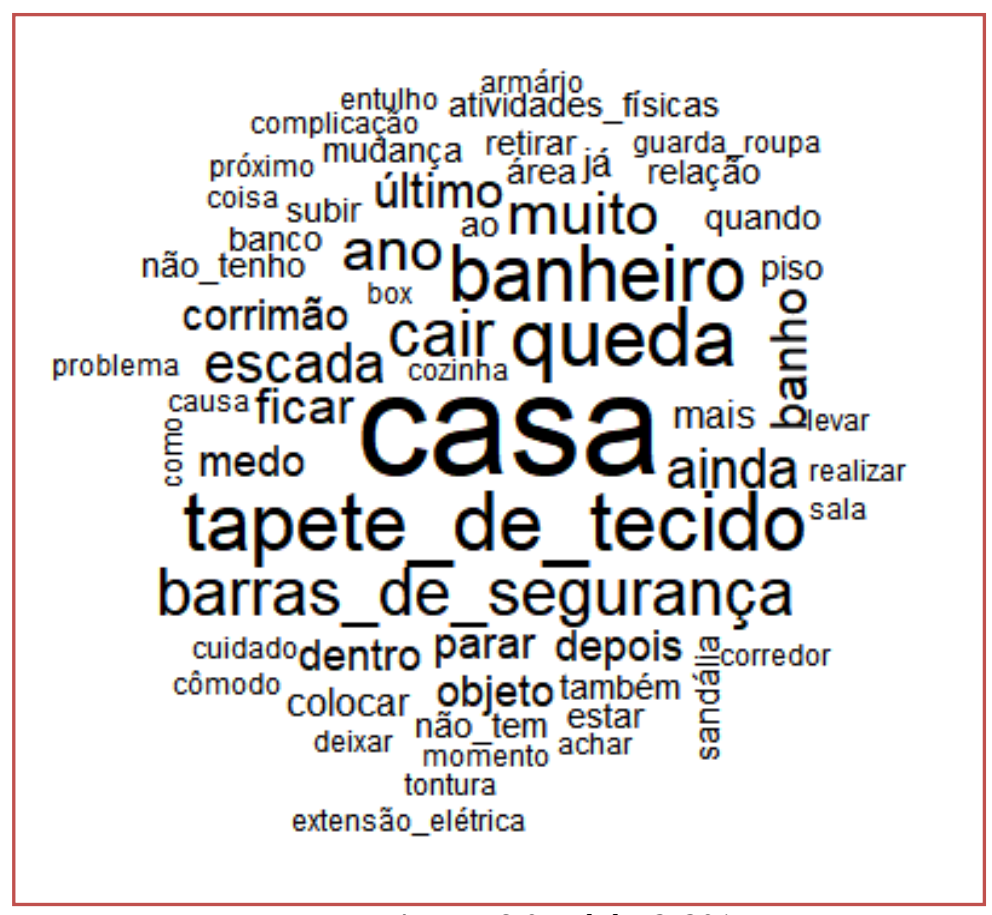

Fonte: IRAMUTEQ 0.7 alpha 2, 2014

A análise dos dados permitiu a identificação das seguintes categorias:

- Fatores de risco extrínsecos que predispõem os idosos às quedas no ambiente domiciliar

- Estratégias utilizadas pelas idosas na prevenção de quedas em domicílios.

FATORES DE RISCO EXTRÍNSECOS QUE PRESDIPÕEM OS IDOSOS ÀS QUEDAS NO AMBIENTE DOMICILIAR

A primeira categoria apresenta os fatores de risco que levaram os idosos a cair no domicílio. 
No último ano, cai dentro de casa, depois da queda, parei de realizar atividades

físicas com medo de cair novamente (Idoso 04).

Assim, o relato apontou a limitação nas atividades diárias relacionadas ao medo de cair, uma vez que a queda pode impactar além do aspecto físico, também com repercussões emocionais.

Tenho tapete de tecido pequeno pela casa, às vezes, os tapetes dobram [...] (Idoso 02).

[...] No banheiro, não tem barras de segurança nem cadeira no Box (Idoso 01).

Desse modo, as falas dos participantes sinalizaram os fatores extrínsecos que podem sofrer adaptação para redução das quedas.

\section{ESTRATÉGIAS UTILIZADAS PELAS IDOSAS NA PREVENÇÃO DE QUEDAS EM DOMICÍLIOS}

A segunda categoria complementou a categoria anterior, posto que a prevenção de quedas, por meio da remoção ou substituição dos riscos evitáveis e modificáveis, constitui medida estratégica fundamental para redução de complicações e melhor qualidade de vida de idosos e dos respectivos familiares no contexto domiciliar.

[...] Fiz algumas mudanças na casa para me prevenir contra outras quedas (Idoso 04).

[...] Tentarei remover os tapetes de tecido para prevenir futuras quedas (Idoso 02).

Realizei várias adaptações, no intuito de me proteger das complicações que são causadas pelas quedas (Idoso 05).

Minha nora e meus filhos são muito cuidadosos comigo, ficam pegando no meu pé para retirar meus tapetes de tecido (Idoso 07).

No último ano, tive uma fratura ocasionada por uma queda dentro de casa, após isso, eu e minha família começamos a fazer mudanças preventivas na casa (Idoso 06).

De forma geral, as falas das participantes apresentaram referências inerentes aos fatores de riscos nos domicílios dos idosos, além de reflexão acerca das medidas de prevenção voltadas para redução de quedas e do cuidado à saúde do idoso.

\section{DISCUSSÃO}

As particularidades inerentes ao processo de envelhecimento e as complicações relacionadas aos fatores extrínsecos no ambiente trazem consigo preocupação com a saúde da pessoa idosa. Neste sentido, identificaram-se os riscos evitáveis que potencializam quedas de idosos em domicílios, o que evidencia a importância de medidas preventivas para adaptações que auxiliem nas atividades da vida diária e redução do medo em cair. Assim, percebe-se que a prevenção e promoção em saúde são pilares que elevam a qualidade de vida de idosos e familiares.

Ao longo do processo de cuidado, é relevante desenvolver estratégias que proporcionem conhecimento e instrução aos idosos sobre os fatores de risco para queda. Assim, amplia-se a adoção de medidas de prevenção, por meio da participação ativa do idoso (CHEHUEN et al., 2017). Estudo realizado acerca da percepção de idosos institucionalizados sobre o autocuidado na prevenção de traumas ocasionados por quedas identificou que os idosos adquirem hábitos de segurança por meio de medidas protetoras (MATIAS et al., 2019).

Nessa perspectiva, o aumento da percepção sobre os acidentes é capaz de reduzir a exposição do risco e os fatores desencadeadores, visto que o conhecimento acerca da temática prepara o indivíduo a vivenciar o processo de envelhecimento, identificar as vulnerabilidades no percurso para receber o suporte de qualidade (CHEHUEN et al., 2018). Enfatiza-se, assim, a relevância da educação em saúde na reprodução do conhecimento na comunidade, nos círculos de convivência social e no reconhecimento dos riscos, além do apoio enquanto medida de promoção (GARCIA et al., 2020). 
Observou-se que os idosos que captaram os conhecimentos discutidos na atividade educativa, apropriamse das informações, somadas aos conhecimentos prévios que possuíam sobre a temática (PINHEIRO et al., 2020). Nessa linha, a promoção em saúde proporcionada por meio da educação em saúde tem repercussão positiva na qualidade de vida, pois associa o conhecimento obtido à realidade e vivência de cada indivíduo.

Nesse ínterim, identificou-se a melhoria da consciência em relação às conexões sociais, como outro resultado prático da prevenção de quedas em ambiente residencial, em que se oportuniza fazer contatos, compartilhar ideias e participar de fórum de discussão (FRANCIS-COAD et al., 2018).

Em relação à atuação dos profissionais de saúde, destaca-se o desenvolvimento de ações integrais na prevenção de quedas que é de suma importância na diminuição das consequências negativas deste evento sobre a saúde dessa população (GUERRA et al., 2016).

O envolvimento dos profissionais é fundamental para prevenção da queda e, no atendimento pós-quedas, as orientações sobre medidas protetoras impactam positivamente na qualidade de vida de idosos (OLIVEIRA; MARINHO, 2018).

Diante o exposto, aponta-se que a estruturação de programas de prevenção com orientações quanto aos riscos necessita de equipe multiprofissional e olhar interdisciplinar para qualificar e tornar as ações mais resolutivas. Deste modo, as medidas de prevenção devem ser conduzidas de maneira planejada e articulada com políticas públicas intersetoriais (SILVA; NIEROTKA; FERRETTI, 2019; TRALDI et al., 2016).

A alta prevalência de quedas em idosos evidencia que providências precisam ser tomadas para prevenilas, especialmente nos grupos vulneráveis, como idosos com idade mais avançada, baixo nível socioeconômicos e dependentes em relação à capacidade funcional (VIEIRA et al., 2018). Faz-se necessário filtrar os idosos com risco de queda, com propósito de contribuir na diminuição dos danos relacionados ao evento. Ressalta-se a importância da adoção de medidas de prevenção efetivas pelos idosos que ainda não caíram e vigilância aos que a sofreram (ROSA; CAPPELLARI; URBANETTO, 2019).

Ao considerar que o idoso passa a maior parte do tempo em casa, é relevante a conscientização de que simples rearranjo na disposição de móveis, fixação do tapete no chão, percepção de perigo em banheiros com pisos lisos são medidas preventivas na redução de acidentes (TAVARES, 2016; MOURA et al., 2017). Nesse cenário, questões relacionadas à dificuldade na locomoção causam limitação nas atividades da vida diária, no convívio social, bem como evidencia o medo em cair dentro do ambiente domiciliar (SANTOS et al., 2018).

Portanto, são imprescindíveis ações interdisciplinares, para que ocorram intervenções individuais ou coletivas, as quais pesem os aspectos físicos e psicológicos. Nesse último contexto, o medo de cair pode limitar o idoso a realizar as atividades do cotidiano (SOUZA et al., 2019). Dessa maneira, o medo de sofrer novos episódios de queda causa sentimento de insegurança e fragilidade, até mesmo de evitar frequentar o mesmo local da queda (TEIXEIRA et al., 2019).

Os achados permitiram verificar que as práticas preventivas no enfrentamento de quedas são adotadas ao longo do processo de envelhecimento, como ter cuidado ao caminhar, evitar subir em bancos ou escadas e buscar conhecimentos relacionados ao cuidado integral, alicerçados na prevenção e promoção em saúde (GASPAR, et al., 2019).

As limitações do estudo se referem ao distanciamento imposto pelo cenário de pandemia pela COVID-19, em que as pesquisadoras interagiram com os idosos por meio de ligação telefônica ou videochamada. Neste sentido, alguns idosos tiveram dificuldade com o manuseio dos meios de comunicação necessários para manter a comunicação entre profissional e participante.

\section{CONCLUSÃO}

Ao considerar os fatores extrínsecos domiciliares como importante causa de quedas, identificaram-se as medidas preventivas como estratégia de segurança na redução de complicações e impactos negativos na saúde de idosos, os quais perpassam pela saúde física e emocional.

Percebeu-se entre os desafios a conscientização da exposição dos riscos que se tornaram atividades de rotina no ambiente familiar. Assim, uma das restrições observadas no estudo esteve relacionada à necessidade de mudanças e adaptações frente a esses fatores de riscos.

Sugere-se que mais estudos sejam realizados, a fim de ampliar os aspectos identificados, bem como fortalecer a educação em saúde como ferramenta importante na prevenção e promoção de saúde, nos âmbitos individual, familiar e coletivo. 


\section{REFERÊNCIAS}

[1] BARDIN, L. Análise de conteúdo. São Paulo: Edições 70, 2011.

[2] CAMARGO, B.V.; JUSTO, A.M. IRAMUTEC: um software gratuito para análise de dados textuais. Temas em psicologia, v.21, n.o 3, p. 513-18, 2013. Disponível em: http://dx.doi.org/10.9788/TP2013.2-16

[3] CHEHUEN NETO, J.A. et al. Fall awareness as a determining factor of this event among elderly community residents. Geriatrics Gerontology and Aging, v.11, n. 1, p. 25-31, 2017. Disponível em: http://www.ggaging.com/details/413/en-US/fall-awareness-as-a-determining-factor-of-this-event-among-elderlycommunity-residents

[4] CHEHUEN NETO, J.A.et al. Percepção sobre queda e exposição de idosos a fatores de risco domiciliares. Ciência e Saúde Coletiva, v.23, n. 4, p. 1097-1104, 2018. Disponível em: DOI: http://dx.doi.org/10.1590/141381232018234.09252016

[5] CRUVINEL, F.G.; DIAS, D.M.R.; GODOY, M.M. Fatores de risco para queda de idosos no domicílio. Brazilian Journal of Health Review, v. 3, n. 1, p. 477-490, 2020. Disponível em: http://doi.org/10.34119/bjhrv3n1-036

[6] FRANCIS-COAD, J.; ETHERTON-BEER, C.; BULSARA, C.; BLACKBURN, N.; CHIVERS, P.; HILL, A.M. Evaluating the impact of a fall's prevention community of practice in a residential aged care setting: a realist approach. BMC Health Services Research, v. 18, n.1, p.21, 2018. Disponível em: https://doi.org/10.1186/s12913-017-2790-2

[7] GARCIA, S.M.; ARISTELA, C.; GRASSI, L.T.; ARAUJO, C.C.; HARTWIG, S.V.; VALADARES, T.A.B. Educação em saúde na prevenção de quedas em idosos. Brazilian Journal of Development, v. 6, n. 7, p.48973-48981, 2020. Disponível em: https://doi.org/10.34117/bjdv6n7-517

[8] GASPAR, A.C.M.; MENDES, P.A.; AZEVEDO, R.C.S.; REINERS, A.A.O.; SEGRI, N.J. Quedas: conhecimentos, atitudes e práticas de idosos. Enfermagem em Foco, v. 10, n. 2, p. 97-103, 2019. Disponível em: http://revista.cofen.gov.br/index.php/enfermagem/article/view/1947

[9] GUERRA, H.S.; SOUSA, R.A.; BERNARDES, D.C.F.; SANTANA, J.A.; BARREIRA, L.M. Prevalência de quedas em idosos na comunidade. Saúde e Pesquisa, v.9, n.3, p. 547-555, 2016.. Disponível em: https://periodicos.unicesumar.edu.br/index.php/saudpesq/article/view/5605.

[10] INSTITUTO BRASILEIRO DE GEOGRAFIA E ESTATÍSTICA IBGE. Estatísticas Sociais em 2018, expectativa de vida era de 76,3 anos. Rio de Janeiro: IBGE, 2019.

[11] LUZARDO, A.R.; PAULA JÚNIOR, N.F.; MEDEIROS, M.; WOLKERS, P.C.B.; SANTOS, S.M.A. Repercussions of hospitalization due to fall of the elderly: health care and prevention. Revista Brasileira de Enfermagem, v.71, suppl.2, p. 763-769, 2018. Disponível em: http://dx.doi.org/10.1590/0034-7167-2017-0069

[12] MATIAS, D.T. et al. Fisioterapia na prevenção de quedas em idosos institucionalizados: a percepção do idoso. Revista Uningá, v.56, S4, p.161-169, 2019. Disponível em: http://34.233.57.254/index.php/uninga/article/view/2832

[13] MINISTÉRIO DA SAÚDE. Secretaria de Atenção à Saúde. Diretrizes para o cuidado da pessoa idosa no SUS: proposta de modelo de atenção integral. Brasília: Ministério da Saúde, 2014 . Disponível em: http://bvsms.saude.gov.br/bvs/publicacoes/diretrizes_cuidado_pessoa_idosa_sus.pdf

[14] MOURA, S.R.B.; PINHEIRO, J.P.; SANTOS, A.M.R.; MESQUITA, G.V.; RIBEIRO, J.L.V. Percepção de idoso sobre o risco de queda. Revista Interdisciplinar, v.10, n.4, p.1-13, 2017. Disponível em: https://dialnet.unirioja.es/servlet/articulo?codigo $=6772043$

[15] OLIVEIRA, S.M.C.; MARINHO, R.C.N. Estudo sobre a prevalência de quedas em idosos. Revista Humanidades e

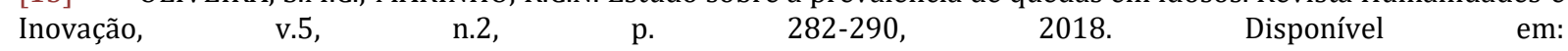
https://revista.unitins.br/index.php/humanidadeseinovacao/article/view/510

[16] PEREIRA, S.G.; SANTOS, C.B.D.; DORING, M.; PORTELLA, M.R. Prevalence of household falls in long-lived adults and association with extrinsic factors. Revista Latino-Americana de Enfermagem, v.25, e2900, 2017. Disponível em: https://doi.org/10.1590/1518-8345.1646.2900

[17] PINHEIRO, R.K.F. et al. Exploratory study using educational activities to prevent home falls for the elderly. Research, Society and Development, v. 9, n.9, e608997718, 2020. Disponível em: https://doi.org/10.33448/rsdv9i9.7718

[18] ROSA, V.P.P.; CAPPELLARI, F.C.B.D.; URBANETTO, J.S. Análise dos fatores de risco para queda em idosos institucionalizados. Revista Brasileira de Geriatria e Gerontologia, v.22, n.1, e180138, 2019. Disponível em: http://dx.doi.org/10.1590/1981-22562019022.180138

[19] SANTOS, J.; MORAIS, C.S.; FONTES, F.L.L.; COELHO, I.S.L. Prevenção de quedas em idosos na estratégia saúde da família: prevenir para não cair. Brazilian Journal of Surgery and Clinical Research - BJSCR, v.23, n.1, p.32-38, 2018. Disponível em: 
https://www.researchgate.net/publication/331558104_Prevencao_de_quedas_em_idosos_na_Estrategia_Saude_da_Fa milia_prevenir_para_nao_cair.

[20] SILVA, M.R.; NIEROTKA, R.P.; FERRETTI, F. Quedas em idosos: uma realidade complexa. Revista FisiSenectus, v.7, n.1, p.1-2, 2019. Disponível em: https://core.ac.uk/download/pdf/270294722.pdf

[21] SOUZA, A.Q.; PEGORARI, M.S.; NASCIMENTO, J.S.; OLIVEIRA, P.B.; TAVARES, D.M.S. Incidência e fatores preditivos de quedas em idosos na comunidade: um estudo longitudinal. Ciência e Saúde Coletiva, v.24, n.9, p.35073516, 2019. Disponível em: https://doi.org/10.1590/1413-81232018249.30512017

[22] SOUZA, M.A.R.; WALL, M.L.; THULER, A.C.M.C.; LOWEN, I.M.V.; PERES, A.M. The use of IRAMUTEQ software for data analysis in qualitative research. Revista da Escola de Enfermagem da USP, v.52, e03353, 2018. Disponível em: https://doi.org/10.1590/s1980-220x2017015003353

[23] TAVARES, Z.D.V. Um novo olhar sobre as quedas em idosos: proposta de diagnóstico ambiental e prevenção. 2016. Dissertação (Mestrado em ??) - Centro de Ciências da Saúde da UFRN, Natal, 2016. Disponível em: https://repositorio.ufrn.br/jspui/handle/123456789/22168

[24] TEIXEIRA, D.K.S.; ANDRADE, L.M.; SANTOS, J.L.P.; CAIRES, E.S. Quedas em pessoas idosas: restrições do ambiente doméstico e perdas funcionais. Revista Brasileira de Geriatria e Gerontologia, v. 22, n. 3, e180229, 2019. Disponível em: http://dx.doi.org/10.1590/1981-22562019022.180229

[25] TRALDI, M.C.; CHIQUETTO, C.P.; PELISSOLI, F.Z.; FONSECA, M.R.C.C. Frequência e fatores associados à queda em idosos no domicílio. Revista Saúde, v. 10, n. 1-2, 2016. Disponível em: http://revistas.ung.br/index.php/saude/article/view/2144/1827

[26] VIEIRA, L.S. et al. Quedas em idosos no Sul do Brasil: prevalência e determinantes. Revista de Saúde Pública, v. 52, n. 22, 2018. Disponível em: https://doi.org/10.11606/S1518-8787.2018052000103

[27] VIEIRA, R. Saúde do idoso e execução da política nacional da pessoa idosa nas ações realizadas na atenção básica à saúde. Revista de Direito Sanitário, v. 17, n. 1, p. 14-37, 2016. Disponível em: https://doi.org/10.11606/issn.2316-9044.v17i1p14-37

[28] XIMENES, M.A.M.; AGUIAR, J.R.; BASTOS, I.B.; SOUSA, L.V.; CAETANO, J.A.; BARROS, L.M. Risco de queda de pacientes hospitalizados: fatores de risco e atuações de enfermagem. Revista Brasileira em Promoção da Saúde, v. 32, p.9003, 2019. Disponível em: https://doi.org/10.5020/18061230.2019.9003 


\section{Capítulo 16}

Prevalência de HIV/AIDS em adultos no município de Tucuruí de 2007 a 2017

\section{Tayanne de Sousa Almeida}

Ariane da Silva Santos

José Claudo de Sousa Monteiro.

Juliana Cristina Schneider

Resumo: A Síndrome da Imunodeficiência Adquirida (AIDS), causada pela infecção do HIV (Vírus da imunodeficiência humana) é uma doença que leva a perda da imunocompetência do organismo, infecção esta que afeta milhões de pessoas, e, as estimativas da Organização Mundial da Saúde (OMS) de 2017 são de 36,9 milhões soropositivos no mundo. No Brasil são registrados 40 mil novos casos de Aids anualmente, sendo o Pará o quarto estado com o maior número de casos notificados, logo o número de casos de HIV/AIDS vem aumentando ao longo dos anos. A presente pesquisa teve como objetivo avaliar a prevalência dos casos de HIV/AIDS em adultos no município de Tucuruí/PA entre o período de 2007 a 2017. Para a realização da mesma, foram analisados dados fornecidos pelo Centro Epidemiológico de Tucuruí/PA, que possibilitou identificar a prevalência em relação a faixa etária, categorias de exposição e distribuição de casos entre homens e mulheres. Os resultados revelaram que em relação a faixa etária, os maiores índices de prevalência se encontram entre as faixas de 20-34 anos, nas categorias de exposição prevalentes são os heterossexuais que predominam. Com relação a distribuição entre homens e mulheres, os homens foram os que apresentaram maior prevalência. A despeito de todas as informações, não houve diminuição no número de notificações de casos de AIDS, mas passou a concentrar-se em segmentos da população, indicando que há uma falha nos esforços de prevenção contra a infecção.

Palavras-chave: Epidemiologia. Prevalência. HIV/AIDS. Tucuruí/PA. 


\section{INTRODUÇÃO}

A Síndrome da Imunodeficiência Adquirida (AIDS) é causada pela infecção do HIV (Vírus da Imunodeficiência Humana), levando à perda gradual da imunocompetência do portador da síndrome. 0 primeiro caso documentado, mas não reconhecido na época, da infecção pelo HIV em humanos, foi reportado em uma amostra de soro em Kinshasa (República Democrática do Congo) que estava armazenada desde 1959 (MURPHY; TRAVERS; WALPORT, 2014).

Em meados de 1981 os primeiros casos da nova síndrome foram reconhecidos devido à aglomeração de casos de Sarcoma de Kaposi e pneumonia pelo Pneumocistis carinii em pacientes homossexuais masculinos, provenientes de cidades norte-americanas (Nova Iorque, Los Angeles e São Francisco) (ABBAS et al. 2015). Na época muitos dos pacientes diagnosticados eram homossexuais, o que fez suspeitar que a doença estivesse relacionada à este estilo de vida (GAPA, 2000).

Tratava-se então de uma doença aparentemente ligada a uma conduta sexual, o homossexualismo e às classes sociais de baixa renda, levando à conclusão que se tratava de uma nova doença não classificada de etiologia possivelmente infecciosa e transmissível (BRASIL, 2002).

A realidade da doença começou a ser interpretada ao longo do tempo e hoje se sabe que a AIDS não é apenas uma doença, mas um fenômeno de grande magnitude, gerando impactos sociais nos princípios éticos, morais e religiosos, este último no que diz respeito ao uso do preservativo, nos órgãos de saúde pública são levantadas questões quanto ao uso de procedimentos adequados e a atenção no atendimento aos diversos grupos que a infecção atinge, entretanto, mesmo com as diversas informações disponíveis sobre a infecção, o estigma e preconceito persistem até atualidade representando assim um dos principais obstáculos para eliminar de vez a AIDS do cenário mundial (GAPA, 2000; GRECO, 2016).

No Brasil, os primeiros casos de AIDS surgiram na década de 1980, com rápida propagação na época. No entanto, apenas entre os anos de 1985 e 1986 a AIDS passou a ser reconhecida como problema de saúde pública, quando foi fundada a primeira organização não governamental com atividade em HIV/AIDS (VILLARINHO et al. 2013).

A Organização Mundial da Saúde (OMS) estima que desde o início da epidemia, em 1981 até 2017, cerca de 35 milhões de pessoas morreram de complicações da AIDS. Vários países têm adotado a prevalência do HIV como importante indicador da importância da vigilância em saúde, no qual associa o resultado do teste de HIV à comportamentos de risco (SZWARCWALD; CASTILHO, 2011).

A epidemia pelo HIV/AIDS no Brasil é um fenômeno de grande dimensão, desde 1980 até 2018, o país identificou 982.129 casos de AIDS, sendo que a região norte de 2006 a 2016 praticamente dobrou sua taxa de detecção de $14,9 \%$ para $24,8 \%$, representando um aumento de $66,4 \%$ nos estados desta região (BRASIL, 2017, 2018).

\section{JUSTIFICATIVA}

O mais recente boletim epidemiológico do Ministério da Saúde aponta que o estado do Pará consta no ranking como a $4^{\circ}$ Unidade Federativa do Brasil com maior número de casos confirmados no período de 2015 a 2019, sendo que Tucuruí ocupa a $32^{\circ}$ posição no ranking dos 100 municípios a nível nacional com maior número de casos notificados no mesmo período, constatando-se um aumento na frequência por ano de diagnóstico, visto que, nos períodos de 2013 a 2017 Tucuruí ocupava $46^{\circ}$ posição a nível nacional (SESPA, 2017; BRASIL, 2018, 2020).

Dado este significativo aumento na frequência de diagnóstico por ano no município de Tucuruí, faz-se necessário uma pesquisa que enfatize a necessidade de constante atualização dos dados epidemiológicos para que ocorra um repasse destas informações a comunidade, a fim de tornar pública a realidade da infecção, além de evidenciar a sensibilização quanto ao número de casos totais por categoria.

Diante do exposto, o município de Tucuruí foi escolhido para a pesquisa por situar-se no interior do estado do Pará, onde se encontram índices elevados de infectados pelo HIV.

\section{OBJETIVOS}

\subsection{GERAL}

Avaliar a prevalência da infecção por HIV/AIDS no município de Tucuruí entre os anos de 2007 a 2017. 


\subsection{ESPECÍFICOS}

I Verificar faixas etárias prevalentes;

II Verificar a distribuição de casos em homens e mulheres;

III Reconhecer categorias de exposição ao HIV e seus respectivos índices de prevalência.

\section{REFERENCIAL TEÓRICO}

\subsection{ESTRUTURA DO HIV}

O HIV é um vírus esférico com cerca de 100-120nm de diâmetro, que apresenta como material genético duas fitas idênticas de RNA e enzimas virais associadas, como a transcriptase reversa, integrase e protease. 0 material genético está acondicionado em um cerne composto pela proteína de capsídeo p24, envolvida por uma proteína de matriz p17, e toda estrutura circundada por um envelope composto por uma bicamada fosfolipídica derivada da membrana da célula do hospedeiro. A bicamada externa contém as glicoproteínas gp120 e gp41 que são codificadas pelo vírus e fundamentais no processo de infecção da célula hospedeira (SAVI et al. 1999; MURPHY et al. 2014; ABBAS et al. 2015).

O genoma de RNA do HIV é de aproximadamente 9,2 kilobases (kb) de comprimento e apresenta um arranjo básico de sequências de ácido nucleico característico de todos os retrovírus conhecidos, com repetições terminais longas (LTR) em cada extremidade do genoma que regulam a expressão dos genes virais, bem como a integração viral no genoma do hospedeiro e a replicação viral (SANTOS et al. 2008; ABBAS et al. 2015).

Figura 1 - Estrutura do HIV

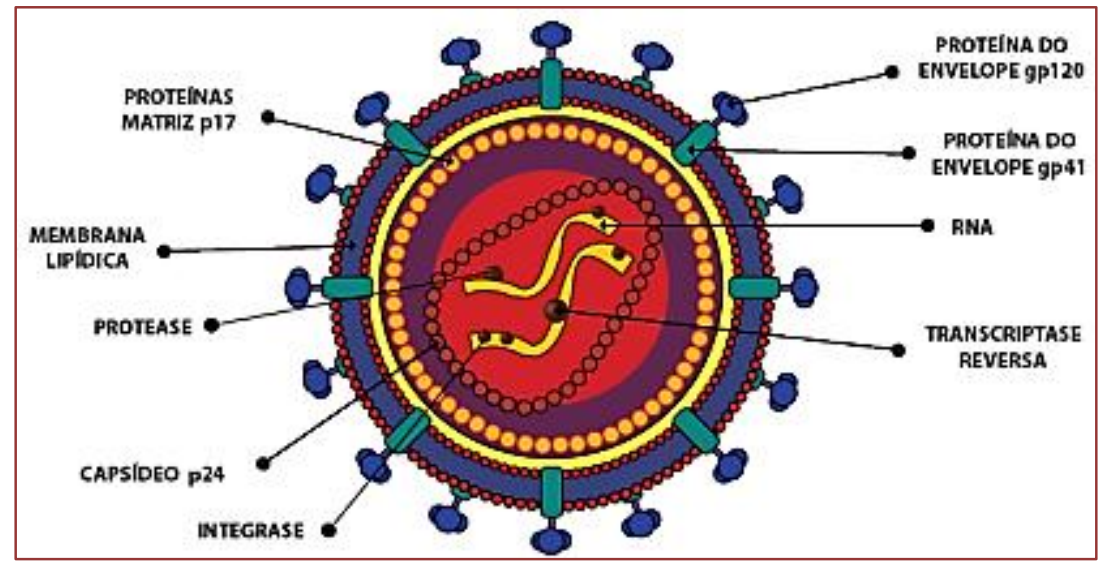

Fonte: BRASIL, 2014.

\subsection{FORMAS DE TRANSMISSÃO}

Segundo Brasil (2002) e Santos et al. (2008) as principais formas de transmissão do HIV são:

- Relações sexuais desprotegidas, sendo esta, a principal forma de exposição em todo o mundo. A presença de outras doenças sexualmente transmissíveis aumenta o risco da infecção pelo HIV;

- Transmissão sanguínea, principalmente quando associada ao uso de drogas injetáveis, devido ao uso compartilhado de seringas e agulhas não esterilizadas. A Transmissão via transfusão de sangue, no que diz respeito ao Brasil, é um tipo de transmissão cada vez menos frequente e irrelevante, pois o país adota medidas de monitoramento e fiscalização rigorosos nos bancos de sangue;

- Transmissão vertical da mãe para o filho, podendo ocorrer durante a gestação, parto ou por aleitamento. Esta transmissão é possível em qualquer fase da gravidez, porém é menos frequente no 
primeiro trimestre, e as infecções ocorridas nesse período não têm sido associadas a malformações fetais;

- Além dessas formas mais frequentes, também pode ocorrer a transmissão ocupacional, ocasionada por acidente de trabalho em profissionais da área da saúde que sofrem ferimentos com instrumentos perfurocortantes ou sofrem exposição de mucosas com sangue de pacientes infectados pelo HIV.

\section{EPIDEMIOLOGIA}

A Aids é considerada pela OMS uma pandemia mundial, e, no Brasil, a disseminação da doença é considerada estável, visto que a epidemia de AIDS apresentou mudanças significativas nos últimos anos. Isto se deve não apenas às terapias antirretrovirais, mas também devido as medidas profiláticas para evitar transmissão vertical, seja na gestação, parto ou amamentação, controle rigoroso em bancos de sangue, informações sobre o HIV e a importância da relação sexual protegida, além da distribuição gratuita de preservativos (BRASIL, 2018).

Apesar dos avanços na prevenção e no controle do vírus HIV a nível nacional, o Pará ainda está entre os estados brasileiros com o maior número de pessoas infectadas, ocupando, segundo último boletim epidemiológico de 2020, o 4o lugar no ranking nacional. Em 2017, o município de Tucuruí chegou a ocupar $20^{\mathrm{a}}$ posição na lista dos 100 municípios com maiores casos notificados, apresentando um total de 5.846 casos entre os anos de 2009 a 2013.

No período de 2012 a 2015 Tucuruí apresentou um total de 5.375 notificações, ocupando a 63a posição no raking dos 100 municípios com maior número de casos notificados. No período de 2015 a 2019 apresentou um total de 5.631 casos, neste houve um aumento de 256 novos casos em relação ao período anterior, passando a ocupar a 32 ${ }^{\text {a }}$ colocação no ranking nacional (BRASIL, 2014, 2015, 2016, 2017, 2018, 2020).

\section{MEDIDAS PREVENTIVAS}

Para a prevenção do HIV, deve-se associar diferentes ferramentas ou métodos, podendo estes ser aplicados ao mesmo tempo ou em sequência conforme a situação, risco e escolhas. 0 preservativo é o método de prevenção mais conhecido, sendo altamente recomendado o seu uso durante as relações sexuais, também é indicado e necessário a utilização de seringas e agulhas descartáveis e o uso de luvas para manipular feridas e líquidos corporais. As mães infectadas pelo vírus devem usar antirretrovirais durante a gestação para prevenir a transmissão vertical, além de contraindicado o aleitamento de seus filhos (FIOCRUZ, 2014).

Em situações que exista risco de contato com o vírus ou ocorra pós exposição ao mesmo, deve-se utilizar medicação antirretroviral, este age impedindo que o HIV se estabeleça no organismo. A profilaxia deve ser iniciada em no máximo 72 horas, sendo mais eficaz se iniciada nas duas primeiras horas após a exposição (UNAIDS, 2017).

\section{ASPECTOS CLÍNICOS}

Os infectados pelo HIV evoluem para uma grave disfunção do sistema imunológico à medida que ocorre uma destruição gradual dos linfócitos TCD4+, uma das principais células-alvo do vírus, esta primeira fase é chamada de infecção aguda, onde ocorre a incubação do HIV. A próxima fase é marcada pela forte interação entre as células de defesa e as constantes e rápidas mutações do vírus, e esse período pode durar muitos anos, e é chamado de assintomático ou fase crônica. Com o frequente ataque, as células de defesa começam a funcionar com menos eficiência até serem destruídas (GABRIEL; BARBOSA; VIANNA, 2005).

A fase sintomática inicial é caracterizada pela alta redução dos linfócitos TCD4+, sendo este um importante marcador da imunodeficiência, pois a contagem de linfócitos TCD4+ é utilizada tanto para estimar o prognóstico e monitorizar a terapia antirretroviral em pacientes, quanto para definição de casos de Aids, com fins epidemiológicos (BRASIL, 2010). Os sintomas mais comuns na fase sintomática são: febre, diarreia, suores noturnos, emagrecimento, aparecimento de gânglios, crescimento do baço e do fígado até alterações elétricas do coração e/ou inflamação das meninges nos casos graves, com isso, atinge-se o estágio mais avançado da doença, a Aids (FIOCRUZ, 2014). 
Outro fator importante a ser abordado é o período entre a infecção e a produção de anticorpos pelo organismo contra o HIV em uma quantidade suficiente para serem detectados pelos testes, como o teste rápido, este período é conhecido como janela imunológica (BRASIL, 2010).

\subsection{TRATAMENTO}

Há várias medicações disponíveis e o tratamento é sempre combinado com pelo menos três drogas, sendo estas tenofovir, lamivudina e efavirenz. Os primeiros antirretrovirais (ARV) surgiram na década de 1980 com o intuito de impedir a propagação do HIV no organismo, esses medicamentos ajudam a evitar a disfunção do sistema imunológico (SANTOS et al. 2013; BRASIL, 2017).

Por isso, o uso regular dos ARV entre os infectados é fundamental, principalmente para aqueles que desejam aumentar o tempo e a qualidade de vida, pois quando utilizados de maneira regular reduzem o número de internações e infecções por doenças oportunistas. 0 Brasil começou a distribuir gratuitamente os ARV desde 1996 a todas as pessoas com HIV (UNAIDS, 2017; BRASIL, 2017).

Quando não há acesso ou adesão ao tratamento, o HIV vai tornando o sistema imunológico incompetente, impedindo que o corpo seja capaz de defender-se em resposta a doenças oportunistas, que ocasionalmente podem levar a pessoa à morte (UNAIDS, 2017).

\section{METODOLOGIA}

\section{1. ÁREA DE ESTUDO}

0 município de Tucuruí (figura 2) localiza-se na porção sudeste do estado do Pará, a aproximadamente $400 \mathrm{~km}$ de distância da capital do estado (Belém) e está situado entre os paralelos: 03 451'58" de latitude Sul e 4940'21 de longitude Oeste de Greenwich. Limita-se ao Norte com o município de Baião, ao Sul com a cidade de Novo Repartimento, ao Leste com a cidade de Breu Branco e ao Oeste com a cidade de Pacajá. O município em questão possui 110.516 habitantes distribuídos em uma área total de $2.086,189 \mathrm{~km}^{2}$, com uma densidade demográfica de 46,56 hab $/ \mathrm{km}^{2}$ (PREFEITURA MUNICIPAL DE TUCURUÍ, 2016; IBGE, 2018).

Figura 2 - Localização do município de Tucuruí

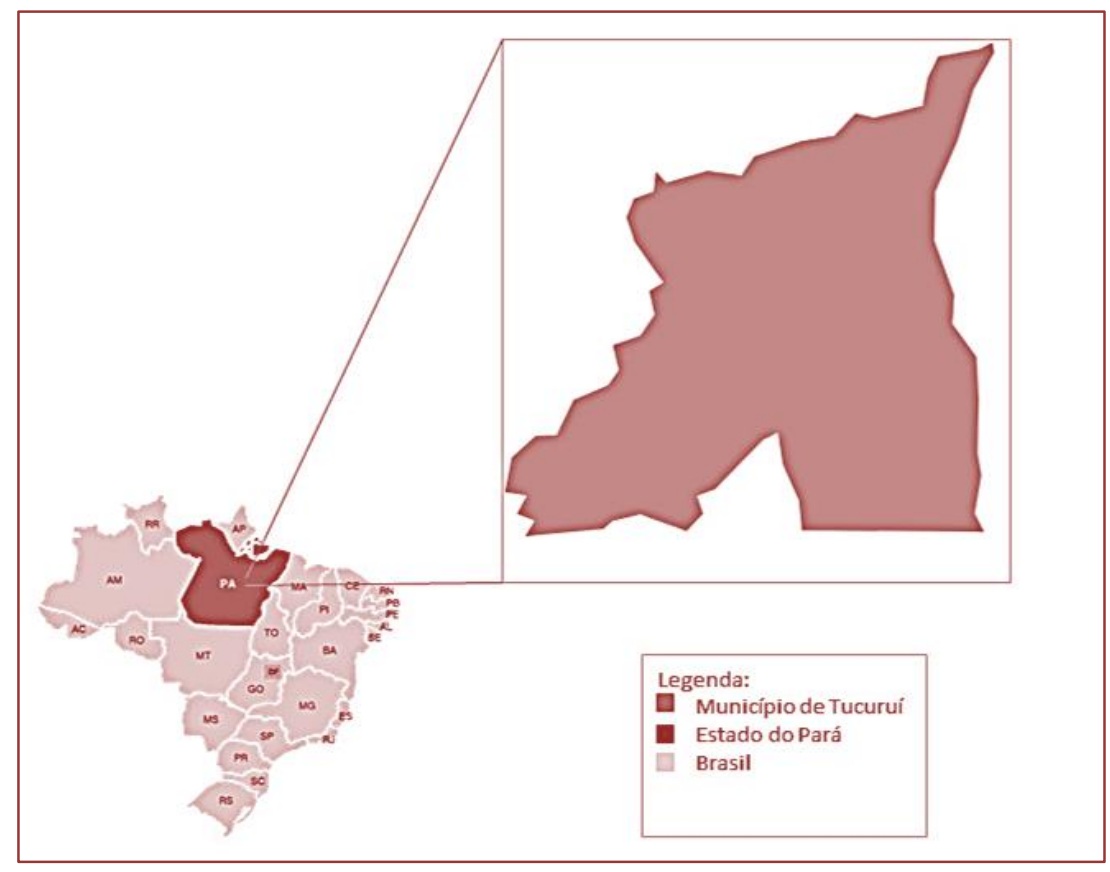




\subsection{COLETA DE DADOS}

Trata-se de uma pesquisa documental e bibliográfica, pois as informações consistem em registros fornecidos por uma organização pública (BARBOSA, 1999; PRAÇA, 2015). As fontes documentais são fundamentais na construção da história, uma vez que possibilitam realizar a análise dos dados e confirmar ou rejeitar hipóteses, de modo a garantir a objetividade da pesquisa (VILLARINHO et al. 2013).

Para realização desta pesquisa, optou-se pela abordagem quantitativa, uma vez que esta permite o emprego da quantificação tanto das modalidades de coleta de informação como o tratamento delas por meio de técnicas estatísticas, sendo que o objeto central deste tipo de abordagem é a objetividade (RICHARDSON, 1989).

Para a construção deste trabalho solicitamos através de ofício institucional número 125/2018 (Anexo 1) dados referentes a infecções por HIV/AIDS ao Núcleo Epidemiológico de Tucuruí. Para tabulação dos dados e posterior construção de tabelas e gráficos utilizamos como auxílio o programa Microsoft Excel versão 2013.

Os dados fornecidos pelo núcleo epidemiológico foram selecionados de acordo com o número de casos notificados por categorias prevalentes, sendo estas: faixas etárias, distribuição de casos em homens e mulheres e categorias de exposição.

Inicialmente pretendeu-se realizar a análise de prevalência do período de 2000 a 2017 da infecção por HIV/AIDS, contudo os dados fornecidos pelo núcleo de epidemiologia constavam apenas do período de 2007 a 2017.

Segundo Richardson (1989), Marconi (2003) e Lakatos (2003) as análises dos dados e gráficos deve-se ser de forma descritiva, este tipo de análise tem como objetivo resumir, sumarizar e explorar o comportamento dos dados, sendo realizado através de tabelas de frequência, buscando estabelecer as relações entre os dados obtidos.

\subsection{ANÁLISE DOS DADOS}

Logo após a disponibilização dos dados pelo núcleo epidemiológico, estes foram tabulados, afim de maior organização das informações, os números também foram ordenados de acordo com a prevalência de infectados, após o mesmo, foram classificados com auxílio de tabelas de frequência, de acordo com suas respectivas categorias, e posteriormente os gráficos foram gerados para melhor visualização dos resultados obtidos. A pesquisa não ofereceu riscos, pois a mesma foi uma análise de dados baseada em números anuais totais de prevalência pelo HIV no município, não envolvendo dados específicos de indivíduos, tampouco a identificação dos mesmos.

\section{RESULTADOS E DISCUSSÕES}

A primeira categoria denominada frequência por ano de notificação segundo faixa etária, revelou que os maiores índices de prevalência de HIV/AIDS se encontram entre as faixas de 20-34 e 35-49 anos. Todavia, observamos também uma significativa prevalência na faixa etária entre 50-64 anos (Tabela 1).

Tabela 1 - Frequência por ano notificação segundo Faixa etária

\begin{tabular}{|c|c|c|c|c|c|c|c|c|c|c|c|c|c|}
$\begin{array}{c}\text { Faixa } \\
\text { etária }\end{array}$ & 2007 & 2008 & 2009 & 2010 & 2011 & 2012 & 2013 & 2014 & 2015 & 2016 & 2017 & Total \\
\hline $15-19$ & 1 & 1 & 2 & 1 & 0 & 2 & 0 & 0 & 2 & 1 & 0 & 10 \\
\hline $20-34$ & 5 & 15 & 8 & 8 & 2 & 8 & 12 & 6 & 3 & 13 & 15 & 95 \\
\hline $35-49$ & 7 & 9 & 10 & 5 & 3 & 3 & 6 & 4 & 3 & 9 & 7 & 66 \\
\hline $50-64$ & 0 & 2 & 2 & 2 & 1 & 1 & 1 & 0 & 3 & 4 & 4 & 20 \\
\hline $65-79$ & 0 & 0 & 1 & 0 & 0 & 0 & 0 & 0 & 0 & 1 & 0 & 2 \\
\hline
\end{tabular}


A prevalência de diagnóstico de 20-34 anos apresentou uma tendência de aumento em praticamente todos os anos, todavia, nos anos de 2011 e 2015 há uma redução no número de casos, as maiores contagens foram registradas nos anos de 2008 e 2017, como mostra o gráfico 1.

Gráfico 1 - Frequência por ano notificação segundo Faixa etária

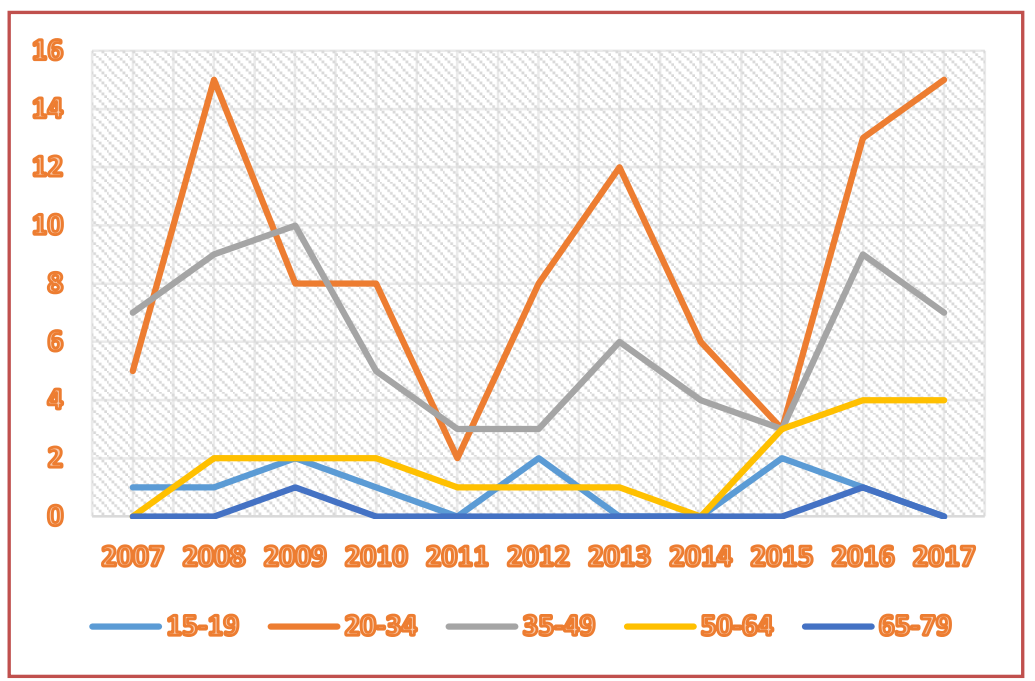

Fonte: Própria autoria, 2019.

Os números elevados de prevalência nas populações de jovens adultos (20-34), pode estar vinculado ao contexto de prevenção das campanhas contra o HIV, pois segundo Melo et al. (2012) e Pereira et al. (2014) a prevenção contra o HIV precisa ser inserida no contexto de vida de cada indivíduo, sempre respeitando a especificidade de cada grupo social, logo, se a campanha não tem alcançado todas as pessoas e grupos, permite assim que a epidemia continue crescendo.

Os dados evidenciados pela meia idade (35-49) revelam-se de modo transcendente, com significativo aumento nos últimos dois anos, apresentando-se de maneira semelhante ao de jovens adultos (20-34). 0 crescente aumento de infectados nesta faixa etária é um dilema que subsiste a nível nacional, e pode estar relacionado a importância do fator sexual, fator este que passou a ser visto como componente vital da qualidade vida desta faixa, dado que segundo Lazzarotto et al. (2010) estes indivíduos estão mais conscientes sobre a importância do sexo nestes anos de vida, em decorrência da desmitificação da sexualidade nas últimas décadas.

É evidente o índice elevado de infectados, em relação aos números totais de casos, nos representantes da meia idade e idosos (50-64), ademais em dois anos, 2016 e 2017, o número de casos notificados dobraram. Nesse contexto o grupo em questão exibe um novo perfil que funciona como um alerta da proliferação da infecção na faixa etária.

Em um estudo epidemiológico executado por Melo et al. (2012), onde foram analisados 30 idosos e 62 adultos, comparando o conhecimento de ambos os grupos sobre percepção da doença e considerando a escolaridade, constatou-se que apesar de idosos não possuírem um conhecimento satisfatório sobre a infecção com relação aos adultos jovens, observou-se atividade sexual maior neste grupo, evidenciando a necessidade de políticas públicas e estratégias que garantam o alcance dos mesmos.

Nos estudos realizados por Araújo et al. (2007) e Santos e Assis (2011) revelam que existem poucas campanhas de prevenção dirigidas a essa população, logo estas pessoas estão menos informadas sobre o HIV e pouco conscientes de como se protegerem, e consequentemente se encontram em condição de vulnerabilidade. Estes fatores corroboram com o que encontramos nesta pesquisa, pois os dados demostram que há uma incidência elevada nesta idade.

Em adolescentes e jovens (15-19), os casos notificados se apresentam de modo estável e controlado, diferentemente do esperado, pois segundo uma publicação do Boletim Epidemiológico de 2018 o número de infecções nesta faixa etária saltou 700\% na última década no Brasil, entre 2007 a 2017. 
Já nas populações de idosos e anciãos (65-79) de modo geral a prevalência apresenta-se constante em praticamente todos os anos, com leve acréscimo em 2009 e 2016, todavia, não está fora do esperado para essa faixa etária. Segundo Alencar et al. (2014), são diversas as razões que interferem a atividade sexual em idosos, tendo como principais fatores as mudanças na fisiologia corporal e a ocorrência de doenças nos representantes desta faixa.

No geral, todas as categorias apresentam em comum um acréscimo significativo nos últimos dois anos, incremento este que pode estar relacionado a falhas nas políticas públicas no município ou até mesmo a falta delas, visto que é de extrema importância a elaboração de programas que alcancem e atendam às necessidades de toda população, pois segundo Fonseca et al. (2007) e Villarinho et al. (2013), a paralização das inciativas de combate à AIDS ou a falta de busca de qualidade da assistência, pode vir a favorecer a reemergência da epidemia na população.

A segunda categoria denominada como categorias de exposição por ano de notificação (Tabela 2), demostra que entre os anos de 2007 a 2017 a categoria que apresentou maior frequência foram os indivíduos que se declararam heterossexuais, sendo que de um total de 193 casos notificados nesse período, 166 pertencem a essa categoria. Observa-se uma diminuição nos casos entre homossexuais ao longo dos anos, as demais categorias mantiveram-se constantes, exceto os casos ignorados que apresentou um aumento entre os anos de 2015 e 2017.

Tabela 2 - Frequência por ano da notificação segundo categoria de exposição

\begin{tabular}{|l|c|c|c|c|c|c|c|c|c|c|c|c|c|}
$\begin{array}{c}\text { Cat. de } \\
\text { exposição }\end{array}$ & 2007 & 2008 & 2009 & 2010 & 2011 & 2012 & 2013 & 2014 & 2015 & 2016 & 2017 & Total \\
\hline Ignorado & 0 & 0 & 0 & 0 & 1 & 0 & 0 & 0 & 0 & 1 & 3 & 5 \\
\hline Homossexual & 2 & 3 & 0 & 4 & 1 & 2 & 0 & 1 & 0 & 0 & 0 & 13 \\
\hline Bissexual & 0 & 1 & 0 & 0 & 0 & 0 & 0 & 0 & 1 & 0 & 0 & 2 \\
\hline Heterossexual & 8 & 22 & 22 & 12 & 4 & 11 & 18 & 9 & 10 & 27 & 23 & 166 \\
\hline $\begin{array}{l}\text { Heterossexual/ } \\
\text { Drogas }\end{array}$ & 3 & 0 & 1 & 0 & 0 & 1 & 0 & 0 & 0 & 0 & 0 & 5 \\
\hline Drogas & 1 & 0 & 0 & 0 & 0 & 0 & 0 & 0 & 0 & 0 & 0 & 1 \\
\hline Perinatal & 0 & 0 & 0 & 0 & 0 & 0 & 1 & 0 & 0 & 0 & 0 & 1 \\
\hline
\end{tabular}

Fonte: Dados do Centro Epidemiológico de Tucuruí (adaptado pelo autor), 2019.

Assim como representado no Gráfico 2, fica notório que a categoria heterossexual é a que apresenta maior frequência de casos entre os anos de 2007 a 2017, com três aumentos significativos nesse período. Observa-se também que entre os anos de 2009 a 2011 houve uma diminuição expressiva no número de casos notificados, entretanto, no período de 2015 a 2016 ocorreu um relevante aumento, sendo o ano de 2016 com maior número de casos heterossexuais notificados no período de 2007 a 2017.

Segundo Maia et al. (2008) em seu estudo realizado no Distrito Federal, e Moura e Faria (2017) em seu estudo no município de Passos/MG esse aumento no número de casos heterossexuais pode ter ocorrido devido ao uso restrito de preservativo, principalmente entre parceiros fixos, visto que, o uso do mesmo está historicamente ligado a relações extraconjugais e prostituição, situação que faz com que os casais restrinjam o seu uso acreditando que estão protegidos contra o HIV, uma vez que mantém relações sexuais apenas com um parceiro. Outros fatores que levam ao abandono do uso do preservativo são a utilização de outros métodos contraceptivos, o fato do parceiro não gostar do seu uso e realização de exames anti-HIV, tornando-os vulneráveis à infecção pelo vírus.

Os casos entre homossexuais atingiram seu maior índice de prevalência no ano de 2010 como representado no Gráfico 2, a partir deste ano os números de casos notificados diminuíram significativamente.

Gruner e Silva (2005) no seu estudo em Florianópolis/SC e Terto Jr (2002) sugerem que essa diminuição entre homossexuais esteja ligada ao fato de que no início da epidemia essa categoria era a mais afetada, assim, a homossexualidade passou a ser sinônimo de HIV/AIDS aumentando o preconceito contra os mesmos. Desta forma, a própria categoria passou a se mobilizar para enfrentar os desafios da doença, que teve como resposta a criação de várias organizações não-governamentais de serviços em AIDS 
(ONGs/AIDS), produção de manuais sobre as formas de transmissão, sexo seguro, promoção dos direitos humanos e solidariedade como princípios básicos do trabalho de prevenção.

Apesar da contribuição dessas respostas para a diminuição dos casos notificados entre os homoss exuais, a associação entre AIDS e homossexualidade ainda é muito debatida, e sendo uma categoria de alta vulnerabilidade devem sempre haver esforços voltados para a prevenção da transmissão entre os homossexuais.

Gráfico 2 - Frequência por ano de notificação segundo categoria de exposição

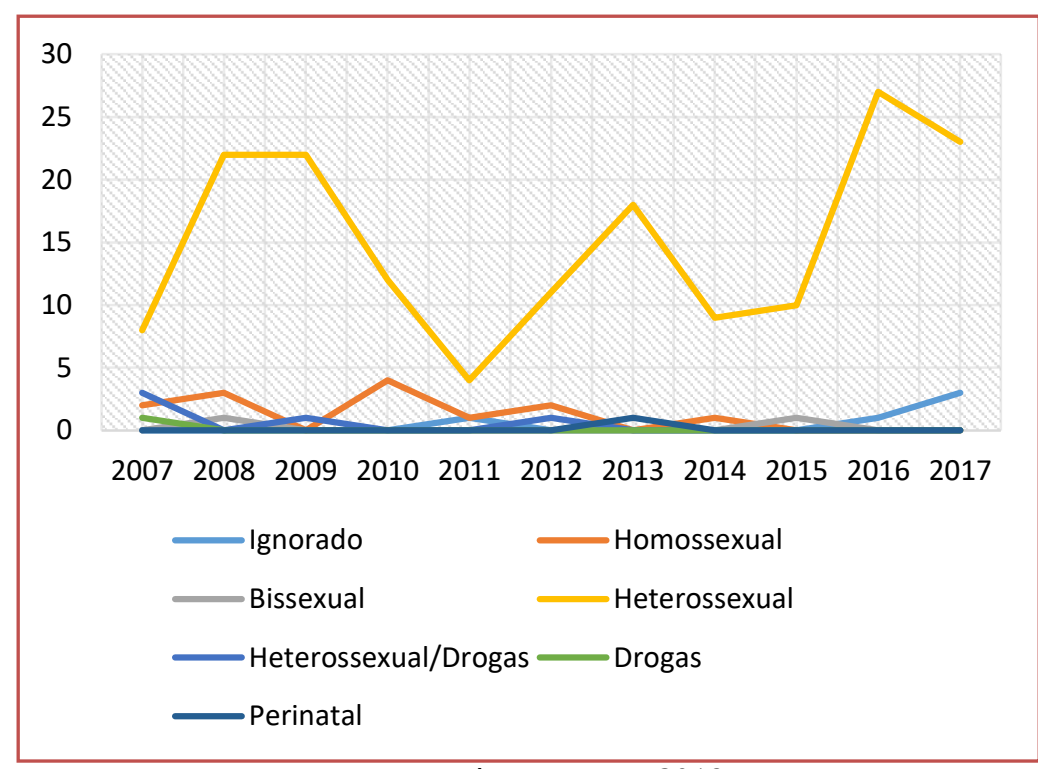

Fonte: Própria autoria, 2019

Os casos onde a categoria de exposição foi registrada como ignorada mostrou-se um aumento entre os anos de 2015 e 2017, segundo Pereira et al. (2018) em seu estudo epidemiológico de HIV e AIDS no Rio Grande do Sul onde os dados obtidos também mostraram um aumento nessa categoria, passando de 10,1\% para 35,5\%, dificultando a caracterização do perfil de exposição.

A diminuição entre os casos notificados na categoria de exposição drogas segundo Gruner e Silva (2005) se deve a programas voltados para a troca de agulhas e seringas contaminadas seguidas de orientação à população de usuários de drogas injetáveis.

Os dados disponibilizados pelo núcleo em relação a distribuição dos casos em homens e mulheres, não foram padronizados por ano notificação, os mesmos foram distribuídos por faixa etária, representando o número total de homens e mulheres adultos infectados no período de 2007 a 2017, conforme representado na Tabela 3.

Tabela 3 - Frequência do número de casos entre homens e mulheres

\begin{tabular}{|c|c|c|c|}
\hline Faixa etária & Masculino & Feminino & Total \\
\hline $15-19$ & 2 & 8 & 10 \\
\hline $20-34$ & 56 & 39 & 95 \\
\hline $35-49$ & 38 & 28 & 66 \\
\hline $50-64$ & 12 & 8 & 20 \\
\hline $65-79$ & 2 & 0 & 2 \\
\hline
\end{tabular}


Os dados revelam que a categoria que exibe maior prevalência é do sexo masculino, apontando dominância em praticamente todas as faixas etárias, especialmente entre as faixas de 20-34 anos. 0 exposto não é um problema restrito da cidade de Tucuruí, pois dados do último boletim epidemiológico de 2018 do HIV/AIDS mostram que 73\% (30.659) dos casos ocorreram em homens.

É nítido que há uma forte tendência ao aumento de casos em homens, especialmente na faixa etária de 20 34 anos, como mostrado no Gráfico 3.

Gráfico 3 - Frequência do número de casos entre homens e mulheres

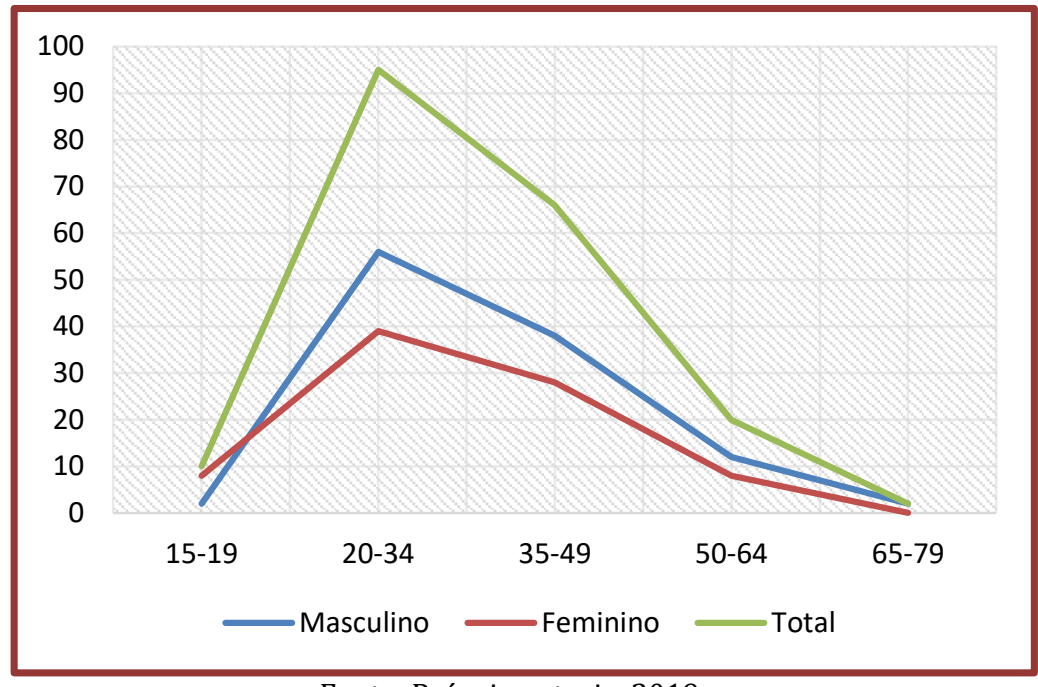

Fonte: Próprio autoria, 2019.

A elevada prevalência no número de casos de AIDS em homens pode está diretamente relacionado à uma questão cultural associada a aspectos da masculinidade, visto que em um estudo qualitativo de Guerriero; Ayres; Hearst (2002), revelou diversos fatores sociais que colocam os homens em condição de vulnerabilidade. Constatou-se no estudo que a infidelidade masculina é considerada como algo natural e o uso de preservativo durante o ato sexual é visto como um recurso apenas de prevenção contra gravides indesejada, quando solicitada pela mulher. Os entrevistados também não se consideravam vulneráveis ao HIV.

De acordo com o gráfico 3 o sexo feminino apresenta queda em praticamente todas as faixas etárias com relação ao sexo masculino, prevalente em somente uma das categorias, sendo esta de jovens de 15-19 anos, predomínio esse ligado a diversas razões associadas às questões anatômicas, fisiológicas e normas culturais.

Estudos de Sanches (1999) e Ferrian et al. (2007) demostraram que adolescentes mulheres estão mais vulneráveis devido as alterações inflamatórias do colo uterino, comum nesta fase da vida, ocasionado pela imaturidade dos órgãos genitais, estas inflamações facilitam a penetração do HIV e associada ao fato dessas adolescentes não ligarem o sexo seguro ao uso de preservativo, mais ao parceiro único e "escolhido", colocam esta faixa em iminente situação de risco, no qual é justificado pelas mesmas pela confiança no parceiro.

Novaes (2006) em seu estudo sobre a Importância da colpocitologia na adolescência afirma que tais inflamações também ocorrem devido á certas infecções, como as vulvovaginites e cervicites, geralmente ocasionadas pelo início precoce da vida sexual, pois qualquer mulher que começa a sua atividade sexual antes dos 20 anos de idade apresenta risco de apresentar neoplasia intra-epitelial, que é uma condição em que algumas células se parecem anormais, as mesmas podem ser causadas pelo HPV, considerados porta de entrada para o vírus da imunodeficiência humana.

Segundo Antunes et al. (2002), contribuem também para o aumento de casos de AIDS em jovens adolescentes mulheres a rejeição do parceiro ao uso do preservativo, onde o contexto cultural contribui de modo significativo na manutenção do hábito, visto que tradicionalmente existe uma submissão das mulheres às regras estabelecidas pelo homem, colocando estas em condições de vulnerabilidade. 
Logo observa-se que ambas categorias, tanto de homens quanto de mulheres, a prevalência dos casos de HIV/AIDS está associada a questões culturais, questões estas que continuam resistindo ao tempo e perduram até os dias atuais, contribuindo assim na incidência da infecção na população.

\section{CONSIDERAÇÕES FINAIS}

A população de 20 a 34 anos representa em Tucuruí a faixa etária mais atingida pela infecção.

A categoria de exposição com maior número de notificação é a heterossexual, evidenciando a vulnerabilidade da exposição da infecção em mulheres, visto que a categoria de investigação de AIDS em adultos revela também que o sexo masculino exibe maior prevalência no número dos casos notificados.

Em suma, os resultados obtidos na cidade indicaram que os homens estão desproporcionalmente sujeitos ao maior risco de novas infecções, e revelam que estratégias para controle da disseminação da epidemia nesse grupo populacional são essenciais e urgentes.

A respeito de todas as informações, não houve diminuição no número de notificações da AIDS, mas passou a concentrar-se em segmentos da população, tendo como mais vulneráveis à epidemia as categorias de jovens adultos, meia idade, idosos e os heterossexuais, indicando uma urgente necessidade de uma avaliação da situação do HIV/AIDS no município.

O aumento do número de casos nos últimos dois anos 2016-2017, na maioria das categorias é um forte indicador da ineficiência das políticas públicas para prevenção e atenção ao HIV/AIDS em Tucuruí, pois sem soluções ou melhoras no atendimento para se introduzir o uso de preservativos no cenário sexual não haverá melhoras nas situações de maior vulnerabilidade.

\section{REFERÊNCIAS}

[1] ABBAS, et al. Imunologia: Celular e Molecular. 8. ed. São Francisco: Elsevier. 2015. Disponível em: <https://drive.google.com/file/d/0Bxl59ePGU40sNUlxSkpNc0NmbFU/view> Acesso em: 18 jul. 2018.

[2] ALENCAR, et al., M; M, L; J,C,M. Fatores que interferem na sexualidade de idosos: uma revisão integrativa. São Paulo. Rev Saúde Pública. v.19, n.08, p.3533-3542. 2014. Disponível em: <http://www.scielo.br/pdf/csc/v19n8/14138123-csc-19-08-03533.pdf>Acesso em: 7 fev. 2019.

[3] ANTUNES et al., M; C, A, P; V, P; R, S; N, H. Diferenças na prevenção da Aids entre homens e mulheres jovens de escolas públicas em São Paulo, SP. São Paulo. Rev Saúde Pública. v. 36, n. 4, p.88-95, 2002. Disponível em: <http://www.scielo.br/pdf/rsp/v36n4s0/11168.pdf> Acesso em: 5 abr. 2019.

[4] ARAÚJO, V. L. B et al., Características da Aids na terceira idade em um hospital de referência do Estado do Ceará. Brasil. Rev Bras Epidemiol. v. 10, n. 4, p.544-554, 2007. Disponível em:<http://www.scielo.br/pdf/rsp/v36n4s0/11168.pdf>Acesso em: 7 fev. 2019.

[5] BRASIL. Ministério da Saúde. Programa Nacional de DST-AIDS. 1999. (Texto digitado). Disponível em: <http://bvsms.saude.gov.br/bvs/publicacoes/cd03_17.pdf>. Acesso em: 20 jul. 2018.

[6] BARBOSA, E. Curso de Especialização em Metodologias. Desenvolvimento e Avaliação de Projetos Educacionais. SEE-MG/CEFETMG/1999. Disponível em: <https://www.google.com/url?sa=t\&source=web\&rct=j\&url=http://www2.unifap.br/midias/files/2012/03/coleta_d ados.pdf\&ved=2ahUKEwijvoHl4fHjAhW5GrkGHRu8CYQQFjACegQIBRAB\&usg=AOvVaw0fHmyF3X2NTh3Lan0KPPS\&cshid=1565215862293 >. Acesso em: 30 mar. 2019.

[7] BRASIL. Ministério da Saúde. AIDS: etiologia, clínica, diagnóstico e tratamento. Brasília: 2002, Unidade de assistência. Disponível em: <http://bvsms.saude.gov.br/bvs/publicacoes/Aids_etiologia_clinica_diagnostico_tra tamento.pdf>. Acesso em: 20 jul. 2018.

[8] BRASIL. Ministério da Saúde: Doenças Infecciosas e Parasitárias. 8ª̣ ed. DF: Revista: BRASÍLIA. 2010. Disponível em:<http://bvsms.saude.gov.br/bvs/publicacoes/doencas_infecciosas_parasitaria_gui a_bolso.pdf $>$. Acesso em: 23 jul. 2018.

[9] BRASIL; Ministério da Saúde: Protocolo clínico e diretrizes terapêuticas para manejo da infecção pelo hiv em crianças e adolescentes. Brasília, 2014. Disponível em: < http://www.aids.gov.br/pt-br/pub/2017/protocolo-clinicoe-diretrizes-terapeuticas-para-manejo-da-infeccao-pelo-hiv-em-criancas-e> Acesso em: 11 jul. 2018.

[10] BRASIL. Ministério da Saúde: Boletim epidemiológico, 2014. (Texto digitado). Disponível em: <http://www.aids.gov.br/pt-br/node/73 > Acesso em: 18 mar.2018. 
[11] BRASIL. Ministério da Saúde. Diagnóstico do HIV, 2014. (Manual online) Disponível em: <https://telelab.aids.gov.br/moodle/pluginfile.php/22163/mod_resource/content/2/HIV\%20\%20Manual\%20Aula\%201_SEM.pdf> Acesso em: 18 mar. 2018.

[12] BRASIL. Ministério da Saúde: Boletim epidemiológico, 2015. (Texto digitado). Disponível em: <http://www.aids.gov.br/pt-br/pub/2015/boletim-epidemiologico- hivaids-2015 > Acesso em: 18 mar. 2018.

[13] BRASIL. Ministério da Saúde: Boletim epidemiológico, 2016. (Texto digitado). Disponível em: <http://www.aids.gov.br/pt-br/pub/2016/boletim-epidemiologico- de-aids-2016> Acesso em: 18 mar. 2018.

[14] BRASIL. Ministério da Saúde: Departamento de Vigilância, Prevenção e Controle das IST, do HIV/Aids e das Hepatites Virais. 2017 (Texto digitado). Disponível em:<http://www.aids.gov.br/pt-br/publico-geral/o-que-ehiv/tratamento- para-o-hiv> Acesso em: 23 jul. 2018.

[15] BRASIL. Ministério da Saúde: Boletim epidemiológico, 2017. (Texto digitado). Disponível em: <portalms.saude.gov.br/images/pdf/janeiro/05/2016_034- Aids_publicacao.pdf> Acesso em: 16 jul. 2018.

[16] BRASIL. Ministério da Saúde: Boletim epidemiológico, 2018. (Texto digitado). Disponível em: <http://www.aids.gov.br/pt-br/pub/2018/boletim-epidemiologico- hivaids-2018> Acesso em: 16 mar. 2019

[17] BRASIL. Ministério da Saúde: Boletim epidemiológico, 2020. (Texto digitado). Disponível em: <http://www.aids.gov.br/pt-br/pub/2020/boletim-epidemiologico- hivaids-2020> Acesso em: 1 mar. 2021

[18] FARIA, N.R. et al., The early spread and epidemic ignition of HIV-1 in human populations. Rev. Science v. 346, n. 6205, p.56-61. 2014. Disponível em: <https://science.sciencemag.org/content/346/6205/56> Acesso em: 1 mar. 2019.

[19] FERRIAN, Andréa Marta, Simões, Fernanda Cristina, Caruso, Paula Catarina, Cappi Maia, Edna Marina. Vulvovaginites em crianças e adolescentes: uma revisão qualitativa. Perspectivas Médicas [online] 2007. Disponível em: <https://www.redalyc.org/pdf/2432/243217495009.pdf>. Acesso em: 21 mar. 2019.

[20] FIOCRUZ. Instituto de Tecnologia em Imunobiológicos. HIV: sintomas, transmissão e prevenção. 2014 . Disponível em:<https://www.bio.fiocruz.br/index.php/sintomas-transmissao-e-prevencao-hiv- dpp>. Acesso em: 21 jul. 2018

[21] FONSECA, E et al. Descentralização, AIDS e redução de danos: a implementação de políticas públicas no Rio de Janeiro, Brasil. Rio de janeiro: Saúde pública. v. 23, n. 9, p.2134-2144, 2007. Disponível em: <http://www.scielo.br/pdf/csp/v23n9/14.pdf> Acesso em: 14 fev. 2019.

[22] GABRIEL, R.; BARBOSA, D. A.; VIANNA L. A. C. Perfil epidemiológico dos clientes com HIV/Aids da unidade ambulatorial de hospital escola de grande porte - município de São Paulo. Rev Latino-am Enfermagem. v. 13, n. 4, p. 509-513, 2005. Disponível em: <http://www.scielo.br/pdf/rlae/v13n4/v13n4a08.pdf> Acesso em: 29 mar. 2019.

[23] GAPA. GAPAS: Uma Resposta Comunitária à Epidemia da AIDS no Brasil. 2000. Disponível em: <http://bvsms.saude.gov.br/bvs/publicacoes/179_2Gapas.pdf> Acesso em: 16 jul. 2018.

[24] RECO, Dirceu Bartolomeu. Trinta anos de enfrentamento à epidemia da Aids no Brasil, 1985-2015. Ciênc. saúde coletiva. v. 21, n.5, p. 1553-1564. 2016. Disponível em: <http://www.scielo.br/pdf/csc/v21n5/1413-8123-csc21-05-1553.pdf> Acesso em: 18 jul. 2018.

[25] GUERRIERO, I; AYRES, J.R.; HEARST, N. Masculinidade e vulnerabilidade ao HIV de homens heterossexuais, São Paulo, SP. São Paulo. Rev Saúde Pública. v. 36, n. 4, p. 50-60. 2002 . Disponível em: <http://www.scielo.br/pdf/rsp/v36n4s0/11163.pdf> Acesso em: 28 mar. 2019

[26] GRUNER, M. F; SILVA, R. M. da. Perfil epidemiológico de pacientes com HIV/AIDS em um hospital de referência: análise comparativa entre os anos de 1997 e 2001. Arquivos Catarinenses de Medicina. v. 34, no. 3, p. 63 67, 2005.Disponível em: <http://www.acm.org.br/revista/pdf/artigos/294.pdf> Acesso em: 1 jul. 2018.

[27] GUILOSKI, I. C. Estudo da prevalência da infecção pelo HIV no estado do Paraná. 2004. 39 f. Monografia (Bacharel em Ciências Biológicas). Curitiba, $2004 . \quad$ Disponível em: <https://www.acervodigital.ufpr.br/bitstream/handle/1884/33187/Monografia\% 20Izonete\%20Cristina\%20Guiloski.pdf?sequence=1> Acesso em: 20 fev. 2018.

[28] IBGE. Instituto Brasileiro de Geografia e Estatística. Cidades, 2018. Disponível em: <http://cidades.ibge.gov.br/xtras/perfil. php?codmun=150178>. Acesso: 27 jan. 2019.

[29] LAZZAROTTO, A et al. HIV/aids e meia idade: avaliação do conhecimento de indivíduos da região do Vale do Sinos (RS), Brasil. Ciência \& Saúde Coletiva. v. 15, n. 1, p. 1185-1190. 2010. Disponível em: <http://www.scielo.br/pdf/csc/v15s1/027.pdf> Acesso em: 30 de março de 2019.

[30] MAIA, C et al. Vulnerabilidade ao HIV/Aids de pessoas heterossexuais casadas ou em união estável. Rev Saúde Pública. v. 42, n. 2, p. 242-248. 2008. Disponível em: <http://www.scielo.br/pdf/rsp/v42n2/6357.pdf> Acesso em: 28 mar. 2019. 
[31] MARCONI, Marina de Andrade; LAKATOS, Eva Maria. Fundamentos de metodologia científica. 5. ed. São Paulo: Atlas, 2003. Disponível em:< https://docente.ifrn.edu.br/olivianeta/disciplinas/copy_of_historia -i/historiaii/china- e- inia> Acesso em: 30 mar. 2019.

[32] MELO, H. M. de A et al. O conhecimento sobre Aids de homens idosos e adultos jovens: um estudo sobre a percepção desta doença. Ciência \& Saúde Coletiva. v. 17, n. 1, p. 43-53, 2012. Disponível em: <http://www.scielo.br/pdf/csc/v17n1/a07v17n1.pdf> Acesso em: 17 abr. 2019.

[33] MOURA, J. P. de; FARIA, M. R. de. Caracterização e perfil epidemiológico das pessoas que vivem com HIV/Aids. Rev enfermagem UFPE online. Recife, v. 11, n.12, p. 5214-20, dez. 2017. Disponível em: <file://C:/Users/estagiario/Downloads/22815-76759-1-PB.pdf> Acesso em: 30 mar. 2019.

[34] MURPHY, R.; TRAVERS, P.; WALPORT, P. Imuno Biologia de Janeway. Tradução Ana Paula e franco Lambert.[et al.]. 8. ed. Porto Alegre: Artmed, 2014.

[35] NOVAES, J.M.C. Importância da colpocitologia na adolescência. Rev. Adolescia \& Saúde. UERJ. v. 3, n. 1, p.1821. 2006. Disponível em:<http://adolescenciaesaude.com/detalhe_artigo.asp?id=148> Acesso em: 19 mar. 2019.

[36] PEREIRA, G. F. M et al., Epidemiologia do HIV e aids no estado do Rio Grande do Sul, 1980-2015. Epidemiol. Serv. Saude, Brasília. v. 27, n. 4, e2017374, 2018. Disponível em: < https://www.scielosp.org/scielo.php?script=sci_arttext\&pid=S2237-96222018000500300 > Acesso em: 01 mar. 2019.

[37] PEREIRA, B. S et al., Fatores associados à infecção pelo HIV/AIDS entre adolescentes e adultos jovens matriculados em Centro de Testagem e Aconselhamento no Estado da Bahia, Brasil. Ciênc. saúde coletiva. v.19, n.3, p.747-758. 2014. Disponível em:<http://www.scielo.br/pdf/csc/v19n3/1413-8123-csc-19-03-00747.pdf> Acesso em: 5 abr. 2019.

[38] PINTO, M. E; STRUCHINER, C. J. A diversidade do HIV -1: uma ferramenta para o estudo da pandemia. Cad. Saúde Pública, Rio de Janeiro. v. 22, n. 3, p. 473- 484, 2006. Disponível em: < https://www.scielosp.org/scielo.php?pid=S0102-311X2006000300002\&script=sci_arttext\&tlng=en> Acesso em: 15 mar. 2019

[39] PRAÇA, F. S. G. Metodologia da pesquisa cientifica: organização estrutural e os desafios para redigir o trabalho de conclusão. Diálogos Acadêmicos, São Paulo. v. 08, no 1, p. 72-87, JAN-JUL, 2015. Disponível em: <http://uniesp.edu.br/sites/_biblioteca/revistas/20170627112856.pdf> Acesso em: 30 de mar. 2019.

[40] PREFEITURA MUNICIPAL DE TUCURUÍ. Nossa história, $2016 . \quad$ Disponível em:<http://Tucuruí.pa.gov.br/nossa-história/> Acesso em: 20 mar. 2019.

[41] RICHARDSON, Roberto Jarry. Pesquisa social: métodos e técnicas. 5. ed. São Paulo: Atlas. 1989. p. 70-73.

[42] SANCHES, Kátia Regina de Barros. A AIDS e as mulheres jovens: uma questão de vulnerabilidade. 1999. $153 \mathrm{f}$. Tese (Doutorado em Saúde Pública)- Escola Nacional de Saúde Pública. Fundação Oswaldo Cruz. Rio de Janeiro, 1999. Disponível em: <https://portalteses.icict.fiocruz.br/pdf/FIOCRUZ/1999/sancheskrbd/capa.pdf> Acesso em: 13 abr. 2019.

[43] SANTOS, A; ASSIS, M. Vulnerabilidade das idosas ao HIV/AIDS: despertar das políticas públicas e profissionais de saúde no contexto da atenção integral: revisão de literatura. Rio de janeiro. Rev. Brasileira geriatria e gerontologia. v. 14, n. 1, p 147-157. 2011. Disponível em: <http://www.scielo.br/pdf/rbgg/v14n1/a15v14n1.pdf> Acesso em: 30 mar. 2019.

[44] SANTOS, N. S. de 0 et al., Introdução a Virologia Humana. 2. ed. Rio de Janeiro: Guanabara Koogan, 2008.

[45] SAVI, M. A. Dinâmica da interação entre o sistema imunológico e o vírus HIV. Revista Militar de Ciência e Tecnologia, $\quad$ v. $15, \quad$ n. $\quad 3, \quad$ p. $15-26, \quad 1999 . \quad$ Disponível <http://rmct.ime.eb.br/arquivos/RMCT_3_quad_1999/dinamica_inter_sist_imuno_e_virus_HIV.pdf> Acesso em: 30 mar. 2019.

[46] SESPA, Secretária de saúde pública. Centro integrado de inclusão e reabilitação: Sespa intensifica campanha contra DST/Aids nos municípios paraenses. 2015. Disponível em: <http://www.saude.pa.gov.br/2015/02/20/sespaintensifica-campanha-contra- dstaids-nos-municipios-paraenses/>. Acesso em: 18 jul. 2019.

[47] SZWARCWALD, C. L.; CASTILHO, E. A. The HIV/AIDS epidemic in Brazil: three decades. Cad. Saúde Pública, Rio de Janeiro: vol.27 sup 1:54-55, 2011. Disponível em: <http://www.scielo.br/pdf/csp/v27s1/pt_01.pdf>. Acesso em: 18 jul. 2018.

[48] TERTO Jr, V. Homossexualidade e saúde: desafios para a terceira década de epidemia de HIV/AIDS. Horizontes Antropológicos. v. 8, n. 17, p. 147-158, 2002. Disponível em: <http://www.scielo.br/pdf/ha/v8n17/19080.pdf> Acesso em: 28 mar. 2019.

[49] UNAIDS: Prevenção Combinada do HIV. 2017. (Texto digitado). Disponível em: <https://unaids.org.br/wpcontent/uploads/2017/08/2017_08_15_preven\%C3\%A7\%

C3\%A3o_combinada_FINAL.pdf > Acesso em: 16 jul. 2018. 
[50] UNAIDS BRASIL: Você sabe o que é HIV e o que é AIDS. 2017. Disponível em: <https://unaids.org.br/2017/03/voce-sabe-o-que-e-hiv-e-o-que-e-aids/> Acesso em: 16 jul. 2018.

[51] VERAS, RP, et al., orgs. Epidemiologia: Contextos e Pluralidade. Rio de Janeiro: Editora FIOCRUZ, 1998.172 p. Epidemiológica series, n4. Disponível em: <http://books.scielo.org>. Acesso em: 20 jul. 2018.

[52] VILLARINHO, M. V et al., Políticas públicas de saúde face à epidemia da Aids e a assistência às pessoas com a doença. Rev Bras Enferm. Brasília, v. 66, n. 2, p. 271-277, 2013. Disponível em: <http://www.redalyc.org/articulo.oa?id=267028666018>. Acesso em: 20 mar 2019. 


\section{ANEXO I}

Ofício institucional

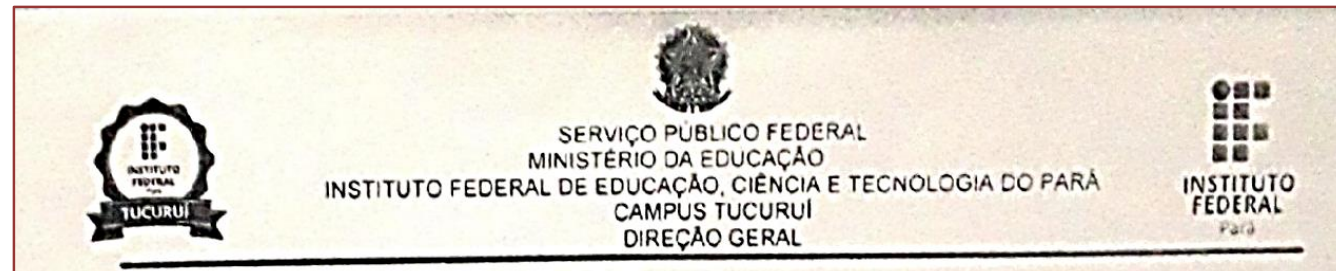

OFICIO n` 125/2018-DG/ CAMPUS TUC.

Tucurui - PA, 11 de Julho de 2018.

À Núcleo de Epidemiologia do Município de Tucuruí, $\mathrm{Dr}^{3}$ Cecilia de Fátima Barbosa Ranieri.

\section{Assunto: Solicitacãa de Visita Acadêmica}

\section{Prezado Senhor,}

Venho solicitar a Disponibilização de dados sobre o HIV no município de Tucuruí durante o período de 2000 a 2017, para realização de trabalho de conclusão de curso das discentes de Biologia Ariane da Silva Santos e Tayanne de Sousa Almeida, com titulo: Prevalência do número de infecçôes pelo HIV em Tucurui, nos anos de 2000 a 2017. Tendo como objetivo Geral: Avaliar a prevalência da infecção por HIV no Município de Tucuruf, nos anos de 2000 a 2017; objetivos específicos: verificar as faixas etárias prevalentes; verificar a distribuição de casos de AIDS em homens e mulheres; reconhecer categorias de exposição ao virus HIV e seus respectivos índices de prevalência; verificar o número de casos diagnósticos e que realizam o tratamento; e verificar os indices da infecção nos bairros de Tucurui. Com a orientação da Professora Especialista Juliana Cristina Schneider, SIAPE: 3044967.

E-mail para contato: juliana.schneider@ifpa.edu.br

Telefone: $91-99153-5675$

Cordialmente,
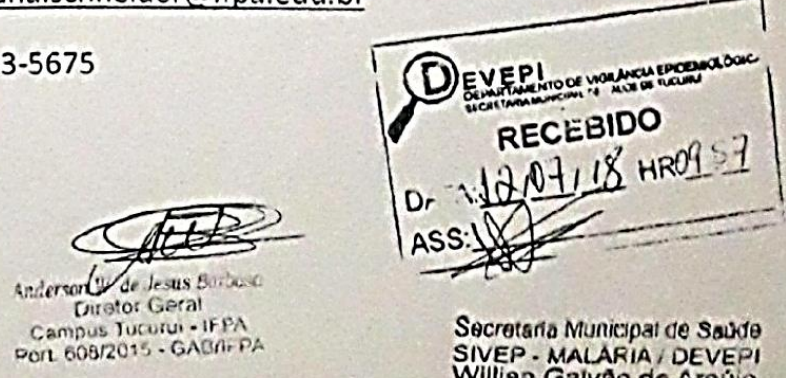

Secretaria Municipat de Saude SIVEP - MALARIA / DEVEPI Willian Gaivao de Araújo Matncula. Ciraye 


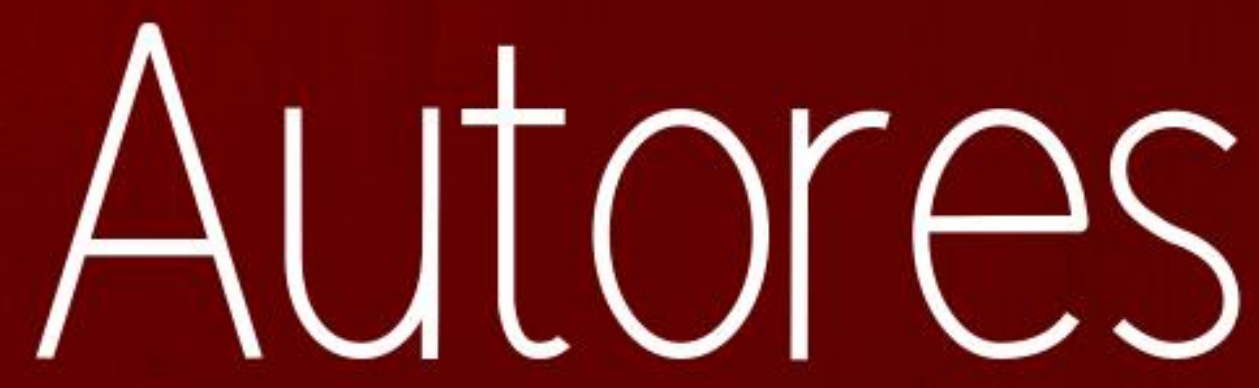




\section{GLEICA SOYAN BARBOSA ALVES (ORGANIZADORA)}

Farmacêutica (UFAM - 2013), mestre em Saúde, Sociedade e Endemias na Amazônia (UFAM 2016) professora assistente da Universidade Federal do Amazonas (UFAM) e Coordenadora do Curso de Engenharia Sanitária do Instituto de Ciências Exatas e Tecnologia (ICET). Tem experiência na área de Microbiologia, Epidemiologia, Biologia Molecular e Controle de Qualidade de Alimentos e Medicamentos.

\section{ELIENE DE OLIVEIRA (ORGANIZADORA)}

Graduada em Odontologia pela Universidade Estadual de Montes Claros - Unimontes (2017) e em Enfermagem pelas Faculdades Unidas do Norte de Minas - FUNORTE (2011). Especialista em Saúde da Família. Especialista em Educação a Distância. Servidora pública efetiva no cargo de Odontológo na Prefeitura Municipal de Montes Claros/MG. Docente na Escola Técnica de Saúde do Centro de Educação Profissional e Tecnológica da Unimontes. Professora supervisora do Estágio em Saúde da Família do curso de Odontologia da FUNORTE. Possui experiência em Saúde Coletiva/Saúde da Família.

\section{ADRIANA DE CASTRO RODRIGUES}

Enfermeira UFSM/EBSERH Santa Maria - RR Especialização: Preceptoria no SUS - PSUS; Linhas de Cuidado em Enfermagem - Área: Atenção Psicossocial e Gestão da Clínica nos Hospitais do SUS

\section{ALESSANDRA RODRIGUES MARTINS}

Mestranda do Programa de Pós Graduação Stricto Sensu em Ciências da Saúde - UEPG.

\section{ALEXANDRE BEZERRA SILVA}

Bacharel e Licenciado em Enfermagem; Enfermeiro da Secretaria Municipal de Saúde de Natal/RN; Enfermeiro da Secretaria de Saúde Pública do Rio Grande do Norte (SESAP); Mestre em Saúde da Família pela Universidade Federal do Rio Grande do Norte (UFRN); Pesquisador do Grupo de Estudo em Saúde Coletiva da Faculdade de Ciências da Saúde da Universidade do Estado do Rio Grande do Norte (FACS/UERN).

\section{ALEXANDRE DE OLIVEIRA ZAMBERLAN}

Possui graduação em Informática pela Unijuí - RS, especialização em Sistemas de Informação e Telemática pela UFRGS, mestrado em Ciência da Computação pela PUCRS e doutorado em Nanociências pela Universidade Franciscana (antigo Centro Universitário Franciscano) com ênfase em modelagem e simulação de biossistemas e nanomateriais pela abordagem de Sistemas Multiagentes. Além disso, é Professor dos cursos de Ciência da Computação, Jogos Digitais e Sistemas de Informação dessa instituição. Tem experiência na área de Ciência da Computação, com ênfase em Inteligência Artificial, atuando principalmente nos seguintes temas: teoria e modelagem de agentes e sistemas multiagentes; simulação multiagente em ambientes nanoparticulados; engenharia do conhecimento e sistemas de conhecimento.

\section{ALISSON JUNIOR DOS SANTOS}

Enfermeiro, Mestre em Ciências pelo Programa de Pós-Graduação Mestrado Profissional Tecnologia e Inovação em Enfermagem pela Escola de Enfermagem de Ribeirão Preto/Universidade de São Paulo - EERP/USP (2020), Licenciatura em Educação Profissional e Tecnológica pelo Instituto Federal de Educação, Ciência e Tecnologia do Sul de Minas Gerais IFSULDEMINAS Campus Muzambinho (2021), Controle de Infecção Hospitalar pela AVM Faculdades Integradas (2015), Urgência e Emergência pela Fundação de Ensino Superior de Passos/Universidade do Estado de Minas Gerais - FESP/UEMG (2012) e Bacharelado em Enfermagem pela Fundação de Ensino Superior de Passos/Universidade do Estado de Minas 
Gerais - FESP/UEMG (2010). Docente do Curso de Bacharelado em Enfermagem da Universidade do Estado de Minas Gerais - UEMG Unidade Passos desde 2015.

\section{ANA PRISCILA DUARTE DE AGUIAR}

Enfermeira. Especialista em Estomaterapia pela Universidade de Pernambuco (UPE).

\section{ANDRÉA TIMÓTEO DOS SANTOS DEC}

Possui graduação em Farmácia e Bioquímica pela Universidade Estadual de Ponta Grossa (1992), mestrado em Educação pela Universidade Estadual de Ponta Grossa (1998) e doutorado em Medicina (Hematologia) pela Universidade Federal de São Paulo (2009). Atualmente é professora adjunta da Universidade Estadual de Ponta Grossa e compõe o corpo docente da disciplina de Estágio Supervisionado em Análises Clínicas. Tem experiência na área de Farmácia, com ênfase em Análises Clínicas, atuando principalmente em hematologia, imunologia e saúde pública.

\section{ANNA LAURA MARTINELLI}

Enfermeira. Mestre em Tecnologia em Saúde pela PUC/PR. Professora do Curso de Bacharelado em Enfermagem da Universidade Estadual de Ponta Grossa, Paraná (DENSP-UEPG)

\section{ARIANE DA SILVA SANTOS}

Graduada em licenciatura plena em ciências Biológicas pelo Instituto de Educação, Ciência e tecnologia do Estado do Pará.

\section{ASSEMCLEVES AGUIAR DA SILVA}

Bacharel em Enfermagem; Esp. em Enfermagem em Oncologia pela Faculdade Metropolitana de Ciências e Tecnologia (FAMEC)

\section{BÁRBARA ADRYA PRESTES DA SILVA}

Graduação em andamento em Enfermagem. Universidade Estadual de Ponta Grossa, UEPG, Brasil. (2018). Bolsista pelo Programa Institucional de Bolsas de Extensão Universitária PROEX/UEPG.

\section{BRENDA HELEN FREIRE BARBOSA}

Bacharel em Enfermagem; Esp. em Urgência e Emergência pela Faculdade de Venda Nova do Imigrante (FAVENI).

\section{BRUNA RODRIGUES MAZIERO}

Possui graduação em Terapia Ocupacional pelo Centro Universitário Franciscano (2008), especialização em Saúde Mental e Atenção Psicossocia (ULBRA, 2012), Especialização em Preceptoria do SUS (IEP-HSL, 2017) e Mestrado no Programa de Pós Graduação em Gerontologia (UFSM). Possui experiência na docência do ensino superior e em Saúde Mental Coletiva e Gerontologia.

\section{CAMILA ANDRIELE NUNES MARTINS LOPES}

Graduada em Terapia Ocupacional pela Universidade Federal de Santa Maria (2014). Especialista em Saúde Mental pelo Programa de Residência Multiprofissional em Saúde Mental da Universidade Franciscana (2016-2018). Atualmente é Servidora Pública na Prefeitura Municipal de Pomerode, estando alocada na Secretaria de Saúde do município e atuando no Centro de Atenção Psicossocial - CAPS e Núcleo Ampliado de Saúde da Família - NASF. 


\section{CAMILA FRANCO}

Possui graduação em Farmácia pelo Centro Universitário Franciscano (2005), mestrado em Ciências Farmacêuticas pela Universidade Federal do Rio Grande do Sul (2007) e doutorado em Ciências Farmacêuticas pela Universidade Federal do Rio Grande do Sul (2015) tendo ênfase em Tecnologia Farmacêutica. Tem experiência em Análise e Controle de Qualidade físico-químico de Medicamentos, Estabilidade de medicamentos, Complexação de Fármacos com Ciclodextrinas, Estudo de Permeação Cutânea, Desenvolvimento de Nanopartículas Poliméricas e Nanoemulsões, Síntese Orgânica de Polímero e de Peptídeos, Cultura Celular e Vetorização Ativa de Fármacos. Docente no Centro Universitário Franciscano (2009-2018) e desde 2018 é docente na Universidade Franciscana, atuando também como coordenadora do curso de Farmácia a partir do ano de 2018 até o momento.

\section{CYNTHIA PIRES LORENTZ}

Discente do $7^{0}$ semestre do curso de Fisioterapia da Universidade Franciscana (UFN) de Santa Maria - RS.

\section{DANIELA COMELIS BERTOLIN}

Graduação em enfermagem pela Faculdade de Medicina de São José do Rio Preto-FAMERP, mestrado em Enfermagem Fundamental e Doutorado em Ciências pela Escola de Enfermagem de Ribeirão Preto- SP-USP. Atuou como enfermeira assistencial na área de nefrologia. É docente em cursos de graduação e pós-graduação. Pesquisa temas na área de doenças crônicas nãotransmissíveis, com ênfase em: estresse; enfrentamento; aceitação da doença; apoio social; educação em saúde; ensaio clínico; diabetes mellitus e insuficiência renal crônica.

\section{DANIELA SANCHOTENE VAUCHER}

Docente do curso de Fisioterapia na Universidade Franciscana (UFN) de Santa Maria -RS. Especialista em Saúde Coletiva pela Universidade Franciscana (UFN) de Santa Maria - RS. Mestrado em Distúrbios da Comunicação Humana pela Universidade Federal de Santa Maria (UFSM) de Santa Maria - RS.

\section{DANIELE ALCALÁ POMPEO}

Possui Graduação em Enfermagem pela Faculdade de Medicina de São José do Rio Preto FAMERP (2000); Especialização modalidade Residência pela Universidade Federal de São Paulo UNIFESP (2002); Mestrado em Enfermagem pela Escola de Enfermagem de Ribeirão Preto da Universidade de São Paulo EERP,USP (2007); Doutorado pelo Programa Interunidades de Doutoramento em Enfermagem da Escola de Enfermagem de Ribeirão Preto da Universidade de São Paulo, USP (2012). Professora Doutora Adjunta da Faculdade de Medicina de São José do Rio Preto, FAMERP. Coordenadora do Programa de Pós-Graduação da FAMERP, nível mestrado acadêmico. Desenvolve atividades científicas nas seguintes linhas de pesquisa: Processo de cuidar nos ciclos de vida, atuando, principalmente, nas seguintes temáticas: processo de enfermagem, diagnóstico de enfermagem, Sistemas de Linguagem Padronizados, saúde mental e autoestima.

\section{DANIELE KNOPP RIBEIRO}

Mestranda de Enfermagem pelo Programa de Pós Graduação em Enfermagem da Universidade Federal de Juiz de Fora, graduada e licenciada em Enfermagem pela mesma instituição.

\section{DAVI PEREIRA COELHO}

Acadêmico de Enfermagem da Universidade Federal de Juiz de Fora (UFJF) - Campus Juiz de Fora, MG. 


\section{DENISE BARBOSA DE CASTRO FRIEDRICH}

Graduada em Enfermagem pela Faculdade de Enfermagem da Universidade Federal de Juiz de Fora -UFJF (1983), Mestrado em Enfermagem pela Universidade Federal de Minas Gerais (2000) e Doutorado em Saúde Coletiva pela Universidade do Estado do Rio de Janeiro (2005). É professora convidada da Faculdade de Enfermagem e professora do quadro permanente do Programa de Pós Graduação Enfermagem da UFJF.

\section{EDITH MONTEIRO DE OLIVEIRA COELHO}

Mestra em Enfermagem pela Universidade Federal de Juiz de Fora (UFJF) (2020); Possui graduação em Enfermagem pela Universidade Severino Sombra de Vassouras - RJ (2014) , Pós Graduação Lato Sensu em Segurança do Paciente para Profissionais da Rede de Atenção às Urgências e Emergências pela Escola Nacional de Saúde Pública Sérgio Arouca (ENSP) - Fundação Oswaldo Cruz (FIOCRUZ) (2017) e Pós-Graduação Lato Sensu em Saúde da Família pelo Centro Universitário Estácio de Sá (2018). Membro do Grupo de Estudo e Pesquisas sobre Autocuidado e Processos Educativos em Saúde e Enfermagem (GAPESE) da Faculdade de Enfermagem da UFJF.

\section{EDUARDA FLORES DE LIMA}

Cursando graduação em Farmácia pela Universidade Federal de Santa Maria.

\section{ELAINE CRISTINA DOS SANTOS OLIVEIRA HOLANDA}

Enfermeira. Especialista em Gestão em Envelhecimento Humano pela Faculdade de Ciências da Saúde, Santa Maria- Rio Grande do Sul- Brasil.

\section{ELIDIANE LIRA DA SILVA PEREIRA}

Fisioterapeuta. Especialista em Saúde da Família pela Universidade de Pernambuco (UPE).

\section{ELISA CLERICI LÜTDKE}

Possui graduação em Farmácia (2011-2016) e Especialização em Terapia Intensiva: Ênfase em Oncologia e Infecção Hospitalar (2018-2019) pela Universidade Franciscana. Atuou como Assistente Técnico Farmacêutica na empresa Farmácia Sindifarma - Santa Maria-RS (2017) e como Diretor Responsável Técnico Farmacêutico na empresa Farmácia Agafarma 634 - São Pedro do SulRS (2017-2020). Atualmente é sócia proprietária da empresa Farbel Comercio de Medicamentos e Cosméticos LTDA. (Texto informado pelo autor).

\section{EMERSON ROBERTO DOS SANTOS}

Possui Graduação em Enfermagem pela Faculdade de Quatro Marcos (2008). Especialização em Enfermagem do Trabalho, pela Faculdade de Medicina de São José do Rio Preto - FAMERP, 2009, Especialização em Enfermagem em Unidade de Terapia Intensiva, pela Faculdade de Medicina de São José do Rio Preto - FAMERP, 2017. Possui experiência em Cuidado ao Idoso Não Hospitalizado, obtida durante estágio voluntário na instituição HABITARE Assistência ao Idoso, em São José do Rio Preto - SP e atuação profissional com pacientes particulares, e em Enfermagem Nefrológica Diálise Peritoneal, obtida durante estágio voluntário no Instituto de Urologia e Nefrologia - IUN, em São José do Rio Preto. Enfermeiro do setor de EMERGÊNCIA (Convênio) do Hospital de Base (HB-FUNFARME) de julho de 2014 a junho de 2018. Enfermeiro do setor de UNIDADE DE TERAPIA INTENSIVA da Associação Portuguesa de Beneficência - São José do Rio Preto /SP desde 01 de novembro de 2018 e da UNIDADE DE TRANSPLANTE DE MEDULA ÓSSEA da Associação Portuguesa de Beneficência - São José do Rio Preto /SP desde 2019. Mestre em ENFERMAGEM pelo Programa de Pós Graduação Strictu Sensu em Enfermagem da FAMERP. 


\section{FABIANE ROSADO LORENZONI}

Possui ensino médio/segundo grau pelo Instituto Metodista Centenário(2012). Graduanda em Direito pela Universidade Franciscana, UFN. Atualmente exerce função no Cartório de Registro de Imóveis de Santa Maria/RS.

\section{FABÍOLA LISBOA DA SILVEIRA FORTES}

Doutora em Enfermagem pela Escola de Enfermagem Anna Nery da Universidade Federal do Rio de Janeiro. Professora Adjunta II do Departamento Materno Infantil e Saúde Pública da Faculdade de Enfermagem da Universidade Federal de Juiz de Fora. Pesquisadora do GAPESE/CNPQ - Grupo de Estudo e Pesquisa sobre Autocuidados e Processo Educativo em Saúde e Enfermagem.

\section{FLÁVIA REIS DA SILVA}

Acadêmica de Enfermagem da Universidade Federal de Juiz de Fora (UFJF) - Campus Juiz de Fora, MG. Possui graduação em Serviço Social pela Universidade Federal de Juiz de Fora (UFJF) - Campus Juiz de Fora, MG.

\section{GABRIELE DOS SANTOS MOTA}

Discente do $7^{\circ}$ semestre do curso de Fisioterapia da Universidade Franciscana (UFN) de Santa Maria - RS.

\section{GIULIA LOPES COSTA DA SILVA}

Discente do $7^{\mathbf{0}}$ semestre do curso de Fisioterapia da Universidade Franciscana (UFN) de Santa Maria - RS.

\section{GLEIDA MARIA MARTINS}

Enfermeira, Bacharelado em Enfermagem pela Fundação de Ensino Superior de Passos FESP/UEMG (2010), Pós-Graduação em APH (2012) e Cardiologia e Cuidados Intensivos (2013) pelo Centro Universitário Hermínio Ometto - UNIARARAS. Enfermeira Assistencial da UTI Adulto da Santa Casa de Misericórdia de Passos desde 2012.Docente do curso de Bacharelado em enfermagem da Universidade do Estado de Minas Gerais (UEMG) Unidade de Passos. Tem experiência na área de Enfermagem, com ênfase em Enfermagem em Cardiologia, Emergência e Cuidados intensivos, Atendimento Pré Hospitalar.

\section{GUILHERME ARCARO}

Enfermeiro. Mestre em Ciências da Saúde pela UEPG. Professordo Curso de Bacharelado em Enfermagem da Universidade Estadual de Ponta Grossa, Paraná (DENSP-UEPG).

\section{GUILHERME CHAGAS KURTZ}

Possui graduação em Ciência da Computação pelo Centro Universitário Franciscano (2009) e mestrado em Informática pela Universidade Federal de Santa Maria (2011). Atualmente é professor titular da Universidade Franciscana. Tem experiência na área de Ciência da Computação, com ênfase em Ciência da Computação, atuando principalmente nos seguintes temas: bioinformatica, sistemas distribuídos, processamento de imagens, computação pervasiva, computação móvel e linguagens de programação.

\section{ISADORA BALESTRIN GUTERRES}

Possui ensino médio completo na Escola Cenecista de Ensino Médio Padre Anchieta - CNEC/SA (2012-2014). Graduanda em Direito pela Universidade Franciscana, UFN. Participou do grupo de 
estudo "Direitos Humanos e Cosmopolitismo: Uma análise da proteção da Criança e do Adolescente" na UFN. Exerceu estágio no Programa de Proteção e Defesa do Consumidor (PROCON/SM), na Defensoria Pública do Estado do Rio Grande do Sul na comarca de Santo Augusto/RS, e na $1^{\circ}$ Vara Criminal da Comarca de Santa Maria/RS. Atualmente, exerce estágio na Defensoria Pública do Estado do Rio Grande do Sul na comarca de Santa Maria/RS.

\section{JOSÉ CLAUDO DE SOUSA MONTEIRO}

Graduado em Licenciatura Plena em Ciências Biológicas pelo IFPA. Especializado em Análises Clínicas e Microbiologia. Atualmente está cursando Mestrado em Zoologia pela UFPA.

\section{JOSÉ DEUSVANDO FREIRE CAMPOS}

Bacharel em Enfermagem; Esp. Enfermagem em Dermatologia e Tratamento de Feridas pela Universidade Potiguar (UNP).

\section{JOSIVAN FELIX DA SILVA}

Bacharel em Enfermagem; Esp. em Gestão e Auditoria em Serviços de Saúde pela Faculdade de Venda Nova do Imigrante (FAVENI)

\section{JULIANA CRISTINA SCHNEIDER}

Graduada em Ciências Biológicas pelo IFPA, Especializada em Gestão Ambiental pela UFPA e Mestranda em Engenharia de Barragem e Gestão Ambiental pela UFPA.

\section{JULIANA DA ROSA MARINHO}

Psicóloga graduada pela Universidade Franciscana (UFN - Santa Maria/RS) em janeiro de 2014. Especialista em Saúde Mental pelo Programa de Residência Multiprofissional em Saúde Mental da Universidade Franciscana (2016-2018). Mestranda do Programa de Pós-Graduação em Psicologia da Universidade Federal de Santa Maria, turma de 2019, Bolsista CAPES. Membro do grupo de pesquisa do Programa de Cooperação Acadêmica (PROCAD / 2018 - 2020) e da Rede de Estudos e Pesquisas sobre Desenvolvimento na Infância, Adolescência e Juventude (REDIJUV - Departamento de Psicologia da UFSM).

\section{JÚLIO CÉSAR ANDRÉ}

Possui graduação em Medicina pela Faculdade de Medicina de São José do Rio Preto (1987), Mestrado (1991) e Doutorado (1997) em Morfologia - Biologia Celular pela Faculdade de Medicina de Ribeirão Preto (USP). Especialista em Avaliação Institucional (2004) pela Universidade de Brasília (UNB). Fellow Foundation for Advancement of International Medical Education and Research - FAIMER BRASIL 2015 Especialista em Desenvolvimento Docente para Educadores das Profissões da Saúde pela Universidade Federal do Ceará (2017). É docente da Faculdade de Medicina de São José do Rio Preto desde 1988, tendo atuado por 32 anos nas áreas de Biologia Celular e Tecidual e Histologia. Em 2013 assumiu a Coordenação do Curso de Medicina da Faculdade de Medicina de São José do Rio Preto (FAMERP) e voltou-se completamente para a área da educação médica. Permaneceu por 4 anos nesta função e à partir daí ampliou sua área de interesse para a educação para as profissões da saúde com intensa atividade de orientação de projetos de pesquisa em nível de iniciação científica (IC). Esteve Diretor da Regional São Paulo da Associação Brasileira de Educação Médica (ABEM), para a gestão 2018-2020, até 31/05/2020. Á partir de 2017 passou a integrar, como pesquisador, o Centro de Estudos e Desenvolvimento de Educação em Saúde da FAMERP (CEDES - FAMERP). Líder do Grupo de Pesquisa ESTUDOS, FORMAÇÃO E DESENVOLVIMENTO EDUCACIONAL NA SAÚDE, no Diretório dos Grupos de Pesquisa no Brasil - LATTES do CNPq, desde 2020. Suas áreas de pesquisa são: AMBIENTE EDUCACIONAL, AVALIAÇÃO EM EDUCAÇÃO PARA AS PROFISSÕES DA SAÚDE, COMPETÊNCIAS HUMANÍSTICAS NAS PROFISSÕES DA SAÚDE, INTERFACE DAS CIÊNCIAS SOCIAIS COM A 
MEDICINA, MÉTODOS DE ENSINO-APRENDIZAGEM, QUALIDADE DE VIDA E SAÚDE MENTAL DE ESTUDANTES E PROFISSIONAIS DA ÁREA DA SAÚDE e RESPONSABILIDADE SOCIAL DAS INSTITUIÇÕES DE ENSINO.

\section{JUSSANY CRISTINE MIRANDA}

Enfermeira Residente em Urgência e Emergência HU-UEPG

\section{KAREN BRIÃO DA COSTA}

Graduada em Serviço Social pela Universidade Católica de Pelotas(UCPEL), Especialista em Gestão e Atenção Hospitalar, com ênfase na área Materno Infantil, pela Universidade Federal de Santa Maria(UFSM), Especialista em Saúde Mental pela Universidade Franciscana (UFN), Assistente Social na Secretaria Municipal de Assistência e Habitação Social na Prefeitura da Cidade de São Sepe -RS.

\section{LAÍSE ÁVILA DE SIQUEIRA}

Graduada no curso de Terapia Ocupacional na Universidade Federal de Santa Maria (UFSM) . Em sua graduação integrou o Programa de Educação pelo Trabalho para a Saúde/PET-Saúde como monitora(2010-2012) e integrou também o Programa de Educação pelo Trabalho para a Saúde/PET-Saúde Rede de Atenção- aréa de concentração Álcool e drogas como bolsista(2014) . Foi Terapeuta Ocupacional do consultório Espaço Saúde na cidade de Santa Maria-RS, no ano de 2016. Foi residente pelo Programa de Residência Multiprofissional em Saúde Mental na Universidade Franciscana (UFN)- (2017-2019). E foi a 2ª secretária da Associação Cultural dos Terapeutas Ocupacionais do Rio Grande do Sul (ACTORGS) gestão (2018/2020). Atualmente é mestranda pelo Programa de Pós-graduação em Psicologia na UFSM e bolsista da Coordenação de Aperfeiçoamento de Pessoal de Nível Superior (CAPES).Integrante do grupo de pesquisa CNPQ Estéticas, Saúde e Políticas de Subjetivação, na linha de pesquisa Dispositivos em Saúde, Saúde Mental e Ciências do Cérebro.

\section{LARA SIMONE MESSIAS FLORIANO}

Enfermeira, Doutora em Ciências pela Escola de Enfermagem da Universidade de São Paulo (USP); Professora Adjunta do Departamento de Enfermagem da Universidade Estadual de Ponta Grossa, Paraná (DENSP-UEPG); Coordenadora do Programa de Extensão UEPG Abraça, Coordenadora do Programa de Residência Multiprofissional em Saúde Mental da UEPG

\section{LARYSSA GRAZIELLE FEITOSA LOPES}

Enfermeira. Doutoranda da Escola de Enfermagem de Ribeirão Preto pela Universidade de São Paulo (USP-EERP).

\section{LIGIA MARIA BUENO VERDIANI}

Biomédica Residente do Programa Multiprofissional em Atenção Clínica Especializada com Ênfase em Infectologia e Neurologia

\section{LOIANE LETÍCIA DOS SANTOS}

Possui Graduação em Psicologia pela Faculdade de Quatro Marcos - FQM (2014) Especialista em Psicologia da Saúde - Modalidade Aperfeiçoamento Profissional pela Faculdade de Medicina de São José do Rio Preto - FAMERP em parceria com o Hospital de Base de São José do Rio Preto (2016) Especialista em Intervenção Sistêmica Familiar e de Casal - FAMERP (2016) Mestra no Programa de Psicologia e Saúde - FAMERP. Especialista em Cuidado a Obesidade - UNESP Botucatu (2019). Doutoranda da Faculdade de Ciências Médicas (UNICAMP) - Programa Ensino em Saúde. Atuou como Psicóloga no Centro Regional de Atenção aos Maus Tratos na Infância (CRAMI) Docente no 
Instituto Municipal de Ensino Superior de Catanduva (IMES) Docente Colaboradora na Faculdade de Medicina de São José do Rio Preto (FAMERP) e Psicóloga no Instituto do Câncer (ICA) do Hospital de Base de São José do Rio Preto/SP.

\section{MACKELLY SIMIONATTO}

Graduada em Farmácia com habilitação em Análises Clínicas pela Universidade Estadual de Ponta Grossa (1998). Possui especialização em Microbiologia e Imunologia Clínicas pela Universidade Estadual de Ponta Grossa (2000) e mestrado pelo Programa de Pós-Graduação em Ciências Farmacêuticas pela Universidade Federal do Paraná (2009). Atualmente, é doutoranda no Programa de Pós-Graduação em Ciências Farmacêuticas da Universidade Estadual de Ponta Grossa em associação ampla com a Universidade Estadual do Centro-Oeste. Profissionalmente, atua como professora na supervisão de estágio no Laboratório Universitário de Análises Clínicas da Universidade Estadual de Ponta Grossa. Tem experiência na área de Farmácia, com ênfase em Análises Clínicas, atuando em Hematologia Clínica.

\section{MARGARETE APARECIDA SALINA MACIEL}

Farmacêutica Bioquímica com habilitação em Análises Clínicas pela Universidade Estadual Paulista Júlio de Mesquita Filho (UNESP - Araraquara, 1990). Mestrado (1996) e Doutorado (2002) em Ciências Biológicas, área de Microbiologia Aplicada pela UNESP Campus de Rio Claro. Professor Associado do Departamento de Análises Clínicas e Toxicológicas da Universidade Estadual de Ponta Grossa (UEPG). Compõe o corpo docente da disciplina de Estágio Supervisionado em Análises Clínicas. Atuou como Membro da Comissão de Ética em Pesquisa envolvendo seres humanos da UEPG e integrou a Comissão de Assessoramento Técnico-Científico da Pró-Reitoria de Extensão - PROEX. Atualmente coordena o Centro Rural Universitário de Treinamento e Ação Comunitária de Itaiacoca.

\section{MARIANA KRISTOSCH DOS SANTOS}

Graduação em Psicologia pela Universidade de Santa Cruz do Sul - UNISC. Especializanda em Educação em Saúde e Preceptoria no SUS pelo Instituto Sírio Libanês de Ensino e Pesquisa ? IEP/HSL Projeto de apoio ao SUS - PROAD ? SUS. Servidora Pública na Prefeitura Municipal de Santa Maria, estando alocada na Secretaria de Saúde do Município. Psicóloga no Caps infantojuvenil O Equilibrista e na Policlínica Municipal do Rosário. Atuação na psicologia clínica privada. Preceptora de campo dos Programas de Residência em Saúde Mental da Universidade Franciscana (UFN).

\section{MARLICE CEOLIN DRUCK}

Enfermeira Mestre em Saúde e Sociedade pela UFSC ; Enfermeira Especialista em Enfermagem do Trabalho; Especialista em Epidemiologia e Enfermeira da Prefeitura Municipal de Santa Maria,RS; Ex. Professora da Universidade de Santa Cruz do Sul - UNISC.

\section{MILENA DZAZIO DE OLIVEIRA}

Acadêmica do $4^{\mathrm{o}}$ ano do Curso de Bacharelado em Enfermagem da Universidade Estadual de Ponta Grossa (UEPG).

\section{MONICA RITA DA SILVA SIMPLICIO}

Enfermeira. Especialista em Pneumologia Sanitária pela Escola Nacional de Saúde Pública Sergio Arouca (ENSP)/FIOCRUZ 


\section{MORGANA CRISTINA LEÔNCIO DE LIMA}

Doutoranda e Mestre em enfermagem em promoção da saúde do programa associado de pósgraduação e enfermagem UPE/UEPB.

\section{NAIARA ALMEIDA GUEDES}

Pós-graduação em Docência em Enfermagem (Online)- Faculdade Dom Alberto - março de 2021. Bacharel em Enfermagem. Universidade Brasil - Campus Mooca, São Paulo - SP, dezembro de 2019. Inglês, Módulo I. CETEF, São Paulo - SP, 2016-2017. EXPERIÊNCIA PROFISSIONAL Educadora de saúde - Azimute Med. 06/2020 (Atual) - Autônomo - Realização de teste de COVID19 - Coorporativa Preserve - 09/2020 - 01/2021 - Autônomo - Eventos de saúde em multinacionais - Coorporativa Vital Equilibrius. 02/2020 - 12/2020. QUALIFICAÇõES E ATIVIDADES PROFISSIONAIS: ESCOLA FIOCRUZ DO GOVERNO - UNA-SUS Manejo clínico da COVID-19 na atenção primária à saúde (18h) - junho de 2020. CONGRESSO NACIONAL DOS ESTUDANTES DE ENFERMAGEM ON-LINE: Curso de Urgência e Emergência (40 h). 2019. Curso de cuidados de Enfermagem com feridas e curativos (40 h). 2019 WK CURSOS E SAÚDE: Atualização em punção venosa periférica. (8h). São Paulo - SP, 2018. ASSOCIAÇÃO BRASILEIRA DE EDUCAÇÃO ONLINE - ABELINE Cuidados paliativos (120h) - 2015; Administração em Enfermagem (40h) - 2016; Saúde da mulher (100h) - 2016; Atenção pré-natal e puerperal (120h) - 2017; Atividade física para gestantes (110h) - 2018. PRONATEC: Auxiliar administrativo 10/06/2013 a 24/09/2013 - IFMA - Paraibano - Ma. INFORMÁTICA: Digitação; Microsoft Office Word 2010; Microsoft Excel 2010; Microsoft Office PowerPoint 2010; Internet; Windows. Paraibano - MA. 2012 ATIVIDADES EXTRACURRICULARES: - Edição especial do Congresso Nacional dos Estudantes de Enfermagem On-line. (50h). 20/03/2020 - 15/04/2020. - Participação na Edição Especial do Congresso Nacional dos Estudantes de Enfermagem Online. (50h). 2020. Trabalho voluntário no INSTITUTO LOCAL FERRAZ DE VASCONCELOS.

\section{NAYARA MARTINS RIBEIRO}

Biomédica especialista em Urgência e Emergância; Técnica no Hamonúcleo da $11^{a}$ aEgional de SAúde do Estado do Paraná

\section{PATRÍCIA DA SILVA FUCUTA}

Possui graduação em Medicina pela Universidade Federal do Paraná (1996) e doutorado em Ciências pelo Programa de Pós-Graduação em Gastroenterologia da Universidade Federal de São Paulo (2010). Atualmente é Professora de Medicina do curso de Medicina da Faculdade Ceres (FACERES) em São José do Rio Preto; médica docente do Serviço de Gastro-Hepatologia do Hospital de Base de São José do Rio Preto; orientadora no Programa de Pós-Graduação em Psicologia e Saúde da Faculdade de Medicina de São José do Rio Preto (FAMERP) e coordenadora da disciplina de Estatística do mesmo Programa. Tem experiência na área de Medicina, tutoria em PBL e Bioestatística.

\section{PRISCILLA LA FLOR DUARTE}

Graduada em Serviço Social pela Universidade Federal de Santa Maria (UFSM), Especialista em Saúde Mental pela Universidade Franciscana (UFN), Experiência profissional na orientação de indivíduos, famílias e instituições sobre os seus direitos e deveres sociais, atuando na triagem, assistência e acompanhamento de casos até a sua finalização, agindo em conformidade às normas e diretrizes legais determinadas. Suporte a área de Recursos Humanos, auxiliando no atendimento de colaboradores com problemas familiares, financeiros e/ou de alcoolismo e drogas, visando à facilitação do acesso aos recursos de saúde, emprego, moradia, alimentação, lazer, cultura, entre outros direitos. 


\section{REBECA BEZERRA BONFIM DE OLIVEIRA}

Enfermeira. Especialista em Saúde Coletiva e Especialista em Saúde da Família pela Faculdade Cidade Verde.

\section{RICARDO FROHLICH DA SILVA}

Atualmente é Professor Assistente I e coordenador do curso de Jogos Digitais na Universidade Franciscana (UFN). Mestre em Ciência da Computação pela Universidade Federal de Santa Maria (2015) onde trabalho com Safety-Critical Systems. Licenciado através do Programa Especial de Graduação de Formação de Professores para a Educação Profissional na Universidade Federal de Santa Maria (2016). Possui graduação em Sistema de Informação pela Universidade Franciscana (UFN), onde trabalhou com análise e desenvolvimento de aplicativos para dispositivos móveis. Possui experiência em Cartões Inteligentes (Smart Cards), Sistemas Críticos (Safety-Critical Systems), Sistemas para Dispositivos Móveis e Informática na Educação.

\section{ROBERTSON EBLING DOS SANTOS}

Possui graduação em Sistemas de Informação pelo Centro Universitário Franciscano. CEO e Cofundador ER Clinic - Programador Web com a linguagem Python e framework Django. Tem experiência na área de Sistemas de Informação com ênfase em desenvolvimento de software para Internet. Entusiasta de software livre.

\section{SUELLEN VIENSCOSKI SKUPIEN}

Enfermeira. Mestre em Tecnologia em Saúde pela PUC/PR. Professora do Curso de Bacharelado em Enfermagem da Universidade Estadual de Ponta Grossa, Paraná (DENSP-UEPG)

\section{SYLVIO ANDRE GARCIA VIEIRA}

Associado da Sociedade Brasileira de Computação (SBC), possui graduação em Sistemas de Informação pela Associação Catarinense de Ensino (Joinville/SC). Doutor e Mestre em Nanociências pela UFN - Universidade Franciscana (Santa Maria/RS), atua nas áreas de banco de dados, biologia computacional, bioinformática, Informática aplicada à medicina, modelagem matemática computacional e redes de computadores. Atualmente é professor nos cursos de Sistemas de Informação, Ciência da Computação, jogos digitais e Medicina na Universidade Franciscana. Atualmente é o coordenador do Laboratório de Práticas dos cursos de computação e coordenador do Laboratório Tecnológico do Mestrado Profissional em Saúde Materno Infantil, ambos da UFN - Universidade Franciscana.

\section{TACIELY CAMPANA COLLI}

Acadêmica de Enfermagem da Universidade Federal de Juiz de Fora (UFJF) de Minas Gerais

\section{TAYANNE DE SOUSA ALMEIDA}

Graduada em licenciatura plena em ciências Biológicas pelo Instituto de Educação, Ciência e tecnologia do Estado do Pará.

\section{THAINÁ RIBEIRO REZENDE DE MORAIS}

Acadêmica de Enfermagem da Faculdade de Enfermagem da Universidade Federal de Juiz de Fora (UFJF) - Campus Juiz de Fora, MG. Membro do Grupo de Estudo Tecnologia, Cultura e Comunicação em Saúde e em Enfermagem (TECCSE) da Universidade Federal de Juiz de Fora. 
THAIS FERNANDA CHELSKI

Acadêmica do $3^{\circ}$ ano do Curso de Bacharelado em Enfermagem da UEPG.

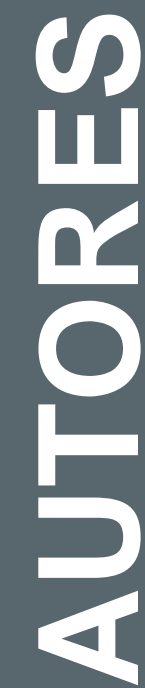




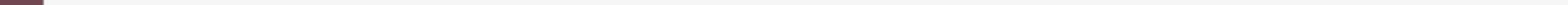

